Awakenings:

\title{
Autobiography, Memory, and the Social Logic of Personal Discovery
}

\author{
by \\ Thomas E. DeGloma Jr. \\ A Dissertation submitted to the \\ Graduate School-New Brunswick \\ Rutgers, The State University of New Jersey \\ in partial fulfillment of the requirements \\ for the degree of \\ Doctor of Philosophy \\ Graduate Program in Sociology \\ written under the direction of \\ Eviatar Zerubavel \\ and approved by
}

New Brunswick, New Jersey

October, 2009 


\title{
ABSTRACT OF THE DISSERTATION
}

Awakenings:

Autobiography, Memory, and the Social Logic of Personal Discovery

\author{
By THOMAS E. DEGLOMA JR.
}

\author{
Dissertation Director: \\ Eviatar Zerubavel
}

Taking a formal, sociocognitive approach to narrative analysis, I explore autobiographical stories about discovering "truth" in political, psychological, religious, and sexual realms of social life. Despite (A) significant differences in subject matter and (B) conflicting and often oppositional notions of truth, individuals in very different social environments tell stories that follow the same awakening narrative formula. Analyzing accounts from a wide variety of social and historical contexts, I plot the temporal structure of the awakening narrative formula to show how individuals and communities use these autobiographical stories to define salient moral and political concerns and weigh in on cultural and epistemic disputes. Awakening narratives are important mechanisms of mnemonic and autobiographical revision that individuals use to redefine their past experiences and relationships, testify to "truth," and plot future courses of action while explaining major transformations of worldview. Awakeners use two ideal-typical vocabularies of liminality to justify traversing the social divide between different autobiographical communities within contentious 
autobiographical fields. They divide their lives into discrete autobiographical periods and convey a temporally divided self, performing a figurative interaction between past and present versions of the self - a storied self-interaction that expresses a contentious dialogue between different autobiographical communities. Individuals use this autobiographical formula to reject the cognitive and mnemonic norms of one community and embrace those of another. Advancing a "social geometry" of awakening narratives, I illuminate the social logic behind our seemingly personal discoveries of "truth." Expanding on the central themes of this analysis, I suggest that a cultural and cognitive sociology of autobiography should uphold five interrelated tenets: (1) autobiography is a form of social memory, (2) autobiography is a form of social time, (3) autobiography is a form of social epistemology, (4) autobiography is a form of social drama, and (5) autobiography is a communicative act directed at multifarious audiences. By explicitly focusing on autobiography as an analytic domain, we can reveal important ways that individuals do cultural work and perform meaning by telling stories about their lives. 


\section{Acknowledgement}

No dissertation is possible without the concerted guidance of one's mentors and the invaluable support of friends and family. I am incredibly fortunate to have had a supportive committee who provided me with thoroughly insightful comments and suggestions. Allan Horwitz, Ann Mische, and Arlene Stein all provided rich and constructive insights and steered me through multiple revisions. Each of them helped me to shape the general cultural theory and perspective of the project. I am truly grateful for their guidance. Robin WagnerPacifici was the outside reader that most doctoral candidates hope for. She grasped the intellectual spirit of this project from the beginning stages and helped me to delve deeper and hone my analysis of the cultural and symbolic dimensions of the narratives and images that grace these pages. Most significantly, I owe an extraordinary debt of gratitude to Eviatar Zerubavel, who has been a truly giving and inspirational mentor, friend, and committee chair. In addition to providing an immeasurable amount of constructive guidance and intellectual direction, Eviatar always encouraged me to take intellectual risks. He showed me, by example, how to follow my heart in an academic world that often punishes intellectual risk-taking and marginalizes those who choose to take one of the (unfortunately) many paths less traveled. Further, my sociological imagination has been deeply influenced by Eviatar's remarkable ability to see social patterns and explore the fascinating social dimensions of mental life.

I am also very grateful for the comments and suggestions of several people, including (in alphabetical order) Rachel Brekhus, Wayne Brekhus, Yael Bromberg, Karen Cerulo, Dan Chambliss, Lynn Chancer, Karen Danna-Lynch, 
Audrey Devine-Eller, Jeffrey Dowd, Asia May Friedman, Judith Gerson, Daina Cheyenne Harvey, Jennifer Hemler, Jenna Howard, Christena Nippert-Eng, Carol Rambo, Dan Ryan, and Ruth Simpson. I have also been fortunate to have the caring support of family and friends, including my parents, Thomas DeGloma, Sr. and Cathi DeGloma, my siblings, Michael, Melanie, Peter, Paul, and Angela, as well as friends Michael Bacchione, Blair Brown, Thomas Hansen, Xavier Hansen, and way too many other good friends and comrades to list.

Last, but certainly not least, I owe a special recognition to Lena Posner, a true partner and friend who, in addition to giving astute intellectual comments, accompanied me every step of the way along this journey. Through storms and discoveries, times of excitement and grief, moves to Ithaca and then Brooklyn, and crazy adventures with Maya and Rio, Lena has helped me to truly know the meaning of heart space. Her love and support has been and continues to be a refuge. She is a gift in a challenging world. She helps me to be the best person I can be.

A synopsis of this dissertation, along with select cases and analytic themes, will appear in the journal Sociological Forum sometime in the not-too-distant future. Some of the cases, narratives, and themes specifically pertaining to those individuals who recover memories of childhood sexual abuse and those who retract memories of childhood sexual abuse previously appeared in the journal Symbolic Interaction (Vol. 30, Issue 4, 2007). It was while struggling with the article that I published there, titled "The Social Logic of 'False Memories': Symbolic Awakenings and Symbolic Worlds in Survivor and Retractor Narratives," that I first developed the idea for this broader project that focuses on 
awakening narratives more generally. Finally, certain small sections and themes that appear in Chapter 2 (specifically in the section titled "Modern Sectarian Awakenings: Communities of Common Experience") originally appeared in the journal Social Psychology Quarterly (Volume 72, Issue 2, 2009) in my article titled, "Expanding Trauma through Space and Time: Mapping the Rhetorical Strategies of Trauma Carrier Groups.” 


\section{Table of Contents}

$\begin{array}{lll}\text { Abstract } & \text { ii }\end{array}$

Acknowledgement iv

List of tables $\quad x$

List of illustrations $\quad$ xi

Chapter 1. Autobiography and the Discovery of Truth 1

$\begin{array}{ll}\text { Awakeners and Awakenings } & 1\end{array}$

The Awakening Story as an Autobiographical Formula $\quad 10$

The Awakener as a Social Type of Storyteller $\quad 21$

Autobiographical Communities \& Autobiographical Fields 26

Autobiographical Time and Autobiographical Memory 34

$\begin{array}{ll}\text { Methods and Data } & 38\end{array}$

Foundational and Popular Awakening Narratives $\quad 40$

Virtual Narrative Environments $\quad 41$

$\begin{array}{ll}\text { Outline of the Book } & 48\end{array}$

Chapter 2. Awakenings: A Socio-Cultural History 53

$\begin{array}{ll}\text { Zarathustra } & 56\end{array}$

Plato's Allegory of the Cave 60

Foundational Religious Awakenings $\quad 65$

$\begin{array}{ll}\text { Foundational Political Awakenings } & 71\end{array}$

Freud and the Psychoanalytic Case Study 80 
Autobiographical Revisions and Autobiographical Projects

Sociomental Express Elevators

Sociomental Staircases

Combining Elevators and Staircases

Autobiographical Gulfs and Autobiographical Discontinuity

Conclusion 
The Late-Modern and Postmodern Traditions 


\section{Lists of tables}

Table 1: Virtual Narrative Environments 


\section{List of illustrations}

Figure 1: The Structure of an Awakening Narrative 17

Figure 2: A Visual Representation Plato's Allegory of the Cave 62

Figure 3: Alternative Autobiographical Trajectories and

Contending Projects in an Autobiographical Field

99

Figure 4. Visual Depiction of Re-awakening Narratives 118

Figure 5. Visual Depiction of Cultural Antagonisms 126

Figure 6. Sociomental Express Elevators and Sociomental Staircases 152

Figure 7: Michelangelo's Conversion of Saint Paul 179

Figure 8: Painting from a Laotian Temple Depicting

Siddhārtha Gautama's Initial Expedition out of his Father's Castle

181

Figure 9: Painting from a Laotian Temple Depicting

Siddhārtha Gautama leaving his Ascetic Comrades

182

Figure 10: Portraying and Crossing the Autobiographical Gulf 191

Figure 11: William Holman Hunt's The Awakened Conscience 200

Figure 12. Turning Point Narrative Models Compared to

an Awakening Narrative Model $\quad 202$

Figure 13. Rod Manney Displays, Engages, and

Undermines his Past Self

Figure 14. Brooke Displays her Temporally Divided Self 224

Figure 15. Victor Displays, Engages, and

Undermines his Past Self

Figure 16. Bob Davies and Alan Chambers Display

Their Awakened heterosexual Selves

236

Figure 17: Eric, David, and Randy Display their

Enlightened, Homosexual Selves

Figure 18: Visual Depiction of a Cognitive Migration 244 


\section{Chapter 1}

\section{Autobiography and the Discovery of Truth}

"I once was lost, but now am found, Was blind, but now I see."

$\sim$ John Newton, Amazing Grace.

\section{AWAKENERS AND AWAKENINGS}

In March of 2008, over one hundred veterans of the U.S.-led wars in the Middle East gathered in Silver Spring, Maryland "to testify about their experiences in Iraq and Afghanistan" and provide "eyewitness accounts of the occupations" in order to give "an accurate account of what is really happening day in and day out, on the ground."1 This event, called "Winter Soldier: Iraq and Afghanistan," was scheduled to commemorate the fifth anniversary of the invasion of Iraq by U.S.-led forces. Organized by a social movement organization, Iraq Veterans Against the War, the event's title was chosen to pay tribute to a similar public testimonial organized by Vietnam Veterans Against the War in 1971. ${ }^{2}$ Now, over thirty-seven years after the Vietnam-era event, a diverse group of veterans testified to civilians and media about the atrocities of war. Over the 
course of four days (March 13-16), they addressed issues from the devastation and dehumanization of Iraqi and Afghani civilians to the lack of adequate healthcare for returning soldiers.

While focused on exposing the political and moral atrocities of war, these "winter soldiers" 3 were able to assert a unique authoritative perspective because they drew on their own personal experiences to show what was "really happening." Like testimony more generally, 4 these veterans derived their authority to speak on a controversial social issue from the details of their autobiographies. In other words, they "were there" 5 and could consequently offer a profound, credible, and special insight into the question at hand by recounting an important part of their life experiences. Beyond this issue of autobiographical presence, however, many of these speakers derived further authority to define the wars at hand (and U.S. politics more generally) from another dimension of their testimonies - one that is explicitly noted in the online personal profiles of many members of Iraq Veterans Against the War (even if only implicit in many of the testimonies offered at the Winter Soldier event). This second claim to authority stems from the notion that many of these individuals once wholeheartedly believed in the rationales or ideological justifications for the wars they are now condemning. Many voluntarily joined the military and/or entered the war effort donning a patriotic worldview in the wake of the September $11^{\text {th }}$ attacks on the World Trade Center and Pentagon buildings in New York and Washington D.C. Others had a more ambivalent or less-defined outlook but were not previously committed to an anti-war worldview. So sometime between then and now, as such autobiographical stories go, these soldiers experienced a major change of 
mind, an awakening to the "truth" about the war, and they began to convey what psychiatrist Robert J. Lifton described with reference to Vietnam Veterans as a shift from the paradigm of John Wayne to the paradigm of Country Joe and the Fish. ${ }^{6}$ Their testimonies thus combined two seemingly contradictory points of view - they are both insiders who carry the experience of war and outsiders who no-longer share the mindset or uphold the values of the once-embodied insider.7

For centuries, individuals have told stories about discovering truth in their lives. They describe having held false beliefs about the world and consequently having lived a significant part of their lives "blind" to reality. Simultaneously, such storytellers also describe discovering truth, a discovery that is usually spurred by some momentous set of circumstances or preceded by a protracted quest or journey. They tell of "seeing the light" or "waking up" to discover the "truth" about themselves and the "reality" of the social world, at once knowing that their prior beliefs and perceptions were "false" and "deluded" while their current understanding is "true” and “enlightened.” Like many members of Iraq Veterans Against the War, other individuals who belong to various groups and communities also describe awakening to "truth" in their lives. Some describe discovering a new religious "truth," typically to explain their conversion to a new faith or their decision to reject a church in which they once believed. Others account for a new-found psychological "truth," often finding causes for their psychological troubles in newly-discovered or redefined childhood experiences. Still others describe discovering a sexual "truth," commonly accounting for their awakening to a newly-acquired sexual orientation or identity. Despite the notable differences in these various issues of concern, all such individuals use their 
autobiographical accounts to take a stand on some significant issue. They tell personal stories about awakening to truth in order to define some morally or politically controversial situation. ${ }^{8}$

This book explores such awakening narratives: autobiographical stories people tell about having been contained in a world of darkness and ignorance and subsequently awakening into an enlightened understanding of their experiences, their relationships, and the connection between their lives and the world around them. Awakening stories do not concern relatively mundane or "seamless" developments in the storyteller's life. ${ }^{9}$ Rather, awakening narratives provide a socially patterned, narrative "patch" for otherwise radical transformations in our perception, comprehension, and explanation of our experiences and relationships. People tell such stories in order to account for a major change of mind - to describe what Peter Berger describes as an "'alternation [...] between varying and sometimes contradictory systems of meaning." 10 They use such stories to explain their rejection of one worldview and justify their embrace of new attitudes, beliefs, perceptions, and actions. These awakening stories are quite prevalent; they span many different subject matters and a wide variety of social and historical contexts. These stories also demarcate the boundaries of social disputes and cultural tensions concerning the nature of "truth" in the world.

Rather than study a specific group (like a social movement organization) or a particular issue (such as sexuality or religious conversion), I am interested in a type of autobiographical story. ${ }^{11}$ This story type is used by otherwise very different individuals who are dealing with otherwise different issues. I analyze the personal accounts of Iraq war veterans who experienced a major 
transformation of their views on the war and, more generally, the political policies of the US government. However, I also analyze the testimonies of Mormon and Born-Again Christian converts as well as the personal stories of apostates to the Mormon Church - those who once believed in the tenets of Mormonism and have since rejected the Mormon faith. In addition, I analyze various stories people tell about "recovering" memories and discovering that they were sexually abused in childhood. I also explore the stories of individuals who once believed they were sexually abused but now "retract" those memories and recant their accusations. Further, I analyze several accounts written by individuals who describe discovering the truth about their sexuality (and sexuality in general). These include the stories of those who once believed they were homosexual and later "discovered" the "truth" about sexuality in "sexual reparative therapy" as they embraced a heterosexual lifestyle and a heteronormative worldview. They also include the stories of individuals who once underwent therapy to rid themselves of homosexual attractions and have since "discovered" the "truth" about their sexuality as they embraced a homosexual lifestyle and queer-positive worldview. I also analyze a variety of other political, religious, sexual, psychological, and philosophical stories from various times and places that add to this diverse range of cases. Despite the many differences among this eclectic combination of autobiographical accounts, they are all about the experience of "awakening." All of the storytellers I mention describe a major transformation of mind. Such awakeners use a common, socially patterned story to describe discovering the "truth" about experiences and relationships that are central to their lives. 
However, while awakening narratives convey a personal discovery of "truth," I am not interested in measuring the objective character of truth and falsehood, nor do I take a position on the issue of what really happened in an individual's life and what did not. I know nothing of these individuals except the stories they tell. Further, I do not take their accounts at face value. Instead, building on Denzin's discussion of the "major epiphany,"12 I am interested in how individuals use awakening stories to construct accounts of truth and falsehood in order to give meaning to their lives and weigh in on salient moral and political concerns. In this sense, I am building on the tradition established by literary theorist Kenneth Burke and others who recognize that the meaning we attribute to important life experiences is a narrative accomplishment. ${ }^{13}$ In The Grammar of Motives, Burke advances a pentadic schema - what he calls "the five key terms of dramatism" - to investigate the literary attribution of motives as a means of understanding human social interactions. He identifies these key terms as he writes,

[...] any complete statement about motives will offer some kind of answer to these five questions: what was done (act), when or where was it done (scene), who did it (agent), how he did it (agency), and why (purpose). ${ }^{14}$

By outlining such a "grammer of motives," Burke gives us an analytic devise with which we can interpret narratives as social dramas, as dramaturgical worlds of meaning that illuminate social life. Further, he provides a framework with which we can interpret the way individuals use stories to ascribe meaning to the world. Building on Burke's theory, C. Wright Mills calls on sociologists to investigate the ways that social actors explain and account for their actions and the actions of 
others. In his 1940 article, "Situated Actions and Vocabularies of Motive," 15 Mills argues,

Human actors do vocalize and impute motives to themselves and to others [...] Rather than fixed elements "in" an individual, motives are the terms with which interpretation of conduct by social actors proceeds. This imputation and avowal of motives by actors are social phenomena to be explained. The differing reasons men give for their actions are not themselves without reasons. ${ }^{16}$

Mills suggests that the stories people tell - the accounts they give - are an important subject matter of sociology. More than any "objective" happenings or experiences, the vocabularies we use to explain the world - and our situation within it - provide a window into the meanings of social life. Broadening Mills's approach to suggest a theory of "narrativity," Hayden White argues that narrative is a "meta-code" that we use to give meaning to our experiences and transmit a shared reality. "To raise the question of the nature of narrative," White comments, "is to invite reflection on the very nature of culture." ${ }^{17}$ Using such a perspective, Joseph Davis argues, “Stories configure selected past 'events' (meaning both actions and experiences) into a plot, which portrays them as a meaningful sequence unfolding from the beginning event toward a valued endpoint or 'moral' the story anticipates." 18 Further, as Arlene Stein notes, storytelling can be "a vehicle for self-transformation, collective identification and social action." 19 Engaging in a "sociology of stories," 20 I adopt a similar cultural and constructionist approach here. When telling their stories, awakeners give narrative life to ideas of truth and falsehood. In the process, they attribute meaning to their lives and to the world around them. Regardless of the objective 
veracity of their claims or the accuracy of their perceptions, and regardless of whether the individuals who tell these stories believe their own accounts, these storytellers all make strong claims that they have discovered the "truth." Their notions of "truth" or objective "reality" take form within socially patterned stories about major changes of mind. ${ }^{21}$

Because individuals use socially patterned awakening narratives to address a wide variety of subject matters and concerns, this story type pervades a wide variety of otherwise different realms of social life. I use the phrase realms of social life to refer to worlds of human activity and discourse that are typically attributed some degree of autonomy in the world, including the psychological, political, religious, and sexual. In various writings, notably his "Religious Rejections of the World and their Directions," Max Weber argued that different "spheres of value" (of which he distinguished between the religious, the economic, the political, the aesthetic, the erotic, and the intellectual/scientific) increasingly operate by their own, unique cultural logics, becoming more "purified" (autonomous) with the progress of the modern world. ${ }^{22}$ However, whereas Weber stresses the emergent distinctions and evolving autonomy among different realms of social life, I focus on something that they hold in common - a type of storyteller and story formula that pervade all of them. Despite the divergent cultural logics of the variant discourses ${ }^{23}$ that define otherwise different realms of meaning and human activity, individuals and communities construct and deploy surprisingly similar awakening narratives as they navigate the social contours and dynamics of each. I thus highlight the social and cultural 
prevalence of the very same awakening story formula across otherwise different cultural and historical realms of social life.

Awakening stories provide storytellers with a socially rooted mechanism to assert cognitive authority, regardless of the content of the story. Conceived broadly to mean the ability to shape the meaning of events, experiences, relationships, and identities, cognitive authority is an important dimension of social power. ${ }^{24}$ As opposed to relatively localized discoveries (such as discovering the cause of an ongoing health problem) or accounts of a particular misperception (such as realizing a friend or lover "is not the person you thought they were"), awakenings involve a narrated substitution of one worldview - what Snow and Machalek call a "master attribution scheme" 25 - for another. All awakeners use their autobiographies to defend one version or truth and reality while undermining and debunking another. As opposed to individuals who use their life stories to claim authority based on an ambivalent or multivocal outlook, ${ }^{26}$ awakeners base their current belief system on the negation of their old perspective. When they tell their stories, they reject any possibility of integrating these two worldviews as well. ${ }^{27}$

While sociologists have traditionally taken autobiography to be "accounts of identity, narratives of the self," 28 and others have elaborated the ways that individuals account for major changes of identity, ${ }^{29}$ I primarily focus on the ways that individuals articulate new epistemic standpoints as they switch thought collectives. $3^{\circ}$ Further, when individuals tell stories about discovering truth, they weigh in on a cultural dispute over meaning that illuminates a link between autobiographical accounts and the intersubjective, "impersonal social 
mindscapes that we share in common" ${ }^{11}$ with some but also hold in contrast to others. As awakeners convey a personal discovery of "truth," they use their autobiographical stories to assert authority over the definition of some morally or politically salient issue or situation while simultaneously undermining competing knowledge claims, contentious definitions of the situation, variant memories, and alternative worldviews. In short, they express, and take a stand on, a cultural tension in autobiographical form. Thus, while I am engaging in a sociology of stories, I am also advancing a sociological perspective on knowledge, cognition, and memory 32 - one that calls attention to the ways individuals and communities use personal stories for strategic cultural purposes.

\section{The Awakening Story as an Autobiographical Formula}

Awakening narratives are autobiographical accounts in which the storyteller's understanding of truth undergoes a radical change over time, whatever that understanding may be at the point in which the story is told. Like other autobiographical stories, and narratives in general, awakenings have plot lines, turning points, characters, and vocabularies that conform to observable social patterns. 33 Individuals use this type of story to describe a past incongruence between their personal, subjective mindset and objective reality (a fissure between their subjective perception and what is "really" going on). They distinguish this phase of incongruence or "false" consciousness from a more current state of harmony between their personal, subjective outlook and objective reality (they describe mending the fissure between their mind and the world 
around them; they describe coming to see what is "really" going on). Despite various differences in content or focus, all awakening stories conform to this basic story formula. All individuals who use such a story formula describe taking on a new worldview that that they position in diametric contrast to their previous mindset.

I became interested in awakenings while studying trauma narratives. In particular, as I was researching stories about "recovered" memories of childhood sexual abuse, I began to notice that the process of recovering memories involves a formulaic discovery of "truth" (in this case, the memory of abuse) and a consequent, formulaic account of the narrator's "false" belief (their prior, mistaken perception that the abuse wasn't there). Self-identified survivors of childhood sexual abuse tell scripted stories about awakening to the truth about their lives. 34 Phillip's account, for example, was published in a therapeutic treatment manual. Phillip recalls,

When I was 14, my mother used to come into my bed in the early hours of the morning, arouse me sexually, and sexual intercourse would take place. Until recently (I am now 52) I thought I had dreamed those sessions, because I must have never been fully awake [...] I can't tell you how I felt when this dawned on me.35

Phillip is telling us that what he used to believe was a dream, he now - quite suddenly at the age of 52 - knows was sexual abuse. As he tells us this story, he is describing his prior state of "false" consciousness ("I thought I had dreamed those sessions"), while testifying to the "truth" (intercourse, sexual abuse) and radically redefining his relationship with his mother. In remarkably few words, he describes a major transformation of consciousness - a major discovery of 
"truth" and "reality" that has significant implications for his future attitudes, behaviors, and relationships.

Phillip’s story is certainly very personal. His “dawning” or awakening, however, is far from unique. Many other individuals tell similar stories about recovered memories of childhood sexual abuse in therapeutic or support-grouplike settings. Further, while such stories involve a psychological subject matter, they are formally similar to stories about religious conversion, attaining political consciousness, discovering one's sexuality, and more. For example, Eleonai "Eli" Israel, an Army National Guard Specialist and member of the social movement organization Iraq Veterans Against the War, describes a major transformation of consciousness with regard to an explicitly political subject matter. Eli recounts,

Like many after September $11^{\text {th }}$ I wanted to serve, again. I felt I owed something more to my country after my years of training. I trusted my president and my leadership to tell me the truth. I also trusted my own integrity. I knew that I would never willingly do anything that I knew to be immoral or wrong [...] I reasoned that my actions during these missions were justified in the name of "self-defense." However, I came to realize my perception was wrong. I was in a country that I had no right to be in, violating the lives of people, and doing so without regard to the same standards of dignity and respect that we as Americans hold our own homes and our own lives to [...] I have taken and/or destroyed the lives of people who were defending their families from being the "collateral damage" of the day. ${ }^{36}$

Like Phillip, Eli describes a significant personal discovery, a dawning in which he realized his old perceptions and beliefs were false while coming to understand the true nature of his actions, experiences, and relationships. Despite dealing with very different subject matters, both of these storytellers juxtapose a past state of cognitive constraint (a false or deluded mental state) with a more current state of 
cognitive emancipation (a newly enlightened mental state). Their stories conform to a common social pattern and formula of storytelling.

By focusing on the formal properties shared by these two stories at the expense of their otherwise significant differences, we can begin to see how this story formula has a generic social logic that both Phillip and Eli use to give meaning to their lives and justify their current beliefs and perceptions. Various individuals - with different backgrounds, in different stages of life, facing a variety of different circumstances and situations - use a socially patterned awakening story formula to explain and justify a major change of mind. Some (like Phillip) describe an inductive awakening by accounting for a particular event or memory that spurs a major change in worldview. Others (like Eli) account for a deductive awakening by describing how their loss of faith in one worldview and simultaneous embrace of another leads them to reinterpret their more specific experiences and memories. However, all such awakeners combine a formulaic story type with the particular details of their lives and concerns in order to assert the truth of their current perceptions, beliefs, and moral convictions by contrasting them with their former "false" worldview. They posit one as the negation of the other. In the process, they use their autobiographical accounts to corroborate particular - and often controversial - knowledge claims in the world. Notably, this social logic is inherent in the grammatical organization of such stories. One can "discover" or "see" the truth, but we rarely hear someone say, "I see the false." In fact, "false" is not even a noun. It does not have the object character of "truth," which can be found, discovered, seen, heard, spoken, preached, and shared. 
The generic properties of the awakening story formula are evident in the following example in which neo-conservative activist David Horowitz describes realizing that his long-held Marxist worldview was in fact "false." Horowitz writes,

One evening [...] I had a sudden shock of recognition [...] [As] I visualized a pyramid whose apex was Marxism, which was my life's work and which provided the key to all other knowledge [...] a previously unthinkable possibility entered my head: The Marxist idea, to which I had devoted my entire intellectual life and work, was false. All around me, the room went black. In the engulfing darkness, the pyramid flattened and a desert appeared in its place, cold and infinite, and myself an invisible speck within it [...] For the first time in my conscious life I was looking at myself in my human nakedness, without the support of revolutionary hopes, without faith in a revolutionary future. (emphasis in original) 37

Horowitz goes on to describe his realization of political "truth" as he rejects his prior, left-wing beliefs in favor of a conservative worldview. However, regardless of the particular details of his autobiography, Horowitz uses a generic awakening story formula to depict his life and engage in an ongoing dispute over truth and meaning. The genericity of his account can be seen when we eliminate a mere four words from the passage and replace them with others. By ignoring the stricken words below, the account becomes generic. By replacing them with either set of words printed above the strikethroughs, we completely change the meaning of the story, illustrating the remarkable flexibility of the story formula. 
One evening [...] I had a sudden shock of recognition [...] [As] I visualized (a) Catholicism

(b) Neo-Conservatism

a pyramid whose apex was Marxism, which was my life's work and which

provided the key to all other knowledge [...] a previously unthinkable

(a) Catholic

(b) Conservative

possibility entered my head: The Marxist idea, to which I had devoted my

entire intellectual life and work, was false. All around me, the room went

black. In the engulfing darkness, the pyramid flattened and a desert

appeared in its place, cold and infinite, and myself an invisible speck

within it [...] For the first time in my conscious life I was looking at myself

(a) religious

(b) conservative

in my human nakedness, without the support of relutionary hopes,

(a) religious

(b) conservative

without faith in a revolutionary future [...].

As a result of changing just a few words, we can use Horowitz's rendition of the awakening narrative to create an entirely different meaning. By replacing the stricken words with the words designated as Set A, we make the story about religion as opposed to political revolution. By using the words in Set B, we turn the story into its ideological “opposite.” Further, we could continue to make similar minor content-based changes to the narrative and apply it to any of a wide variety of subject matters and moral or political positions (for example, we 
might use psychoanalysis, nationalism, or any other system of thought in place of Marxism and the adapted narrative would be just as plausible as the original). The versatility of the basic story framework (the fact that it can be applied to a wide range of subjects with just minor changes) is exactly what makes the narrative formulaic. With slight changes, the narrative formula can be used to undermine and reject any one ideology and pave the way to justify and defend any newly acquired worldview.

Figure 1 is a temporal map of the awakening narrative formula. ${ }^{8}$ The $\mathrm{X}$ axis represents autobiographical time. To move leftward is to move into the past; to move rightward is to advance into the present and future. Alternatively, the $\mathrm{Y}$ axis represents the awakener's distinction between "falsehood" (structurally represented by the lower plane) and "truth" (structurally represented by the higher plane). The defining character of the awakening narrative, then, is a temporally situated, binary distinction between "falsehood" and "truth." The starburst in the center of the figure symbolizes the narrated awakening experience - an event or process that is required to jump the border marking the dichotomy of enlightenment. The dashed line represents the way that awakeners plot their autobiographical accounts in relation to this two-dimensional narrative map. 
Figure 1: The Structure of an Awakening Narrative.

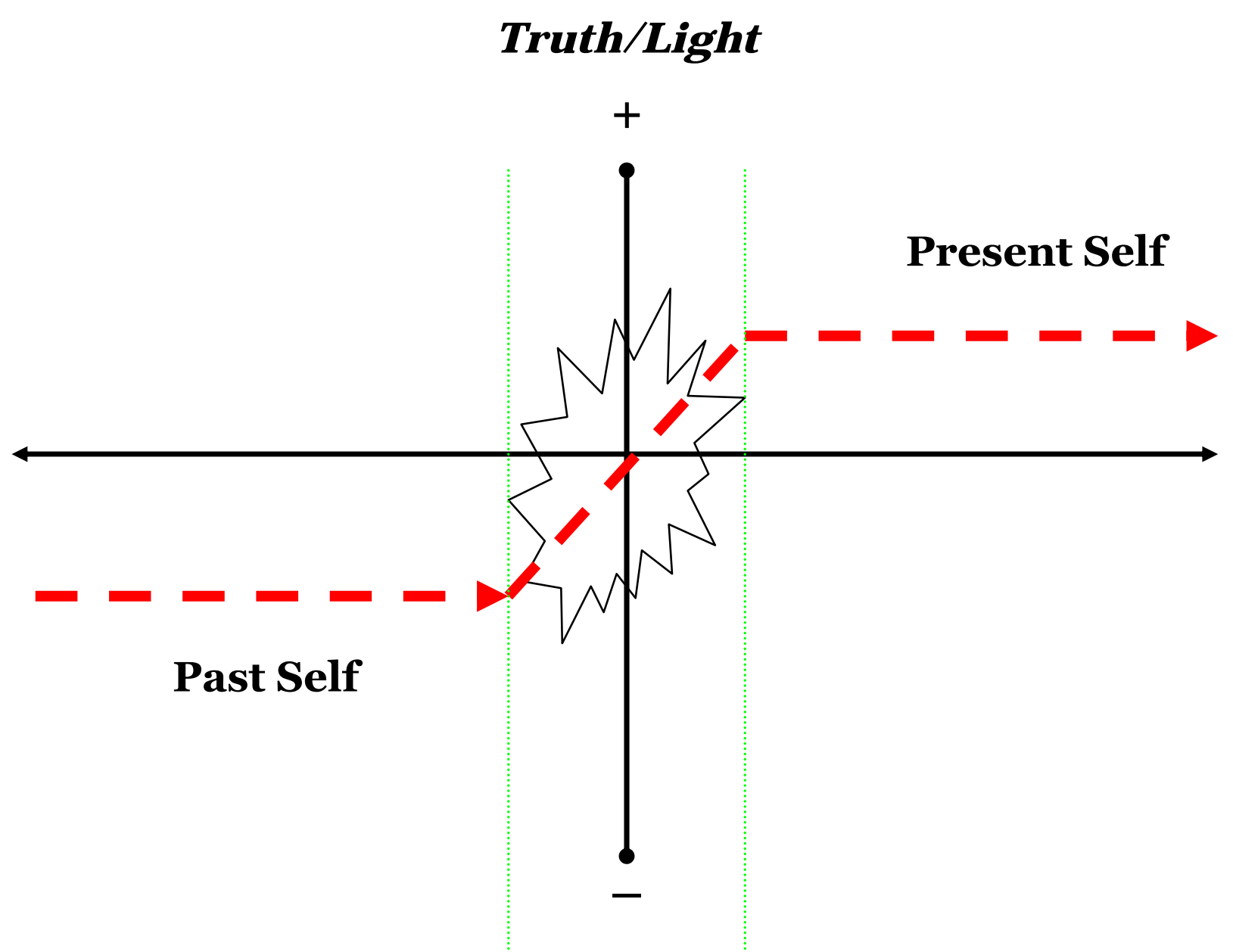

Falsehood/Darkness

X Axis = Autobiographical Time

Y Axis = A Dichotomy of Enlightenment

Dashed Line $=$ The Autobiographical Account 
Awakenings are stories that adhere to this generic story formula or model of autobiography. Individuals use this culturally established story formula to account for life-changing realizations of "truth" regardless of whether their stories pertain to psychological, political, religious, sexual, or other subject matters. Further, different individuals use the same generic story formula to convey otherwise antithetical or oppositional versions of truth. The same story formula can be used to embrace or undermine any given worldview. Thus, selfidentified survivors of childhood sexual abuse (who are "recovering" memories and making accusations of childhood sexual abuse) and retractors of sexual abuse accusations (who once claimed to recover a memory of abuse that they now believe to be false) tell formally similar stories. ${ }^{39}$ Similarly, religious converts (who are joining the Mormon religion) and religious apostates (who are quitting the Mormon religion) tell stories that are formally similar despite manifesting oppositional standpoints in a broader cultural environment. Likewise, those who undergo "sexual reparative therapy" and awaken to discover their "true" heterosexuality tell stories that are formally similar to the stories told by those who reject sexual reparative therapy and discover their "true" homosexuality. Storytellers who are conventionally said to be in "opposing" camps tell stories that adhere to the same awakening formula. With regard to the content and orientation of their stories, they have "reverse" narratives. Structurally, however, they are the same.

By primarily focusing on a narrative formula, my approach stands in marked contrast to studies that highlight the idiosyncratic dimension of autobiographical stories, such as traditional psychoanalytic case studies, ${ }^{40}$ or 
Fichter's study of religious conversion, for example, which opens with the caveat, "The autobiographical statements of the eighteen Unificationists in this book are personal and specific, and they cannot be generalized as the typical Unification mode of conversion and recruitment." 41 My formal comparative approach can also be distinguished from ethnographic or case-specific studies that focus on the construction of autobiography in one particular context or occasion 42 as well as critical analyses of personal accounts or life experiences that focus on one particular substantive issue such as "illness experience," 43 sexual "coming out," 44 religious conversion, 45 or "job loss," 46 for example. Using a story formula to guide my analysis of content, I elucidate general narrative features and social patterns that transcend any one particular story, case, or substantive realm of focus. In the process, I advance an explicit "social geometry" 47 of awakening stories that illuminates the ways that individuals and communities use autobiographical stories weigh in on unresolved cultural tensions or disputes over the definition of salient moral and political concerns. As they reject one version of truth and embrace another, individuals who tell awakening stories convey a partisan view of a cultural tension in autobiographical form.

Highlighting the generic temporal structure of the awakening narrative formula, I advance several foundational arguments. First, there are important formal similarities and observable social patterns among awakening narratives despite significant differences in subject matter. Second, such similarities in story formula exist despite the divergent or oppositional claims and disparate agendas of storytellers. Third, individuals resolve the tension between different, mutually exclusive worldviews in their autobiographical accounts in order to associate with 
a specific autobiographical community and advance that community's definition of the some morally or politically salient issue or situation. Fourth, as individuals use their personal accounts to advance one socially grounded view of reality, they also undermine competing versions of truth. Finally, when individuals tell awakening stories, they express a cultural and epistemic tension between different communities within an autobiographical field - a broad social arena where individuals construct their personal stories in mutual relation (and competition) with one another. Awakening stories thus contain both a positive expression of an epistemic claim and its negation; they express a cognitive and epistemic contradiction between contentious worldviews that marks the sociomental boundaries between different communities. So while I outline the formal similarities common to a variety of substantively different stories, I also illuminate the ways that individuals and communities use autobiographical stories to compete for the cognitive and mnemonic authority to define the parameters of reality and attribute meaning to important events, experiences, and relationships. These foundational arguments or premises underlie all of the themes I discuss throughout this book. Using the general properties of the awakening story formula to drive my analysis of story content, I shed light (to adopt a pertinent metaphor) on questions concerning social memory, time, cognition, knowledge, identity, social conflict, and the profound social significance of autobiography. 


\section{The Awakener as a Social Type of Storyteller}

In addition to viewing awakenings as an autobiographical formula, I also consider the awakener to be a "social type" of storyteller. The notion of a social type was pioneered by Georg Simmel, who sought to identify the generic characteristics of actors that stem from their dynamic position vis-à-vis others their place and part in the social structure. ${ }^{48}$ Simmel coined the notion of a social type to identify the generic actor-positions that give rise to various "forms of sociation" or "particular kinds of reciprocal attitude and behavior" 49 that exist despite the content of the interaction. Simmel identified several examples of such social types, including the "stranger," the "mediator," the "dude," and the "poor." As Coser notes,

Simmel conceives of each particular social type as being cast by the specifiable reactions and expectations of others. The type becomes what he is through his relations with others who assign him a particular position and expect him to behave in specific ways. His characteristics are seen as attributes of the social structure.50

Thus, social types exist because of their relationally-situated position in the social world, regardless of the personal, idiosyncratic characteristics of any individual that stands in that position.

Adapting the notion of social types to a narrative perspective, one is an "awakener" because one uses a patterned story formula to account for discovering truth in one's life, not because of any personal or idiosyncratic attributes. Indeed, people hold awakenings to be central to the evolution of their individual mind, soul, psyche, and/or personality. They often use them to describe life-changing 
experiences that are deeply personal - rooted in their sense of self and their psychological, emotional and/or spiritual well-being. In telling such stories, they justify their personal beliefs, lifestyles, or objectives and plot their prospective future lives, relationships, and courses of action. However, as opposed to viewing this patterned story formula "as a manifestation of the underlying personality" of a few individuals or "as a key to understanding the personality of the teller," ${ }^{11} \mathrm{I}$ view the awakening story formula as a generic cultural resource that a great variety of individuals use and adapt to their particular lives for strategic purposes. Despite any given storyteller's personality, psyche, identity, or particular situation, individuals who use this story formula take on a common, socially situated narrative orientation vis-à-vis others in the social world. These social relations are the key to understanding the cultural significance of this type of autobiographical story. By transcending the personal aspects of such awakenings and the idiosyncratic characteristics of such awakeners, we can illuminate the socio-cultural power and meaning of awakening stories in everyday social life.

In their influential treatise, The Social Construction of Reality, Peter Berger and Thomas Luckmann suggest that the process of "alternation," or "cases of near total transformation [...] in which the individual 'switches worlds', ' is exemplified by religious conversion but has expanded to be "imitated by secular agencies." ${ }^{2}$ Building on Berger's prior discussion of alternation, they establish a theoretical foundation for the sociological study of subjective transformations that has informed the study of religious conversion in subsequent decades. Following Berger and Luckmann, David Snow and Richard Machalek first 
proposed the notion that the "convert" is a social type of actor. ${ }^{53}$ Reasoning inductively from Snow's ethnographical work in the Nichiren Shoshu Buddhist movement, they show that converts to religious groups share some important, general characteristics with converts to other ideologically-based groups, such as communist organizations and psychoanalytic communities. Moving beyond these prior studies, I emphasize the generic characteristics of awakeners by exploring the formal properties of awakening stories. Further, I compare cases from a diverse array of social and historical contexts. "After all, the wider the range" of cases I study, "the more generalizable [my] argument."54 Deliberately using multicontextual evidence, I consider how various individuals use an awakening story formula to wield their autobiographies in a contentious social environment. In the process, I detail four main dialogical orientations that characterize awakeners as a social type of storyteller.

When I use the concept of "dialogical orientations," I stress the ways that awakeners formulate their autobiographical accounts with multiple audiences in mind. Despite the content of their stories, they speak or write in anticipation of the different ways that separate groups of people will hear and react to their accounts, and these multiple audiences are inherent in the story itself, as well as, I argue, the story formula. They manifest in narrative (autobiographical) form. As Mikhail Bahktin argues more generally,

[...] the utterance occupies a particular definite position in a given sphere of communication. It is impossible to determine its position without correlating it with other positions. Therefore, each utterance is filled with various kinds of responsive reactions to other utterances of the given sphere of communication. 55 
Like "utterances" more generally, awakening stories contain the "responsive reactions" and "evaluative tones" 56 of multiple parties that are situated in relation to one another in a broader "sphere of communication." Further, such spheres of communication contain both contemporaneous and temporally-situated links or channels of influence. 57 The particular constellation of dialogical orientations inherent in the awakening story formula can be used to define the awakener as a social type of storyteller.

First, awakeners take a contentious dialogical orientation towards the proponents of a rejected worldview (one that the awakener has left in the past). This antagonistic orientation is not necessarily directed against the members of the awakener's former community (for whom the awakener may feel sympathy), but towards the cognitive authority figures and mnemonic agents that uphold the institutionalized ideology that the awakener is working to undermine (whether that institution is a family, military, religion, or sexual identity group). Second, awakeners take a harmonious dialogical orientation towards the proponents of a newly embraced worldview. These include cognitive authority figures and cognitive confederates that make up a new community of like-minded others with whom the awakener expresses solidarity and achieves a sense of ontological security. ${ }^{8}$ Third, awakeners take a proselytizing dialogical orientation towards individuals in the world at large (who are often conceived to be the "sleeping" or the "blind"). This group may or may not include the members of the awakener's former community who the awakener feels are still "in the dark" and in need of “enlightenment.” Finally, awakeners take a figurative dialogical orientation 
towards their past self. Giving narrative form to a particular type of "selfinteraction," 59 awakeners symbolically portray, engage, and defeat their past selves in order to undermine their previous worldview. In the process of portraying a figurative interaction between their past and present selves, awakeners perform elements of the contentious, harmonious, and proselytizing orientations mentioned above. 60

Moving beyond prior discussions, I argue that dialogue is embedded in the awakening story. ${ }^{61}$ From a narrative perspective, these dialogical orientations signify storied forms of social interaction. They illustrate how awakeners take social relations into their autobiographies and enact them as they strategically portray their lives and utilize their personal stories. Awakeners are a social type of storyteller, but in telling their stories they are also social actors. They draw on a cultural "toolkits" 62 and a repertoire of meaningful vocabularies and narrative resources to perform "truth" in a social context. They do autobiographical work to justify and solidify their own worldviews and to shape how others see the world. Inversely, interest groups and thought collectives spotlight awakeners as role models that others can emulate to "see the light." These groups wield awakening narratives to legitimate their worldview in the face of competition. Treating awakeners as a social type of storyteller allows me to weave back and forth between a formal analysis of autobiographical stories and a discussion of the ways actors use their personal stories in dialogic relation to others within a broader social context. This approach also allows me to bridge the sociological study of individual- and collective-level cognitive and mnemonic norms, exploring the interaction between these levels of analysis in ways that are absent 
in prior discussions. Despite a variety of idiosyncratic differences among the individuals whose stories grace the pages of this book, it is their common, formulaic pattern of storytelling that makes them all "awakeners."

\section{AUTOBIOGRAPHICAL COMMUNITIES \& AUTOBIOGRAPHICAL FIELDS}

People tell stories about their lives on various "autobiographical occasions" 63 and in a variety of social contexts that influence the process of remembering and recounting. Therapy sessions, ${ }^{64}$ high school reunions, ${ }^{65}$ Alcoholics Anonymous meetings, ${ }^{66}$ and other social contexts serve as "narrative environments" 67 where individuals learn to tell their life stories in socially patterned ways. Robert Zussman has stated that "a distinctly sociological approach to autobiography" must attend to "the social structures that dictate the occasions for and character of those narratives." 68 Zussman later defined "autobiographical occasions" as "the moments at which narrative and social structure meet." 69 Jaber Gubrium defines narrative environments as those contexts that affirm or privilege "particular kinds of accounts for institutional purposes."70 Such institutional contexts also compel certain perceptions and enforce particular definitions of reality. ${ }^{71}$ In these times and places, individuals adopt shared autobiographical scripts and present personal accounts with attention to (often unacknowledged) social rules of storytelling. They face socially mediated pressures (from other individuals, from the group as a whole, and from the context itself) to accentuate certain details of their lives while ignoring others. 
However, the feeling of personal experience in these accounts is rarely lost in the process. Individuals artfully adapt their personal experiences and sentiments to socially approved scripts in order to convey information to a particular audience. ${ }^{72}$ Thus, they are simultaneously saying, "This is me, these are my experiences" and, "I stand in solidarity with a group of people who share my story; we share experiences." The individual and the group interact in a dynamic dance as group members cooperate to attribute meaning to their lives.

The concepts of "autobiographical occasion" and "narrative environment" have served to enhance our understanding of how specific times and spaces influence the way individuals account for their lives. However, many of the groups that affirm particular autobiographical scripts and enforce social rules of personal storytelling transcend the temporal and spatial boundaries that define particular occasions and environments. Further, because most studies of autobiography are limited to the analysis of a single case or setting (as are most studies of narrative identity), they cannot detail how and why individuals tell formally similar awakening stories in a variety of different settings - with regard to a variety of different subject matters - despite advancing divergent and often contentious versions of truth. Moreover, single-case studies fail to consider how individuals and communities tell autobiographical stories in dialogue with - and often in opposition to - other individuals and communities. Beyond temporally or spatially defined settings, I am particularly concerned with autobiographical communities. Autobiographical communities are relatively durable social groups that privilege particular autobiographical scripts that individuals use to construct their life stories for specific purposes. Such communities use autobiographical 
stories to compete with other communities for the cognitive authority to define significant moral and political issues. While affirming some particular autobiographical scripts, they simultaneously negate and undermine others, outlining the contours of a broader autobiographical field where individuals and communities use life stories to wage a cultural contest over meaning.

Autobiographical communities sometimes cohere in one particular social setting at one particular time, but like other communities, they often transcend these geographical and temporal constraints. Beyond providing socially situated contexts and occasions for autobiographical accounting practices, these are meso-level "thought collectives" in sense meant by Ludwig Fleck.73 As Tamotsu Shibutani noted with regard to reference groups more generally, such communities shape their members' perceptions, beliefs, and orientations to the world as "one comes to perceive the world from [the group's] standpoint." 74 They exert "social control" - a group-mediated "force through which the social order is confirmed and, moreover, one's identity within that order is defined and assigned"75 according to community standards. Thus, while autobiographical communities are defined by the way members tell similar stories about their lives, they are also "optical communities" with shared cognitive norms and "mnemonic communities" with norms of remembering and recounting the past.76 Consequently, autobiographical communities provide group members with a sense of cognitive security that accompanies the sense of ontological security that individuals typically express as a coherent autobiographical narrative. 77

Awakeners use their autobiographical stories to advance a particular definition of some morally or politically salient situation or issue while 
simultaneously undermining competing definitions and perceptions. In Ideology and Utopia, Karl Mannheim explains that such distinct "ontological judgments" that stem from "different systems of thought, which are often in conflict with one another" are indeed grounded in different social groups that each "move in a separate and distinct world of ideas." ${ }^{78}$ As awakeners undermine one worldview and embrace another, they distinguish between their community and other groups that are not like them - specifically an autobiographical community to which the awakener used to belong. They combine a culturally durable and widespread awakening story formula with a particular "group style" 79 of storytelling to distinguish between antagonistic communities within a broader autobiographical field.

Building on Foucault's notion of a "field of discourse," 80 I use the concept of autobiographical field to mean a broad, multifarious social arena where individuals construct and deploy autobiographical stories in mutual relation to one another for strategic purposes. As they tell their personal stories, awakeners establish their social location or standpoint in a community that is situated in a pluralistic and contentious world. ${ }^{81}$ In the process, they use their autobiographical stories to define the relationships between groups with different ideas about "truth." Inversely, the structured social relations between different autobiographical communities "commonly determine our experience of meaning and value" 82 by providing discursive tools for individuals to construct meaningful stories about their lives. Thus awakeners formulate (as narrative) and deploy (as social action) their autobiographical accounts in dialogic relation to other actors who use "different repertoires of meanings and values" 83 to produce alternative 
autobiographical accounts in a broader cultural arena. Therefore, just as social discourses in general "both reflect and reproduce power relations that 'live' in social structures," 84 autobiographical stories can reflect and reproduce cultural contests over the cognitive authority to define ongoing and past issues of significant moral and political concern.

In his introduction to Healing Homosexuality: Case Stories of Reparative Therapy, psychologist Joseph Nicolosi argues,

The Gay Liberation Movement has been very successful through the drama of personal testimony. When all the theoretical arguments were presented to the American Psychiatric Association in 1973, both for and against the idea of homosexuality as pathology, it was the socio-political perspective that had the most influence. Listening to some gay men's personal stories of frustration in treatment, the psychiatric association omitted homosexuality as a diagnostic category. Now, exactly twenty years later, we are offering the opposite sort of personal testimony, that of homosexual men who have tried to escape the gay identity but were dissatisfied and then benefited from psychotherapy to help free them of the gender identity conflict that lies behind most homosexuality. ${ }^{85}$

In this passage, Nicolosi outlines a cultural contest over the meaning of sexuality. Further, in order to take a stand in this cultural contest he deploys a collection of biographical sketches ("personal testimony" in the form of psychotherapeutic case studies) that detail the lives of individuals who have discovered the "truth" about their sexuality as they rejected homosexuality and embraced a heterosexual lifestyle. Further, he explicitly frames these accounts in opposition to the stories of gay men who testified to the American Psychiatric Association and, more generally, the "coming out" stories of the Gay Liberation movement. In doing so, Nicolosi works to legitimate and defend one (heteronormative) worldview at the expense of another (what he refers to as a "Gay Affirmative" view) while 
pathologizing the latter. Undermining the notion that any individual's

homosexuality can be considered a legitimate "truth," he continues,

Many homosexuals prefer to believe "I was born this way," thus avoiding the challenge of addressing the issues we deal with here. However, no conclusive evidence has been found for any such biological basis for homosexuality. Although some men may be temperamentally predisposed to passivity and sensitivity (and therefore the gender identity injury that can lead to homosexuality), it has always seemed to me that "I was born this way" is just another way of saying, "I just don't want to look at the developmental issues that made me homosexual." 86

The individual awakening stories that are published in Nicolosi's collection (as well as other, similar autobiographical accounts of "repaired" heterosexuals) are part of a cultural and cognitive battle between dueling autobiographical communities within a broader autobiographical field. As a loosely defined autobiographical community, the sexual reparative movement offers the awakening stories of "repaired" heterosexuals as autobiographical models for homosexually-identified people to jump ship and switch sociomental camps. Further, individuals in this autobiographical community conceive their life stories in dialogical contrast to those who regard their homosexual identities to be an honest expression of truth.

Likewise, in his Forward to the 2001 Edition of Richard H. Crossman's The God that Failed - a collection of autobiographical stories written by former communists that was originally published in the wake of World War II historian David C. Engerman outlines the contours of a different cultural contest. He argues that "[w]hile the essays here are deeply personal, they also represent the close intertwining of private lives with national and international politics" 87 
and that this collection of autobiographical stories serves "as a how-to manual for transforming interwar radicals into Cold-War liberals." 88 Thus, Crossman’s collection of awakening narratives is to communists what Nicolosi's is to homosexuals. Both editors pit their community of awakeners against another group in order to weigh in on broadly important topics of moral and political concern. While there are certainly multiple dimensions of power operating in both of these cultural disputes (in both cases some stories may be more socially privileged in certain places and at certain times and some stories may be more honestly conceived than others), both camps are vying for the cognitive authority to define the moral parameters of a contested issue (in one case, the cultural and identity-based topic of sexuality; in the other, the international politics of the Cold War). Both wield patterned, formally similar awakening narratives as ammunition in these broader cultural contests.

No matter what the topic at hand, when individuals account for a personal discovery of "truth" they convey their standing with a community of like-minded others who share a certain perception of the universe, a certain worldview. Truth involves cognitive solidarity; it necessitates a community of truth in which particular ideas, perceptions, and memories are grounded. Such communities provide interactive access to cognitive confederates with whom individuals cooperate to tell stories about their lives and recount their past experiences. ${ }^{89}$ The act of writing or telling an awakening story thus involves allying with a new autobiographical community and adopting that community's distinctive "mental lenses."9o Autobiographical communities share common ways of wielding the 
personal story as a cultural tool. They perform, display, and promote personal accounts toward common group objectives.

At the same time that "truth" necessitates social harmony among a community of believers, it likewise involves social discord or conflict between a community of believers and a community of non-believers. To stand in solidarity with an autobiographical community also requires cognitive alienation from competing groups. Consequently, as awakeners explain the "falseness" of their previous (mis)perceptions and beliefs and the "trueness" of their current worldview, they cooperate to mark the social distinction between the awakened and those who are still asleep, widening the mental gulf between these camps while downplaying intracommunity distinctions. While truth necessarily stands in opposition to falsehood, which by definition means that which is antithetical to the truth, its also means establishing a social distinction between those who uphold the truth and those who do not. Awakeners incorporate and express these socially constituted epistemic tensions in their autobiographical accounts. Attending to the way individuals formulate knowledge claims and accounts of personal discovery in autobiographical communities, and the way autobiographical communities exist within contentious autobiographical fields, provides a powerful way to approach a distinctly cultural and cognitive sociology of autobiography. 


\section{AUTOBIOGRAPHICAL TIME AND AUTOBIOGRAPHICAL MEMORY}

Writing to an audience of fellow apostates, an ex-Mormon who goes by the name Moonshine comments,

Like many of you, I have spent the last several years trying to make sense out of the most extraordinary experience of my life - my evolution through and beyond traditional Mormon beliefs [...] [I now have] an acute awareness of the [...] fear and dependence the church fosters in it's faithful members [...] What a trip! [...] The cognitive dissonance I felt set in motion a chain of events that led to some painful conclusions. ${ }^{91}$

Using phrases like "evolution through and beyond," "a chain of events," and "What a trip!," Moonshine lays out a rudimentary temporal map of her life with just a few words. She uses the general metaphor of a journey92 to shape her life along a timeline. As she goes on to fill in more detail, her audience is already given a sense of her personal awakening. We are aware of a sharp distinction between her past mindset (defined by her "traditional Mormon beliefs") and her present worldview (as an apostate who has moved "beyond" Mormonism). From her current narrative standpoint, Moonshine sees things very differently than she used to.

As awakeners tell stories about their lives, they reach backward in time and reinterpret their past beliefs, perceptions, experiences, and relationships. They reconstruct their personal memories as they work to redefine some significant issue or situation. Thus, awakening narratives facilitate explicit mnemonic revisions. Because they are explicit, such mnemonic revisions inherently strike a sharp distinction between the awakener's past and present worldviews. As they "nihilate" the past, 93 awakeners build a sharp historical 
discontinuity 94 or temporal rupture into their stories that provides for a sense of subjective transformation.

Although Maurice Halbwachs briefly discussed the social foundations of autobiographical memory when he first introduced the notion of collective memory, ${ }^{95}$ very few memory scholars have theorized the relationship between these two levels of analysis. ${ }^{6}$ As awakeners redefine their personal memories they also work to influence the mnemonic norms of some multifaceted or morally divided social group. Some use autobiographical memories to shape collective memory in the sense originally proposed by Halbwachs - "an image of the past which is in accord $[\ldots]$ with the predominant thoughts of the society" 97 - meaning the shared memories of a macro-level community. They use their personal stories to make a statement about how "the society" should remember. Others use their autobiographical memories to shape the accepted social framework for individual memory with regard to a particular moral issue. They use their personal stories to say something about how individuals should account for certain issues and remember certain experiences. In both cases, the awakening story formula provides a socially constituted vehicle for the storyteller to assert mnemonic authority - the authority to define or redefine past experiences, events, and social relationships that are more broadly relevant than the life experiences of any one individual.

Awakeners also reach forward in time and re-invent their future life plans and personal trajectories. While such future projections ${ }^{8}$ may be explicit or implicit, they are a necessary consequence of the awakener's mnemonic revisions. Redefining the past paves the way for an alternative future. To say, for example, 
quoting John Newton's Amazing Grace, “I once was blind, but now I see," is to make a distinction between your past mindset (constrained or limited by your metaphoric "blindness") and your present outlook (emancipated by a newly acquired "sight"). When we make such a statement, we are juxtaposing the past and present, but further we are retrospectively reinterpreting the past in order to establish and justify our newly acquired vision, whatever that vision may be. We define our present and future life in reactive contrast to our newly (re)understood past. Notably, the second half of Newton's phrase is redundant. To (re)define your past by asserting your once-suffered "blindness" implies your current and ongoing ability to "see."

When awakeners reinvent their personal histories, they use autobiographical time and autobiographical memory to distinguish between two different and contentious ways of understanding some situation, event, or issue. In the process, they construct and emplot their life course as a testimony to the "truth." The power and logic of the awakening story is thus inherently cognitive and temporal in essence, but with the qualification that both our cognitive make-up and the temporal flow we associate with our life course are inherently social in character. As they reinterpret their autobiographical past, awakeners use autobiographical time to convey a radical shift in cognitive orientation and assert commitment to a new system of cognitive norms. In the process, they convey what Kuhn described as a paradigm shift 99 while inviting others to attend to specific details of their new personal reality. Moreover, there is a master temporal pattern to these stories, a formulaic narrative structure that spans a timeline. A state of "falsehood" always precedes a state of "truth" (and the 
inverse, to say "I once knew the truth but now I've discovered falsehood," is culturally absurd.). An awakening experience or episode (whether drawn out over time or relatively instantaneous) serves as a narrated liminal phase - a period "betwixt and between"100 the pre-awakening period of life and the postawakening period. The liminal awakening experience also serves as a narrative bridging mechanism that awakeners use to maintain biographical continuity despite such a radical subjective discontinuity.

When I use the concepts "temporal pattern" and "narrative formula," I am referring to the patterned succession of episodes as well as the projective implications that are central to the meaning of the account conveyed by the storyteller. I distinguish autobiographical time from any notion of chronometric or biological time. Whereas chronometric time refers to a relatively standard unit of temporal measurement and biological time refers to an organism's physiological growth and eventual decline, autobiographical time refers to the way that storytellers arrange their life stories as an ordered course of events and perceptions, situating themselves in the world by giving their lives "historicity and relationality"101 in the process. My approach is distinct from the notion of story structure developed by Propp ${ }^{102}$ and currently used by those who study narrative sequencing ${ }^{103}$ or turn-taking in conversational analysis. ${ }^{104}$ The sequencing approach uses the concepts of "form" and "structure" (especially the latter) to mean the "morphology" 105 of actual narratives as objective social artifacts. Rather, I focus on the formulaic properties of narrative plots, ${ }^{106}$ or "time maps" in Zerubavel's words. ${ }^{107}$ This latter approach is more typical to literature on time, history, and memory ${ }^{108}$ and the social construction of the 
self. ${ }^{109}$ Both approaches to temporality lend themselves to formal analysis and narrative "mapping" and both contribute to the sociological understanding of cognition. However, rather than emphasize the structural organization of narrative, I stress how awakeners use the narrative organization of time and the emplotted flow of events to convey meaning with their autobiographical accounts.

Personal accounts vary in type and style; some autobiographies account for large sections of the narrator's life; others focus in on key, defining moments. ${ }^{110}$ Awakening stories take both forms. Despite various differences, all awakeners reinterpret the past and make a sharp distinction between the past and the present. They use autobiographical time to distinguish between truth and falsehood. In the process, awakeners use their life stories to distinguish between different autobiographical communities and define the parameters of various sociomental tensions and conflicts in the world.

\section{METHODS AND DATA}

Methodologically, I approach my study of awakening narratives from the perspective of social pattern analysis. ${ }^{111}$ In the methodological tradition of Georg Simmel, ${ }^{112}$ social pattern analysts "distill generic social patterns from [multiple] cultural, situational, and historical contexts" in an effort to identify crosscontextual similarities, "thereby making their essentially decontextualized findings more generalizable." ${ }^{113}$ As Cerulo has also shown, by focusing on the common structural or cultural attributes of very different narrative contexts, we 
can identify similarities across otherwise different spheres of social life. ${ }^{114}$ This approach involves selective attention to similarities across seemingly different and unrelated cases. The more diverse the sample of cases, the better. Further, social pattern analysis requires a strict analytic focus. Rather than commit to a particular case or setting, it requires committing to a particular theme, such as "social control," "115 "abstinence," 116 or "notification norms," 117 for example. Such an approach is particularly well-suited to the task of developing "multi-area formal theory" 118 in general and studying narrative formula in particular (See Appendix A for further methodological discussion).

In order to demonstrate the cultural prevalence and diverse relevance of the awakening story formula, I expose the formal similarities among an otherwise eclectic sample of accounts at the expense of substantively salient differences. Viewing story content though the analytic lens of story formula, I reveal common, underlying social patterns among a variety of cases and discourses that are otherwise rarely discussed together. I analyze narrative data in a variety of formats from multiple cultural and historical settings. These include a number of published autobiographical memoirs, various biographical sketches, and fictional stories - what I call popular awakening narratives. I consider several of these to be foundational awakening narratives - historical or theoretical manifestations of the awakening story type that are held to be sacred by particular communities. However, the bulk of my data are autobiographical accounts that are published online in what I call virtual narrative environments. 


\section{Foundational and Popular Awakening Narratives}

Foundational and popular awakening narratives are stories about individual and collective discoveries of truth that circulate in various forms in the public sphere. Many are sacred or iconic to a particular community. Whether extremely well-known or relatively obscure, such narratives provide story templates and cultural tools that modern individuals use to construct their personal stories. As I outline the patterned characteristics of the awakening narrative formula, I analyze the story of Zarathustra, the ancient Persian prophet, which, dated to roughly the $6^{\text {th }}$ century BCE, provides one of the earliest known awakening narratives. I also interpret and discuss Plato's allegory of the cave as a classic philosophical version of the awakening story. Further, I analyze the awakening stories of various prophets and saints, including Siddhārtha Gautama (the Buddha), Paul (the Christian Apostle), Augustine of Hippo, Muhammad (the prophet of Islam), and Joseph Smith (the prophet and founder of Mormonism), as well as stories about those who once subscribed to a particular faith and then rejected that religious worldview, such as Julian the Apostate, Charles Templeton, Fritz Williams, and Julia Sweeney. ${ }^{119}$ I also discuss theoretical accounts of the Western enlightenment ${ }^{120}$ and Marxist theories of false consciousness, ${ }^{121}$ as well as the autobiographical memoirs of notable figures who awoke to reject a once-embraced left-wing worldview, including Arthur Koestler, Richard Wright, André Gide, Lois Fischer, David Horowitz, Peter Collier, P. J. 
O’Rourke, Xavier Arguello, David Ifshin, Carol Iannone, and Joshua Muravchik. ${ }^{122}$

In addition, I analyze psychoanalytic and other psychological theories of the unconscious, repression, and dissociation as a theoretical framework for awakening, ${ }^{123}$ as well as the psychoanalytic case study as a foundational awakening narrative model, with particular attention to Freud's famous and controversial analysis of Dora. ${ }^{124}$ The psychoanalytic case study provides a framework for my analysis of several published "sexual reparative" case studies ${ }^{125}$ as well as autobiographical and theoretical accounts concerning the "recovery" of repressed traumatic memories, especially memories of childhood sexual abuse. ${ }^{126}$ I also explore stories published by individuals who once recovered and then retracted memories of childhood sexual abuse. ${ }^{127}$ Further, I analyze the autobiographical accounts of other modern political figures like Malcolm $\mathrm{X}^{128}$ and Leslie Feinberg, ${ }^{129}$ as well as fictional stories that highlight the main themes of awakening, such as H.G. Wells's “The Country of the Blind” and Kate Chopin's The Awakening. ${ }^{130}$ I also discuss the awakening narrative as it manifests in visual art as well as various films, including Chen Kaige's 1984 film The Yellow Earth and Larry and Andy Wachowski's 1999 science fiction film The Matrix. Despite their many differences, all of these foundational and popular narratives employ the same generic story formula.

\section{Virtual Narrative Environments}


In addition to several foundational and other popular awakening narratives, I base my data analysis on over a dozen websites that I call virtual narrative environments. These are online storytelling contexts where individuals post personal accounts of important life experiences. Sociologists have previously considered the performance of self online, the organization and interaction of individuals who form online communities, and the Internet as a forum for storytelling and making claims about social problems. ${ }^{131}$ Building on these prior studies, I analyze autobiographical stories that individuals post to several websites. These websites serve as the online home base for various autobiographical communities. Among other reasons, individuals use such sites to share personal stories which are often posted with frames, links, photographs, and other images that compliment their accounts. With the relatively new and rapidly evolving technological properties of these online narrative environments in mind, I analyze the personal stories of Iraq War veterans who experienced a transformation of their views on war, people who "recover" and people who "retract" memories of childhood sexual abuse, religious converts and religious apostates, individuals who undergo "sexual reparative therapy" in order to stop their homosexual attractions, as well as individuals who once underwent sexual reparative therapy and have since rejected their "repaired" heterosexuality in favor of a homosexual lifestyle (See Table 1). All of the sites listed in Table 1 host autobiographical communities by providing online space where individuals and interest groups use a shared set of cultural resources and technologies to construct and display autobiographical stories (see Appendix B for a more detailed description of these sites and communities). Notably, many of these 
communities would not otherwise coalesce in one narrative environment without the Internet.

\section{Table 1. Virtual Narrative Environments}

\begin{tabular}{|c|c|}
\hline $\begin{array}{c}\text { VIRTUAL NARRATIVE } \\
\text { ENVIRONMENT } \\
\end{array}$ & DESCRIPTION \\
\hline Iraq Veterans Against the War & $\begin{array}{l}\text { A site hosted by an organization of veterans who } \\
\text { oppose the U.S.-led wars in Iraq and Afghanistan }\end{array}$ \\
\hline $\begin{array}{l}\text { Susan Smiles - Surviving Childhood } \\
\text { Sexual Abuse }\end{array}$ & A site for survivors of childhood sexual abuse. \\
\hline $\begin{array}{l}\text { Safeguarding Our Children - } \\
\text { Uniting Mothers }\end{array}$ & A child abuse awareness and resource site. \\
\hline $\begin{array}{l}\text { The False Memory Syndrome } \\
\text { Foundation }{ }^{132}\end{array}$ & $\begin{array}{l}\text { A site hosted by an organization focused on "false } \\
\text { memories" of childhood sexual abuse. }\end{array}$ \\
\hline Precious-Testimonies & A Born Again Christian site \\
\hline Faith-Travels & A Born Again Christian site \\
\hline MormonConverts & A Mormon Conversion site \\
\hline Recovery from Mormonism & $\begin{array}{l}\text { Interactive discussion board and resources for } \\
\text { Mormon apostates }\end{array}$ \\
\hline Postmormon & $\begin{array}{l}\text { Interactive discussion board and resources for } \\
\text { Mormon apostates }\end{array}$ \\
\hline People Can Change & $\begin{array}{l}\text { A "sexual reparative" site for men "struggling } \\
\text { with unwanted homosexual feelings." }\end{array}$ \\
\hline Courage & A faith-based sexual reparative site \\
\hline Beyond ExGay & $\begin{array}{l}\text { "An online community for those who have } \\
\text { survived ex-gay experiences." }\end{array}$ \\
\hline
\end{tabular}


Possessing certain characteristics of traditional narrative environments ${ }^{133}$ and "free spaces," 134 virtual narrative environments are social spaces of meaningmaking and storytelling. Individuals "gather" in these online settings and use the tools of new media to produce and display autobiographical accounts. However, more than just an amalgam of personal accounts, communities use these virtual spaces to cohere and advance collective definitions of ongoing and past issues and situations. Thus, these websites provide analytic access to the links between individual and collective expression that have been overlooked by many scholars of autobiography and collective memory. These sites are spaces where "challenging codes" 135 and counter-memories ${ }^{136}$ often take form with regard to the particular "group style"137 of the autobiographical community hosted there. However, compared with traditional free spaces, narrative environments, and autobiographical occasions, virtual narrative environments are more "portable"138 (in that they are accessible from multiple and roving locations) and publicly exposed (in that anyone with Internet access is privy to their ongoings). Further, because they are published by interested parties and "moral entrepreneurs," 139 these sites are monitored and edited, providing a mechanism of formal editorial control that that goes beyond the social control characteristic of traditional narrative contexts. Virtual narrative environments range from a "public message board" style (where individuals freely post stories) to a "selective publication" style (where interest groups publish personal stories for specific 
purposes). ${ }^{140}$ Despite these differences, all of these sites host autobiographical communities that stress story-sharing and promote socially-rooted rules of storytelling. They are also virtual spaces of memory where individual participants publicly (re)interpret their past beliefs, experiences, and relationships.

Websites are an important yet underexplored social site of both autobiographical and collective and memory. Just as the phonograph shaped popular memory in the early twentieth century, ${ }^{141}$ Internet technology affects the way we perceive and experience the past. When members of Iraq Veterans Against the War post their stories to the IVAW website, when self-identified survivors of childhood sexual abuse describe recovering memories of abuse on the Susan Smiles - Surviving Childhood Sexual Abuse website, or when Mormon apostates share their personal stories about leaving the Mormon church on the Ex-Mormon Forums, they embed and store personal memories and socially patterned autobiographical accounts in these online spaces. Thus, these sites provide a publicly available means for people around the world to experience mnemonic empathy with individuals they may not otherwise encounter. When individuals post personal accounts about discovering "truth" on these sites, the World Wide Web becomes a medium that facilitates a transmission of both emotion and memory as users are expected to identify with the transformative experiences that are recounted and displayed there. I consider the act of posting autobiographical stories, personal information, blog threads, photos, and videos to these sites to be a new type of commemorative action, one that often involves challenging the official or default memories of another community (whether a 
family, religious community, sexual identity group, or nation) in order to advance an alternative view of past experiences, events, and relationships.

Due to the rise of Internet technology, the act of writing, publishing, and sharing autobiographical accounts has radically expanded. Blogs often contain personal reflections. Social networking sites like MySpace and Facebook not only afford us new ways to (rather easily) perform ourselves online, but also give us a means to provide a theoretically limitless number of "friends" with autobiographical information in the form of personal profiles, wall posts, status updates, digital photo albums, instant messages, and more. The Internet not only serves to popularize and publicize the autobiographical genre, but also allows for a greater degree of autobiographical flexibility. The web allows us to tell personal stories with a variety of new and exciting (if at times unnerving) technologies of communication.

Further, the Internet allows for new modes of communicative social interaction ${ }^{142}$ to span previously obstructive geographic and temporal divides. Beyond traditional autobiographical contexts (such as family or high school reunions, psychotherapy sessions, or job interviews), online autobiographical communities are relatively durable and perpetually accessible to the growing number of people with the means to access the Internet; many individuals can "log on" when and wherever they please. Internet technology allows individuals around the world to form enduring associations and actively deliberate over salient moral, political, psychological, religious, and other concerns. Many of these concerns typically do not arise in face-to-face contexts where social norms and taboos prohibit their discussion. These online autobiographical communities 
consequently serve as virtual base camps of cultural production where a variety of alternative thought styles, epistemological claims, and mnemonic norms are produced, shared, and broadcast to the world. Autobiographical communities use the Internet to combine personal stories and profiles, collective accounts (such as group sanctioned statements of purpose, press releases, news stories, etc.), digital photography, art, video, and a variety of other forms of expression into an online cultural and cognitive lens. Users can then gain access to the community's version of the truth with regard to some important issue, including that community's perspective on the past and their beliefs about future courses of action. When individuals post personal awakening stories to these sites, they testify to the authenticity and validity of that particular lens. These awakening stories then provide other individuals (irrespective of their geographic location) with a formulaic script they can use to "see the light" or "wake up" to discover new "truths" and affiliate with these autobiographical and mnemonic communities.

Finally, Internet technology allows us to more easily see how the various realms of social life, epitomical of the increasingly diverse and complex modern, world manifest as multiple contexts of storytelling. Because these spaces are "virtual" in the technological sense, I am able to compare twelve different narrative environments and observe the formal social patterns common to the accounts produced in each. Such sites provide public (and analytical) access to countless awakening stories while elucidating the ways that these personal accounts reinforce the moral, political, and epistemic claims of various communities. From a Weberian perspective, the internet hosts a multiplicity of 
"orders and values." 143 As a research site, it is ideally suited for gathering multicontextual evidence, comparing different narrative environments in general, and analyzing the various manifestations of awakening stories in particular.

Considering a purposefully eclectic variety of cases, I outline the general properties of the awakening narrative formula to better understand how individuals and communities use autobiographical stories to advance particular belief systems and affect social change. In the process, I consider what these stories say about the social construction of truth and falsehood, the cultural and political dimensions of autobiography, and the connection between personal memories and collective worldviews.

\section{OUTLINE OF THE BOOK}

In this book, I advance a sociological study of autobiographical stories that contributes to important discussions in the field of cognitive sociology ${ }^{144}$ and the sociology of memory. ${ }^{145}$ In distinct contrast to the individual psychological dimensions of personal discovery, I am primarily concerned with the sociomental processes at work with individuals tell stories about discovering truth. Therefore, I stress the ways that individuals take part in communities of truth and cooperate to enforce cognitive and mnemonic norms when they formulate and express their seemingly personal accounts. As opposed to focusing on the nuances and idiosyncrasies of each individual story, I highlight the way individuals use a socially-rooted narrative formula to account for their lives. Because I use story formula to drive my analysis, the cases I discuss pertain to various subject 
matters. Therefore, this book also touches on themes that are relevant to the sociological analysis of trauma and mental health, religion, nationalism and patriotism, sexuality and gender, knowledge and ideology, and the emerging sociology of new media technologies.

In Chapter 2, I outline the rich socio-cultural history of the awakening narrative formula. Historically, ideas about the location and character of truth have multiplied throughout the Western world. However, the awakening narrative formula dates back to roughly around the $6^{\text {th }}$ century BCE with the story of Zarathustra, the Persian prophet. With the evolution and proliferation of competing notions of truth throughout the Western cultural arena, awakening narratives also proliferated, marking the tensions both within and between various communities and the broader realms of social life - from the religious to the political, the psychological, and the sexual; from ancient religious and philosophical camps to modern sectarian communities that include sexual and cultural identity groups. Consequently, different communities have their own foundational awakening accounts that, although not all purely autobiographical, adhere to the same narrative formula. I examine a select group of cases in order to show how awakening stories emerged in various historical contexts to mark the distinction between different communities. I also explore what these foundational awakening narratives tell us about the general properties of the story formula.

As they tell stories about their lives, awakeners explicitly revise the past in order account for their discovery of truth. They simultaneously, if only implicitly, plot their future lives in reaction to their newly revised autobiographical past. 
Chapter 3 focuses on autobiographical memory. I advance the concept of mnemonic authority and discuss the ways that awakeners use autobiographical memory to weigh in on cultural disputes concerning the definition of morally and politically salient issues and situations. Some awakeners use their autobiographical stories to shape the collective memory of important social events. Other awakeners use their autobiographical narratives to shape the social frameworks for individual memories that pertain to a specific issue. Despite this difference, awakening narratives reveal how individuals and communities use autobiography to shape social memory. I also explore the connection between autobiographical memory and social memory, arguing that the former is too often neglected by sociologists who study collective memory and commemoration.

Chapter 4 explores that ways that awakeners describe having a liminal awakening experience - a major, life-changing discovery of truth that separates past and present periods of the awakener's life. Arguing that liminal spaces - in this case spaces that separate two distinct worldviews in the awakener's life take narrative form, I make an analytic distinction between two ideal-typical vocabularies of liminality - the sociomental express elevator and the sociomental staircase. Making this analytic distinction, I explore the relationship between autobiographical time and agency in awakening narratives. Guided by the theories of Kenneth Burke and Erving Goffman, I also show how awakeners use various props, characters (cognitive authority figures), and settings to convey their sociomental transformations. In the process, awakeners also use their autobiographical accounts to articulate a mental quantum leap to a higher epistemic plane. Awakeners use the vocabularies of liminality detailed in chapter 
four to reinforce their knowledge claims and they divide a past period of falsehood from a present period of truth in their life stories.

As they make a sharp distinction between the pre-awakening and postawakening periods of their lives, awakeners portray and perform a temporally divided self. Chapter 5 examines the way that awakeners symbolically engage and undermine a past version of self that stands as a symbolic proxy for their former autobiographical community. In this chapter, I consider the sociocognitive implications of such a performance of self and introduce a discussion of the way autobiography can serve to incite a socially-founded sense of security and solidarity with some and disdain and alienation from others. Further, I discuss the implications of such identity performances for the analysis of mnemonic battles and cultural disputes over the definition of important issues and concerns. As they perform a temporally divided self, awakeners distinguish between the social contexts and communities they associate with light and truth and those they associate with darkness and falsehood, using various metaphors to divide the world into dichotomous, morally charged camps.

Chapter 6 concludes the book with a discussion of how my analysis of awakening narratives suggests the contours of a more general cultural and cognitive sociology of autobiography. After briefly considering the social and historical conditions that favor awakening narratives, I revisit the concept of the autobiographical community and outline five dimensions that can inform a sociological approach to life stories. Arguing for the benefits of explicitly recognizing autobiography as an analytic domain, I ask what my analysis suggests about the significance of autobiography for the sociology of culture, 
cognition, memory, and knowledge. Related to this theme, I conclude my discussion of the link between autobiography and cognitive authority that has been developing in prior chapters. 


\section{Chapter 2}

\section{Awakenings: A Socio-Cultural History}

One of his students asked Buddha, "Are you the messiah?" "No", answered Buddha.

"Then are you a healer?"

"No", Buddha replied.

"Then are you a teacher?" the student persisted.

"No, I am not a teacher."

"Then what are you?" asked the student, exasperated.

"I am awake", Buddha replied.

$\sim$ Buddhist proverb ${ }^{1}$

"General, abstract truth is the most precious of all blessings; without it, man is blind; it is the eye of reason."

$\sim$ Jean-Jacques Rousseau ${ }^{2}$

"From error to error, one discovers the entire truth."

$\sim$ Sigmund Freud 3

When individuals tell awakening stories, they use their autobiographical accounts to articulate and perform cultural tensions that have emerged and evolved through history. They use a historically durable narrative formula to weigh in on a social dispute over the nature of truth and meaning in the world. Focusing on the Western cultural tradition, I sketch a socio-cultural history of awakenings narratives. In the process, I advance two seemingly contradictory arguments. First, awakening narratives proliferated over time with the emergence of different and contentious "spheres of 
value,"4 in Max Weber's terms, or what Michel Foucault called "discourses of truth." 5 Consequently, different autobiographical communities have their own foundational awakening narratives that, although not all purely autobiographical, provide story templates and cultural tools that individuals use to construct their personal awakening accounts. Second, despite the evolution and proliferation of competing notions of truth throughout the Western cultural arena (and the simultaneous fractioning of various autobiographical communities), the root awakening story formula remains fundamentally the same.

Centuries before the modern era, religious conceptions of truth were culturally predominant. Cultural disputes occurred between moral and political communities with different views on how to define religious (i.e. divine and universal) truth. ${ }^{6}$ However, challenges to religious notions of truth, initially sparked by classical Greek philosophy, became culturally entrenched with the age of Western Enlightenment (roughly 16501789). Subsequently, various contentious notions and discourses of truth emerged (including multiple and divergent political, scientific, psychological, and sexual discourses). Such a fractioning of different and contentious discourses of truth led to a "late modern" cultural milieu marked by a multiplicity of autobiographical communities that contend for the allegiance of individuals. Further, such a cultural milieu affords late modern individuals the potential to repeatedly and reflexively reconstitute themselves by abandoning one "truth" in favor of another.7 However, despite this historically "emerging multiplicity in perspectives" 8 on the content and character of truth, and despite an increase in cultural emphasis on what Robert N. Bellah and colleagues call "expressive individualism,"9 individuals and communities continue to articulate patterned, formally similar awakening narratives as they use their life stories to express 
cultural tensions over truth and meaning. The basic formula of this awakening story is evident in foundational awakening narratives that span multiple realms of social life, historical periods, and storytelling contexts.

Foundational awakening narratives are historical and/or theoretical manifestations of the awakening story type that are sacred to particular communities. These established awakening stories provide a cultural and theoretical basis for the general idea that one can be mentally unaware of "truth" or "reality" and awaken to grasp that reality. They are also entrenched story models that serve as social referents for individual awakeners and, consequently, such foundational awakening narratives illuminate some of the central themes and vocabularies that re-occur throughout lay or popular versions of the story. These stories span different social contexts, belief systems, historical periods, and subject matters. They deal with philosophical, religious, political, scientific, psychological, and sexual subject matters. They also span different levels of analysis, from the micro-individual to the macro-collective. Like popular versions of the awakening narrative, they conform to the same basic story formula despite a variety of otherwise significant differences.

In this socio-cultural history, I briefly discuss several important foundational awakening narratives while focusing my attention on eight cases: the story of Zarathustra, Plato's Allegory of the Cave, the Buddhist story of Siddhārtha Gautama, the Christian story of Paul the Apostle, the Western Enlightenment narrative, the Marxist account of false consciousness, Freud's theory of psychoanalysis and the psychoanalytic case study, and finally, the new sectarian awakening stories that accompany the rise of identity politics in the 1970's and 80's. There are other foundational awakening stories that might be mentioned here. However, I have chosen 
to focus on these eight cases because each exemplifies an important dimension or aspect of the awaking narrative formula more generally. Further, because these story models accrue rather than supplant one another, in combination they show how Western notions of truth have evolved and proliferated over time. While my focus limits my treatment of these foundational narratives, I give a brief summary of each basic story and then highlight the specific characteristics of each case that serve to illuminate my subsequent discussion of the awakening narrative formula. What follows, then, is a brief socio-cultural history of this story type.

\section{Zarathustra}

The story of Zarathustra, the ancient Persian philosopher, poet, and founding prophet of the Zoroastrian religion, provides one of the earliest awakening accounts. Today, Zarathustra is regarded as a prophet in the Islamic and Bahá'í faiths and there are scattered populations of Zoroastrians living around the world, mostly in Iran and India, although some of the central tenets of Zoroastrianism "were adopted by Judaism, Christianity and Islam, as well as by a host of Gnostic faiths, while in the East it has some influence on the development of Northern Buddhism." ${ }^{10}$ References to Zarathustra's enlightenment can be found throughout various Greek philosophical treatises, where he became known as Zoroaster, a name more commonly used in the Western world. Notably, the Greek translation of Zoroaster means "undiluted” (zōrós) "stars" (ástra), associating this prophet’s name with pure light and, figuratively, unadulterated truth. There is some controversy over the time of Zarathustra's life, with some scholars placing him as early as the $15^{\text {th }}$ century B.C.E. and others as late as the $6^{\text {th }}$ century B.C.E. ${ }^{11}$ 
The story of Zarathustra is notable here because it provides one of the earliest notions that the universe is divided into a polar dichotomy between truth and falsehood. As described throughout various Zoroastrian scriptures, most notably the Gathas which consist of seventeen hymns attributed to Zarathustra himself, ${ }^{12}$ the Persian prophet is said to have "sought a revelation of the purpose of man's troubled days on earth." 13 Zoroastrian tradition upholds that the prophet-priest spent years searching for truth while repeatedly witnessing evils, violence, and social conflict and yearning for moral order. One day, at the age of thirty, while emerging from a river at dawn during a spring festival (notice the rich symbolism of purity and rebirth associated with water, dawn, and spring) he had a vision of several radiant figures, most notably the god Ahura Mazda, who bestowed upon Zarathustra a revelation. ${ }^{14}$ Upon his awakening, Zarathustra became the first to assert that the universe is defined by a conflict between the forces of good (aša or asha, meaning "order," "truth," and "justice") and evil (druj, meaning both "disturbance" and "lie" or "deception"). ${ }^{15}$ Further, he discovered that the god Ahura Mazda was the omnipotent and eternal creator of all other gods, mankind, and life in general, as well as the primary force of order, truth, and goodness in the world. In addition, according to this doctrinal awakening story, Ahura Mazda was opposed by an adversary, Angra Mainyu, who was "equally uncreated, but ignorant and wholly malign"16 and the two (god and anti-god) were locked in a struggle for supremacy. Proclaiming this moral dichotomy, the Gathas state (in Zarathustra's voice),

Now I will proclaim to those who will hear the things that the understanding man should remember, for hymns unto Ahura and prayers to Good Thought; also the felicity that is with the heavenly lights, which through Right shall be beheld by him who wisely thinks. Hear with your ears the best things; look upon them with clear-seeing thought, for decision between the two Beliefs, each man for himself before the Great consummation, bethinking you that it be accomplished to our 
pleasure. Now the two primal Spirits, who reveal themselves in vision as Twins, are the Better and the Bad, in thought and word and action. And between these two the wise ones chose aright, the foolish not so. And when these twain Spirits came together in the beginning, they created Life and Not-Life, and that at the last Worst Existence shall be to the followers of the Lie, but the Best Existence to him that follows Right. Of these twain Spirits he that followed the Lie chose doing the worst things; the holiest Spirit chose Right, he that clothes him with the massy heavens as a garment. So likewise they that are fain to please Ahura Mazda by dutiful actions. ${ }^{17}$ (emphasis added)

Humanity's purpose, as the prophet discovered according to this ancient awakening story, is to uphold aša by living a good life so that evil and darkness may be defeated and eternal peace may be achieved. ${ }^{18}$ Thus, in depicting a universal binary struggle between the forces of Right and the forces of Lie, Zarathustra separates humanity into two contentious camps - "the followers of the Lie" and any "that follows Right." Expressing the culturally contentious character of his binary spiritual worldview, Zarathustra writes, "on him who threatens to be my undoing, that I may fetter the men of the Lie in their violence against my friends."19 Mary Boyce writes,

An essential element in this revelation is that the two primal Beings [Ahura Mazda and Angra Mainyu] each made a deliberate choice (although each, it seems, according to his proper nature) between good and evil, an act which prefigures the identical choice which every man must make for himself in this life. The exercise of choice changed the inherent antagonism between the two Spirits into an active one, which expressed itself, at a decision taken by Ahura Mazda, in creation and counter-creation, or, as the prophet put it, in the making of 'life' and 'not-life' $[\ldots]^{20}$

The division of the universe into two diametric, mutually exclusive, and antagonistic morally charged realms (good god and anti-god; truth/"Right" and falsehood/“Lie;" "Life and Not-Life;" heaven and hell) is a central feature of Zarathustra's story. Notably, both "truth" and "good" are associated with light while "lie" and "evil" are associated with darkness. As I will discuss, such morally charged 
epistemic planes are central components of all autobiographical awakening stories. In the tradition of Zarathustra, awakeners make a diametric distinction between spaces of darkness and spaces of light in the world. In fact, such a diametric division of the world is necessary to the very notion of awakening, which by definition involves moving from darkness to light. Awakeners use such a polarized vision of the world to convey notions of a dualistic self and life course in their personal accounts. Such a dichotomous association of the true and the false also contributes to the intersubjective organization of various social environments and autobiographical communities.

Finally, Zarathustra used an awakening narrative formula to establish himself as a prophetic figure. By asserting his revelation that the universe is defined by conflict between the forces of good/truth/light and the forces of evil/falsehood/darkness he put forth a destiny for humankind. At the core of this destiny was a moral imperative: people ought to devote themselves to truth and goodness so that evil will be defeated and cast out of the world and humankind will know peace. Thus, Zarathustra used his awakening to project the future progress of humanity beyond a state of darkness. Somewhat ironically and satirically, Friedrich Nietzsche mimics this prophetic aspect of Zarathustra's awakening in his philosophical novel Thus Spake Zarathustra in order to proclaim that "God is dead," undermine the moral authority of religion, and theorize human evolution beyond a religious moral framework to the era of the Übermensch (theoretically and symbolically heightening - Über - man over god). ${ }^{21}$ Nietzsche used the Zoroastrian formula to undermine its content, inspiring German composer Richard Strauss (1896) to write the symphonic poem by the same name, a piece that was adapted for Stanly Kubrick's (1968) film, 2001: A Space Odyssey. Like Nietzsche, Kubrick deals with the theme of human evolution from "The Dawn of Man" (the film's opening scene) 
through the age of modern/future technology. Following this tradition first set forth in Zarathustra's foundational and influential awakening narrative, awakeners use their personal stories to establish a moral imperative and set a future course of action for others, a theme that will reemerge in subsequent chapters.

\section{Plato's Allegory of the Cave}

Plato's allegory of the cave is the archetypical philosophical version of the awakening account. Roughly dated to around 380 B.C.E., Plato used this allegory to illustrate how individuals can become enlightened and acquire knowledge of the "essential Form of Goodness," arguing that goodness "is itself sovereign in the intelligible world and the parent of intelligence and truth." ${ }^{22}$ After giving a brief summary, I want to highlight three aspects of this account that are central to my purposes here. First, there are important structural implications of Plato's use of the cave metaphor, specifically Plato's association of ignorance and illusion with a confinement in a cave (below ground) and enlightenment with the freedom to ascend to the surface of the earth (above ground), where the sun is visible. Second, there are important figurative dimensions to Plato's allegory. Specifically, falseness is associated with confinement and freedom with movement. Finally, Plato warns about a strong social tension between those who are enlightened and those who are not that stems from their various understandings of reality.

In this allegorical lesson, Plato describes a cave where several prisoners are confined by chains that are attached to their legs and neck, prohibiting them from leaving and from turning their heads to see anything but the wall in front of them. On 
this wall there are several shadows cast from artificial objects that are moved along a roadway behind them, between the prisoners' backs and a fire that casts the shadows on the wall (see Figure 2). ${ }^{23}$ As several have noted, a modern version of Plato's cave might look more like a movie theatre, where the fire is replaced by a projector. Given their situation, the prisoners in Plato's allegory have very limited knowledge of the world. Their conception of the world is limited to their perception of the shadows in front of them; these shadows are the prisoners' reality. Plato states, "In every way, then, such prisoners would recognize as reality nothing but the shadows of those artificial objects." Plato thus makes a sharp distinction between "appearance" and things "as they are," a distinction that informs his analysis of the division between the darkness of ignorance and enlightened knowledge. ${ }^{24}$ 


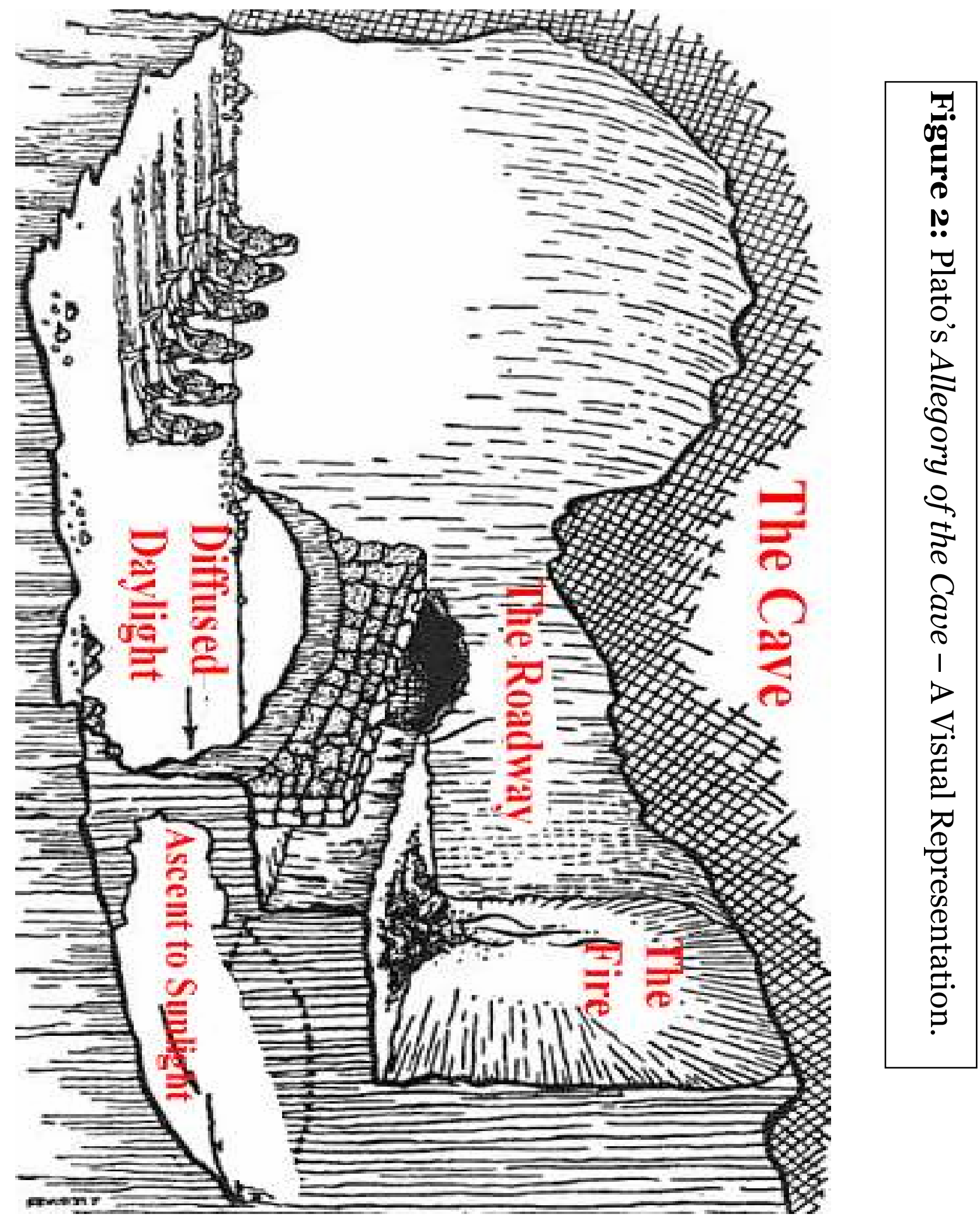


After describing the cave world, Plato then hypothesized about the plight of a prisoner who escapes his captivity and ascends to the surface world where, for this first time in his life, he sees sunlight. The prisoner's ascent is a symbolic representation of philosophical enlightenment. However, the process of ascent is marked by notable pain that is associated with the rise to a new state of knowledge and awareness. The newly emancipated prisoner, Plato comments, would be disoriented as his eyes are burned by the newly experienced sunlight. His eyes, Plato says, would be "so full of its radiance that he could not see a single one of the things that he was now told were real." $\mathrm{He}$ would be tempted to "turn back to the things that he could see distinctly, convinced that they really were clearer than these objects now being shown to him." 25 Plato then argues that a freed prisoner would eventually grow accustomed to the "upper world." If, however, he were to return to free his former bondsmen,

... his eyes would be filled with darkness. He might be required once more to deliver his opinion on those shadows, in competition with the prisoners who had never been released, while his eyesight was still dim and unsteady; and it might take some time to become used to the darkness. They would laugh at him and say that he had gone up only to come back with his sight ruined; it was worth no one's while even to attempt the ascent. If they could lay hands on the man who was trying to set them free and lead them up, they would kill him. ${ }^{26}$

Plato's cave metaphor captures important figurative dimensions of the awakening narrative. First, Plato depicts personal enlightenment by describing a freed prisoner's ascent from a cave (contained below ground) to the surface of the earth (above ground, the open space of sunlight). The freed prisoner makes this journey though a tunnel, a liminal space between the two worlds that, although hardly discussed in Plato's account, is absolutely necessary to the transition. Notably, the structure of Plato's allegory closely maps to the structure of autobiographical awakening stories as displayed in Figure 1, 
Chapter 1 . This structural affinity may, in part, be due to the fact that René Descartes, whose system of Cartesian dualism makes the graph in Figure 1 possible, was inspired by Plato's allegory. ${ }^{27}$ The structural distinction between the cave and the upper word also maps to the prisoner's past mental state of ignorance and his more current enlightenment. Further, this structural distinction is rooted in the social distinction between those who reside in the cave and those who live in the upper world, a relationship that is played out in the frustrating interaction between the freed prisoner and his former bondsmen. Thus, Plato uses the biography of his hypothetical prisoner to illustrate the social distinction between those who are blind and those who have come to see the light. The generic character of the allegory is evident when one considers that it might be interpreted from a religious, intellectual, political, artistic, or any other perspective. ${ }^{28}$

Second, Plato represents ignorance with both physical constraint (leg chains) and perceptual constraint (neck chains), metaphorically associating access to truth and knowledge with freedom of movement and perceptual flexibility. Leg chains prevent physical escape by restricting bodily movement. Neck chains, however, prevent mental escape by restricting perceptual mobility, constraining the cognitive options of the prisoners. From a sociological perspective, these neck chains symbolize socially enforced rules of seeing and social constraints on perception that often exist without material fetters. For example, as Gordon Horwitz shows, Austrian locals during the Nazi Holocaust commonly obeyed unwritten yet strict social conventions to avoid turning their heads to see the events of local concentration camps. ${ }^{29}$ Plato thus directly associates truth with sight, and more importantly, the ability to see from different angles. Notably, Plato's prisoners are not blind; every one of them has the capacity to 
see, but their sight is restricted by their figurative fetters (an optical restriction that is reinforced by Plato's use of "shadows," which exist when light is blocked from one's view, to portray ignorance). This beautiful symbolism informs Plato's view that every person has the capacity to "see" the "truth," and his view that education involves a process of redirecting the student's "vision" to "see" what is already there. Plato comments that education is,

an art whose aim would be to effect... the conversion of the soul, in the readiest way; not to put the power of sight into the soul's eye, which already has it, but to ensure that instead of looking in the wrong direction, it is turned the way it ought to be. 30

Plato's views are remarkably compatible with a sociological view of knowledge and cognition. As opposed to modern cognitive science, which advances the notion that an individual's "newly acquired" worldviews are already present in the "embodied mind" as part of a vast "cognitive unconscious," ${ }^{1}$ a sociological perspective shows how newly acquired worldviews involve a socially mediated shift in attention structure. Such paradigm shifts typically result from our socialization into a new optical community ${ }^{2}$ even when one's sense of discovery is felt to be independent of such a group-mediated phenomenological forces and deeply personal.33 Plato's figurative association of sight with knowledge and truth informs my discussion of what I call cognitive constraint and cognitive emancipation in subsequent chapters.

\section{Foundational Religious Awakenings}

Most, if not all, religions have foundational awakening stories. They are central to both Eastern and Western traditions. Like Plato's philosophical allegory, religious 
awakenings are based on the idea of a universal truth that exists outside and independent of the individual (a theme that also characterizes early political versions of the story). Religious awakening narratives demarcate the divisions between various religious sects and communities, each claiming to hold the key to a universal divine truth. The stories of prophets, saints, gurus, and spiritual founders provide autobiographical models that potential adherents can use to convert to a religious thought collective. In such accounts, the "truth" is a divine, universal constant that the awakener must somehow access or achieve in order to be among the enlightened or the saved. However, while Plato believed that philosophical enlightenment was possible only for the special few (the philosophers who he believed should govern the unenlightened masses), religions are typically much more inclined toward assimilation. As Weber explains, the rise of prophetic religions involved a new ethical emphasis on a "universalist brotherhood." 34 Thus, in accounting for the lives of prophets, saints, gurus, and spiritual founders, religious dogma provides narrative models that masses of potential adherents can use to account for awakenings in their own lives.

Before introducing other important cases, I focus my discussion on two foundational religious accounts of far-reaching significance. First, Siddhārtha Gautama, the Buddha (which literally means "the Awakened One"), achieves enlightenment at the end of a six-year journey. 35 Second, Paul, the Christian Apostle, awakens after being struck by lightning while traveling to Damascus in order to persecute Christians. ${ }^{36}$ Despite their religious content, these stories exemplify two ideal-typical accounts of a transformative awakening experience that transcend the realm of religion. Each story conveys a different idea about how individuals access or acquire "truth." Both versions 
of the awakening experience can be found in more popular autobiographical versions of the awakening story that pertain to a diversity of themes and issues.

The story of Siddhārtha Gautama is dated to the $6^{\text {th }} / 5^{\text {th }}$ century BCE. This account was passed down orally for at least three generations before being recorded and there are several versions of the story today. What follows is a sketch of the story that accentuates the basic elements while admittedly avoiding many nuances, details, and controversies.

Siddhārtha Gautama was the son of a Brahmin (a member of the highest cast, a king or lord) who protected the young prince from any awareness of the human condition, especially suffering and death. Destined to be a great king, Siddhārtha was provided a life of privilege and power, a life that he ultimately rejected. While Siddhartha's life was certainly more comfortable than Plato's confined prisoner, both characters suffered from an intellectual and philosophical "confinement." When he was 29 years old, Siddhārtha left his palace for the first time, against his father's wishes. During this initial expedition, he encountered a very elderly man and, for the first time perceived the realities of death. Shortly after, Siddhārtha encountered a sickly man, a corpse, and an ascetic monk who, along with the elderly man are said to have been holy "messengers" who introduced the sheltered prince to the realities of the human condition.

This initial excursion marks Siddhārtha's first awareness of human suffering and the starting point of a protracted quest for enlightenment. Following these eye-opening experiences, Siddhārtha fled his father's palace and rejected his life of privilege and power. He intended to live the life of an ascetic in hopes of avoiding otherwise inevitable old age and death. Here Siddhārtha departed on a journey that will take him six years. 
He studies with various teachers, each time moving on after becoming frustrated with the limits of their teachings. He then went deeper into an ascetic life looking for answers, eventually rejecting this course as well. Towards the end of his quest, Siddhārtha meditated under a Bodhi tree for weeks until, it is told, he attained Enlightenment. He became aware of the "Truth" and, consequently, realized that human suffering was caused by ignorance. Thus, one of the main objectives of Buddhism is to "help people... 'wake up' from restricting delusions: delusions which cause attachment and thus suffering" while also emphasizing the process of "attaining liberation by one's own efforts." 37

Turning our attention now to the story of Paul, we are given a foundational religious awakening story that presents an alternative type of the awakening experience. The story of Paul, who was initially known as Saul of Tarsus, is primarily recounted in the New Testament's Book of Acts. Paul, who accounts for his "previous way of life" by describing "how intensely [he] persecuted the church of God and tried to destroy it," 38 was traveling with a band of Pharisees on the road to Damascus with the intention of arresting Christians. According to the Book of Acts,

As he neared Damascus on his journey, suddenly a light from heaven flashed around him. He fell to the ground and heard a voice say to him, "Saul, Saul, why do you persecute me? [...] I am Jesus, whom you are persecuting [...] Now get up and go into the city and you will be told what you must do. 39

In his later defense to King Agrippa, Saul recalls that "the Lord replied,"

I will rescue you from your own people and from the Gentiles. I am sending you to them to open their eyes and turn them from darkness to light, and from the power of Satan to God, so that they may receive forgiveness of sins and a place among those who are sanctified by faith in me.40 (emphasis added) 
While Paul was first blinded by his awakening experience (a symbolic representation of the ultimate "darkness" in his life), he later draws on this experience to justify his newly acquired Christian faith to others and "open their eyes and turn them from darkness to light."

Because he could not see, Saul had to be led into the city of Damascus by his compatriots, where, after three days of blindness and abstinence from food and drink, he was visited by the Christian disciple, Ananias. Ananias, who was already aware of Saul's reputation for persecuting Christians, is fearful at first,

But the Lord told him, "Go! This man is my chosen instrument to carry my name before the Gentiles and their kings and before the people of Israel. I will show him how much he must suffer for my name. ${ }^{41}$

Ananias went to Saul, and laid hands on him. Immediately, scales fell from Saul's eyes and he regained his sight. Saul was then baptized and later became known as Saint Paul the Apostle, an ardent proselytizer for the Christian faith.

It is notable that nowhere in the New Testament is Paul's name change elaborated, even though it is conventionally said to mark the difference between his preand post-conversion selves. Acts 13:9 simply says, "Saul, who was also called Paul." This is perhaps due to the fact that Paul commonly evokes his pre-conversion self and recounts his pre-conversion life in order to defend himself in front of a crowd of Jews in Jerusalem ${ }^{42}$ and to King Agrippa shortly thereafter. 43 He is thus both Saul and Paul in his personal accounts and his past identity is only portrayed from the perspective of his present concerns and objectives. The "darkness" and "sins" of his pre-conversion life is all that we are told about Paul's previous existence. Notably, Paul (as "Saul") took part in 
the stoning to death of Saint Stephen, the "first martyr" of the Catholic Church. 44 However, it is the contrast between the two personas that gives Saint Paul a foundation to claim religious authority and therefore to proselytize for Christianity, as is perhaps most evident in his well-known (and frequently read in Christian masses) "Epistle to the Romans." 45

The story of the Buddha and the story of Paul illustrate two ideal-typical accounts of a pivotal awakening experience - story models that various individual's use and adapt to account for their discovery of truth and justify major changes of mind in religious, psychological, political, sexual, and other realms of social life. These stories exemplify two vocabularies of personal discovery and transformation that transcend the realm of religion. As with the awakening of Zarathustra and the story of Plato's escaped prisoner, light (whether the gold aura of enlightenment or a bolt of lightning) is associated with truth in both accounts. Further, many of the general themes evident in both of these stories also occur in other foundational religious awakening narratives. Muhammad, the founding prophet of Islam, awoke to his destiny and discovered the tenets of the Islamic faith after being visited by the angel Gabriel in a cave on Mount Hira. ${ }^{46}$ Saint Augustine of Hippo spent years searching for theological truth until one day, after a child's voice led him to read Saint Paul's Epistle to the Romans, he converted to Christianity. 47 Joseph Smith founded Mormonism after two visions. The first vision was of two radiant figures - said to be god and his son, Jesus - who appeared to the fourteen-year-old Smith in a wooded grove and informed him that all existing religions were "false." The second, years later, was of the angel Moroni who led Smith to the source material for the Book of Mormon (and thus revealed the "truth"). $4^{8}$ Some religious awakenings (Paul, Augustine) are classic conversion stories. Others (Siddhārtha, Muhammed, Smith) are 
more aptly described as "revelation" or "discovery" accounts. In both cases, such quests, visions, revelations, voices, spiritual visits, and divine interventions represent the awakening experiences of iconic religious figures. Each of these examples is a foundational awakening narrative that a particular religious community deploys to defend its vision of religious truth and repudiate all other antagonistic worldviews.

\section{Foundational Political Awakenings - The Enlightenment and Marxism}

Foundational political awakening narratives establish an ideological framework for human progress and impel the collective transformation of society. I focus on two cases: the story of the Western Enlightenment and the Marxist account of false consciousness. Both of these collective-level awakening stories function as a "master frame" 49 for autobiographical awakening accounts grounded in the political realm of social life. A thorough consideration of either case undoubtedly requires much greater attention than my focus here allows. I thus limit my discussion to two broad and related points. First, both the Western Enlightenment and Marxism link the discovery of truth to sharable worldly experiences. In doing so, they advance the notion that human beings have an inherent capacity to discover truth via their interaction with the natural world. Worldly experience thus becomes central to the notion of personal discovery in a new way. Second, these foundational political narratives bind the notion of truth and discovery to the idea of collective progress and emancipation. For the Enlightenment thinkers, the principal unit of awakening was the nation. For Marx and the Marxists, the principal unit of awakening was the socially and economically constituted class. In both cases, truth was conceived to be inseparable from the historically plotted progress of 
humanity (which itself could be determined by the scientific study of worldly conditions). In each case, a collective awakening formula - one that is part of a grand historical narrative of human progress - sets a cultural stage for individuals to tell autobiographical awakening stories of a political character.

The age of Western Enlightenment ushered in a growing wave of philosophical, scientific, and ultimately political challenges to religious universalism. With the dawn of the Enlightenment and the rise of modern political philosophy, the notion of political awakening was deployed in reaction to Feudalism and the dominance of the religious mindset leading to a "dynamic tension" between the social worlds of religion and politics (a tension that Weber referred to as a "mutual strangeness" to describe the logical contradiction between the two realms). $5^{\circ}$ Further, the Enlightenment spurred the separation and "purification" of other realms of social life (in addition to the religious and political spheres, Weber discussed the purification of the economic, the esthetic, the erotic, and the intellectual spheres) ${ }^{51}$ ultimately causing a proliferation of competing discourses of truth and, consequently, "the saturation of society by multiple voices." ${ }^{2}$ Just as awakening stories expressed the cultural tensions between various religious communities, they came to express the cultural tensions within and between other, newly separating values spheres. The Enlightenment allowed for autobiographical communities to separate from religion and fractionalize over time, spurring the cultural and epistemological multiplicity of the modern Western world.

The story of the Western Enlightenment is a metanarrative - a master story or plot "in which we are embedded as contemporary actors in history" 53 - that links the notion of universal truth with the concept of reason and the idea of national and political progress. This historic narrative accounts for humanity's awakening from the 
ignorance of the Dark Ages and its subsequent progress into the Modern era. The Enlightenment also typically refers to the philosophical, scientific, and political movement that began around the time of the English Civil Wars (1642-1651) and culminated in the American (1776) and French (1789) revolutions over a century later. Its core thinkers were German, French, British, and American, but its influence was much more diffuse. Early Enlightenment thinkers included Thomas Hobbes, who wrote Leviathan in 1651, Sir Isaac Newton, whose Philosophiae Naturalis Principia Mathematica was published in 1687, and John Locke, whose Second Treatise on Civil Government was published in 1690. Later Enlightenment philosophers include Jean Jacques Rousseau (The Social Contract, 1762), Adam Smith (The Wealth of Nations, 1776), and Immanuel Kant (Answer to the Question: What is Enlightenment?, 1784 and Groundwork of the Metaphysics of Morals, 1785).54 Although different in many ways, each of these thinkers advanced the notion that human beings could access truth by means of their reason-driven interactions with the world. Defending "the light of the intellect" and rational thought from the "ridiculous mysteries" of religious dogma, Benedict de Spinoza argued that religion prevents individuals from "distinguishing truth from falsehood.” 55 In contrast to religion's emphasis on the transcendence of worldly activity, the empiricists stressed the role of earthly experience in the acquisition of truth and knowledge. $5^{6}$ In his Critique of Pure Reason, Kant attempts to synthesize Enlightenment empiricism with the tenets of philosophical rationalism, arguing that human beings are endowed with the innate mental capacity to reason. 57 In all cases, these theorists posited a universal truth distinct from religious conceptions of the divine and formulated a collective awakening account that featured humanity's "enlightenment" and progress from a "state of nature" to civil society. From the motives 
of human behavior to the motion of inanimate objects, the world was said to operate by a set of universal and knowable natural laws that, if discovered and mastered, would be the key to humanity's collective emancipation from ignorance and darkness. As is evident in the title of Kant's 1784 essay, "Answer to the Question: What is Enlightenment?," the German Enlightenment was one of the first secular political movements to self-consciously refer to itself as an "enlightenment."

As with the religious ideologies they were seeking to undermine, Enlightenment thinkers continued to see truth as a universal constant. There was one "Truth" that anyone could theoretically access. However, the Enlightenment challenged the religious understanding of the source of that truth. According to the religious view, sin was innate to humanity and truth was a property of the divine. According to Enlightenment thinking, however, the capacity to reason was innate to humanity and it allowed for a rational engagement with the external world..$^{8}$ Truth was thus made to be inherent in worldly experience - specifically knowable and verifiable via empirical, scientific inquiry and philosophical deliberation - not by a connection to the divine. Further, truth became inseparably intertwined with the notion of personal and collective progress, as is perhaps most evident in the work of Condorcet, who established the "progress of the human mind" as a condition for the progress of society toward an ideal state.59 Thus the Enlightenment flipped religion's view of the source of truth on its head. In doing so, the Enlightenment established a cultural framework for individuals to reject a religious worldview and awaken to scientific and political truths in their life stories (thus also setting the cultural stage for later Marxist and Freudian accounts of personal discovery as well). Along with the political ideologies of the Enlightenment came a new faith in the 
rational scientific model of discovery. "Enlightenment" came from the use of reason to escape the yoke of darkness and ignorance.

While undermining religion's view of the source of truth, the Enlightenment used the same basic awakening narrative formula to justify its own version of truth. ${ }^{60}$ Such a (collective) awakening formula is evident in the political and philosophical deliberations of the Enlightenment thinkers, who commonly theorized about humanity's progress from a "state of nature" to "civil society." The Enlightenment thinkers had different ideas about what such a state of nature looked like. For Hobbes, the state of nature was a state of war marked by "continual fear and danger of violent death" and life was "solitary, poor, nasty, brutish, and short," 61 for Rousseau, life in the state of nature was organically simple and human beings were ignorant and animal-like. ${ }^{62}$ Despite a variety of differences, however, most Enlightenment thinkers argued that human beings used their reason to progress out of the state of nature and establish the social and legal framework of civil society. The state of nature symbolized pre-civil society (and thus served as a proxy for the Dark Ages and social immersion in ignorance) while the Enlightenment was associated with a newly conceived and secular age of reason (and the collective discovery of political and scientific truth). This collective awakening account, one that completely ignored the role of women until Mary Wollstonecraft's publication of Vindication of the Rights of Women in 1792, ${ }^{63}$ provided a philosophical justification for the moral authority of secular governments and for the laws of the secular state. Echoing Plato's views of more than two millennia prior, it was the task of the "enlightened" to use the newly discovered truth to craft the laws that bound person to person in a civil society. Such an Enlightenment conception of truth provided the rationale for numerous social movements and political revolutions and continues to 
shape modern liberal thought, as well as the cultural drive to discover one's "true self," today.

The Enlightenment idea of the political awakening was expounded and transformed by Marx and the Marxists who anticipated the day that the modern proletariat "awakens" to class consciousness. Retaining the Enlightenment emphasis on a scientific rationality and universal laws of progress, Marx mapped "truth" to social structure in a new way. In the Marxist version of the story, the structural conflict between classes in a given historical epoch (mode of production) is reflected in the superstructural realm of ideas, which includes everything human beings "say, imagine, conceive" or otherwise believe, including "morality, religion, metaphysics [philosophy], all the rest of ideology and their corresponding forms of consciousness.” 64 In other words, the hierarchically-organized conflict between social classes in the "material" world maps to a hierarchical conflict in the realm of consciousness. Unlike Plato, who portrayed his hypothetical prisoners to be confined solely to symbolize their lack of philosophical awareness, Marx saw the unenlightened masses as exploited (robbed of the fruits of their labor), alienated (separated from the process an product of their labor as well as denied their connection to nature), and oppressed (politically dominated and disenfranchised) wage slaves. Their "false" consciousness reflected their economic and political oppression. Thus, Marx comments,

The ideas of the ruling class are in every epoch the ruling ideas, i.e. the class which is the ruling material force of society, is at the same time its ruling intellectual force. The class which has the means of material production at its disposal, has control at the same time over the means of mental production, so that thereby, generally speaking, the ideas of those who lack the means of mental production are subject to it. The ruling ideas are nothing more than the ideal expression of the dominant material relationships, the dominant material 
relationships grasped as ideas; hence of the relationships which make the one class the ruling one, therefore the ideas of its dominance. 65

It is the task of the subordinate class to throw off the ideological yoke of the dominant class and awaken to an enlightened understanding of their role in history. ${ }^{66}$ In the modern era, society is principally characterized by conflict between the bourgeoisie (the ruling capitalist class that controls the means by which society produces its wealth, and therefore the dominant ideas) and the proletariat (a revolutionary working class that is destined to overthrow the bourgeoisie, seize control of the means of production, and remake society in its own interests). Truth, and more particularly, true consciousness, again, becomes something the oppressed must discovery - a necessary condition for revolutionary upheaval. ${ }^{67}$ Such a view was elaborated by Vladimir Lenin, who later argued,

People always have been the foolish victims of deception and self-deception in politics, and they always will be until they have learnt to seek out the interests of some class or other behind all moral, religious, political and social phrases, declarations and promises. ${ }^{6}$

Both Marx and Lenin viewed such "deception and self-deception" as a product of bourgeois ideology in the capitalist age. In the Marxist view, the proletariat at first suffers from a deluded acceptance of bourgeois consciousness; they treat bourgeois ideas as the ultimate "truth" even though these ideas are merely the expression of (outdated) bourgeois class interests (and are therefore in conflict with proletarian interests). Second, the proletariat suffers from a more amorphous ignorance that class interests and class mentalities exist at all. Thus, the proletariat needs to awaken first, to an understanding of itself as a class and then, to an understanding of its historically 
determined role - the overthrow of the bourgeoisie, the abolition of the capitalist mode of production, and the establishment of a socialist society. Such a theoretical framework establishes the ideological conditions for any individual to reinterpret their personal “past as captivity in the 'false consciousness' of a bourgeois mentality.” ${ }^{69}$ More generally, Marxist theory provides a broad ideological framework for individuals to account for a discovery of political truth by articulating two simultaneous processes. First, political awakeners (no matter their political orientation!) account for their personal political blindness or ignorance as a "false consciousness" that stems from political power relations. Second, they account for their discovery of truth as an imperative to abolish those power relations.

While Marx never explicitly used the term "false consciousness," this dimension of Marx's work gave rise to later ideas about the distinction between "false" and "class" consciousness. The term "false consciousness" is first noted by Friedrich Engels in a letter to Franz Mehring ten years after Marx's death. Here, Engels comments that "Ideology is a process accomplished by the so-called thinker consciously, it is true, but with a false consciousness. The real motive forces impelling him remain unknown to him."70 The distinction between "false consciousness" and "class consciousness" is later elaborated by the György Lukács. Lukács sought to use Marx’s dialectical method "to investigate this 'false consciousness' concretely as an aspect of the historical totality and as a stage in the historical process." 71 Finally, this aspect of Marxist theory was central to Antonio Gramsci's elaboration of "hegemony," or the process by which a ruling class uses cultural ideas to secure the "spontaneous consent" of oppressed groups to the conditions of their oppression and thereby maintains the social relations of dominance and subordination. ${ }^{72}$ 
While a nuanced analysis of Marx's writings and neo-Marxist theory lay outside the focus of this book, it is important to note that Marxism relies on a collective version of the awakening story that continues to influence revolutionary-minded social movements today. Marx's whole theoretical lens is grounded in a structural and dialectical division between a dominant, ruling class and a subordinate, yet emergent, revolutionary class that "awakens" to remake society in its own interests. Like the Western Enlightenment narrative, Marxism stresses the notion that truth stems from shared worldly experience. Truth and, more particularly, true consciousness, for Marx and the Marxists, is attained by becoming aware of one's position in the social structure and relation to the material processes of collective, human production. Further, Marxism also associates the "discovery" and awareness of truth with the historical progress of humanity toward an ideal state. Here, however, truth takes a step (albeit a small one) away from the universal character of the religious and Enlightenment conceptions. While Marxism holds the social and historical principles of human progress to be universal, truth is relative to one's class position and this notion of relativity will be appropriated and transformed by the post-modern thinkers and activists of the late twentieth century. Fundamentally, the Marxist narrative is a story about a class awakening to its revolutionary role in a grand historic plot.73 This collective awakening narrative provides a framework for individuals to articulate the discovery of political truths with regard to their own lives while also providing a prospective justification for and impetus to social change.

Both the story of the Western Enlightenment and the Marxist account of false consciousness advanced the notion that the source of truth lay within collectively rooted, historically situated worldly experiences. Further, both accounts advance the 
notion that collective and individual political awakening is necessary to human social progress and emancipation from the darkness of past eras. In both cases, individual autobiographical accounts are conceived within a collective awakening formula.

\section{Freud and the Psychoanaly tic Case Study}

While the Western Enlightenment valued universal truth and declared the process of its discovery to involve a rational engagement with the external world, Freud moved the locus of truth to the interiority of the individual and established a new "ethic of self-exploration."74 By founding the theory of psychoanalysis, Freud established a cultural framework for individuals to "awaken" by discovering the hidden "truths" buried deep within the unconscious recesses of their minds. While pre-Freud notions of awakening certainly allowed for individuals to tell stories about personal awakening experiences, each relied on the idea that one can discover an external, universal truth. Alternatively, the Freudian version of awakening, as typically elaborated in the Freudian case study,75 is based on the notion that "truth" resides deep within our personal unconscious and is only knowable through psychoanalysis, a theory that shaped countless clinical awakening accounts told throughout academic and popular literature. Given this foundational tenet, the goal of psychoanalysis (and most forms of psychotherapy in general) is often to rescue "truth" from the depths of oblivion.

Freud's theory of the unconscious posited an inner world of symbolic meaning where individuals could unlock the secret causes or origins of unexplained impulses, feelings, and behaviors. Although the idea of a "subconscious" was fairly prevalent in late $19^{\text {th }}$ century dynamic psychiatry (e.g. Pierre Janet introduced this term), it was 
typically thought to be impersonal. Non-Freudian notions of a "subconscious" involved the internal storage of socially shared meanings. Freud, however, conceived the unconsciousness to be deeply personal and even idiosyncratic. This personal unconscious could be explored and discovered. It was unknown and waiting to be known. As Eli Zaretsky so eloquently notes,

The founding idea of psychoanalysis, the idea of a dynamic or personal unconsciousness, reflected this new experience of personal life. According to that idea, stimuli that came to the individual from the society or culture were not directly registered but were first dissolved and internally reconstituted in such a way as to give them personal, even idiosyncratic meanings. Thus there was no direct or necessary connection between one's social condition and one's subjectivity. Equally important, Freud's idea of the unconscious signaled the absence, under modern conditions, of any pregiven fit or harmony between larger, public patterns of cultural symbolism and the private, inner symbolic worlds of individuals. The idea of the unconscious marked a lived sense of disjuncture between the public and the private, the outer and the inner, the sociocultural and the personal. 76

Thus, with the advent of psychoanalysis in the early twentieth century the personal inner world of the self became a frontier that individuals explored in hope of discovering new truths about their lives. Freud commonly used the term "enlightenment" as well as a variety of related optical metaphors to describe the process of discovering such inner "truths". 77 Guided by an analyst who was "engaged in an effort to change the patient's mind,"78 individuals learned to reinterpret their lives and their memories as they discovered the "truth" in the form of long-repressed components of their psychic-selves. Externally situated sociological variables certainly factored into Freudian theory and the process of psychoanalysis, 79 but they were subordinated to the idea that the idiosyncratic self was the core unit of analysis (an idea that was itself a social 
construction). Personal and emotional deliberation was accentuated over impersonal and rational calculation. Nancy Chodorow comments,

Psychoanalysis is first and foremost a theory about the creation of personal meaning in the clinical encounter. This encounter illuminates the power of feelings, the ways that powerful unconscious inner realities and processes shape, enliven, distort, and give meaning and depth to our experience. Psychoanalysis tells us why we feel deeply about certain things, certain experiences, and certain people and why these powerful feelings are part of a meaningful life (emphasis added). ${ }^{80}$

In addition to positing such powerful and personal inner realities, Freud also introduced the related concepts of "resistance" and "defense." Both are central to psychoanalytic theory and inseparably connected to the idea that individuals can "repress" their memories of painful experiences. Defining resistance as a "striving against the acceptance of a painful piece of reality" and an idea that is "a pillar upon which the edifice of psychoanalysis rests," 81 Freud goes on to comment that the psychoanalyst is,

confronted with a resistance which opposes and blocks the analytic work by causing failures of memory [...] The theoretical value of the fact, that this resistance is connected with amnesia, leads unavoidably to that concept of unconscious psychic activity which is peculiar to psychoanalysis, and distinguishes it markedly from the philosophical speculations about the unconscious. ${ }^{82}$

In Psychopathology of Everyday Life, Freud argued "that even in healthy, not neurotic persons, resistances are found against the memory of disagreeable impressions and the idea of painful thoughts." ${ }_{3}$ The theory of resistance added three significant and related dimensions to the foundational Freudian awakening theory. First, the idea of resistance firmly granted a distinctly cognitive authority to interpret the inner self to the 
psychoanalyst. Second, this idea provided a framework for any individual to believe that they (likely) have painful memories of which they not yet aware (and which might explain their present psychological problems). Exploration of the inner world was focused on unearthing the negative, for by the logic of resistance there is no need for one to defend against the positive or pleasant experiences in one's life. Third, this idea provided a cultural framework for individuals to be perceived as reluctant to embrace deeply personal "truths." The notion of resistance posits self-protective individuals who defend themselves against painful realities, and thus somewhat willfully embrace a false worldview. Even, and especially, when an individual defies the authoritative analyst's interpretation, their defiance could now be seen, like the religious shaman who is reluctant to embrace his holy destiny, as an avoidance of a necessary truth.

Freud's theory launched a revolution in psychiatry, replacing the earlier asylum psychiatry with a more modern psychoanalytic form of psychiatry that recognized aberrant psychological states and neuroses to be linked to normal childhood experiences. ${ }^{84}$ Aberrant behaviors operated like clues or codes that needed to be deciphered. Even when an individual's behavior was unexceptional, the unconscious was said to be operating "behind the scenes" and thus was laying in wait of realization. In the psychoanalytic relationship, analyst and patient cooperate to discover unconscious drives and motivations, allowing the patient to awaken into a new, healthier self-awareness. Thus, Freud established a cultural framework wherein any individual could tell an awakening story concerning a psychologically-rooted subject matter, including but not limited to stories about recovering long-repressed memories. Throughout his work, Freud stressed that truth could be revealed by recovering repressed memories, typically of early childhood experiences, that would provide clues 
to more "primal scenes" that are at the core of the psychological symptoms and unexplained behaviors at issue. Taking one example from his analysis of "The Wolf Man," Freud explains the patient's fears and anxieties by working through memories recovered from the unconscious. He writes,

It thus became clear that behind the screen-memory of the hunted butterfly the memory of the nursery-maid lay concealed [...] Very soon after this there came the recollection of a scene, incomplete, but, so far as it was preserved, definite. Grusha [the nursery-maid] was kneeling on the floor, and beside her a pail and short broom made of a bundle of twigs; he was also there, and she was teasing him or scolding him [...] When he saw the girl scrubbing the floor he had urinated in the room and she had rejoined, no doubt jokingly, with a threat of castration [...] By means of the accompanying associations and the inferences that followed from them, it was possible with certainty to supply this significant element that was lacking in the patient's memory. ${ }^{85}$ (emphasis added)

Freud then uses this recovered memory of the nursery-maid to build a bridge between more primal and repressed scenes in the patients even earlier childhood and his current neuroses in adulthood. By highlighting the unconscious dimensions of our memories of childhood experiences in this way, psychoanalysis provided a foundational awakening model that allowed individuals to discover personal truths by delving into the mind and reinterpreting the past in light of present psychological "symptoms." Thus, Freud established the ideological framework upon which more modern theories of repressed memories and dissociative amnesia could be built. ${ }^{86}$

Freud elaborated and defended his theories through the careful presentation of psychological cases. From Freud's self-analysis at the core of his Interpretation of Dreams $^{87}$ to the famous cases of Dora and the Wolf Man, Freud established the psychoanalytic method of presenting biographical sketches of individuals who, through the process of psychoanalysis, discovered the underlying cause of their neurotic 
thoughts and behaviors in the personal unconscious. He used such biographical cases to develop new notions of the unconscious and the related concepts of "defense," "resistance," and "repression." In the process, Freud made it possible for anyone to explain present day feelings and behaviors as psychological "symptoms" by "discovering" previously unconscious "truths" rooted in the personal past. The theory of psychoanalysis and the psychoanalytic case study provided a new cultural paradigm with which individuals could "awaken" to new truths and make sense of their own dreams, impulses, and actions - from slips of the lip to compulsions, sexual fantasies, and more.

\section{Modern Sectarian Awakenings: Communities of Common Experience}

Finally, with the rise of a new "politics of identity" 88 that was both postsocialist ${ }^{89}$ and post-Freudian $9^{\circ}$ and the evolution of the modern trauma narrative ${ }^{91}$ in the later half of the twentieth century, "truth" comes to depend on one's location in an experientially-based community, one that is often defined by its members' shared social location or "standpoint" in a class/gender/race/sexuality nexus. ${ }^{92}$ Feminists, cultural activists, Vietnam veterans, and post-modern theorists uprooted the Freudian focus on a distinctly personal introspection (a looking within) and replaced it with a focus on identifying the conditions, troubles, and needs of an etiological community (a looking among). Etiological communities are groups of individuals who derive a shared sense of identity, values, and a shared political outlook from the cooperative process of realizing their common experiences. Typically, such etiological communities sought to remedy their social marginalization and/or expressed victimization by banding together and 
raising their previously ignored and now publicly defined interests to the fore of social attention. 93 Such groups often look to the past to find the origins of their common conditions in the present. Articulating such a sectarian vision to elaborate the condition of African American women, Patricia Hill Collins writes,

Overall, these ties between what one does and what one thinks illustrated by individual Black women [scholars and activists] can also characterize Black women's experiences as a group. Historically, racial segregation in housing, education, and employment fostered group commonalities that encouraged the formation of a group-based, collective standpoint [...] Historically, Black women's' group location in intersecting oppressions produced commonalities among individual African-American women.94 (emphasis in original)

Collins later explains how such an approach relies on a multifarious conception of truth, writing,
Alternative epistemologies challenge all certified knowledge and open up the question of whether what has been taken to be true can stand the test of alternative ways of validating truth. The existence of a self-defined Black women's standpoint using Black feminist epistemology calls into question the content of what currently passes as truth and simultaneously challenges the process of arriving at that truth. 95

Whether taking the form of a "lesbian feminist social movement community," 96 a veterans "rap group,"97 a Black Nationalist movement, or a support group for victims of childhood sexual abuse, 98 such etiological communities are also autobiographical communities where group members produced new sectarian accounts of sexual, cultural, and clinical awakening. In an early popular example of such a sectarian awakening story, Malcolm X accounts for his awakening to Black cultural nationalism and a related version of Islam while studying under the guidance of the Nation of Islam movement in prison. ${ }^{99}$ In a later example, transgender activist Leslie Feinberg describes 
his entire life as a "journey" in which he discovers the "truth" about his sex/gender identity while coming to a broader political consciousness as a communist. ${ }^{100}$ While different in many ways, both awakeners hold their location within a particular etiological community, marked by unique historical and structural conditions, to be the key to their newly-discovered identities and personal awakenings. The sectarian character of such personal stories is perhaps most clearly expressed by the common sentiment that others (those outside the awakener's community) are unable to comprehend the awakener's experiences, feelings, and needs. These others are unable to grasp the awakener's truth. Such sectarian epistemologies epitomize the fractionalization and proliferation of autobiographical communities that began with the Enlightenment challenge to religious domination and continues through the late modern era of identity politics. The rise of this new politics of identity was accompanied by an accelerated sense of identity crisis ${ }^{101}$ and a newly reformulated impetus to search for truth, a social phenomenon that is evident in the collection of essays that cultural critic and radical feminist Ellen Willis titled Beginning to See the Light to convey her search for freedom and meaning in post-1960's America. ${ }^{102}$

Before the era of identity politics, sexual awakenings were closely linked to the notion that sexuality was deeply personal. For Freud, sexuality was the core of the personal unconscious. To mention one example of many, Freud famously interpreted Dora's hysteria to result from her inability to resolve a personal, unconscious conflict between male and female objects of her sexual desire. ${ }^{103}$ However, with the cultural turn away from Freudianism and the emergence of second-wave feminism, along with the rise of diverse lesbian, gay, bi-sexual, and transgender movements, sexual awakenings became grounded in the notion that sexuality was something that the members of a 
sexual identity group shared. Individuals began to cooperate to tell stories about discovering shared sexual "truths," often adopting a new sexual worldview in the process. As Ken Plummer notes,

The modern world is cluttered with all kinds of sexual stories. Yet one major pattern has proliferated and developed most rapidly in the latter part of the twentieth century. These are the stories of sexual suffering, surviving, and surpassing. They have grown from being insignificant to being widespread; they have prefigured major social changes as a result of being told; and, like all good stories - they have been replayed, copied and borrowed over and over again. They are a story of our time. ${ }^{104}$

While these sexual stories "of our time" include "coming out" and "breaking the silence" types of accounts, ${ }^{105}$ I am specifically concerned with those stories that express a discovery of sexual "truth" - an awakening of a sexual nature. Typically, the coming out stories of the queer-liberation movement dramatized the tension between a privately known or hidden truth about one's counter-normative sexuality and the public proclamation of that truth. This social movement sought to challenge the cultural stigma and institutional biases against homosexually-identified individuals by creating an undeniable public presence. As the movement drama unfolded, "participant and movement narratives [became] closely linked in much the same fashion that individual interpretive frames and collective action frames are aligned and personal and collective identity overlap and fuse." 106 Thus, the queer-liberation movements of this era stressed the courageous and contentious act of making one's privately known counter-normative sexuality public. However, sexual awakening narratives are not primarily about "revealing" the truth but about "discovering" it. To hone my attention on this underexplored, although controversial, ${ }^{107}$ dimension of modern sexual stories, I deliberately focus on the sexual "reconversion" or "reparative" stories that arose as part 
of a cultural backlash against queer-liberation and queer-identity movements. The stories of once-homosexually-identified individuals who come out "again,"108 sometimes driven by religious beliefs, 109 typically foreground the dimension of personal discovery that is backgrounded or downplayed in traditional "coming out" stories.

The sectarian etiological community was also central to the development of the modern concept of trauma and the advent of the Post-traumatic Stress Disorder (PTSD) diagnosis. ${ }^{110}$ While Freud rejected the notion (advanced by Pierre Janet ${ }^{111}$ and others, including Freud himself in his earlier work) that a particular external event or experience led to a particular adverse psychological condition, ${ }^{112}$ this idea was at the core of the trauma narrative that emerged in various social movement communities in the 1970's, over three decades after Freud's death. The PTSD diagnosis initially took embryonic form in the "rap groups" organized by Vietnam Veterans Against the War113 before the American Psychiatric Association included an official version in the third revision of the Diagnostic and Statistical Manual of Mental Disorders (DSM) in 1980. Vietnam veterans congregated in these semi-private settings to talk about their experiences in Vietnam and their current psychological troubles. Often in the presence of a psychological professional, they found commonalities in their personal stories and began to conclude that their current troubles stemmed from their common war experiences. Around the same time, the feminist and overlapping child protection movement mounted public campaigns highlighting the prevalence and psychological consequences of sexual assault in general and childhood sexual abuse in particular. ${ }^{114}$ Like the veterans, feminists organized "consciousness-raising groups" where individuals began to link psychological troubles to their common experiences. In both cases, individuals cooperated to make their psychological problems into social problems. As 
the collective memory of the Holocaust was evolving into a "trauma drama," 115 these and other groups told powerful stories about traumatic experience and its aftermath, mounting social criticisms with a clinical vocabulary. ${ }^{116}$

In these morally and politically charged "safe spaces," a particular type of the free spaces first discussed by Sarah Evans and Harry C. Boyte and later described by others to be fundamental to social movement mobilization, ${ }^{117}$ individuals rewrote their personal biographies with a collectively produced and rooted script. In the process, they reinterpreted their personal troubles to be public issues. According to Mills, personal "troubles properly lie within the individual as a biographical entity and within the scope of his immediate milieu - the social setting that is directly open to his immediate experience." ${ }^{118}$ Alternatively, public "issues have to do with matters that transcend these local environments of the individual and the range of his inner life [...] with the ways in which various milieux overlap and interpenetrate to form the larger structure of social and historical life." ${ }^{119}$ Post-traumatic communities thus formed to make both the causes and consequences of trauma into a social problem. In the process, they produced a common etiological account of shared adverse mental health symptoms. Psychological and other symptoms came to be seen as metaphoric "clues" to a yet-to-be discovered or fully-understood past event. ${ }^{120}$ Sufferers of PTSD are encouraged, by the very logic of the diagnosis, to seek the meaning of their psychological symptoms in past, external experiences, often "awakening" to the truth about past experiences and events in the process. For example, Vietnam Veterans Against the War member, Dave Cline, writes,

I would wake up suddenly, soaked in sweat and afraid. I couldn't forgive myself for having taken other people's lives and for being naive enough to believe the US government's lies and winding up in the war zone to begin with. I thought that if others knew my story, they would shun me as a murderer. Sometimes when I was 
alone I would cry and I never talked to anyone about what was going on inside my head. I heard about Post-Vietnam Syndrome (now called Post-Traumatic Stress Disorder, or PTSD) but didn't understand that I was experiencing it (emphasis added). ${ }^{121}$

Whereas with Freudian psychoanalysis awakenings and psychological exploration were deeply personal and idiosyncratic, this new trauma paradigm expanded the psychoanalytic awakening narrative to link the personal discovery of psychological "truth" to the collective discovery of psychologically-relevant social problems. The personal and emotional deliberation that is central to the psychoanalytic framework was still valued over impersonal, rational calculation, but common, external experience was stressed over idiosyncratic, internal processes. Laura Davis exemplifies such a focus on common experience in her personal statement for the preface to the controversial self-help book for survivors of childhood sexual abuse, The Courage to Heal. Reflecting on a personal realization that occurred while conducting interviews for the book, Davis writes,

There were tremendous similarities in the stories. The Black ex-nun from Boston and the ambassador's daughter from Manila described the stages of their healing process the same way. A pattern started to emerge. What I was going through started to make sense. ${ }^{122}$

Thus, Davis makes sense of her own life as she finds commonality in the lives of others. In a similar vein, groups of veterans, feminists, and others blended the psychotherapeutic process of looking within the self with the process of looking among themselves for clues and, consequently, looking into the social world for answers. They stressed commonality over idiosyncrasy; they shared the process of awakening and personal discovery. With the advent of the modern trauma narrative, personal discovery 
becomes linked to the etiological community, and autobiographical memory to the memory of identity groups. Like other sexual and cultural communities of the time, these groups cooperated to refocus and reinterpret the past, construct narrative linkages between past experiences and present conditions, and establish autobiographical communities rooted in sectarian conceptions of truth.

\section{Summary}

Foundational awakening narratives are historical manifestations of the awakening story formula that are held sacred by particular communities. Some take form as biographical accounts of an iconic figure. Others take form as a theoretical account of falsehood and truth. In all cases, these foundational narratives serve as cultural referents and story models for individuals and autobiographical communities. They set a cultural stage for individuals to tell autobiographical stories about once being "lost" in "darkness," unaware of truth and reality, and then "awakening" to "see the light" as they discovered truth in their lives. Consequently, these foundational accounts provide narrative mechanisms and storytelling rules that individuals can use to ally themselves with an autobiographical community by affirming that community's worldview while undermining competing versions of truth.

The foundational awakening narratives outlined in this chapter span different social settings and time periods, ranging from several centuries B.C.E. to the modern era. Spurred by the Western Enlightenment, new dynamic ideas about self-exploration, and the developing cultural politics of the late-modern era, awakening narratives proliferated and diversified through history with the emergence of different and 
contentious value spheres and discourses of truth. Consequently, the stories I highlight pertain to different subject matters and rely on different ideas about the locus and character of truth. Some of these narratives posit a universal truth rooted in collective life while others posit more particular - even idiosyncratic - truths rooted in an individual's personal life. Despite these significant differences, it is their adherence to a common underlying narrative formula that ties this eclectic set of stories together. As I will continue to show, this story formula plays a determining role in the cultural tensions and epistemic disputes of the modern world. 


\section{Chapter 3}

\section{Revising the Past, Plotting the Future}

"Only a good-for-nothing is not interested in his past.”

$\sim$ Sigmund Freud ${ }^{1}$

\section{AUTOBIOGRAPHICAL REVISIONS \& AUTOBIOGRAPHICAL PROJECTS}

As awakeners account for their lives, they explicitly redefine important experiences, events, perceptions, and relationships of the past. In particular, awakeners negate or "nihilate" 2 their prior beliefs and perceptions as they describe a personal discovery of "truth." In order to convincingly argue that their newly acquired conceptions are true and enlightened, they must claim that the beliefs and meanings they once took for granted were somehow false and delusional. By negating their former beliefs and perceptions, awakeners build a sharp, temporally structured cognitive discontinuity into their life stories. They reinvent and mobilize their autobiographical memories as they contrast their current and former worldviews to articulate a major transformation of mind. Thus, awakeners revise the past in order to distance themselves from it, justify their current beliefs about the world, and re-plot their future lives in reaction to their newly constructed memories. 
While such mnemonic revisions ${ }^{3}$ are seemingly very personal, they take form in various autobiographical contexts, 4 during various autobiographical occasions, and in solidarity with various autobiographical communities where we cooperate with others to give meaning to the past. 5 Consequently, such narrative environments are distinctly social spaces of memory and such autobiographical communities are also "mnemonic communities" ${ }^{6}$ whose members share distinctive ways of recalling and recounting the past. To offer an account of one's life, a story we must provide "whenever an action," or in this case a major change of mind, "is subjected to valuative inquiry," 7 inherently involves recounting personal experiences; it involves memory work. Both the act of recounting and the subject matters of memory (the events, experiences, and relationships that are recounted) are always set in a social milieu.

Autobiographical communities provide shared scripts and formulas and enforce recounting conventions that individuals use to shape their personal memories and put them into narrative form. Awakeners thus combine newly acquired, community-specific conventions and "traditions" 8 of remembering with the culturally durable awakening narrative formula to make sense of the past in strategic, socially patterned ways. The generic awakening narrative formula is a cultural tool and storytelling mechanism that individuals use to rewrite their particular autobiographical stories and, in the process, express mnemonic solidarity with a group of others who define the past (i.e. who remember) in similar ways. Such communities provide awakeners with a sociomental reference group that also serves as a narrative standpoint from which the awakener perceives the past amidst a multifarious and contentious autobiographical and mnemonic field. Given the social logic of awakening stories, awakeners always associate their current autobiographical community with "light" and "truth" and their past 
autobiographical community with "darkness" and "falsehood." They use their personal stories to corroborate and advance the socially rooted recounting conventions and mnemonic norms of their current community while undermining and negating those of another. As they tell their stories, awakeners use their (revised) autobiographical memories to undo their past community's way of defining an important issue or event. They wield autobiographical memory as as a cultural tool in social contest over the meaning of some widely significant and contentious moral issue.

Awakening stories thus have a distinct "backward" reach. Generally speaking, they rely on a social logic of historical and autobiographical revision that trumps the particularities of any given case. The awakening story formula requires the past to be rewritten in some way, regardless of the subject-matter at hand. As awakeners redefine their autobiographical memories, they work to assert mnemonic authority: a sociallyrooted ability to determine how salient moral and political issues are remembered. Some awakeners (for example, those who recover memories of childhood sexual abuse) selectively redefine particular past events, experiences, perceptions, and relationships to shape the accepted social framework for individual memories pertaining to a particular moral-interpersonal issue. They use their autobiographical memories to say something about how other individuals should account for certain culturally contentious issues in their lives. Others (for example, members of the social movement organization Iraq Veterans Against the War) use their autobiographical memories to shape the collectively held definitions and memories pertaining to the shared experiences of a broader social group. As they tell awakening stories, they make a statement about how "society" should remember a certain event or issue. In all cases, the objective details of the past do not change but the awakener's perception an understanding of the past transforms. 
Thus, awakening stories suggest there is a dynamic interplay between autobiographical memory and genuinely collective memory. While autobiographical memories are actually quite social in character (and therefore only seemingly personal), 9 collective memories are often only knowable because they manifest in the recollections and accounts of individuals. ${ }^{10}$ As awakeners revise important events, experiences, perceptions, and relationships of the past, they commit their memories and their life stories to one version of truth and memory while undermining others. They work to shape the mnemonic norms of a multifarious social group that contains multiple and contentious communities.

Awakening stories also have a distinct "forward" reach. As awakeners revise their past experiences and relationships, they pave the way for an alternative autobiographical future, sometimes, as in the case of most religious conversions, beyond the point of death. While some awakeners explicitly discuss their future plans and objectives, all awakeners imply a future life that stands in contrast to their past beliefs and behaviors. They lay out a new trajectory for their lives and "project" ${ }^{11}$ themselves into the future. This future-orientated trajectory is a necessary consequence of the temporality inherent in the narrative itself; the life story and the life course throughout time are one and the same. Further, this future-oriented projection typically and primarily takes form as an implication of the awakener's negation of the past. Consequently, awakeners typically pay more attention to the details of the past than to the details of the future as they plot their future life in reaction to their newly redefined past experiences. Thus, mnemonic revisions carry major implications for awakeners' future attitudes, beliefs, relationships, and courses of action. Revising the past is inseparable from establishing a new orientation to the future. 
Finally, not only do awakeners contrast their new future-oriented autobiographical projects to their newly-revised past, but also to the potential future course of "darkness" that is implied by their past "false" state of mind. Just as surrenders, as a social performance, "interrupt and reroute specific historical timelines and alter identities and fealties," ${ }^{12}$ awakenings reroute autobiographical timelines. Awakeners contrast their new life trajectory with an implied, could-have-happened future of "darkness" and use their autobiographical accounts to mark the boundaries between "contending projects" 13 in a broad autobiographical field (See Figure 3). By projecting an alternative future, awakeners distinguish their current beliefs, perceptions, values, and actions from the characteristics of those who still adhere to the awakener's former worldview. They distinguish the objectives of their current community from the objectives of their former community. In the process, awakeners cast their lives as a living testament to "truth" and "enlightenment" and a warning to all those who have not yet "seen the light." As with forms of testimony more generally, "recalling the personal past" becomes a strategic way of "actively creating the public future." ${ }^{14}$ As awakeners look to the future, they express a projective solidarity with others who share similar autobiographical trajectories and a common moral agenda. 
Figure 3: Alternative autobiographical trajectories reveal contending projects in an autobiographical field.
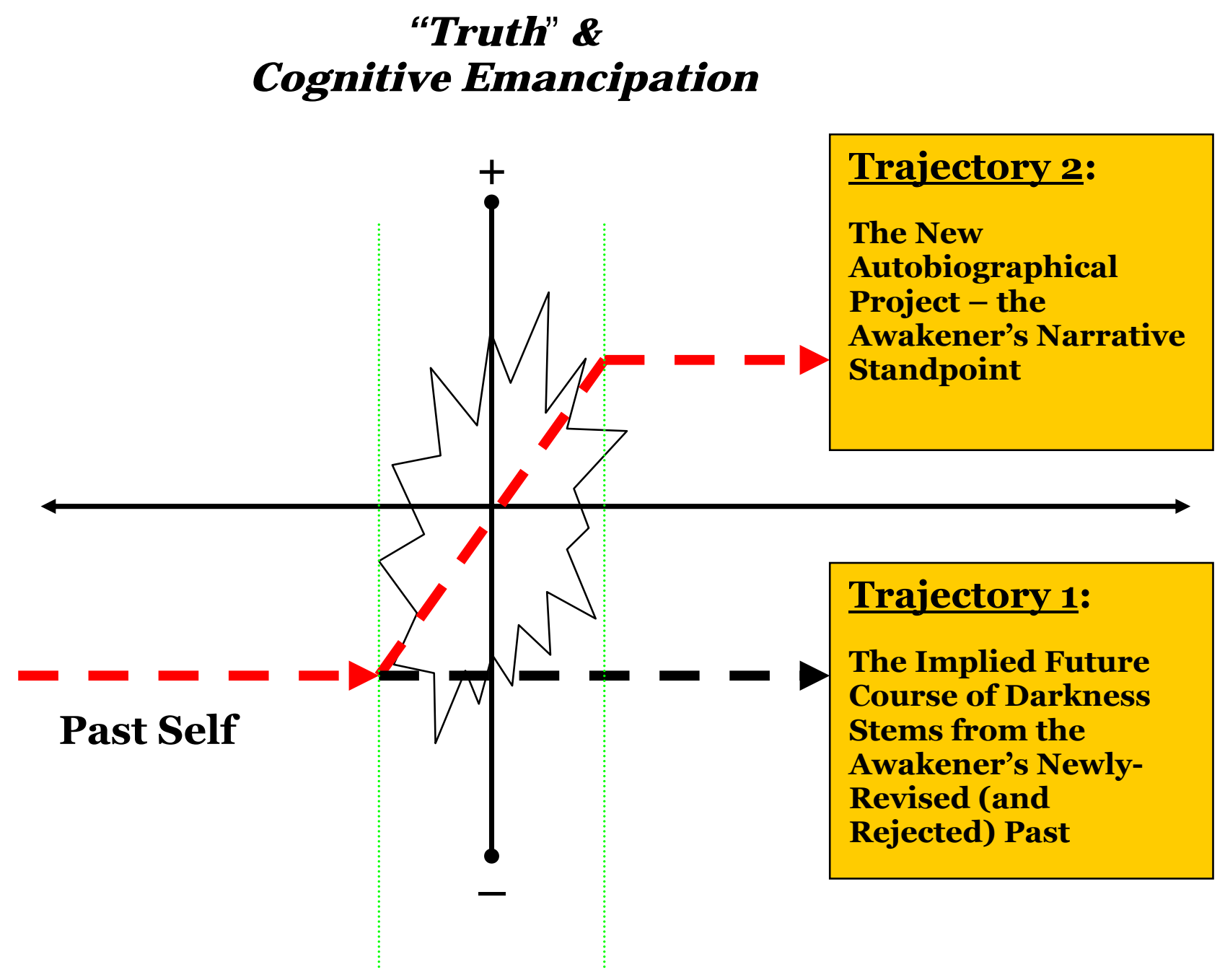

Falsehood \& Cognitive Constraint 
Consider the following examples. Despite a variety of differences among them, each storyteller describes and redefines past perceptions, experiences, and relationships in order to account for a discovery of "truth." Further, each storyteller's mnemonic revisions carry significant implications for his or her future life. By telling their stories, each awakener lends mnemonic authority to some autobiographical community, be it a socially diffuse thought collective or well-defined organization. In each case, the storyteller describes a personal transformation of consciousness in order to weigh in on a cultural tension or dispute concerning some morally or politically contentious issue.

Melissa, a self-identified survivor of childhood sexual abuse, writes,

I have been remembering more, more details [...] the pieces started coming together [...] My own father. He SA [sexually assaulted] me for all of my toddler years, and more. We were "married" he had given me a "special ring," he told me I was special and this was just between him and I, not to be shared with Mommy. I remember the downstairs bathroom and how he "washed" me, I remember how he "dried" me when I was naked by our pool at night, I remember our "cloth game", the cloth was my "blankie." I remember how my mother commented when I was an adult, that I was inseparable from my father, that she was jealous of me. ${ }^{15}$

While describing her recovered memories of childhood sexual abuse, Melissa uses quotation marks to describe, discredit, and reinterpret her prior perceptions and memories of certain childhood experiences. She rejects her previously held perceptions (“washing," "drying," "games," her "blankie") in favor of what she now believes to be a true understanding of the sexual abuse that occurred in her childhood. Like P. J. O’Rourke, the 1960's leftwing radical turned anti-left satirist who undermines and rejects his prior perceptions of Bob Dylan, Mao Tse-Tung, The Vietnamese National Liberation Front, Yoko Ono, the I Ching, and his own long hair, ${ }^{16}$ or Neo, the fictional protagonist of the Wachowski brother's 1999 film The Matrix who learns that the world 
his once perceived to be real was actually a computer generated fantasy, Mellissa expresses a sharp sociomental discontinuity in her life. In the process, she redefines important family relationships and adopts a new way to account for her current psychological state, providing a prospective justification for her future needs, attitudes, behaviors, and associations. She establishes a future-oriented project as an adult victim of childhood sexual abuse. Likewise, Angel writes,

I am 19 years old and in my freshman year in college. I have just remembered the sexual abuse I endured as a child [...] About two months ago, I began having horrible nightmares and flashbacks [...] my father had sexually abused me [...] The first incident I remember is taking a shower with him, and him making nicknames for our private parts [...] I called him Mushroom and he called me Anthill (for very embarrassing but obvious reasons). I remember him bathing me in the bathtub on other occasions, but it wasn't the normal bathing a parent does for their child [...] Then he would lead me into his bedroom and tell me to lie down on the bed and spread my legs so he could "check if I was clean enough". I did, and he would then take a rough washcloth and rub my genitals with it. ${ }^{17}$

Like Melissa, Angel revises her perception of the past. As she recalls memories of childhood sexual abuse, she explicitly reinterprets important childhood events - those associated with bathing in this case - and redefines her relationship with her father (as does Desi, who reinterprets very similar experiences as she redefines her relationship with her grandmother ${ }^{18}$ ). As Melissa and Angel account for their personal discoveries and present awareness of "truth," they throw their autobiographical weight behind a community of self-identified survivors who affirm "recovered memories" in their collective effort to define childhood sexual abuse as a pervasive social problem.

While Melissa and Angel describe recovering memories of sexual abuse (a particular mechanism of autobiographical revision that is embraced by the sexual abuse survivor community), they tell stories that are similar in more general ways to a variety 
of other accounts. Ronn, for example, a member of Iraq Veterans Against the War, also redefines his past experiences and perceptions while accounting for his discovery of "truth." Ronn voluntarily re-enlisted in the army in 2003 in order to fight in the U.S.-led war in Iraq. After killing an Iraqi civilian, he had an awakening that is evocatively captured by the titles of two of his posts, "The Death of a Pro-War Conservative -or- The Day I Got Away with Murder" and "What, Exactly, Are We Dying For?" Ronn writes,

... for those of us who believed in the war at first (like most of the country), we enlisted to be defenders of the American people, not storm troopers in an American-run police state [...] And I believe it's the soldiers/seamen/airmen/marines who enlisted with patriotism in mind that feel the most like I feel. ${ }^{19}$

The more I thought about it, the more I realized that all the reasons for us going into Iraq were false [...] When I first got to Iraq, I felt that the quickest way to end the war was to [...] just [...] Kill them all [...] I bought into the fear, the hype, and the propaganda hook, line and sinker [...] I'm not going to waste any more time on those arguments. Anyone who speaks in absolutes like that is completely selfdeluded. I'm only going to say that [...] the "kill them all" mentality is called genocide when other countries do it. ${ }^{20}$

As Ronn tells his story, he describes awakening to the truth about the Iraq war and, more generally, the political policies of the United States government. Like Melissa, Ronn redefines his personal experiences and perceptions in order to articulate a major transformation of mind, in his case a shift of political paradigm similar to the cognitive shifts observed by psychiatrist Robert Jay Lifton with regard to Vietnam Veterans decades earlier. ${ }^{21}$ Whereas Melissa was redefining important family relationships when accounting for her recovered memories of childhood sexual abuse, Ronn is redefining national political relationships that are important to his life. He rejects his previously held perspectives while describing his realization that the Iraq war is "genocide" and claiming that he was a "murderer." In the process, Ronn provides a prospective 
justification for his future attitudes, behaviors, and relationships and establishes a future-oriented project of brining the war to an end. Just as false memory activist Gail Macdonald redefined her past experiences in therapy as "mind control" to justify her future-oriented project of undermining the social legitimacy of recovered memories, ${ }^{22}$ and Saint Augustine of Hippo redefines his childhood as a life of "sin," "evil," "an abomination," and "a parody of life" 23 to establish a future-oriented project of spreading Christianity, Ronn works to undermine the logic and redefine the details of his former belief-system in order to establish a new future-oriented trajectory in contrast to the course his life would have taken without his awakening. As he redefines his past perceptions and experiences, Ronn uses his personal story to reinforce the cognitive authority of Iraq Veterans Against the War, an organization working to undermine popular justifications for war. While his recollections concern what is, at the time he wrote his stories, an ongoing event, they also serve to shape the mnemonic record of that event. Ronn uses his personal memories to say something about how the war in Iraq should be defined and remembered.

Despite many differences between Melissa (whose story ultimately concerns interpersonal relationships and a psychological subject matter) and Ronn (whose story concerns an international issue and is fundamentally political in character), both describe a "revolution" of consciousness, juxtaposing an explicitly "false" state of mind with their more current found "truth." In both cases, what was proper before is improper after [...] what used to be one's world becomes that which one must overcome." 24 While the objective details of their past experiences have remained the same, their perception and understanding of whose experiences has changed. On a formal level, both of these stories involve the claim, "What I used to think was true is 
actually false." Both storytellers go to great lengths to reinterpret and redefine their previously held beliefs, rejecting what they once held to be the "definition" 25 of some situation that is highly relevant to their lives. They tell their stories as if they are peeling away blinders that concealed the "true" nature of things, as if they were replacing a bogus understanding with an awareness of "reality." In the process, both Melissa and Ronn (as well as P. J. O’Rourke, Gail Macdonald, and Augustine) are adopting the recounting norms of a new autobiographical community. As they reinterpret their personal past experiences and relationships, they take on new social conventions of remembering and recounting.

Similarly, Scott also reinterprets his past, but he does so as he describes a sexual awakening. Scott reinterprets his past childhood experiences in order to explain his unwanted homosexual attractions in adulthood. He writes,

[...] I began to reinterpret my history in a whole new light - a light that illuminated my present turmoil. I recalled a childhood of emotional turmoil and confusion. The boys who were in my class played rough-and-tumble games during recess. I never joined in. I didn't know how to play the games and was afraid of getting hurt. I felt so uncoordinated... Now it is amazingly clear to me that the moment I first felt something like an erotic attraction to another guy was the very moment that I first identified myself as the emotional and physical opposite to that guy. ${ }^{26}$

Scott looks to his past and reinterprets his childhood experiences to account for unwanted homosexual attractions. The objective contours of his past have not changed, but rather his perception and understanding of them have. Like Dora, whose loss of voice and persistent coughing Freud attributes to repressed sexual desires stemming from past encounters and experiences with family members and family friends, ${ }^{27}$ or Malcolm X, whose studies in prison under the guidance of Nation of Islam leader Elijah 
Muhammad led him to reinterpret his former life of crime and hustling to be a consequence of historically entrenched racial oppression, ${ }^{28}$ or Frank, another "repaired" heterosexual whose experience in "sexual reparative therapy" led him to redefine his past homosexual relationships and experiences to be "just a symptom of profound and deep emotional arrest” stemming from unresolved childhood issues, ${ }^{29}$ Scott attributes new meaning to his personal past in order to construct an autobiographical cause-andeffect chain. He finds causes for his current personal troubles ("present turmoil") in past situations and experiences ("a childhood of emotional turmoil and confusion") and uses his autobiographical account to weigh in on a culturally contentious issue of sexual orientation. In the process, Scott redefines significant interpersonal and sexual relationships in his life (in particular, his relationships with other men) and establishes a future-oriented project of heterosexuality. As he "reinterpret[s his] history in a whole new light," Scott vies for mnemonic authority and lends autobiographical support to the sexual reparative movement, a community that works to undermine positive definitions of homosexuality and define same-sex attraction as a developmental disability.

Despite a variety of differences among them, Melissa, Ronn, and Scott reinterpret specific past experiences in order to account for a major transformation of consciousness. As they describe awakening to some newly-found "truth," each storyteller replaces one particular definition of some event or situation (now defined as "false") with another. Alternatively, Steve looks to his past to fill a void in awareness. As opposed to explicitly "replacing" a incorrect perception with a newly acquired correct view, he finds a definition or comprehension (in this case, a memory) that previously was not there in any form and "fills" a blank spot in his consciousness. Reflecting on a 
trip he took to the New York World's Fair in 1964 with a neighborhood man who worked with children, Steve writes,

I was in my underwear, and I remember the terror that I felt when he got into the bed in his underwear, the kind of terror that makes you feel like there is no air in the room to be had. I couldn't look at him; I couldn't look at anyone or anything. At this point, my memory goes blank. The next day, I had excruciating pains [...] It felt like I had a knife sticking into my insides. I remember that I was afraid I was going to die, but I knew I couldn't tell anyone, even though I didn't consciously remember what he had done to me. I just knew to keep quiet [...] I didn't put the pieces together until sometime during therapy, in my forties, when I remembered how I knew to keep quiet the morning after he molested me (emphasis added). ${ }^{30}$

As Steve tells his story, he describes awakening from a "blank" void in memory and comprehension. He describes being aloof and completely unaware of something that happened in his past until, around three decades later, he "put the pieces together" in therapy where he remembered how, as a child, he "knew how to keep things quiet," thus associating a strict social imperative to silence and denial ${ }^{11}$ with a previously unconscious dissociative amnesia. Like Melissa (the self-identified survivor of childhood sexual abuse quoted previously), Steve lends autobiographical support to a community of self-identified survivors of childhood sexual abuse who uphold the veracity of recovered memories. However, whereas Melissa replaces a specific bogus or illusory impression of reality, Steve fills a mnemonic void. He reinterprets his past experiences and relationships by finding something of which he was previously unaware.

Like Steve, Christie, a member of Iraq Veterans Against the War, also describes filling a void in her perception and understanding. Whereas Ronn (the IVAW member quoted previously) describes replacing one moral outlook ("defenders of the American people") with another (the war is "genocide"), Christie describes being completely aloof 
to the moral consequences of her enlistment and eventually discovering what her "contribution" to the "military machine" really meant. She writes,

In 1998 at age 18, I auditioned for the Army Band and enlisted impulsively and without informed consent. I spent a year playing flute in an all-purpose band at Fort Campbell [...] The position offered permanent station, schedule flexibility, and automatic E6 [...] I grew ethically and spiritually strong, over time coming to the realization that my contribution, however indirect, was harming mother earth and her children. To stay would compromise my morals; I was a conscientious objector. In June 2003, I left the military [...] [F]or two years i lived in quietude, avoiding telling anyone I was a veteran out of fear, embarrassment, and overwhelming guilt. In the last year, I've finally felt ready to bring my past out, and I joined IVAW to seek support in speaking out about the mental destruction and emotional trauma the military imprints on all of us. Today I study the science and art of home birth midwifery as a spiritual exercise, a healing ritual, and to bring balance on both a personal and a global level. $3^{2}$ (emphasis added)

Whereas Ronn and other IVAW members "enlisted with patriotism in mind," 33 Christie “enlisted impulsively and without informed consent." As she accounts for her awakening, she reinterprets her past to find the harm that she perpetrated as a member of the military, a perpetration of harm that led to "fear, embarrassment, and overwhelming guilt" when she discovered the "truth" about her "contribution." Like Eileen Lipsker (who remembered witnessing her father murder her best friend twenty years after the fact),34 or Edna Pontellier (Kate Chopin's fictional protagonist who "awakens" to discover her previously unknown sexual desire and dissatisfaction with her traditional life), 35 and like many other veterans who describe joining the military to pay for college only to later learn the "truth" about the military and war, Christie describes filling a void in her past understanding - reinterpreting her past perceptions, attitudes, behaviors, and relationships as she discovers a "truth" of which she was previously 
unaware. In the process, she establishes a future-orientated project as an anti-war activist and midwife who seeks to "bring balance on both a personal and global level."

Mnemonic replacing and mnemonic filling are two ideal-typical strategies that awakeners use to revise the past. They also represent two ideal-typical, socially constituted forms of ignorance - the illusion and the void - both of which awakeners contrast with an ascent to enlightenment in order to define their future lives in contrast to their newly redefined past experiences. In the case of mnemonic replacing, awakeners typically work to describe and undermine a specific illusory belief, perception, or worldview that they once erroneously took for granted. This subtype of awakening story takes the form of a liberation narrative, as awakeners who replace one version of the past with another typically describe being freed from a specific oppressive, confining, or evil worldview. The Christian Apostle Paul, for example, explicitly evoked and "replaced" his prior worldview as a Pharisee as he converted to Christianity and renounced his allegiance to the Roman State. By his own account, Paul is liberated and thus becomes a liberator, as he recalls Jesus saying, "I will rescue you from your own people and from the Gentiles. I am sending you to them to turn them from darkness to light, and from the power of Satan to the power of God (emphasis added)." ${ }^{6}$ Likewise, Charlene Cothran, 37 former lesbian activist and editor of Venus, a magazine she previously published for African American lesbians, explicitly “replaced” her prior worldview as an outspoken advocate of gay-rights in favor of an anti-gay, evangelical worldview. In both of these cases, Paul and Charlene, like Melissa, Ronn, and Scott, use their autobiographical accounts to debunk a specific set of illusory perceptions they once believed to be true. In the process, they "rekey" 38 specific beliefs, experiences, and actions as they account for their awakenings. 
In the case of mnemonic filling, awakeners go to great lengths to account for a prior void of understanding in their lives, emphasizing their previous state of confusion, lack of awareness, or emptiness. This subtype of awakening story takes the form of a creation narrative as awakeners who fill the past typically describe their new worldview as if it were born out of a void of nothingness. 39 For example, Siddhārtha Gautama's awareness was defined by his sheltered, aloof existence of privilege prior to his spiritual journey and enlightenment. Likewise, transgendered activist Leslie Feinberg describes searching for answers regarding his sex/gender identity and eventually filling the void in his consciousness with a sexual and political analysis of transgender history. $4^{\circ}$ In both of these cases, Siddhārtha and Leslie, like Steve and Christie, use their autobiographical accounts to locate and identify something previously absent and undefined. Awakeners use both mnemonic replacing and mnemonic filling strategies, at times in combination, to redefine past experiences and relationships while claiming to discover a previously unknown "truth."

Despite many significant differences among self-identified survivors of childhood sexual abuse, anti-war veterans, "repaired" heterosexuals, religious saints and prophets, former left-wing activists turned right-wing pundits, those who retract memories of childhood sexual abuse, transgender activists, and Black Nationalist Muslim ministers, all of the individuals cited above tell stories that adhere to the same general autobiographical formula. In the process of accounting for their major transformations of mind, each awakener redefines the past and re-plots his or her future life. Awakeners use such mnemonic revisions and future-oriented projections as they emplot their lives to distinguish between "falsehood" and "truth," no matter what the subject matter of the particular story may be. Such mnemonic revisions and autobiographical projections are 
only seemingly personal as they are an inherent feature of a socially shared and culturally prevalent awakening story formula. Awakeners use this story formula to mark the boundaries between two mutually exclusive and contentious communities, rejecting the recounting norms and mnemonic conventions of one group in favor of another. In all of these cases, "darkness" and "falsehood" must necessarily be defined in retrospect it is defined and "discovered" by looking (spect) into the past (retro). No matter what the content of the story, and regardless of whether one is replacing a confining worldview or filling a void in awareness, awakeners revise their personal past in order to define their former state of cognitive constraint and contrast it to their newly acquired cognitive emancipation.

\section{Formulaic Revisions and Cultural Contentions}

A case-specific or content-based approach to autobiography would likely show how individuals moving into a religion, a political ideology, a sexual orientation, or a particular victim identity tell reverse or opposite stories in relation to those moving out of these worldviews. Such stories are conventionally thought to be oppositional or antithetical because they express a cultural tension or dispute. However, such oppositionally positioned individuals tell stories with the same narrative formula. Consider the following set of examples. Martin, a former cocaine addict turned Born Again Christian, describes his experience while fleeing arrest for bank robbery. Martin writes,

As my mind filled with the wonder and peace of nature, questions arose that I had never considered before. I wondered who was responsible for making the stars, the moon, the clouds, and all of creation. As I was pondering these 
questions, it was revealed to me. I realized that only God could create such beauty. It had to be God. It was God! [...] As I stood on the balcony gazing toward the heavens, a series of cold surges radiated throughout my body. This filled me with shivers all over [...] Vivid scenes from my past began to flash before my eyes. I was being shown all the pain and hurt I had inflicted upon others. Only this time the pain was mine. And it was real! Its realness was intensifying the heaviness in my heart. I began crying for the mess I had made of my life. Suddenly I found myself talking to God. 41

Like the awakeners cited above, Martin retrospectively redefines his past experiences, decisions, behaviors, and relationships. While describing his discovery of ontological "truth," Martin looks into the past (in this case, as it comes to "flash before [his] eyes") and discovers "all the pain and hurt" he "had inflicted upon others" along with an overall "mess." As he tells the story of his awakening and redefines his autobiographical past, Martin adopts a new way to account for his personal problems and criminal behavior. Further, he establishes a future-oriented project of Christianity in contrast to his newly reinterpreted life of darkness. Given such a newly established autobiographical trajectory, Martin can then describe his time in prison as "walking in the light" and "fulfilling God's mission."

While Martin’s story might be fairly typical of Born Again Christian conversions, it is also formally quite similar to stories about rejecting a Christian religion. Fritz, a former Episcopal Minister who rejected religion to become an atheist, notes a major turning point in his apostasy to be a ten-day group sensitivity training. He writes,

I was forced to confront my own inconsistencies and hypocrisies. I saw how often I put up a false front, pretended I had everything under control when I wasn't feeling very secure at all. I saw how I repressed my fears, conflicts, and insecurities, lied even when I thought I was telling the truth [...] I packed my bags and left the ministry [...] At times what I experienced was amazingly religious. My new awareness that there's no built-in meaning or purpose for life, no creator and no plan, filled me with a sense of wonder over the miracle of life and the evolution of human consciousness. I had new feelings about the preciousness of a 
human life, short and vulnerable as it is. The loss of the religious beliefs I had once taken for granted opened the way to a kind of spirituality I had never known before. $4^{2}$

Both storytellers - the Born Again Christian convert and the Episcopal minister turned apostate - reinterpret their prior beliefs about life experiences, the nature of the world or universe, and the purpose of humanity's existence. Both "discover" that they had been living a life of delusion and darkness (in Fritz's case, one characterized by "inconsistencies and hypocrisies," "a false front," "repressed [...] fears, conflicts, and insecurities," and lies) in order to account for a major ontological and existential revelation. Both engage in an autobiographical and mnemonic revision, reinterpreting the character of their experiences and relationships in order to justify and legitimate their newly acquired worldviews and future-oriented objectives. Despite manifesting two contentious standpoints in a discursive field, both tell stories that adhere to the same story formula.

Similarly, Deborah reinterprets her past as she describes her awakening to Mormonism. Notice how Deborah assimilates the collective memories of her new religious community into her autobiography. As she tells the story of her awakening, Deborah incorporates the Mormon Doctrine of Pre-existence into her personal past. She writes,

As [the missionaries] began to explain that we lived with our Heavenly Father before birth, I began to remember my conversations with God as a young child [...] I vividly remembered living with my Heavenly Father and His Son, Jesus Christ. I remembered walking with my other brother, Lucifer and begging him to listen to Father and not to be so stubborn. I remembered crying when some of my friends were cast out of Heaven. 43 
As Deborah describes her awakening, she fills a mnemonic void, taking on new memories of her life. In this case, she personalizes the shared Mormon belief that human beings co-exist with God before conception, at which point they transition into a living body.44 Thus Deborah discovers past "conversations with God" and other significant experiences, relationships, and feelings that occurred before she was born. As she tells the story of her awakening, her personal account becomes fused, in a mutually reaffirming relationship, with the collective memories of the Mormon community.

Likewise, apostates to the Mormon religion tell stories that are similar in many ways to the stories of Mormon converts. For example, an apostate who goes by the name "warmfuzzylogic" was raised Mormon and once believed that God spoke to him, saved him from a debilitating depression, and told him to go on a religious mission for the Church of Latter-Day Saints (a collective rite of passage for many young Mormon men). He later reinterprets this central past experience as he rejects his prior worldview and embraces another. Notice how his mnemonic revision paves the way for a new, yet vague and undefined future. He writes,

[...] why couldn't my mind be responsible for my experience [talking to God]? Isn't it our most basic instinct to survive? If one part of my mind was trying to destroy me because of depression then another part of my mind could have been trying to keep me alive. The truth is that I don't know what happened. I may never fully understand that experience, but at least I can have some other possibilities than the original conclusion. I believe that is most likely that I misunderstood it. [sic] [...] With all the possibilities considered I will no longer assume that the voice I heard was God. I will no longer assume that because of this experience I should let the [Latter-Day Saints] church run my life. My future and the challenges it will present will have to be understood using information and resources that do not come from an unexplainable experience. 45

Whereas Deborah, the Mormon convert, redefined her personal past to include newly remembered conversations with God, warmfuzzylogic removes the voice of God from his 
past. He rekeys and replaces his prior interpretation of this experience with a new understanding (his "mind" is now "responsible"). Consequently, this previously influential experience (hearing God speak to him) no longer bears any weight on his future attitudes and decisions. However, despite their antithetical stance on the role of God in their lives, both Deborah and warmfuzzylogic contrast a past state of cognitive constraint with a newly acquired cognitive emancipation. Despite manifesting two contentious standpoints in an autobiographical field, converts and apostates both use the same awakening narrative formula to tell stories about their lives. While formally similar, their life stories express an ongoing cultural tension concerning the nature of truth in the universe.

Similarly, the oppositionally-situated awakenings of Roman Emperors Constantine and Julianus express a key cultural tension of the Roman Empire. Flavius Claudius Julianus (reign as sole emperor: CE 361-363) was raised a Catholic and awoke to Hellenic Paganism while studying philosophy in the years preceding his first stint as Caesar. ${ }^{6}$ Julianus (who is also known as "Julian the Apostate," a title that was obviously bestowed by Christians because to Pagans he would be "Julian the Convert") established official sanctions against Christianity and became a public symbol of Paganism throughout the Roman Empire. To understand the significance of Julianus's awakening to Paganism, however, it must be seen in light of Emperor Constantine's conversion to Christianity decades earlier (Constantine reigned as sole emperor during CE 324-337. He is recognized as a saint by some Orthodox Christians today.). According to legend, Constantine, Julianus's uncle and most likely the murderer of his father, is said to have awoken to Christianity after he was "commanded in a dream that his soldiers write the sign of Christ [...] on their shields." He was then, it is told, shown a cross in the sky with 
a message assuring him victory over his rival, Maxentius, in the Battle of the Milvian Bridge (CE 312).47 Christianity saw unprecedented growth under Constantine's reign, a trend Julianus later sought to reverse. The individual awakening stories of these two men, while employing a common narrative formula, express the historic cultural (religious and political) tensions between Pagan polytheism and Christian monotheism that characterized the Roman Empire for several generations.

Likewise, while Malcolm X (perhaps the most important figure of the American Black Power movement of the mid-twentieth century) and David Horowitz (former vocal supporter of the Black Panther Party and now one of the best-known and most controversial critics of Black liberation ideology) epitomize two contentious and antagonistic standpoints in a broader cultural arena, the autobiographies of both men are formally similar. Both men use their personal awakenings to advance contrasting political agendas. While one person's awakening is another's sleep, and one's beacon of light is another's specter of a darkness passed, such dueling awakeners use the same story formula as they "awaken" to oppositionally situated "truths" in a broader autobiographical field. They use their life stories to establish mnemonic authority in a cultural battle where autobiographical memories are mobilized to defend a specific set of beliefs and future-oriented objectives.

Furthermore, those who "retract" once-recovered memories of childhood sexual abuse tell stories that are similar to "recovered" memory stories. Rejecting her prior belief that she was sexually abused, Beth writes,

At the end of $21 / 2$ years of therapy, I had come to fully believe that I had been impregnated by my father twice. I "remembered" that he had performed a coat hanger abortion on me [...] I also "recalled" that he had inserted a curling iron, 
scissors and a meat fork inside of me, and other "horrors." I came to believe this without a doubt and could "remember" it happening detail by detail. 48

Just as Melissa (cited above) used quotation marks to describe recovering a memory of sexual abuse, Beth uses them to retract a recovered memory of sexual abuse. 49 Whereas self-identified survivors discover abuse in their lives, retractors discover that their oncebelieved-in abuse experiences never actually happened. Consequently, retractors rename "recovered memories" "false memories" and establish a future-oriented project as a victim of "false memory syndrome." 50 As she accounts for her personal discovery of "truth," Beth throws her autobiographical weight behind the False Memory Syndrome Foundation, an organization that denies the legitimacy of recovered memories and defends the sanctity of the family. Both narrators - the "survivor" and the "retractor"reinterpret their past perceptions and relationships as they "awaken" to oppositionally situated "truths" in a cultural contest over the veracity of claims concerning childhood sexual abuse.

As retractors revise the past, they negate a prior awakening experience. While Beth, for example, once had an awakening similar to Melissa's (i.e. she once discovered sexual abuse existed in her childhood), she now reinterprets that prior awakening to have been a false awakening. Such re-awakeners symbolically redefine what was once brought to "light" (in this particular case, a sexually abusive experience) to have really been a delusional "darkness." They use the awakening narrative formula to undermine and reject one awakening in favor of another, reinterpreting their lives while switching autobiographical communities and establishing a new future-oriented trajectory. To this end, Gail reinterprets what she once believed to be a legitimate discovery of "truth" that she was sexually abused as a child - when she writes, "we were living in an unreal 
world of 'recovered memories' of events that never took place [...] We were the lucky ones, the ones who managed to escape back to reality from the insane world." ${ }^{1}$ Likewise Kate, in a letter she wrote to her father who she previously accused of sexually abusing her, writes,

... at least the truth will be known. There is no beauty in a world of falseness. There is no freedom in a cage of lies... I took a wrong turn, a major wrong turn in my life. I have been lost and afraid but I have found my way back. ${ }^{2}$

Each of these re-awakeners uses the awakening narrative formula to retract a previously discovered memory of childhood sexually abuse. In the process, they negate a prior awakening. The content of the story becomes inverted as previously recovered memories are redefined as products of an "unreal" or "insane world" (Gail) or a "world of falseness" and "cage of lies" (Kate), yet the generic story formal remains the same as the re-awakener switches from Model A to Model B in Figure 4 below. 
Figure 4. Re-awakeners use an awakening narrative formula to reinterpret and negate a previously embraced discovery of "truth."

MODEL A: An Awakening Narrative

Truth/Light/Cognitive Emancipation

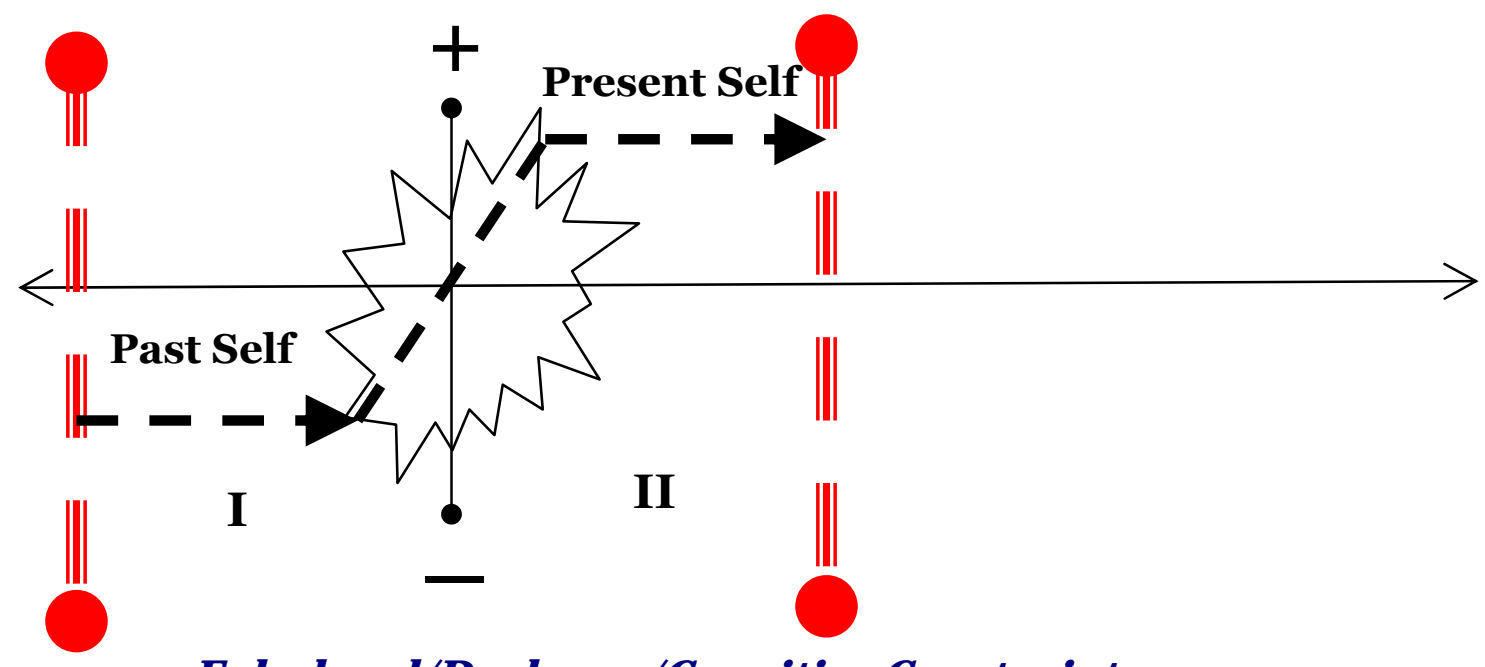

Falsehood/Darkness/Cognitive Constraint

MODEL B: A Re-Awakening Narrative

Truth/Light/Cognitive Emancipation

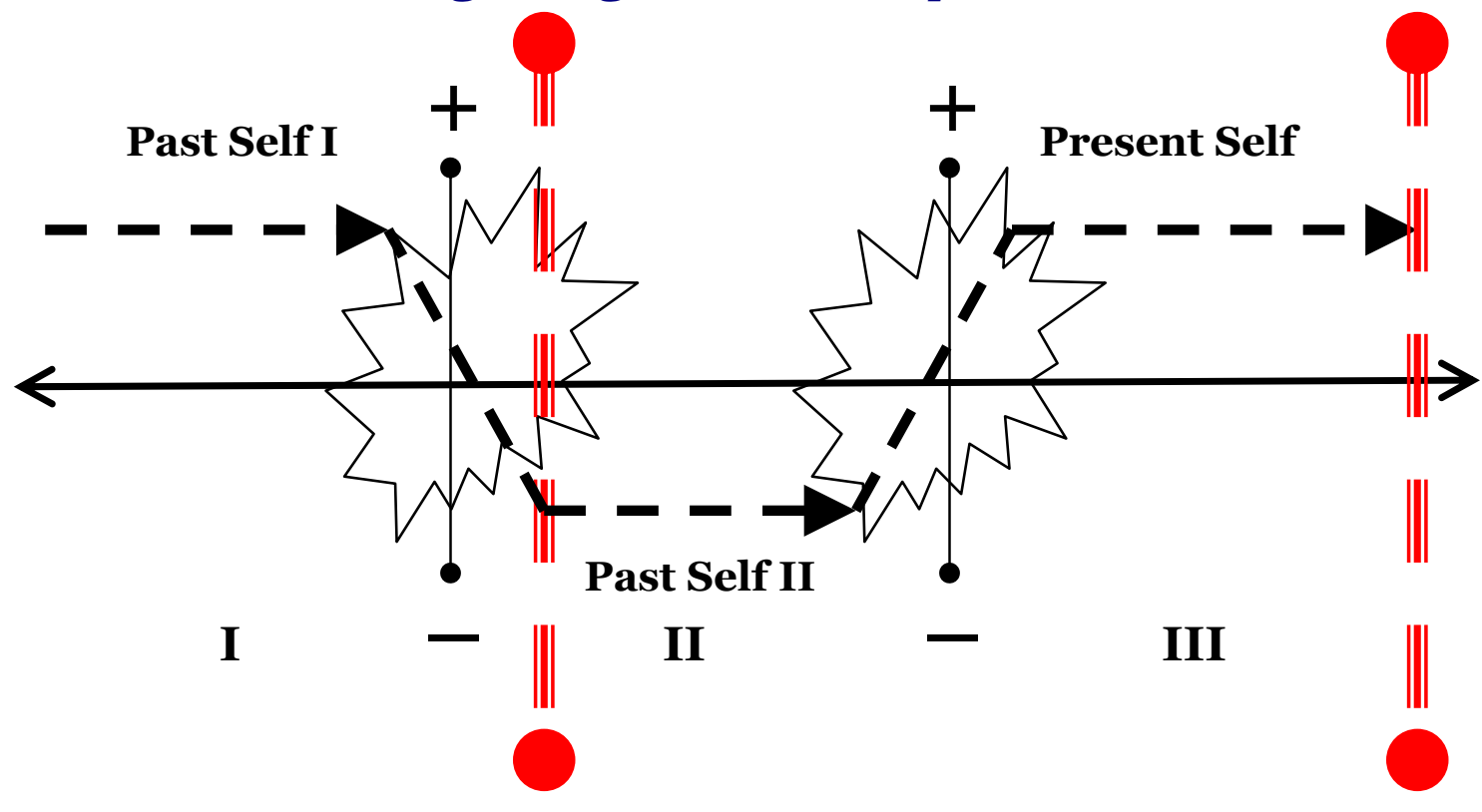

Falsehood/Darkness/Cognitive Constraint 
Regarding Figure 4, the storyteller's movement from position I to position II in Model A (in the section demarcated by the heavy dashed vertical lines) is replicated by their movement from position II to position III in Model B (also demarcated by heavy dashed vertical lines). Re-awakeners are individuals who tell a story about moving from Model A to Model B. In the process, the memories and perceptions they now regard as "false" they previously regarded to be "true" and vice versa. Structurally speaking, the period of the awakener's life denoted by position I moves from the realm of "darkness" (below the $\mathrm{X}$ axis) to the realm of "light" (above the $\mathrm{X}$ axis) as the storyteller transitions to the autobiographical map in Model B. In addition, the period of the awakener's life denoted as position II moves from "light" to "darkness" as the storyteller reinterprets and undermines one awakening in favor of another.

Re-awakening narratives further demonstrate the remarkable flexibility of the awakening narrative formula, which can be adapted to suit multiple changes of mind in a person's life. Re-awakeners express a culturally contentious issue from antithetical perspectives at different points in their life. Such stories often include recantations, retractions, or re-conversions, and involve vocabularies of disillusionment or disenchantment that the storyteller uses to reject a previously discovered ideology or worldview along with the community they previously associated with a discovery of truth. In the process, they use their stories to undermine the legitimacy and authority of other awakeners who claim to have discovered a "truth" that the re-awakener now rejects as "false." In this vein, religious converts-turned-apostates use a re-awakening narrative to revise and undermine their former awakening experiences. For example, an anonymous Mormon apostate going by the name "Exmo \#2" writes, 
I was a convert and highly active in women's leadership callings for nearly 10 years. I had a burning bosom, warm inspirations, converted friends, read the scriptures daily, attended the temple regularly [...] Basically, a card carrying, stamped on the forehead, Golden Convert [...] I loved mormonism. I don't regret most of what I learned about people and myself through my experience. I had some good friends, but now that I'm completely and officially out and have my opinions about it, they don't have any more time for me. They don't brook opposing opinions very well, even when they want to. It's passing a bit too close to the anti christ [sic] and apostate evil world to brush shoulders with someone as far "in" as I was who has gone so far away as to say "Joseph was no prophet, Joseph was just a guy who, like my ex husband, couldn't keep his pecker in his pants and justified it with the temple ceremony and marriage, which just so happens to be so damned sacred it has to be kept a secret. How convenient. " Or, "Not wearing garments is about freedom and choice and not letting 80 year old men determine the fabric and style of your underwear." No.53

As Exmo \# 2 tells her story, she uses a re-awakening narrative formula to redefine and undermine central tenets of the Mormon doctrine she previously "loved" and took to define her worldview. Whereas she once discovered Mormonism to be "true," she now rejects that discovery and redefines Mormonism (including its prophets and customs) as "false." Whereas Exmo \#2 uses a re-awakening narrative to reject her prior conversion to Mormonism and establish a new future-oriented project as an apostate to the Mormon Church, Arthur Koestler uses a similar narrative formula to reject his prior awakening to communism. Koestler writes,

I became converted because I was ripe for it and lived in a disintegrating society thirsting for faith [...] But we all moved happily though a haze of dialectical mirages which masked the world of reality [...] Those who were caught by the great illusion of our time, and have lived through its moral and intellectual debauch, either give themselves up to a new addiction of the opposite type [fascism], or are condemned to pay with a lifelong hangover. Hence the deep, instinctive resistance of the political dope addict to the cure. 54

Similarly, African American author Richard Wright once discovered and upheld a communist worldview, which he associated with "honor and glory," about which he felt 
"passionate hope," and to which he once expressed his "total [...] commitment of faith," he later describes that worldview as "darkness." 55 In the process of accounting for their current discoveries of truth, these re-awakeners reject their prior awakenings and (once again) redefine experiences, relationships, and behaviors that are important to their lives.

Likewise, Brian, David, Jeff, and other "exexgay" 56 individuals reinterpret and reject their prior experiences in sexual reparative therapy as they embrace their oncerejected homosexual attractions and lifestyles. Brian writes,

Around the time I began attending Columbia College I became a member of a cult-like fundamentalist group that espoused the belief that I could be "healed" of my homosexuality and only then could I be saved. This is the faith based version of the so-called "reparative therapy" movement. For three years I had lived as a gay man, but desperate for eternal salvation, acceptance and unconditional love I threw myself into their programs. A central part of their teaching was the "exgay" lie that I was "healed" of my sexual orientation through faith -- and blind faith can believe or justify anything [...] The cult like [sic] group I joined taught that if you quit the homosexual behavior and accept Jesus that you are no longer gay, you are "HEALED!" [...] Part of the inhumanity of the ex-gay myth is the way it draws more people into the unreality of the idea that people are "created" universally heterosexual. By this time, the stakes were very high for me to maintain my sham heterosexuality [...] This restarted the long slide into depression which had haunted me since I was fourteen years old. (emphasis in original) 57

Brian, reinterprets his prior awakening experience to be a "myth" and "lie" of "unreality." He deems his former autobiographical community to be "a cult-like fundamentalist group" as he uses quotation marks to undermine the worldview and basic tenets of sexual reparative therapy. Nell, a retractor, expresses a similar sentiment when she describes her former therapy group by writing, "This was all very culty, in retrospect." ${ }^{8}$ As he describes his re-awakening, Brian embraces his "authentic" self, who happens to coincide with the person he was for "three years [as he] lived as a gay 
man" before embracing reparative therapy and religion. Like David, who was once "led to believe [his homosexuality] was an abnormal and sinful condition," 59 Brian rejects his prior awakening in favor for of an antithetical worldview and takes a strong stand in a cultural battle over the nature and morality of sexuality and sexual orientation. $\mathrm{He}$ closes his re-awakening story with the claim "I am not a victim, I am a survivor -- and I will spend the rest of my life fighting for the rights of my people.”

In each of these cases, re-awakeners use an awakening narrative formula to reject their prior awakening. They use the same story formula to exit an autobiographical community that they once used to enter it. In the process, re-awakeners revise the past, casting what they once thought to be the discovered light of truth to be the darkness of falsehood. Whether focused on political, religious, sexual, or psychological subject matter, all of these re-awakeners, like all of the awakeners cited above reinterpret their past perceptions, beliefs, relationships, and behaviors as they switch autobiographical communities and weigh in on a cultural contest over truth and meaning.

\section{AUTOBIOGRAPHICAL MEMORY AND COLLECTIVE MEMORY}

When Maurice Halbwachs outlined a theoretical foundation for a sociological understanding of memory, ${ }^{60}$ he distinguished between socially shaped autobiographical memories and the truly "collective" memories (sui generis) that contemporary sociologists have shown to manifest as ritual commemorations, ${ }^{61}$ monuments, ${ }^{62}$ mythic stories, ${ }^{63}$ and museums, ${ }^{64}$ for example. Despite the fact that Halbwachs recognized the social significance of autobiographical memory when he first introduced the notion of collective memory, most scholars engaged in social memory studies have yet to embrace 
autobiography as an analytic domain. Further, the interplay between autobiography and group-level mnemonic norms remains in need of much exploration and elaboration. Those who study life stories typically stress patterns in individual identity formation and downplay collective memory (and often memory itself!) as a unit of analysis. ${ }^{65}$ Conversely, those who study collective memory typically ignore or downplay the importance of autobiographical accounts. ${ }^{66}$ Most collective memory scholars see the individual, in the tradition of Durkheim, as a depository of social forces, ${ }^{67}$ with some emphasizing the way monolithic mnemonic norms manifest as individual perceptions of the past. 68 Very few have considered the ways that individuals tell personal, autobiographical stories in order to shape cultural frameworks for perceiving the past.

As Jeffrey K. Olick notes, there is still a need for "an integrated paradigm that identifies the unique structures involved in each of these [individual and collective memory] and shows how they are related" (emphasis added). Calling for a "multidimensional rapprochement between individualist and collectivist approaches" Olick rightly points out, "There is no individual memory without social experience nor is there any collective memory without individuals participating in communal life."69 In line with such a reciprocal view of social memory, Schuman and Scott, building on Mannheim's sociological view of generations, ${ }^{70}$ show that the most profound generational memories often take form at the "intersection of personal and national history." ${ }^{11}$ Others have also added to the analytic breadth of social memory studies by discussing the significance of individual memories to the collective memory of events or iconic figures. ${ }^{72}$ This multidimensional and multilayered view of social memory is also advanced by Zerubavel who, in the classic Simmelian tradition, weaves back and forth between individual and collective cases to show that mnemonic norms, traditions, and 
battles manifest in formally similar and patterned ways at both levels of analysis. 73 In addition, a multidimensional approach to social memory studies is also strengthened by Fine and Beim who suggest that "a fusion of interactionism and collective memory research is conducive to interpreting memory as both process and product." Their call to bridge process- and product-oriented approaches to social memory studies emphasizes, among other things, the analytic need to consider the connection between the microlevel agentic construction of memory and the macro-level collective mnemonic order. 74 Building on the above studies, I combine (1) a focus on mnemonic reciprocity between individual (autobiographical) and collective levels of analysis, (2) attention to formal mnemonic patterns (and patterned mnemonic battles) that elucidate both the micro and macro dimensions of social life, and (3) a focus on the individual agency involved in producing collective-level mnemonic norms. Given this tripartite approach, my analysis of awakening narratives suggests how a formal sociology of autobiography (more generally) can add to a multidimensional and reciprocal view of social memory. Despite the content of an awakening narrative, when individuals tell such stories they mobilize personal memories to define ongoing and past situations. Further, when they use autobiographical time to distinguish between "falsehood" (always in the past) and "truth" (always oriented toward the future) they take a stand in a larger social dispute over the meaning and mnemonic record of morally contentious issues and events. When individuals produce these autobiographical accounts, they use the temporal structure of the awakening story formula to express and structure a contentious or antagonistic dialogue between two contemporaneous autobiographical communities in the world. Such autobiographical communities are also meso-level mnemonic communities where individuals produce autobiographical memories according to group level norms and 
recounting conventions (See Figure 5). These communities serve as base camps where individuals do memory work - either by replacing one version of the past with another or by filling the past with newly-conceived material - in more macro-level and contentious autobiographical fields. Further, such communities use the autobiographical reflections of their members to establish and defend their cognitive and mnemonic authority in the face of competition. As individuals form autobiographical communities and cooperate to defend their version of truth, they also work to define how particular events and experiences should be remembered. 
Figure 5. The Temporal Structure of an Awakening Narrative (Model A) denotes a Cultural Tension or Antagonism between Two Autobiographical and Mnemonic Communities (Model B).

MODEL A:

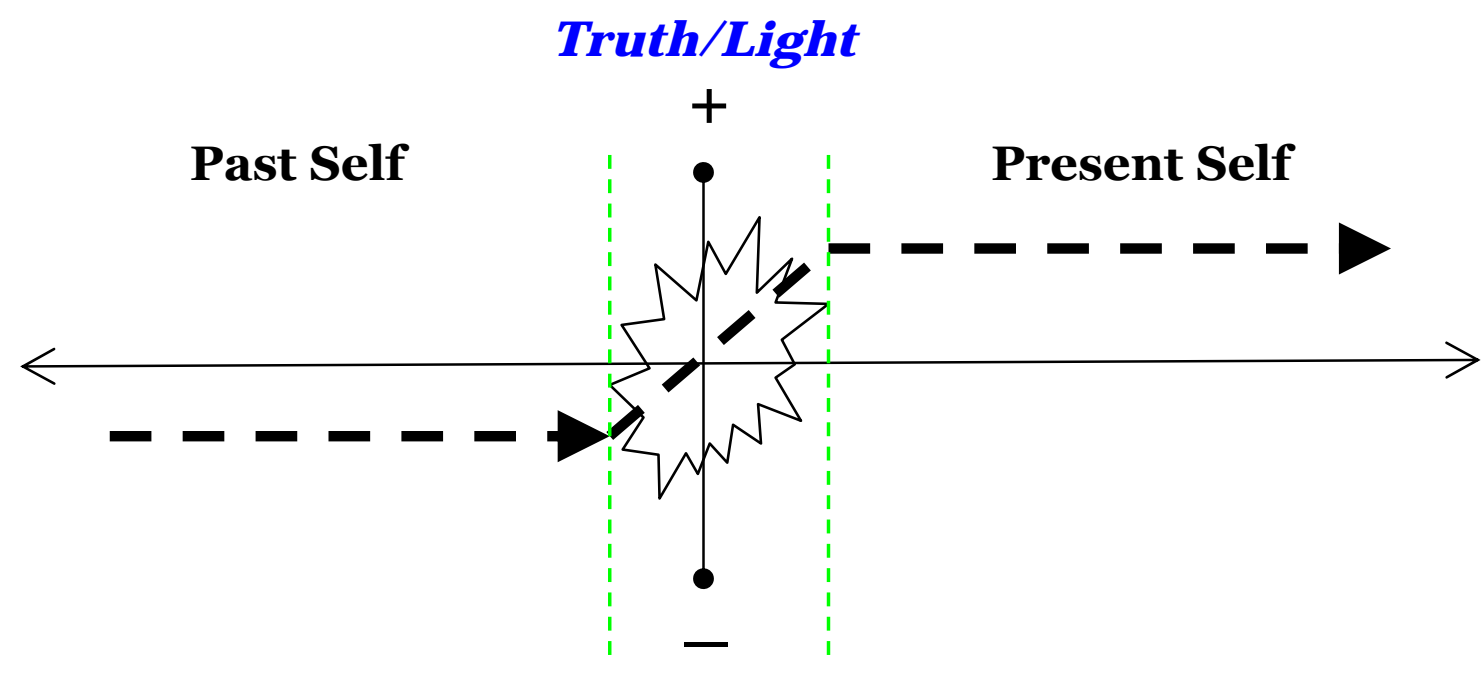

Falsehood/Darkness

\section{MODEL B:}

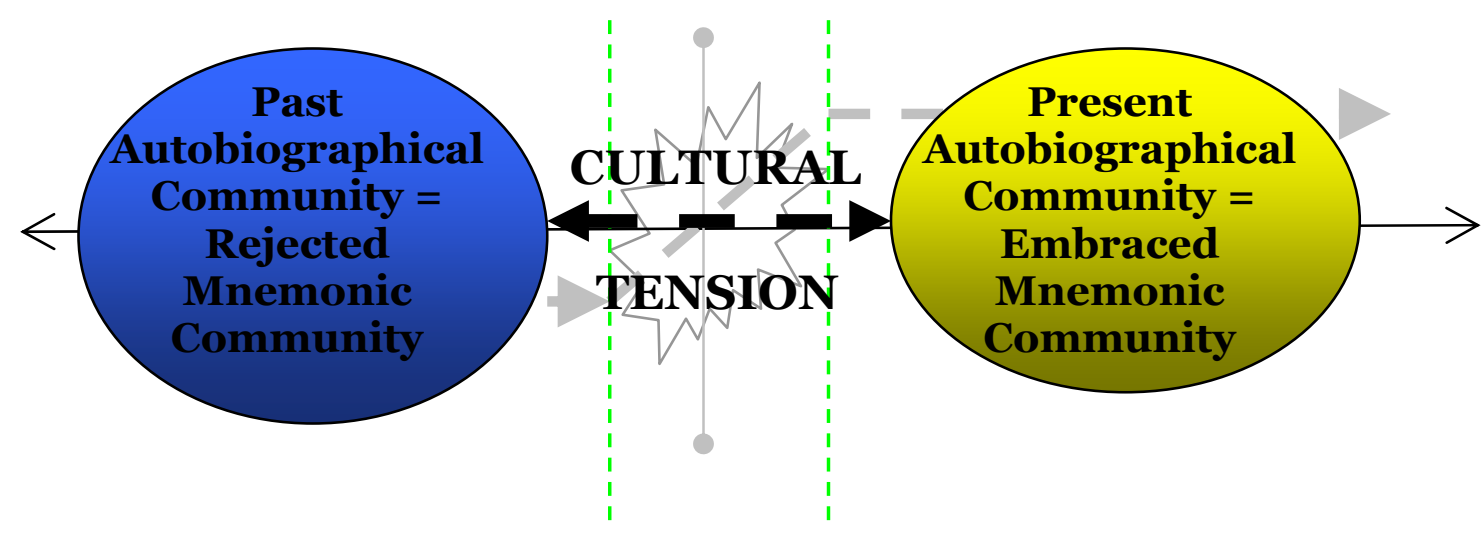


Thus far, we have examined several cases of mnemonic revisions and futureoriented projections that pertain to multiple spheres of social life including the political, religious, psychological, and sexual. Given these cases, as I have already hinted, we can discern two main methods by which individuals use autobiography to engage and shape more macro-level cognitive and mnemonic norms. On the one hand, when some individuals tell awakening stories, they use their autobiographical memories to shape the collective mnemonic record (sui generis) of some ongoing or past event or phenomenon. They use autobiographical memory to assert how others should participate in the project of conceiving collective memory and articulating the shared experiences of a social group. This method is most evident in the political and religious accounts we have explored. On the other hand, when some individuals tell awakening stories they use their autobiographical memories to shape the social framework for individual recollections with regard to a specific moral-interpersonal issue or phenomenon. They use autobiographical memory to assert how others should account for their lives and participate in the project (and politics) of conceiving and articulating a personal identity. This latter method is most evident in the psychological and sexual accounts we have explored. Individuals and autobiographical communities use both methods as they work to shape broader collective-level mnemonic norms and conventions of remembering. Analytically speaking, these two methods are more broadly relevant than my focus on the awakening narrative formula. In combination, they provide an analytic framework to "bring individual men and women into our understanding of collective memory,"75 further revealing memory to exist as a reciprocal and symbiotic exchange between autobiographical and collective accounts of the past. 


\section{Shaping the Collective Memory}

Consider Ronn - the Iraq Veterans Against the War member who rejected his previously-held patriotic worldview while redefining the war as "genocide" and himself as a "murderer." As Ronn reinterprets his personal experiences, he also works to undermine the popular notion, prevalent in the United States at the time of his voluntary reenlistment in the army, that "the innocent giant [the United States] was under attack, and full, legitimate revenge - without guilt or responsibility - was justified." 76 As Ronn reinterprets his personal past, he shapes his story according to the mnemonic norms and recounting conventions of his meso-level autobiographical community (the social movement organization, Iraq Veterans Against the War). He mobilizes his personal memories (in collaboration with others) to challenge the popular drama of "threat, vengeance, and salvation,"77 reminiscent of the historic notion that the Japanese attacks on Pearl Harbor "woke America up,"78 that many use to justify the wars in Iraq and Afghanistan in the name of national defense. By reinterpreting his past, Ronn (like Christie and many other IVAW members) uses his autobiographical recollections to shape the collective mnemonic record of the ongoing war in Iraq. $\mathrm{He}$ works to shape how the war should be understood and remembered (particularly by other Americans) even before the war officially recedes into the past. In the process, Ronn also challenges the cognitive and mnemonic authority of other veterans who use their personal stories to bolster and legitimate pro-war movements like the organization "Vets for Freedom.”79

Similarly, Anuradha also uses his personal memories, in accord with the recounting conventions and mnemonic norms of Iraq Veterans Against the War, to 
make a public statement about how the war should be defined and remembered. Writing in both a personal and collective voice, Anuradha establishes a mutually affirming relationship between his life experiences (his autobiography) and the personal stories of his fellow autobiographical community members. He describes his awakening to truth as part of a common awakening to a shared worldview as he writes,

I joined the Marines in 1999 and I left in 2004 when I realized that my conscience and my values could no longer allow me to serve in uniform. I'm now a part of IVAW--Iraq Veterans Against the War. Perhaps some of you have heard of IVAW. A group of young soldiers who'd been sent to Iraq a few years ago to defend freedom and democracy came home from the war completely changed. They'd experienced the trauma of combat and had witnessed atrocities committed against Iraqis that they were quite sure hadn't been shared with the American public. No matter how it was justified, the hype that they'd been fed by their government didn't add up. So they swore they'd work to expose the darker side of the war on Iraq to Americans, and enlisted the support of all military veterans who'd served since the United States was attacked in 2001. ${ }^{80}$

As Anuradha describes awakening to the "truth" about his past perceptions, experiences, behaviors, and relationships, he includes the members of his new autobiographical community as co-protagonists in his account. Writing in a collective voice, he reveals something about the recounting conventions and mnemonic norms shared by this meso-level autobiographical community. His story is their story. His account of the past is their account of the past. His future "duty" to spread the "truth" is theirs to share. He continues,

Those who have been sent overseas for a bunch of lies have come back home with permanent psychological and physical injuries. Many are trapped in hospitals or at home by nightmares of what they have seen or done in war. Meanwhile, there is a quiet but furious war machine sucking up children off our streets and captivating them into putting on military uniforms and bearing weapons in the name of just about anything. We need to spread the message to young people that heroism is defined in many other ways: by service to your 
fellow human being, by sacrifice to your community, by kindness to your neighbor, by the telling of truth. It is our duty to protect our children, and to wake our country up. ${ }^{81}$ (emphasis added)

In the process of speaking for himself and for his autobiographical community, Anuradha works to shape the collective mnemonic record of the war by asserting how others should perceive this nationally and internationally relevant event. As he writes his awakening story, Anuradha reveals a tension between his autobiographical memories of war and the way it is perceived by other Americans. His "duty [...] to wake our country up" implies that (most of) the country is currently asleep (just as he himself used to be). Thus, Anuradha combines his autobiographical memories with the moral imperative inherent in his awakening account to tell the nation how this war ought to be perceived and remembered.

Ronn, Anuradha and other members of Iraq Veterans Against the War use their autobiographical stories and autobiographical memories to weigh in on a political and moral dispute over the character of the ongoing wars in Iraq and Afghanistan. In the process, many members of this autobiographical community use historical analogies ${ }^{82}$ and collective mnemonic reference points to fuse their personal stories with the national collective memory as they work to shape the official mnemonic record of these wars. For example, Victor writes,

Regarding the meaning of the word "patriotism"- Iraqis fighting for freedom from oppression get called things like "terrorists", "insurgents", "evil-doers", and even ironic things like "Islamo-fascists" by shallow-thinking Americans. Did King George of England call George Washington, Thomas Jefferson, and Ben Franklin similar names? Should we stop celebrating these guys on the 4th of July every year and denounce them as "terrorists", or something else even more hypocritical? What would you do if your country was invaded by another in the name of spreading communism, toppling your despotic leader, and 
removing your illegal WMD's? Would you call yourself a patriot, or a terrorist? 83

As Victor (who volunteered for the army after September 11, 2001 to fight terrorism) describes his own awakening, he uses a temporal frame bridging strategy ${ }^{84}$ to equate Iraqi resistance to the U.S. military with the foundational American collective memory of Patriot resistance to the British during the Revolutionary War. In the process, he equates the current policies of the U.S. military with $18^{\text {th }}$ century British tyranny. As Victor reaches into U.S. collective memory with this historical analogy, he uses a familiar mnemonic framework to elaborate his newly-acquired perspective on his personal experiences in Iraq. In the process, he works to shape the collective mnemonic record of the Iraq War by suggesting that Americans should remember this war as the moral and political antithesis to the values of honor, freedom, and patriotism that they collectively associate with their historic war of independence.

Similarly, when members of Iraq Veterans Against the War give personal testimonies at an event they call "Winter Soldier: Iraq and Afghanistan" (emphasis added), they draw a historical analogy to the "Winter Soldier Investigation" organized by Vietnam Veterans Against the War in 1971. Further, they draw a secondary analogical contrast to the notion of a "sunshine patriot," a term coined by Thomas Paine in 1778 to mean those who only stood by their country during good times (times of "sunshine"). Paine's concept initially inspired members of Vietnam Veterans Against the War to coin the term "winter soldier" to depict their anti-war activism as a patriotic duty; by organizing to end the war, they claimed, they were standing by their country during troubled times. By using the term "winter soldier" to frame their personal testimonies about war, members of Iraq Veterans Against the War fuse their personal accounts and 
future-oriented projects with the American collective traditions and memories of opposing tyranny (in both 1776 and 1971). Framing their personal testimonies with such collective mnemonic references, these storytellers work to shape the collective meaning and memory of the Iraq War. They salt their autobiographical narratives and frame their autobiographical memories with collective mnemonic references so that other might awaken to see the "truth" as they have.

Similarly, by adding his story to David Crossman's collection of anti-Marxist awakening stories titled The God that Failed, Louis Fischer uses his autobiography to shape the cultural perception and mnemonic record of Soviet Bolshevism and midtwentieth century international politics. Like members of Iraq Veterans Against the War, Fischer and colleagues told their stories to define an ongoing situation. However, their stories were certainly also relevant for posterity's sake. From a contemporary perspective, the phenomenon in question (Soviet communism) has already receded into the past and these autobiographical reflections have become part of the mnemonic record of the Cold War. Fischer writes,

[...] now I realize that Bolshevism is not the way out because it is itself the world's biggest agglomeration of power over man. I boil at the injustices perpetrated on the unfortunate residents of company towns in the coal regions of my native state of Pennsylvania, where the mining company owns the workers' homes and runs the only stores [an ideal example of capitalist exploitation]. But all of the Soviet Union is one gigantic company town in which the government controls all the jobs, owns all the homes, and runs all the stores, schools, newspapers, etc., and from which there is no escape, as there is for some from a Pennsylvania company town [...] Capitalism's trusts and cartels are pygmies compared to the one mammoth political-economic monopoly which is the Soviet State. ${ }^{85}$

Using his personal memories to make his case, Fischer argues that communism actually embodies the same problems inherent in monopoly capitalism but exacerbates them to 
the extreme. Whereas he once viewed Bolshevism as the antithesis of capitalism and the answer to the problems of the industrial world, Fischer now uses analogical reasoning 86 to lump both political systems together. Indeed, from the perspective of the early twenty-first century, more than two decades after the collapse of the Soviet Union, Fischer's personal awakening story can be read as "history."

Just as Crossman's The God that Failed uses autobiography and personal memories to redefine Cold War era politics at a time when much of America was divided on the question of socialism, Peter Collier and David Horowitz's Second Thoughts:

Former Radicals Look Back at the Sixties advances several autobiographical reflections for the purpose of redefining the sixties as a period of cultural decline and delusion as opposed to a period of progress. In a striking example, David Horowitz uses a historical analogy to recast a central, iconic faction of the sixties Left as terrorists, criminals, and "ruthless exploiters." After claiming to have discovered a murder perpetrated by members of the Black Panther Party, Horowitz writes,

Because I knew what I knew, I myself now lived in fear of the Panther terror. In my fear it became impossible for me not to connect these events with the nightmares of the radical past. Just as Stalin used the idealism and loyalty of my parents' generation in the 30's, so the Panthers had used my generation's idealism in the '6os. My political odyssey had come full circle [...] My dedication to the progressive cause had made me self-righteous, arrogant, and blind. Now a cruel and unusual crime had humbled me and restored my sight [...] The Stalinists and the Panthers may have operated on stages vastly different in scale, but ultimately their achievements were the same: Stalin and the Panthers were ruthless exploiters of the radical dream; just like our forbears, my comrades and I were credulous idealists who had served a criminal lie. 87

Evoking the collective memory of Stalinism (unpopular on both side of the political spectrum in the U.S. during the 1960's and 70's) as a historical analogy, Horowitz uses his personal story to set the mnemonic record of the 60's. In the process, he equates the 
Black Panther Party with the Soviet regime of the 1930's and 40's. He also equates his self-ascribed “self-righteous, arrogant, and blind” faith in 1960's New Left progressivism with his parents "credulous" belief in the Soviet promise of a generation earlier.

Horowitz opens up his longer autobiography, Radical Son, by describing a scene of that includes himself standing and reflecting at the grave of his parents. In both works, $\mathrm{He}$ revises his history and theirs in order to advance his political agenda and undermine one way of viewing the collective national past in favor another. He uses his personal reflections to set the mnemonic record of a significant political and cultural era of U.S. history.

Similarly, Xavier Arguello uses a frame bridging strategy (one type of analogical reasoning) to cast his (and his community's) rejection of the FSLN's (Sandinista National Liberation Front's) Marxist rebellion in Nicaragua in the same vein as the struggles of ant-Castro Cubans in the late-fifties and sixties. Whereas Arguello used to detest anti-Castro Cubans, he now compares his plight to theirs. Arguello writes,

The duty is a hard one. Can anyone learn form another's experience? I recall how we turned a deaf ear to the Cubans who denounced the tyranny of Castro. For us, that was heresy and required no examination. We made no effort to put ourselves in their place; we dehumanized Castro's victims a second time. They were retrograde and reactionary Batistan worms [a double reference to Fulgencio Batista, the Cuban dictator who was overthrown with the Communist revolution in 1959 and to the Spanish word "gusano," which means "worm," that was used by pro-communist Cubans to refer to anti-communist Cubans]. Now we play the same role they did. That is why we wonder if our preaching will ever convince any of those who think that spiritual and political peace are attainable under the Sandinistas. 88

By comparing his position to the position of anti-Castro Cuban's, Arguello also reinterprets his former Sandinista worldview and laments his own past as someone who "turned a deaf ear" to the worldview he now upholds. In the process, he uses his 
autobiography and his newly-revised memories to rewrite collective memory of those two Latin American revolutions in question. Likewise, Carol Iannone uses her autobiographical reflections to shape the U.S. cultural history of the feminist movement. While feminist scholars shifted the structure of collective mnemonic attention in the U.S. by highlighting the previously ignored role of women in the world, Iannone uses her personal awakening to undermine this shift. She writes,

When I defected from the feminist philosophy some years later, it was largely out of simple, gut-level, personal disillusionment. As time went by, however, I began to see more clearly the extent of the damage feminism has done to women and to our cultural life [...] the damage feminism as a way of thought has done [...] [Early feminist] writers created and peddled a false, fulsome, meretricious view of redemptive womanhood that was a caricature and that cheapened the terms of cultural life. To the extent to which such formulations have been adopted by feminism in our time - and it is to a considerable extent - intellectual life has suffered, with reality split into artificial dichotomies. ${ }^{89}$

Coming from an entirely different angle but employing a similar autobiographical strategy, Malcolm X uses his awakening to revise the traditional Western view of world history. He uses his newly-found Black Nationalist worldview to challenge the very basis of mainstream history when he writes,

History has been so "whitened" by the white man that even the black professors have known little more than the most ignorant black man about the talents and rich civilizations and cultures of the black man of millenniums ago [...] It's a crime, the lie that has been told to generations of black men and white men both. Little innocent black children, born of parents who believed that their race had no history [...] But the truth is pouring out of the bag now. 90

Describing his discovery of "true" history while studying in prison, he continues,

I began first telling my black bother inmates about the glorious history of the black man - things they never dreamed. I told them the horrible slave-trade 
truths that they never knew. I would watch their faces when I told them about that, because the white man had completely erased the slaves' past, a Negro in America can never know his true family name, or even what tribe he descended from: the Mandingos, the Wolof, the Serer, the Fula, the Fanti, the Ashanti, or others. I told them that some slaves brought from Africa spoke Arabic, and were Islamic in their religion [...] I'd explain to them that the real truth was known to some white men, the scholars; but there had been a conspiracy down through the generations to keep the truth from black men. ${ }^{91}$

Malcolm X's inversion of racial perspective on history is perhaps most clearly articulated in his famous saying, "We didn’t land on Plymouth Rock, Plymouth Rock landed on us!" As he awoke to an American, Black Nationalist version of Islam, he used his personal awakening to revise the collectively-rooted past.

Whereas members of Iraq Veterans Against the War, ex-Leftists of various perspectives and generations, and awakened Black Nationalists use their autobiographical memories to shape the collective memory of nationally and internationally relevant political issues and events, Mormon converts use their newlyacquired autobiographical memories to shape the collective memory of humanity with regard to the question of ontological reality. They use their personal stories as an autobiographical testimony to "the restoration of truth"92 that they claim occurred when God delivered the Book of Mormon and established the Mormon Church though his prophet, Joseph Smith. For example, Richard takes on new collectively-rooted memories and models his own autobiographical story on the iconic collective memory of Joseph Smith as he accounts for his awakening to the "truth" of Mormonism. Richard writes,

The missionaries knocked on my door [...] We had the first discussion at the ward building the next day, and when the flip chart showed a young, $14 \mathrm{yr}$ old boy [Joseph Smith], looking up at two bright heavenly beings, I knew upon sight it was an event that actually occurred. The elders asked me if I believed it could be 
true. I told them I could totally believe it happened, because in my own searching's I also became disillusioned in the religions of the day [sic] (emphasis added). 93

As Richard describes his awakening to "truth," he takes on the mnemonic norms and recounting conventions of the Mormon community. On the one hand, he acquires a foundational collective memory of the Mormon community - he is certain of the historic conversion of Joseph Smith as he "knew upon sight it was an event that actually occurred." On the other hand, Richard acquires the recounting conventions of this autobiographical community as he models his life story in a particular way. Like Joseph Smith, who according to Mormon doctrine became disillusioned with all religions before literally seeing the light while kneeling in a grove, Richard "also became disillusioned in the religions of the day." Whereas two radiant beings - God and Jesus - appeared before Smith to restore the "truth," two Mormon missionaries revealed this "truth" to Richard. As Richard models his personal awakening on the narrative of Joseph Smith's conversion, he uses the mnemonic norms and recounting conventions of his new-found autobiographical community to shape the collective memory of humanity by attesting to the truth of a significant past event (Smith's conversion) and performing the relevance of that event in the present (by virtue of his own conversion). He uses his personal story to shape how others ought to conceive and articulate the collective history of humanity. In the process, he (like most other members of his autobiographical community) simultaneously works to undermine all other "religions of the day" as well as nonreligious worldviews.

Similarly, consider Deborah - the Mormon convert who remembered having conversations with God before she was born. As Deborah revised her personal past, she 
incorporated the mnemonic norms and recounting conventions of the Mormon community into her life story. In particular, Deborah personalizes the Mormon Doctrine of Pre-existence as she recalls her experiences and relationships in heaven before she was born. In the process, Deborah uses her personal memories to assert the "truth" of the Mormon idea that all of humanity coexisted with God "the father" before their embodied physical existence on earth. As articulated by Brigham Young, this doctrinal collective memory means,

There is not a person here to-day [sic] but what is a son or daughter of that Being [God]. In the spirit world [heaven] their spirits were first begotten and brought forth, and they lived with their parents for ages before they came here [to earth]. This, perhaps, is hard for many to believe, but it is the greatest nonsense in the world not to believe it. If you do not believe it, cease to call Him Father; and when you pray, pray to some other character. 94

As Deborah tells her awakening story, she works to shape the collective memory of humanity by testifying to humanity's collective pre-existence as a universal family who lived together, as "intelligent" brothers and sisters and common children of God in heaven before life on earth (a collective, historically-oriented belief that, although taking various forms within Mormonism, 95 is not shared by any other Christian religion). She was in heaven before birth because everyone one of "God's children" existed in heaven before birth. Just as she remembers, we all should remember. Deborah, like Richard, uses her autobiographical account and personal memories to say something about how all of humanity ought to remember the past. Like all Mormon converts, she uses her autobiography to weigh in on a cultural contest over the nature of collective ontological reality. 
While different in many ways, political and religious awakeners use their autobiographical stories and autobiographical memories to shape collective memories. As they account for their awakening experiences, they work to define the shared experiences of a social group, whether a nation or all of humanity. In the process, they use their autobiographical accounts to vie for mnemonic authority and establish the mnemonic record of morally and politically significant events and issues.

\section{Shaping the Social Frameworks of Personal Memory}

Whereas political and religious awakeners typically use their autobiographical stories to shape collective memories, sexual and psychological awakeners typically use their autobiographical accounts to shape and reinforce the social frameworks for individual recollections with regard to moral-interpersonal issues. Such awakeners apply the logic behind the Freudian notion of resistance to their own lives as they find painful, already-there "truths" in the past. Further, they articulate these "truths" to explain the causes of present issues, establishing a cause and effect chain between the newly-discovered past and the newly-interpreted present.

For example, "repaired" heterosexuals use their awakening accounts to suggest how others ought to look into their personal past in order to explain their homosexual attractions. Theories of sexual reconversion or sexual reparative therapy provided a new framework for personal memory with regard to sexuality and sexual orientation. They allowed for new autobiographical accounts that radiated outward into the cultural milieu to undermine the "coming out" narratives of the gay-liberation movement. Advocates, practitioners, and "repaired" heterosexuals actively create this social 
framework for personal mnemonic revision by as when, for example, sexual reparative therapist Joseph Nicolosi tells his patient Albert that "It is quite common to find anxious mothers in the backgrounds of heterosexual men. These intrusive, hovering mothers intend the best for their sons but are unable to recognize and respond to their authentic needs." 96 Or, "The essence of therapy is to slowly recall the hurt. Then to slowly reclaim the true [masculine, heterosexual] self that the hurt has made you detach from [...] [T]herapy brings out buried feelings, and this is as it should be."97 As he provides biographical sketches of his patients, Nicolosi reinforces a social framework for individuals to remember with regard to the issue of homosexuality. According to this framework, homosexuals should find "anxious mothers," "hurt," and "buried feelings" in their pasts as they awaken to their "true" (hetero)sexuality. Nicolosi continues,

At a critical period in your development - the gender identity phase - you had to individuate yourself from your mother and develop a masculine identification through your father. I was your father who personified the demands of the outside world [...] But you never received the necessary support from him, or any other masculine figure. (emphasis in original) ${ }^{98}$

He tells his patient Father John,

Most homosexuals overfocus on the penis. So much of homosexual behavior is like two little boys playing show me yours, I'll so you mine. It's fetishistic behavior. The penis has an important symbolic power. It's a symbol of masculinity that you feel you need but don't have. Some trauma, some gap in your development seeks fulfillment in phallic fixation. That's part of the homosexuality. (emphasis in original). 99

By providing mnemonic guidelines for his patients to find causes for homosexual attraction in their pasts, Nicolosi recasts homosexuality as a personal disorder Such a socially constituted framework for personal memory leads Albert to comment, "I feel 
like a little boy in a man's body"100 Likewise, as Charlie describes his awakening, he reinterprets his homosexual attractions to be a previously-unrecognized desire to embrace his own masculinity while simultaneously wishing the same for others. He writes,

Today, my therapy unravels the lies that inflicted this male insecurity upon me. My therapy has been a sophisticated process of discovering the truth, trying it on, and living it out confidently for the first time in my life [...] It is my hope that every man who hurts from homosexuality may open himself to receiving the same grace that I have known. It was this grace that enabled me to see that my homosexual tendencies were not a cry to have another man - but a cry to have a manly me. ${ }^{101}$

Similarly, Alan also mobilizes his autobiographical memories, in line with the shared sentiments of the sexual reparative community, to assert how others should account for homosexual attractions (in particular) and sexual identity (in general) in their lives. He writes,

I came to see that my homosexual problems were largely a problem of undeveloped manhood. Every man has to go through certain developmental stages; there is no real shortcut to growth. I saw that somehow on my road to manhood, I had taken an emotional detour. Fearing that I would never be "man enough" myself, I bailed out of my personal growth into manhood and started obsessing on the manhood of others. ${ }^{102}$

When Alan reinterprets his life in this way, he joins with Albert and Charlie, as well as Scott and Frank (the "repaired heterosexuals" who previously described discovering that their homosexuality was a consequence of stunted development), and others to define homosexuality as a developmental disability. Further, when these awakeners look to their past, they also use their personal accounts to establish heterosexuality as a "normal" and "healthy" course of human development. While each of these "repaired" 
heterosexuals tells their own personal story, they also shape their autobiographies with the shared mnemonic norms and recounting conventions of an autobiographical community. Further, they use their individual stories to establish a collective project of heteronormativity. Without community-based mnemonic conventions and a shared heteronormative worldview, their personal stories would be anomalous and socially insignificant; there could be no normal "road to manhood," no "developmental stages" that "every man has to go through," and thus no "emotional detour" that binds them together. Inversely, without their individual stories, the collective perspective of the sexual reparative community would be hollow and lacking in the "embodied memory"103 and the cognitive and mnemonic authority bestowed by personal testimony and example.

As Alan, Albert, Charlie, Scott, and Frank account for their personal discoveries in sexual reparative therapy, they use their autobiographical stories to counter the notion, prevalent in queer-positive autobiographical communities, that "coming out" as homosexual is an expression of "truth." In the process, they mobilize their autobiographical memories to shape the broader social framework for individual reflections regarding the issue of homosexuality and sexual orientation in general. They use autobiographical memory to assert how other individuals (in this case, other homosexuals) should account for their own sexual orientations and identities. Like those who "recover" and those who "retract" memories of childhood sexual abuse, they mobilize their personal memories (in autobiographical form) to weigh in on a cultural dispute over the correct social framework for personal memories. In the process, they reinforce the cognitive authority and shared worldview of one autobiographical community while undermining the cognitive authority and shared worldview of another. 
Such a social framework for individual memory is contested or undermined by members of "exexgay" or "sexual reparative survivor" communities who re-awaken to (re)discover their "true" homosexuality. As becomes clear when one considers the stories of such once-repaired-heterosexuals who re-awaken to discover and embrace the "truth" and authenticity of their once-rejected homosexuality, what is regarded to be the correct way to account for one's past and what is viewed as the incorrect way to recall depends on the autobiographical and mnemonic community of the storyteller at the time that the story is told.

Similarly, the theory of recovered memories and recovered memory therapy provided a new framework for personal memory with regard to the trauma of childhood sexual abuse. It allowed for new autobiographical accounts that radiated outward into the cultural milieu to advance the notion that many adults (with particular emphasis on women) were suffering from a variety of behavioral and psychological symptoms (from depression to unexplained nightmares) that could be explained by the presence of longforgotten abuse experiences in one's personal past. ${ }^{104}$ Feminist scholars, recovered memory therapists, and many self-identified survivors of childhood sexual abuse actively create this framework for personal mnemonic revision by making claims, advancing theories, and telling stories that reinforced the notion that the presence of certain symptoms indicates the likelihood of a yet-to-be-discovered experience of abuse. Ellan Bass and Laura Davis, cultural pioneers of the notion of recovered memory, advance this idea in the controversial and well-known book The Courage to Heal. They write,

Children often cope with abuse by forgetting it ever happened. As a result, you may have no conscious memory of being abused [...] You may think you don't 
have memories, but often as you begin to talk about what you do remember there emerges a constellation of feelings, reactions, and recollections that add up to substantial information. ${ }^{105}$

By framing the issue of sexual abuse and memory in this way, these and other authors laid the theoretical and cultural groundwork for a new type of autobiographical awakening story to emerge. Self-identified survivors began to use their autobiographical stories and memories to advance this cultural framework and for personal recollection when they shared their stories in various venues, including online environments. Reinforcing such a social framework with their personal accounts, Linda recalls, "I learned young how to cope with 'Daddy's game.' Many a night I spent having a tea party in my mind while we played his game. [...] And the fact that I repressed the memories of my abuse for years only adds to my family's disbelief." 106 Similarly, Ann remembers,

As I read the courage to heal among other books it tells me to tell my story to feel better so well here it goes [sic]. I can remember being so young my dad walking to my room after mom left for work and my younger brother was sleeping [sic]. He would say this is a special game for daddy's [sic] and their girls and not to tell anyone [...] I can't remember all details yet as I repressed a lot of them.107

Both Linda and Ann reinterpret past childhood experiences and interactions as they recover once-repressed memories in order to explain their current traumas and troubles. Both awakeners replace one version of the past (a "game") with another (sexual abuse) and further reinforce the social framework for individual memory advanced by recovered memory therapists such as Bass and Davis.

Whether working to shape the collective memory of some event or phenomenon, or working to define the social frameworks for individual memory pertaining to a salient moral-interpersonal issue, all of these awakeners reinterpret their past experiences and 
relationships in order to explain a major transformation of mind and justify their present beliefs. As they tell their personal stories, they adopt the mnemonic conventions and recounting norms of a new autobiographical community and relegate another community to the realm of "falsehood" by leaving it in the past. Each of these awakeners fuses their personal autobiographical account with the shared narrative and common worldview of some meso-level autobiographical community. As such a mnemonic symbiosis of the autobiographical and the communal implies, awakeners incorporate the mnemonic norms and recounting conventions of a group (a group with an existence independent of any individual) into their personal, autobiographical narratives. Inversely, they use their autobiographical stories and autobiographical memories to reinforce the shared visions and mnemonic revisions of the community, usually in contrast to competing ways of accounting for the past.

The notion of a mnemonic symbiosis between the individual and the autobiographical community suggests that an individual's autobiographical accounts and autobiographical memories are shaped by group-level forces. The groups we belong to shape our seemingly personal memories and model the way we tell stories about our lives. However, the concept of symbiosis also suggests that individual autobiographers are active agents who use their autobiographical stories to participate in the cooperative process of constructing the definitions and mnemonic records of ongoing and past events. Despite focusing on an ongoing event (like veterans who reflect on the Iraq War before it has officially ended) or weighing in on an ongoing controversy (as do those who recover and those who retract memories of sexual abuse), awakeners join autobiographical communities and cooperate with others to set a mnemonic agenda; they work to shape our individual and collective perception and recollection of morally 
and politically salient events and issues. When awakeners then tell their life stories in various social contexts, they strategically deploy their autobiographical accounts and personal memories within the framework of larger, bounded communities that, in turn, inform their personal accounts of the past by sanctioning certain interpretations and meanings while undermining the legitimacy of others.

If "life stories are mediating mechanisms between society and the individual,"108 then it should also be noted, as awakening stories suggest, that "society" as a whole rarely (if ever) comes to a consensus on the mnemonic record of ongoing or elapsed events and issues. When awakeners tell personal stories about discovering "truth," they inherently adopt the cognitive and mnemonic lenses of one community and reject those of another. Their stories encompass and express sociomental contests and mnemonic contentions between different autobiographical communities. Awakeners use their autobiographical accounts and wield their autobiographical memories in a cultural arena marked by multivocal ${ }^{109}$ and fragmented ${ }^{110}$ commemorations. The study of autobiographical memory can show how collective symbols, icons, ${ }^{111}$ monuments, ${ }^{112}$ texts, and events ${ }^{113}$ are fused with or incorporated into personal accounts in multiple and often contradictory ways. When awakeners mobilize their personal memories, they throw their autobiographical weight behind some community taking part in an emerging or established mnemonic battle or "memory war." 114 They embody and personify a particular way of remembering in an effort to shape the broader recounting conventions and mnemonic norms of some divided social group, whether a family (as typical of those who recover and those who retract memories of childhood sexual abuse), the nation (as with war veterans), or humanity more generally (as with religious converts, apostates, and "repaired" heterosexuals). In this sense, autobiography invites a 
form of mnemonic socialization ${ }^{115}$ that lends itself to mnemonic empathy. In other words, if we can imagine ourselves "in the shoes" of the awakener when reading or hearing their awakening story, then their autobiographical story serves as a gateway to the cognitive and mnemonic norms of his or her community.

A comparative and formal analysis of awakening stories reveals the way individuals form autobiographical communities and wield autobiographical stories about discovering "truth" to shape the socially rooted memories of families, nations, and other interested communities. My focus on the generic dimensions of autobiographical formula combined with my notion of mnemonic symbiosis helps to show what is "collective" about personal stories. Viewed in this way, awakening narratives reveal a mnemonic link between the individual and society. By emphasizing the autobiographical dimensions of social memory, especially the way individuals and communities use autobiographical accounts and personal memories to vie for cognitive and mnemonic authority, we can illuminate the role of "agents of memory" 116 and "moral entrepreneurs" 117 in the process of building both genuinely collective memories as well as the social frameworks for personal memories. We can elucidate the interplay between the individual and society in the social act of remembering and the social performance of truth. The endeavor to bridge the sociology of autobiography and sociological approaches to collective memory allows us to better recognize the role individuals play as active contributors to shared cultural realities. Further, the notion that autobiographical memory takes form in symbiotic relation to an autobiographical community amidst a broader autobiographical field emphasizes the contextual and contentious character of meaning, memory, and commemoration. Awakening stories show us that the social construction of truth and memory are often intertwined. Both 
are narrative accomplishments, taking form in different autobiographical communities where we share our stories with some in order to undermine the claims of others. 


\section{Chapter 4}

\section{Mental Express Elevators and Mental Staircases}

"Once repressed, memories can reemerge at any time [...] At times you may experience flashbacks in which you relive aspects of the abuse or reexperience the feelings you had at the time - terror, extreme physical pain, tremendous isolation. These experiences can be disruptive and terrifying. You may respond with shock, horror, or disbelief. You may feel panicky and suicidal, or relieved to finally know the truth about your life."

$\sim$ Laura Davis. Allies in Healing ${ }^{1}$

"In the attitude of silence the soul finds the path in a clearer light, and what is elusive and deceptive resolves itself into crystal clearness. Our life is a long and arduous quest after Truth."

$\sim$ Mahatma Gandhi²

Just like we cannot teach a child that a caterpillar and butterfly are the "same" being without describing the cocoon, awakeners cannot explain such major transformations of mind without reference to a sociomental cocoon. For this reason, awakeners must account for a liminal awakening experience, a transformative episode that separates their "false" and "true" perceptions as well as their past and present phases of life. Building on Van Gennep's analysis of rites of passage, ${ }^{3}$ Victor Turner 
described how liminal spaces - spaces separate and set aside from the regular, common spaces of everyday life - serve the social function of marking ritual transitions or transformations in the lives of a society's members. 4 Turner showed that liminal spaces are spaces of seclusion characterized by an individual's separation from and reintroduction into the lifeworld of society. Further, individuals in transition typically take on a "liminal personae" which involves their reduction to bare essences where they "have nothing" as they exist in a vulnerable "stage of reflection," "divested of their previous habits of thought, feeling, and action." 5 The ritual practice of seclusion marks a distinct ending to an individual's prior phase of life; their social disappearance symbolizes the death of the old. A ritual reintroduction to society marks the beginning of another phase - the birth of the new. Expanding on a class of what Durkheim earlier referred to as rituals of the "negative cult," 6 Turner argued, "If our basic model of society is that of a 'structure of positions,' we must regard the period of margin or liminality as an interstructural situation."7 As awakening stories show, such spaces of liminality take narrative form as well. ${ }^{8}$

Awakeners use vocabularies of liminality in order to distinguish between different and distinct autobiographical periods - discrete sections of their life course that take form in the stories they tell about their lives. Further, they use such vocabularies to justify their adoption of epistemic and cognitive conventions that radically contradict their previous ways of seeing and knowing the world. Whereas Turner's concept of liminality highlighted the process by which individuals occupy a secluded position to signify their passage between two status positions in the social structure, awakeners use vocabularies of liminality to depict the condition of being "betwixt and between"9 two positions in a sociomental structure - two mutually 
exclusive cognitive standpoints or belief systems that are otherwise awkward or difficult to traverse. By articulating such a sociomental liminality in their life stories, awakeners justify and explain their passage through a sociomental gulf or epistemic division that separates contentious autobiographical communities. As awakeners convey such a sacred sociomental transition, they build a sharp discontinuity into their autobiographical accounts. They apply a logic of periodization ${ }^{10}$ to their life stories that is similar to the way national communities associate radical ruptures with political revolutions and religious communities associate major ontological turning points or "raptures" with earthly manifestations of the divine. Awakeners provide an account of a liminal awakening experience in order to justify their rejection of an old way of seeing and knowing the world and their embrace of a newfound enlightened "truth."

Awakeners use two ideal-typical vocabularies of liminality to mark the distinction between "false" and "true" states of mind in their lives. Both versions of liminality are highly marked, central, and sacred in the story. However, they differ in terms of the narrated duration of the awakening episode - exemplifying two distinct variants of what Kenneth Burke would call the "scene-act ratio"11 - and functioning as "vocabularies of motive," 12 in their attribution of agency, intention, and will in the account. They also differ by virtue of the way awakeners use different time-frames, characters, and props to describe their liminal life-altering change of mind.13 The ideal-typical characteristics of these vocabularies of liminality are aptly captured in the metaphoric contrast between sociomental express elevators and sociomental staircases. (See Figure 6). 
Figure 6. Sociomental Express Elevators and Sociomental Staircases.

MODEL A: A Sociomental Express Elevator

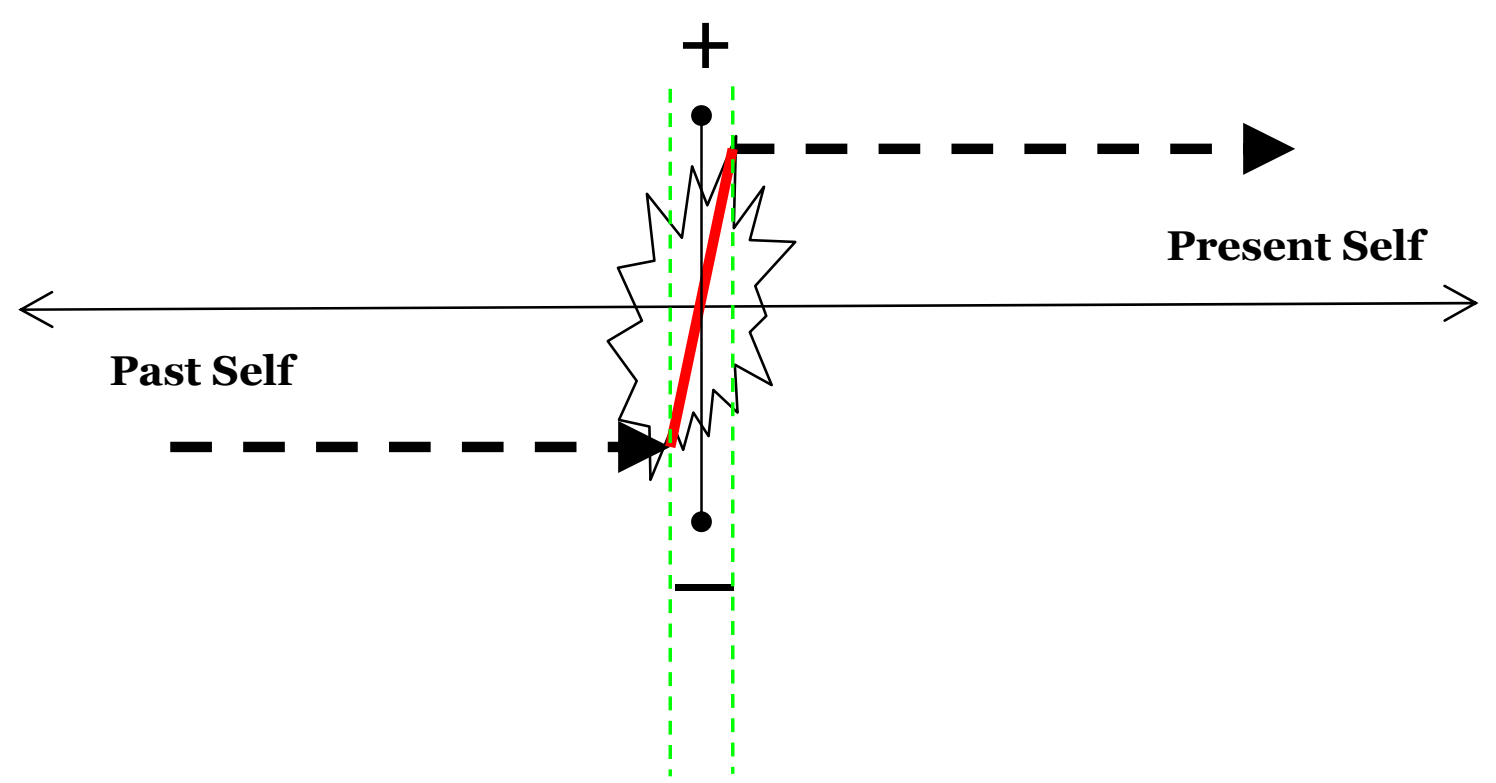

\section{MODEL B: A Sociomental Staircase}

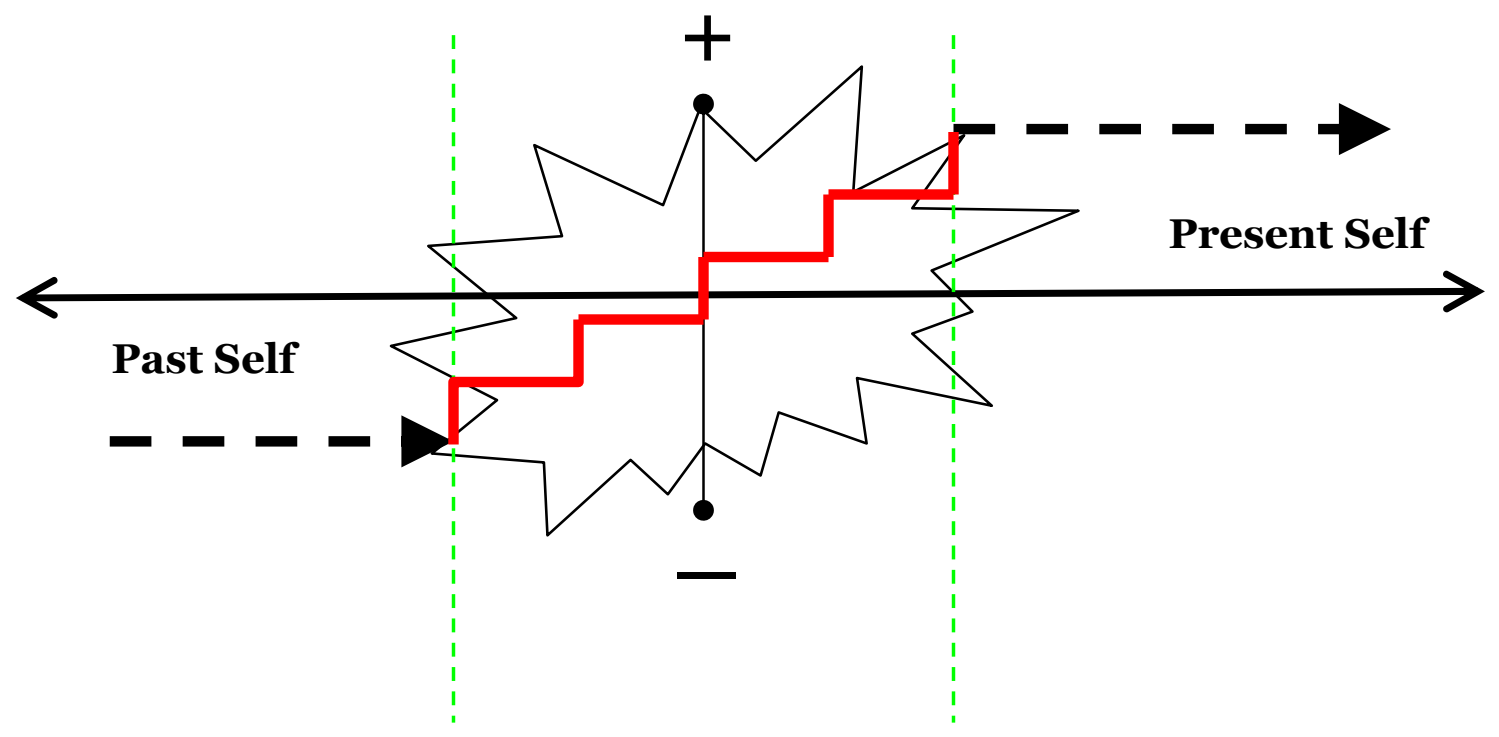


In The Varieties of Religious Experience, William James notes that religious conversions can be gradual or sudden and, citing Starbuck, voluntary and involuntary. ${ }^{14}$ In these seminal works, both authors reinterpret religious conversion from a psychological perspective. From a sociological perspective, their theories exemplify a historical heightening of the cultural tension between psychological and religious realms of meaning. More generally, "sudden" and "gradual" awakenings are characteristic of two ideal-typical vocabularies of liminality that occur in different combinations in myriad stories across various realms of social life (well-beyond religion). The distinction between sharp, sudden discoveries and protracted, cumulative developments of knowledge is also highlighted by Kuhn, who argues that science advances by fundamental "paradigm shifts" that more closely resemble radical gestalt switches than they do a slow, steady growth and accumulation of information. ${ }^{15}$ Similarly, Davis contrasts the "shock" that Schutz showed to occur with an immediate imposition of an alternate reality ${ }^{16}$ with the mental "slide" that occurs with a gradual easing into a sexual mindset. ${ }^{17}$ Building on these distinctions, I develop the metaphors of the sociomental express elevator and the sociomental staircase in order to highlight the ways that awakeners use such vocabularies of liminality to depict an experience of cognitive and epistemic transformation in their lives, construct a distinct and radical autobiographical discontinuity in their stories, and distinguish between "falsehood" and "truth" as they navigate complex and contentious autobiographical fields. 


\section{Sociomental Express Elevators}

The metaphor of the express elevator (Figure 6, Model A) signifies a direct, expedited ascent to a new higher level of consciousness. When we take an express elevator to the top floor of a hotel or an office building, we are literally carried up to a new, higher level; the door opens and we are there. When awakeners use such a vocabulary of liminality, they typically describe being acted upon by some overwhelming force. They portray themselves without agency - as powerless beings who are thrust into a shocking change of mind. Their awakening experiences are usually abrupt, intrusive, and occur despite the awakener's will or intention. Like Martin, the Born Again Christian convert who recounted "a series of cold surges" radiating throughout his body as "vivid scenes" from his past "began to flash before [his] eyes," 18 this version of the awakening story often involves a stunning discovery or sudden, disruptive realization of "truth."

Fiona, for example describes recovering a memory of sexual abuse. She writes,

Then I had a panic attack out of the blue. One morning I woke up and I remembered being a little girl, lying in my bed, door shut, crying my eyes out, my night light all blurry through my tears. And I knew [...] I called [a] sex abuse hotline $[\ldots]$ and the operator referred me to my therapist. ${ }^{19}$

As she recounts having "a panic attack out of the blue" and immediately knowing she was sexually abused as a child, Fiona describes a rather sudden and overwhelming discovery of "truth." Using the narrative mechanism of a "panic attack" - a particular version of a sociomental express elevator - she accounts for a major sociomental transition in her life. Like Martin, Fiona recounts her awakening experiences in a highly dramatic way - as a narrated depiction of the "shock" that typically accompanies reality 
switches. ${ }^{20}$ Likewise, Shadow has an elevator-like awakening experience that is triggered by a contemporary sexual assault. By attributing her discovery of "truth" to an external "trigger" event, Shadow forfeits any claim to having had the conscious intention to discover that "truth." Notice how she uses such an elevator-like vocabulary of liminality to remember and reinterpret childhood experiences as she replaces one version of the past with another. Shadow writes,

the memories \& nightmares began after i was raped last year \& i can't push them away any longer...I lived with my uncle as a child, after my parents had died...he was a preacher... [...] i was 4 yrs old when the sexual touching started. ...he'd give me baths and play naptime games that were in his words 'to make me feel good \& let me know how much he loved me' $[. . .]^{21}$

In the same vein, Robin, who writes as someone suffering from multiple personality disorder, describes an awakening that was triggered by the death of her father, who she accuses of sexually abusing her. Like Shadow, Robin's rather abrupt awakening was triggered by an external event. Taking her forfeiture of agency even further, Robin locates the intention behind her awareness of "truth" in her alternate personalities, effectively removing the will to discover from the first-person "I" in her story. She writes, "A few years ago my father died and I believe that is why my alters [alternate personalities] felt it was time to tell me their stories." ${ }^{22}$ Capturing the involuntary essence of such elevator-like discoveries, Sagha writes, "I was slapped by the cold wave of memories.” ${ }^{23}$ Michele writes, “About two months ago, I began having horrible nightmares and flashbacks... my father had sexually abused me [...] And I just forgot it all until recently, I guess.”24 Similarly, Tanya writes,

The biggest flash back that always haunt me was when i was on the couch taking in the sun rays from the big window [sic]. It was such a nice day with big white 
clouds in the sky. Until my grandfather came up stairs [sic]. He was just snooping around the house and sat by me. Which of course i rest my head on his lap talking to him [sic] [...] Then he told me to sit up in which i did because i thought where going to do something fun [sic]. But instead he put his hand on me. Where at 1st thought he was just resting his hand until i saw he was playing with me. I didn't know what to do so i did the same back. This flash back keeps coming back to me like some type of bad dream. At 1st $i$ thought it was a dream. ${ }^{25}$ (emphasis added)

Tanya's discovery of "truth," like the act of dreaming, is not within her control. Notably, she couples her forfeiture of agency in the awakening experience with her portrayal of her own victimization in childhood. Both experiences, the abuse and the discovery, happen to her, despite her will. Similarly, psychiatrist Lenore Terr describes the case of Eileen Lipsker, who had an elevator-like recovered memory of her father (George Franklin) murdering her best friend (Susan Nason) in front of her twenty years earlier. Terr, who worked with Lipsker, describes a moment in which Lipsker noticed her daughter looking up at her, illuminated by the afternoon light beaming through a window in their home. She writes,

And at exactly that moment Eileen Lipsker remembered something. She remembered it as a picture. She could see her redheaded friend Susan Nason looking up, twisting her head, and trying to catch her eye [...] Eileen was eight years old, stood outdoors, on a spot a little above the place where her best friend was sitting. It was 1969, twenty years earlier. The sun was beaming directly into Susan's eyes. And Eileen could see that Susan was afraid. Terrified [...] Suddenly Eileen felt something move to one side. She looked away from those arresting eyes and saw the silhouette of her father. Both of Georg Franklin's hands were raised high above his head. He was gripping a rock. He steadied himself to bring it down. His target was Susan [...] Eileen Lipsker's buried memory, once it started rising to the surface, could not be stopped [...] On a quiet afternoon in 1989 , a suburban housewife's mind almost shorted out with overload. Her heart pounded mercilessly against her chest. ${ }^{26}$ (emphasis added)

Like Martin, the Born Again Christian, Lipsker's memories are accompanied by an uncontrollable mental and somatic "overload." Memory itself is given the power to act in 
the story, as recalled by Terr, and indeed it does act on Lipsker as "once it started" it “could not be stopped." Whether or not Lipsker wanted to know the truth about her childhood and her father is beside the point. The memory wanted to be known, so it acted.

Similarly, Debbie, a retractor of her once recovered memories of childhood sexual abuse, writes,

I caught part of a show about the False Memory Syndrome Foundation on television just at the point I realized that none of the "memories" in therapy were true. At the time, I was in shock and walking about saying to myself over and over again, "Oh my God, it didn't happen. What do I do now?" [...] I called [the FMSF], scared, and very afraid as I'd heard the FMS people were perps [perpetrators of sexual abuse] and didn't know if I could trust them or not [...] They gave me support, love and they helped me out of the shock I was in so I could start to think for myself again. I was then able to realize even more what was reality and what had not been reality. I realized what the therapy had been like and I could find the answers for myself about what had happened to me and my family. ${ }^{27}$

Like many who recover memories of childhood sexual abuse, Debbie's awakening experience takes the form of a "shock"-like realization that leaves her in a bumbling state of disarray. She is spurred by the television show to relinquish cognitive authority to the False Memory Syndrome Foundation. Similarly, retractor Gerilena describes an elevator-like discovery that her memories of sexual abuse were in fact "false." In a story that is strikingly similar to Debbie's account as well as Fiona's story about recovering memories of sexual abuse, Gerilena writes,

I woke up one morning in tears. It was Father's Day. A loud voice inside me said, "You were not abused by your father. It's a LIE. It's all a lie!" I believe now that it was the Lord speaking to me in His loud voice. About a day or two after my realization, I was told about False Memory Syndrome (FMS) by my sister. I called the FMS Foundation and I started to cry when I read the information they sent that explained everything that happened to me. I began to look at it all with new 
eyes. I became aware, relieved, and crushed inside knowing full well I had been deceived $[\ldots]^{28}$ (emphasis in original)

Gerilena forfeits cognitive authority in her account, first to a voice, then to "the Lord," then to her sister, and finally to the False Memory Syndrome Foundation. Using an express elevator vocabulary, she gives "truth" itself agency as is evident by the title of her story, "The Truth Set Me Free." Despite manifesting two oppositional standpoints in an autobiographical field, self-identified survivors of sexual abuse and retractors of sexual abuse memories account for their awakening experiences by using similar vocabularies and narrative tools. Like Gerilena, many awakeners who account for such overwhelming awakening experiences also describe immediately needing the guidance of a cognitive authority figure to ground their express elevator-like discoveries. Such cognitive authority figures, whether an individual, an organization, an alternate personality, or a non-biological actor ${ }^{29}$ serves as symbolic representatives of what Mead calls the "generalized other." They represent a new autobiographical community "which gives to the individual [in this case a radically new sense of] his unity of self." 30

Similarly, an apostate to the Mormon church who goes by the name "Mountaingirl" describes seeing a television program about the Freemasons. After learning that the Masons used rites that she previously thought were secret and sacred to Mormons, she accounts for her sudden and shocking realization of the "truth" about Mormonism. Like Debbie, her unsolicited mental discovery is triggered by a television program that provides an authoritative clue to the "correct" definition of her situation. She writes,

I saw an educational program on secret societies including free masonry [...] As this TV show was on I was in the other room listening and I was hearing the 
[Mormon] temple rites being recited, verbatim. I quickly ran to the TV and sure enough that was what I was hearing. These were supposedly the rites that Masons practiced! I was reeling with disbelief at first and then a quiet acceptance overcame me that it really was all a lie. ${ }^{31}$

Although a bit more subtle in her story, Mountaingirl conveys an initial moment of shock as she "quickly ran to the TV" and was then "reeling with disbelief" (this shock is also conveyed by her use of an exclamation point in the passage). By using the television program to account for her realization of "truth" (a program that she was not even watching, but only listening to from another room where she was presumably preoccupied with something else), Mountaingirl portrays her awakening as accidental. She did not seek the "truth," rather the "truth" found her. Likewise C. L. describes an elevator-like awakening after realizing that her high school best friend (a Lutheran) held beliefs that contradicted the tenets of Mormonism. She writes,

I remember my moment of epiphany. It hit me that I'd been taught from the cradle by loving parents that the sky is blue, one plus one is two, and Joseph Smith was a true prophet of God. It was for that reason that I believed in my religion, not because of any evidence [...] And that was it. That moment was the end of my belief in Mormonism. ${ }^{32}$ (emphasis added)

C. L.'s elevator-like awakening experience is both powerful and relatively instantaneous - a combination of attributes that is reflected in the common etiological root of the words "momentous" and "momentary." Likewise, Peter Collier describes an elevator-like moment of truth in which he abandoned his 1960's radicalism when he writes,

It was about this time that my daughter Caitlin was born and my father was diagnosed as having terminal cancer. Being sandwiched so suddenly between life and death jolted me and made me feel that I had been living though a kind of rhetorical gaze for the past decade.33 (emphasis added) 
In the same vein, P. J. O’Rourke describes an elevator-like experience that led him to reject his free-floating 1960's hippie progressivism. He prefaces his description of this experience (in which a Maoist collective tried to take over a local newspaper he worked for) by writing "one distinct incident sent me scuttling back to Brooks Brothers." 34 Such a transformative moment also came unexpectedly for an apostate who goes by the name "Astarte Moonsilver" after he went online with the intention of learning to defend the Mormon faith against potential attacks. Comparing his awakening to Neo's experience in the film, The Matrix, Astarte Moonsilver writes,

My exit was very quick, I left after spending two days at the apologetics sites [websites that offer arguments in defense of the controversial aspects of Mormonism] dredging up topics like Mountain Meadows, Kinderhook Plates, Two Cumorahs Theories, Polygamy practices, and the Mark Hoffman scandal. If I hadn't been so sure I could defend the church as well as anyone, I wouldn't have had the occasion to learn about these topics that the apologists were defending. If I had stayed in my place and avoided the Internet, I wouldn't have woke up from the Matrix. 35

Beyond conveying a simple forfeiture of agency in his account, Astarte describes a direct contradiction of his will and intentions. Whereas he sought out to defend his worldview, he was thwarted and thrown into a Neo-like awakening experience. Astarte Moonsilver's reference to Neo's awakening spurred several comments from other ex-Mormons who identified with the analogy he built into his vocabulary of liminality. Dave writes, "Welcome Astartemoonsilver - You are not alone in feeling like you woke up from the Matrix. It ain't always pretty here outside the Matrix, but it is real." 36 Tthom writes, "Like Astartemoonsilver, my waking from Mormonism was a real Matrix moment."37 
Such elevator-like "Matrix moments" or shocking points take the form of panic attacks, flashbacks, blackouts, confused or dazed states, blindness, bodily possessions, intrusive thoughts, body memories, hallucinations, and more. To portray such momentous events, awakeners use various dramaturgical devises including symbolic props and supporting characters such as lightening bolts, films, messengers, spirits, voices, and other narrative mechanisms. Awakeners attribute agency to these props and characters. They give them the ability to convey information and provoke new discoveries. They use these various literary devices to explain an involuntary, near instantaneous, and radical transformation of worldview. In the process, they often describe profound bodily and sensory dimensions of discovery in order to convey the intensity and overwhelming, uncontrollable character of their experiences.

Like many other awakeners who use a vocabulary of liminality that conforms to the express elevator model, Dustin, a Mormon convert, describes a significant bodily component to his awakening experience. He writes,

We sat down in the theater to watch the Joseph Smith video [...] Then it happened, as Joseph was kneeling in the grove [...] I had felt it! For the first time my heart burned, chills ran up my spine and tears rolled down my face [...] The spirit hit me so strong that I didn't care if I was the only blubbering fool in a theater of about 100 people. I knew that the church was true and that I had to be baptized [...] I called the missionary [...] The date was set and I was to go to Pittsburgh the next weekend and be baptized on August 23rd, 2003. From that point forward my life has been blessed so immeasurably that I can't imagine where I would be today without it. 38

Dustin's involuntary bodily sensations (his "burns," "chills," and "tears"), much like the "body memories" described by those who recover memories of childhood sexual abuse 39 and the overwhelming somatic and emotional responses described by military personnel who return from war, ${ }^{40}$ serve to accentuate the loss of control that is typical of all 
express elevator narratives. His body provides a physical manifestation of his lack of agency, a somatic compliment to the uncontrollable character of his mental discovery. Dustin is under the power of an overwhelming force, in this case a holy spirit that possesses him and forces him to know what is "true." Likewise, Anna (who led an "anticult" group against Mormonism for years) forfeits her agency to the same spiritcharacter. She writes that after reading the book of Mormon for the first time, "it was as though scales fell from my eyes [...] the spirit was able to reach me and help me turn my life around." ${ }^{41}$ Richard reports that an "unseen person sat next to me and whispered in my ears that what you just read is true." ${ }^{2}$ Describing an overwhelming bodily possession, Rod, a Born Again Christian, writes,

I was smoking four packs of camel cigarettes a day, and had no intention of slowing down, I pulled a cigarette out of the pack and as I tried to put it in my mouth, my hand threw it to the ground. I was so surprised, because I didn't feel anything in hand, I didn't want to throw it down, and I really wanted a cigarette. So I pulled another one out of the pack and as I tried to put it in my mouth, my hand threw it down [...] So I pulled out the pack and flipped one up and held the pack real tight and started putting it to my mouth, really concentrating to get that cigarette into my mouth and beat whatever this was that was in control of my hand. Suddenly my hand threw the whole pack to the ground [...] Then, while my mind was trying to figure out what was going on, I heard my mouth saying, "O.K. Lord, if you don't want me to smoke. I will never touch another one." Then I thought I had gone crazy. Then I started thinking...who is Lord? Who could make my hand throw down cigarettes? Who could speak through my mouth? Who is Lord? These thoughts were bombarding my mind when suddenly, I met the personality of Jesus Christ (emphasis in original). 43

When Rod is visited by the spirit force, he literally looses control of himself. He forfeits all agency in the account to explain his awakening experience.

Using Oliver Stone’s 1986 film Platoon, Vietnam veteran Arnold Steiber describes an overwhelming sensory-based experience to portray his awakening from a mental void to conscious activism. The film prods him into a new peace-oriented belief system, 
political action, and a new sense of his life's purpose. Like the holy spirit of the religious convert, The film speaks to Arnold and spurs him into, as the title of his essay reveals, “Waking Up to Peace.” Arnold writes,

When I left Vietnam in early 1971, I pretty much closed that chapter of my life [...] But in the background, something was there. Not always. It would fade for years at a stretch [...] About seven months ago I was home alone one night. I turned on the TV. The movie "Platoon" was playing. My first thought was to turn it off. Then I thought, hey, after 30+ years, I can handle this. Besides, I was curious. Wow. Stuff was there. Especially the kids. The violence was real. I could smell Vietnam. I could hear it. I could feel it [...] The next day I went on the Internet and looked up Vietnam Veterans Against the War [...] I discovered peace groups, and "actions." I marched in my first peace demonstration in Ann Arbor, Michigan and helped form the world's largest peace sign. Wow. This was good. Maybe that's why I was in Vietnam - to help others realize that violence is not the answer [...] I woke up, and it feels right [...] I am a Vietnam infantry veteran and a believer in a better world. 44 (emphasis added)

The film in Arnold's story jolted him out of his numb complacency. Even after embracing the agentic political role of the activist, Arnold forfeits power over his mental discovery to the political actions in which he participated. The film and the political events, by his own account, led him to wake up. Likewise, Iraq Veterans Against the War member Adam, once a pro-war Marine, attributes the initial loss of his "shield" - the metaphor he uses to describe the Marine Corps mindset - to his participation in the IVAW direct action "Operation Casualty." In the wake of his experience at this momentous political event, Adam writes, “That's when I got to become human again." 45 Such awakeners often describe political actions and political parties as catalysts for major world-altering transformations of mind. Former communist Ignazio Silone reflects on his youthful elevator-like awakening to communism by writing,

My own internal world [...] [was] shaken to [its] foundations, as though by an earthquake. Everything was thrown into the melting-pot, everything became a 
problem. Life, death, love, good, evil, truth, all changed their meaning or lost it all together $[. .$.$] the whole world took on a different aspect. 46$

In a striking elevator-like awakening, Richard awakens to the "truth" about his homosexuality by recovering a memory of childhood sexual abuse. Richard writes,

While pounding away at what I thought was some abuse caused by my mother, I had a flashback. All of a sudden, I saw male genitals coming toward my mouth. I screamed. I felt shocked. I felt horrified. I cried and the tears flowed for the next few years, as I worked through memories of sexual abuse that occurred when I was between the ages of five and six years old. A friend of the family -- we called him Uncle Dave -- [...] started playing with my genitals and had me do the same with his. It was shocking and horrifying [...] I learned that my neurology was programmed to respond to men in sexual ways. For me, intimacy with a man equaled sex. I learned that to be close to a man, I must give him my body. 47

Richard's unintentional and overwhelming discovery provided the evidence he needed to reinterpret his homosexuality as the adverse consequence of abuse. According to his account, Richard never intended to discover this "truth" but rather the truth forced itself upon him and took command of his affect. Similarly, Charlene Cothran, editor of Venus Magazine (formerly for African American lesbians) awakens to the "truth" about her homosexuality while having an elevator-like religious experience. She writes,

The spirit of God spoke directly into my soul and said you will choose this day who you will serve and if you make the wrong choice, I will allow you to drift so far away from me that you will never hear my voice again [...] I gave God my heart and soul in the parking lot of the mall, right there in my car. A river of tears flowed as Jesus washed me and forgave me and redeemed me for His work. I intend be just as 'out' about my transformation as I was about my lesbian life. I have given every gift I have back to God, including VENUS Magazine. The target audience will remain the same but the mission has been renewed. Our new mission is to encourage, educate and assist those in the life who want change but can't find a way out. My brother, my sister, please follow me out of this. 48 
Whether emphasizing a psychological or religious intervention, both Richard and Charlene forfeit agency to another power in their stories as they discover the "truth' about their sexuality.

Likewise, many individuals who once awoke to discover their "true" heterosexuality and later re-awoke to discover their "true" homosexuality describe similar elevator-like experiences. Christopher writes,

It was while I served on a new church extension team overseas that I had a profound realization: through seven years of countless hours of Bible study, intense counseling sessions, prayer vigils, agonizing and soul-searching, I was still a homosexual. My thoughts, desires and drives had not changed. More than that, I realized that as far back as I could remember, I had always felt the way I did. At no time did I ever choose to be a homosexual - no more than someone chooses to be heterosexual. I just was. My experiences were in direct contrast to what I was taught in church and seminary. 49

Despite his protracted work - his "countless hours" of study, intensive therapy, prayer, and general searching - and despite his long-standing intention to be heterosexual, Christopher unintentionally realizes the "truth" of his homosexuality. His former objectives (to "heal" from homosexuality) are thwarted as he passively experiences a "profound realization.” David finds such a life-changing moment of awakening after a suicide attempt. He writes,

That was the moment that my life truly started to change. I was admitted to a treatment center for my alcoholism and depression and I never returned to the "ex-gay" ministries, churches, or reparative therapists that had been my way of life for almost ten years. Lying in the hospital, I realized that the path I had chosen was literally killing me and I didn't think that God wanted me to die. I started trying to accept myself the way I was. $5^{0}$

Despite many differences, each of these storytellers describes an involuntary discovery of "truth." It happens rather quickly to all of them regardless of their will or 
intention and leaves them temporarily shocked, stunned, or overwhelmed with a new life-changing awareness. Such awakeners portray their "liminal personae" 51 (their confusion and vulnerability) in concentrated form. In each case, the awakener describes being acted upon or mentally transformed by an overwhelming force regardless of his or her will. In each case, the awakener forfeits agency to account for a liminal awakening experience. Such vocabularies of liminality commonly highlight the somatic, sensory, and affective dimensions of personal discovery and/or describe an ecological experience or external authoritative voice that ushers in a profound transformation of mind. The scene or setting of such accounts of liminality expresses "in fixed properties the same quality that the action expresses in terms of its development." ${ }^{2}$ Using such sociomental express elevators, awakeners justify their embrace of a new worldview by appealing to an authoritative force that exists outside their conscious design and beyond their control. Consequently, such accounts typically appeal to faith. Whether psychological, political, sexual, or religious in focus, they ask us to believe in some "power" that often works in mysterious ways.

\section{Sociomental Staircases}

In contrast to the elevator, the metaphor of the staircase (Figure 6, Model B) implies a step-by-step ascent - a gradual transformation of consciousness that unfolds over a relatively greater amount of time, involving the conscious reflection and deliberate activity of the awakener. A staircase will allow us to cover the same vertical distance that an elevator will, it just requires that we ascend in discernable increments, by our own effort. You have to walk up a staircase, one step at a time. When awakeners 
use such a vocabulary of liminality, they typically describe embarking on a selfmotivated quest for truth and knowledge. They exercise agency in their stories and bring about their own discoveries. Like Fritz (the Episcopal Minister turned apostate who started to doubt his faith and look for answers while studying at Princeton, well before leaving the Ministry)53 or Ben (whose sexual reorientation unfolded over 27 months of therapy), 54 these awakeners take charge in their stories, which often highlight the conscious application of mind to the question of truth and typically appeal to reason. 55 In such cases, several notable yet relatively minor experiences are nested in the broader awakening episode. Each of these nested events contributes to the cumulative transformation of the storyteller's consciousness.

Bill, an apostate to the Mormon faith, describes his awakening as a long, intentional search for truth. He writes,

After about a five year process of intense study and introspection, about six months after my visit with the bishop in his office, my conscience finally led me to write my resignation letter [...] The drip drip drip on my conscience began on my mission. The path to my awakening started when I was a missionary in Rio de Janeiro, Brazil [...] $]^{5}$

Bill then reflects on his long search for truth and describes finding several illuminating clues before achieving his full realization. Notably, the "path" to his awakening involves a conscious mental pursuit characterized by study and introspection. He exercises agency to seek answers along the way to "truth.” By articulating a "drip drip drip" on his conscience, Bill uses the metaphor of a leaky faucet - something one cannot ignore so easily - to describe how his emerging doubts spurred him into a quest. Notably, such a "dripping" phenomenon can be contrasted with the "flood" of realization that occurs in express elevator stories. Like Bill, an apostate who goes by the name Moonshine writes, 
Suffice it to say, for me, the beginning of the end came while studying church history from the historian's view. Thirty books and buckets of tears later, I came to realize that 'a church that will not tell the truth simply CANNOT BE TRUE'. 57 (emphasis in original)

Likewise, Preston comes to a similar conclusion while researching a college history paper..$^{8}$ Similarly, an apostate to the Mormon church who goes by the name "dbradhud" writes,

The more I read from the church history, the worse I felt. The more I studied, thought and prayed, the more problems I found with the church and what it claimed to be. I started compiling a list of problems. It became harder and harder for me to go out and teach [...] Finally, I realized that I couldn't do it anymore -tell people that I knew the church was true when I had such serious doubts [...] The most important lesson I learned from the LDS church is this: Living a lie is actually a slow, painful spiritual death. It is much better to face the truth and live. 59 (emphasis in original)

By actively and intentionally reading church history, studying and consciously reflecting, dbradhud, like Moonshine and Preston, takes charge over his awakening. Even when the "truth" is represented as a painful discovery, these awakeners actively look for it, cultivate it, and "face" it.

Like apostates to the Mormon church, Mormon converts also use a such staircase-like vocabularies of liminality to describe their awakenings. For example, Mormon convert Douglass describes his self-motivated and protracted journey to discover the "truth" of Mormonism. Like the foundational story of Joseph Smith, Douglass's account is riddled with false leads, dead ends, and turning points. Douglass writes,

I studied philosophy and theology in the Roman Catholic college-seminary and spent three years in the Society of Jesus, a Roman Catholic Religious order, 
preparing for priesthood. And that is where the first turn in the road appeared [...] My desire to marry and my growing disillusionment with the Catholic Church put me on a long path of searching. I realized that I never really had a personal relationship with Heavenly Father or Jesus Christ and I searched long and hard where I might find that relationship [...] That began a long period of spiritual wandering. I worshipped with Lutherans, Episcopalians, Baptists, and Pentecostals. I visited Hindu Ashrams and practiced Zen Buddhism [...] I eventually found a place in the Russian Orthodox Church, but while its liturgy was most beautiful, I found no spiritual sustenance for the remainder of the week [...] I knew I had to find out what this "Mormonism" was all about. Thus began $a$ ten year investigation [...] [Today] I testify that the Book of Mormon is true and Joseph Smith is a prophet and the Church of Jesus Christ of Latter-day Saints is the True Church and is led by prophets in our day. ${ }^{60}$ (emphasis added)

Likewise, Lindsay writes,

I spent a lot of years looking for a religion [...] When I was 12, I started searching for a religion. I went to churches with friends. I'd say I've been to most of the major Christian sects: Episcopal, Baptist, Non-Denominational, Lutheran, Jehovah's Witness, Catholicism [...] I studied all the major religions in varying detail, including Islam, Judaism, Buddhism and Paganism. I find religion and the ways people worship the Lord to be fascinating [...] I think it was this hunger for knowledge and spirituality that caused me to search, and eventually led me to the finding the Restored Gospel of Jesus Christ [...] The Gospel isn't chains , it sets us free. I spent countless years making endless mistakes because I didn't have this integral piece of knowledge. I didn't realize how much misery I'd created for myself. I didn't know there was a better way. ${ }^{61}$ (emphasis added)

Douglass and Lindsay exercise agency and consciously search for "truth" in their stories.

Despite several set-backs along the way, their intention and will never faltered; it was

clear from the outset. While these disappointing set-backs are typical of the way many

Mormon converts model their accounts on the iconic story of Joseph Smith, such sociomental dead ends, false leads, and cognitive turning points serve a more general function as steps to an end goal, parts of a process of elimination that culminates in their awakening to "truth."

While some awakeners use a staircase-like vocabulary to describe trying and rejecting various answers until they discover the real "truth" (a process of elimination), 
others use such a vocabulary of liminality to account for their gathering of the truth piece-by-piece (a process of accumulation). Rick, a "repaired" heterosexual who titles his account “A Hard-Work Miracle," recalls wanting a "flash of light" but never receiving it. Rick describes reading several books as he searches for the truth and meaning that such flashes of light usually impart. He writes,

I started reading anything I could get my hands on from a reparative-therapy perspective - Nicolosi, Medinger, Eldridge. Their books helped me better understand my desire for men and masculinity. I learned it was a natural drive for gender connection that had been misdirected into sexual desire $[\ldots]^{62}$

Rick later continues this search by attending weekend retreats called "Journey Into Manhood" and "New Warriors," their names expressing the long and agentic character of his quest. Rick uses each book, therapy session, and retreat in his story to describe how he accumulated his awareness of "truth" overtime, step-by-step. Stressing such a process-oriented approach, sexual reparative therapist Joseph Nicolosi prepares his patient, Father John, for a similarly protracted and challenging journey that he will have to "fight for." He writes,

Essential to healing homosexuality is changing this perception you have of yourself as the passive, helpless victim. Real change requires more than just putting the lid on a sexual behavior. We're looking for a larger transformation [...] But this is something you will have to fight for. Forever - I'm not talking about a week. Some days will be big battles; some, small battles. But every day has to be a battle of some sort [...] Otherwise, as they say, it ain't gonna happen. ${ }^{63}$

Acquiring this perspective on the step-by-step process of transformation (as epitomized by everyday "battles" in Nicolosi's view), many "repaired" heterosexuals, like many of those who recover memories of childhood sexual abuse, associate the discovery of 
"truth" in their lives with the protracted process of psychological healing. Using a psychological staircase vocabulary, Scott writes,

The road to healing was a difficult one filled with ups and downs. Along the way, I faced feelings of rejection from my peers and father. I worked to overcome feelings of inadequacy and incompetence as a man. As I worked with my counselor to fill my emotional needs, extinguish harmful behaviors, and heal emotional wounds, I noticed my homosexual compulsions becoming less intense. With time, they began to subside. Then, subtly, I noticed heterosexual feelings starting to emerge. These new feelings grew slowly as I continued progressing through the recovery process. 64

Scott emphasizes the protracted character of his drive to comprehend and change his homosexual attractions. As he works achieve "healing," he discovers the core "truth" about his sexuality - the causes and consequences of his "homosexual compulsions" and the hidden nature of his "heterosexual feelings." The healing process is, among other things, a staircase-like discovery of "truth" that leads to a new sexual worldview and lifestyle. Such a stress on process is evident in Dan's comment that "there is joy in the journey itself" 65 and captured by the Japanese poet Matsu Bashō's sentiment that “everyday is a journey, and the journey itself is home." ${ }^{66}$ Emphasizing the agentic character of such a journey for understanding, Frank writes,

I hate to read, but I had this insatiable hunger for the truth. I read Richard Cohen's book, "Coming Out Straight." I read "Battle for Normality" by Van Den Ardwig. I read Nicolosi's books and countless articles. I could not stop seeking out the truth. Every book had my story in it. I became well versed in father wounds, mother wounds, triadic relationships, defensive detachment, and missing steps in core identity development. My homosexuality was just a symptom of profound and deep emotional arrest. It was indeed the tip of an iceberg. I began therapy with David Matheson through NARTH [the National Association for Research and Therapy of Homosexuality], and have never looked back since. ${ }^{67}$ (emphasis added) 
Some awakeners who recover memories of childhood sexual abuse stress a staircase-like commitment to psychotherapy and link the protracted process of remembering to the process of healing and reinterpreting their lives in therapy. Stephanie writes, "I have started to live my life day by day and [some] days I want to recall more of what he did to me [and some] I don't if I feel I can't deal." ${ }^{68}$ Claire writes,

I don't remember lots of things. I started to face the memories about 3 years ago. I just wasn't ready before then [...] And I have been working with a therapist and I have been very open to my feelings, talking to my child inside, but it's very hard anyway. It's very hard, so hard. I wasn't aware before of how disabling and painful my depression is and how paralyzed I really am, and how much I dislike to be noticed, I wasn't aware how much I hunger for comfort and love, and how confused I am about sex [...] 69

As she works with a therapist to understand the "truth" about her life, Claire slowly takes on new memories. Further, she also slowly acquires an understanding about her present problems, learning how "paralyzed" she really is. Likewise, Lilita writes,

I have been facing my memories and feelings for three years. I knew there was a lot, a lot to face, so it makes sense why I postponed it. At times I wish I hadn't but I was unconscious of a lot of stuff and that made it harder for me to deal with it. Now I am more aware of my hypervigilance, my social phobia, at times I feel agorophobia, I still experience a lot of body aches, back, stomach, chest, limb, head, even face aches. ${ }^{70}$

Like many who recover memories of childhood sexual abuse, several who retract memories of childhood sexual abuse also use a staircase-like vocabulary to describe their re-awakenings. Elizabeth writes,

The truth dawned slowly, gradually, in a process that intensified after I stopped seeing the therapist. My sense that I had made up my memories of abuse became stronger. I had recently married, but within six months my husband and I began having difficulties. We consulted a counselor, who was concerned about my estrangement from my parents, and who told me I could not resolve problems in 
my marriage until I came to terms with my family. That made a deep impression on me, and I became more and more certain that my mother had never abused me. But why had I accepted the [original recovered memory] therapist's theory so easily? ${ }^{1}$

In a similar vein, Beth, a retractor, regards and meticulously details her re-awakening as “The Process” and her “Journey Back Home and to Truth.”72 Like many religious converts, apostates, and "repaired" heterosexuals, many retractors regard their prior understanding of "truth" to have been a sociomental "false lead" on their journey to discovering the real "truth." These re-awakeners use a staircase formula to account for prior promises of truth that they once considered viable but now "know" to be bogus.

Likewise, many individuals who once awoke to discover their "true" heterosexuality and later re-awoke to discover their "true" homosexuality describe similar staircase-like experiences. Cheryl writes,

As I began to deal with my own internalized homophobia, I fully rejected the notion of "ex-gay." [...] What followed was the beginning of a long, hard struggle with spirituality and genuine self-acceptance. I began to wrestle with what it might mean to be a lesbian. I wondered if my sexual orientation and the church were compatible. Reality quickly raised its head and within a couple of weeks, members of the church I attended began to harass me. Phone calls at work, unending questions and Bible beating became a regular part of my life. Finally, the leader of Regeneration [A Baltimore-based ex-gay group] requested that if my partner and I would not change our ways, we needed to leave the church we were attending. We did.73 (emphasis added)

Like the "repaired" heterosexuals quoted above, Cheryl uses a staircase vocabulary to describe her active, "long, hard struggle" of personal discovery in which she "began to wrestle" with meaning. Similarly, Kathryn writes,

I also want to highlight how coming out is not necessarily a linear process, consisting of a single, dramatic coming out, followed by automatic, profound 
transformation. Rather, coming out can be, and was for me, an ongoing, gradual process akin to unveiling - one painful layer at a time. 74

Such an agentic search for truth is also evident in Jerry's story. Jerry, a former "repaired" heterosexual who now identifies as a survivor of sexual reparative therapy and embraces his homosexuality, writes, "I decided to face reality head-on. It was the pain and suffering that caused me to search for truth both spiritually and psychologically." 75 When Cheryl, Kathryn, and Jerry re-awaken, they reinterpret their prior embrace of sexual reparative therapy as a major wrong turn in a more protracted and broadly conceived journey to comprehend the "truth" about their sexuality.

Likewise, in his account titled "Searching All the Wrong Doctrines," Stephen, a Born Again Christian, writes,

[...] in my teens and gradually I decided that church was okay for some but it wasn't essential [...] I drifted from church to church, religion to religion. Each time, I KNEW I'd found the truth, only to drift away when I changed my mind about what I believed. I went from Buddhism, to Hinduism, to Judaism and back again [...] At one point I even became involved in an online Wiccan group [...] I drifted from denomination to denomination in search of God's church. Nothing seemed right and yet everything sounded right! How could this be? [...] The last few years have seen me visiting (and each time joining, never to return) countless churches: Pentecostal, Apostolic, Roman Catholic, Nazarene, Primitive Baptist and lastly Russian orthodox. ${ }^{7}$

After claiming to have been repeatedly "betrayed" while following his "heart" for years and searching "to find the truth," Stephen found his "answers" and his "home," he writes, at an Easter Sunday service at a the Church to which he now belongs. From this, his new autobiographical community and narrative standpoint, he writes,

I accepted Christ as my Savior in a very personal way and have felt a blessed peace ever since. Gone are the doubts. Gone is the tendency to have a complete doctrinal reversal the next morning. 77 
From his current standpoint, Stephen reconceives each of his prior religious affiliations as disappointing steps in his overall staircase-like "search" for ultimate "truth." Likewise, Jerry, a "repaired" heterosexual who sets out on self-labeled "quest" to find the truth about his sexuality, describes seeking answers from two psychotherapists, various "circles" in the gay community, and a pro-gay Catholic group before discovering the "truth" that his homosexuality was a symptom of unhealed psychological wounds. 78 Similarly, Julia Sweeney, former Saturday Night Live cast member and apostate to the Catholic Church, describes exploring the practice of meditation, reading "the Tao Te Ching, the Bhagavad-Gita, the Tibetan Book of the Dead, Rumi, The Essential Kabbalah, and The Way of the Pilgrim," as well as attempting to be a Bhuddist and looking for God in nature as she was searching for spiritual truth. Sweeney, who ultimately rejects religion and "let[s] go of god" to become an atheist, articulates each of these projects as experimental though faulty stages in her self-described "spiritual quest."79 Each of these awakeners describe an extended period of searching that was marked by several disappointing sociomental false leads or dead ends before finding what they now regard as the "truth."

Describing his rejection of his once-embraced pro-Sandinista, pro-Castro worldview, Xavier Arguello, writes, "disenchantment also has something to do with a slow, personal process of maturation [...] To open one's eyes takes time." ${ }^{80}$ Former communist Arthur Koestler writes, "A faith is not acquired, it grows like a tree." Extending this metaphor for a protracted awakening process into the past and future, Koestler continues, "Its crowns point to the sky; its roots grow downward into the past and are nourished by the dark sap of the ancestral humus." 81 Likewise, former 1960's 
radical David Ifshin describes his evolving views on the Vietnam war as "A Political Journey." ${ }^{2}$ Similarly, Iraq Veterans Against the War member Christie's awakening unfolds as she asks questions over time and "[s]lowly [...] began to comprehend what it meant to belong to the service [the U.S. army]." 83 Christie then asks a series of questions that characterize her search for truth and meaning. In a similar vein, Eric Ahlberg, former Army Infantryman and member of Iraq Veterans Against the War, writes,

I started off as a pro-war person when we went to Afghanistan but that started to change when it was decided to start attacking Iraq. That is when I started putting the pieces together that there was more to this then [sic] good vs. bad guys [...] Over in Iraq I got to see the people, talk with the ICDC, get an idea of what was going on there with a first hand knowledge. My time there was not spent helping people, I was there as a show of force pointing my weapon when people got to [sic] close, shooting when needed. I would look around and see what a mess Iraq was. My first thought was that these people lived like animals. But the longer I was there the more I realized that it was out fault, we destroyed the infrastructure, and didn't build it back up [...] The thought of bringing peace and freedom to a country with guns and soldiers expert in killing the enemy is an unfunny joke. But I was part of the machine and my eyes have been opened. This is why I am part of the IVAW, so my story can be heard. ${ }^{84}$

Likewise, Adrienne Kinne, former Arabic linguist for the for U.S. military intelligence and member of Iraq Veterans Against the War, lays out a staircase-like agenda for active duty military personal during an interview with the political newsletter, CounterPunch. An awakener himself, Adrienne assumes the role of cognitive authority figure while giving other veterans a vocabulary with which they can articulate their own transformations of mind. He comments,

I would encourage all soldiers to question everything they have taken for granted as being the truth told to them by their unit, their president, and their country/media and to start thinking for themselves. I would suggest that they shouldn't let some abstract feeling of loyalty to the military override their own 
morals and consciences. I would encourage them to watch [...] documentaries, and start reading books [...] I would also encourage soldiers to start talking to one another, really talking, about their experiences [...] It's very hard for soldiers to break free of the hold the military has over us [...] But in order to make the transition from soldier/veteran to resister/activist, we all have to be open to the concept that everything we thought we knew about reality could be wrong or only half-truths. ${ }^{85}$

Adrienne's agenda stresses the active and conscious mental pursuit characteristic of all staircase-like vocabularies of liminality. He asks other soldiers to rise to the occasion and seek out "truth" for themselves.

Despite the many differences among them, all of these awakeners describe asking questions and searching for answers. They embrace their own cognitive agency. In an express elevator awakening, "truth" makes itself known to the awakener. However, in these staircase-like examples, each awakener first becomes aware of their own doubt and ignorance. “Truth” only comes later, with time and after conscious effort.

Awakeners who use express elevator vocabularies ask us to know on faith that they were acted upon. Those who use staircase vocabularies ask us to know by reason how they acted. In an elevator-like story, truth finds the awakener. In these staircase-like models, the awakener seeks and finds truth.

Despite a variety of differences among them, each of these awakeners describes a voluntary discovery of "truth.” They all describe raising questions, actively seeking answers, and discovering the "truth" over time. They prolong their liminal personae and the scene of their awakening to fit their protracted mission. Whether taking form as stages of accumulation or a frustrating process of elimination, such awakeners portray a step-like process of discovery. In each case, the awakener takes charge in the story and initiates a journey that is typically characterized by an active and agentic mental pursuit. 
Consequently, they portray their current autobiographical community as the culminating point of their quest, the "truth" or "home" that they discovered at the end of their "path."

These two ideal-typical vocabularies of liminality, sociomental express elevators and sociomental staircases, are exemplified by the Christian account of Saint Paul's conversion and the Buddhist story of Siddhārtha Gautama's enlightenment. Further, the ideal-typical characteristics of each vocabulary can be discerned in popular depictions of these stories that portray sociomental liminality in visual form. By analyzing such visual depictions of liminality, we can further see how the scene of liminality fits the organization of the act and the attribution of intention (similar to what Burke calls "purpose") and agency in each case. ${ }^{86}$ In Michelangelo's depiction of Saint Paul's conversion (see Figure 7), Paul is literally overwhelmed by a powerful force (not unlike Iraq veterans who describe having a powerful realization after a firefight and sexual abuse survivors who report having "flashbacks"). Paul's original intention (to persecute Christians in Damascus) is thwarted and his horse is fleeing in the opposite direction. The agency in this image is clearly located in the figure of god, which hovers over Paul and his band of Pharisees in a symbolic depiction of cognitive authority. The narrative mechanism of a lightening bolt serves to bridge the upper and lower sections of the scene, connecting god to Paul and conveying the shock associated with rapid awakening experiences. In this account, the "scales" fell from Paul's eyes a mere three days later and he could "see" the "truth." 
Figure 7: Michelangelo's Conversion of Saint Paul (1542-1545).87

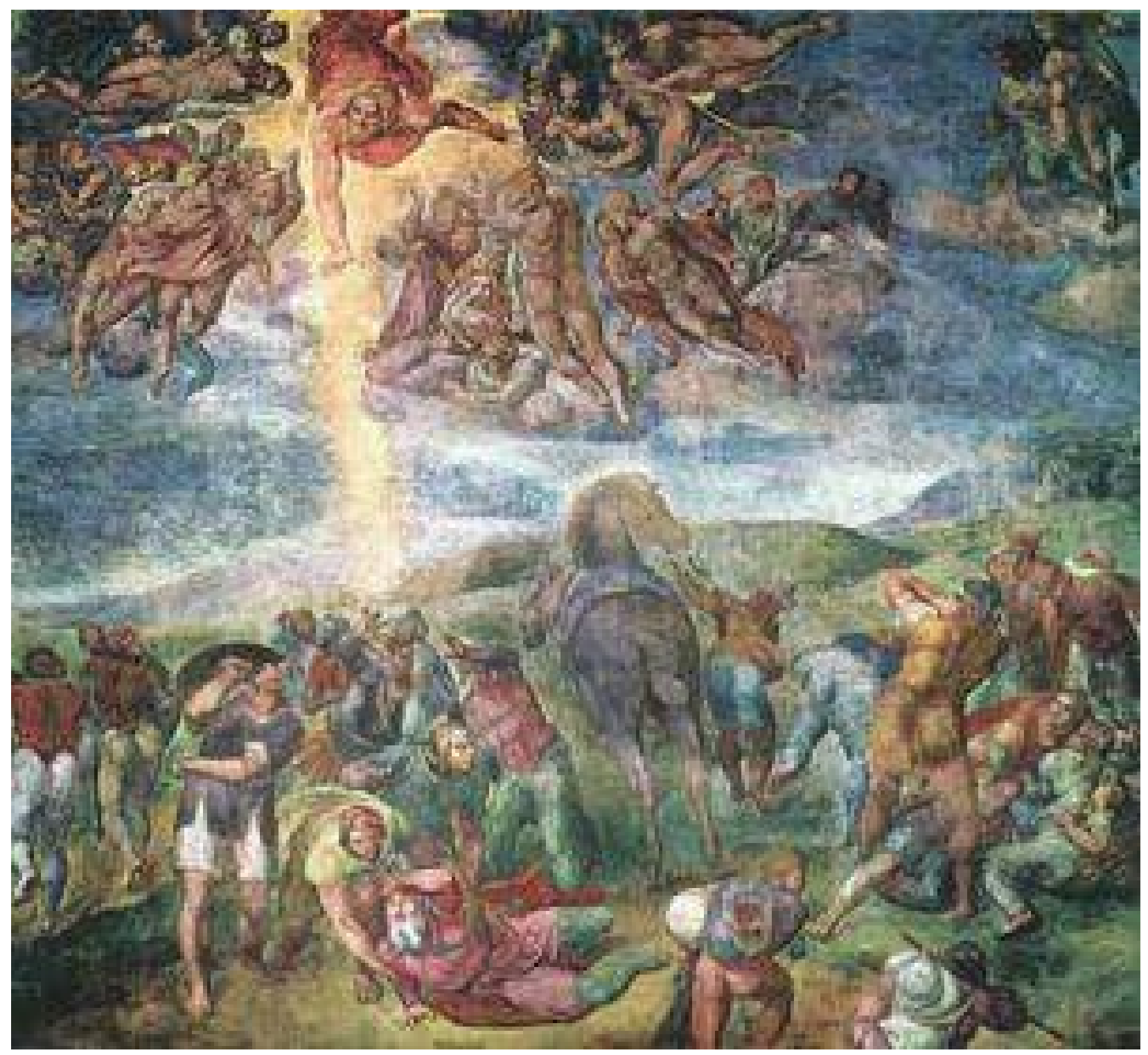


Considering a depiction of Siddhārtha Gautama's journey painted on the wall of a Buddhist temple in Laos (see Figure 8), Siddhārtha willfully disregards his father's will and leaves the protection of his castle (which appears in the far background of the scene, symbolic positioned in Siddhārtha's past). Like Malcolm X, Leslie Feinberg, many Mormon apostates, and many who enter sexual reparative therapy, the young prince initiates a quest for truth. In this image, Siddhārtha exercises his own agency. Notably, he is the highest figure in the scene (as opposed to Michelangelo's depiction of Saint Paul's conversion where god is the highest figure and Paul is the lowest). Siddhartha is clearly in charge of his horse and chariot as he initiates a six-year journey that will culminate in his enlightenment. Taking these initial "steps," he encounters four messengers - an elderly man (who is depicted on the road, behind Siddhārtha's chariot), a sick man, a corpse, and an ascetic - who provide "clues" to the "truth." This painting visually synchronizes several occurrences (portraying successive messengers in one scene) that are not synchronous in the narrative in order to portray the process of movement along a road. Unlike the elevator-style conversion of Saint Paul, only specific snippets of Siddhārtha's staircase-style awakening can be captured in any one painting (symbolized by the suggestion that Siddhārtha's horses are moving down the road, out of the frame that surrounds the scene). In another depiction, the young Prince abandons his fellow ascetics after outgrowing and rejecting their teachings (see Figure 9). In the wake of this sociomental false lead, Siddhārtha intentionally moves onto the next step in his quest. We see his back as he leaves his former community in the past. 
Figure 8: Painting from a Laotian Temple depicting Siddhārtha Gautama's initial expedition out of his father's castle. ${ }^{88}$

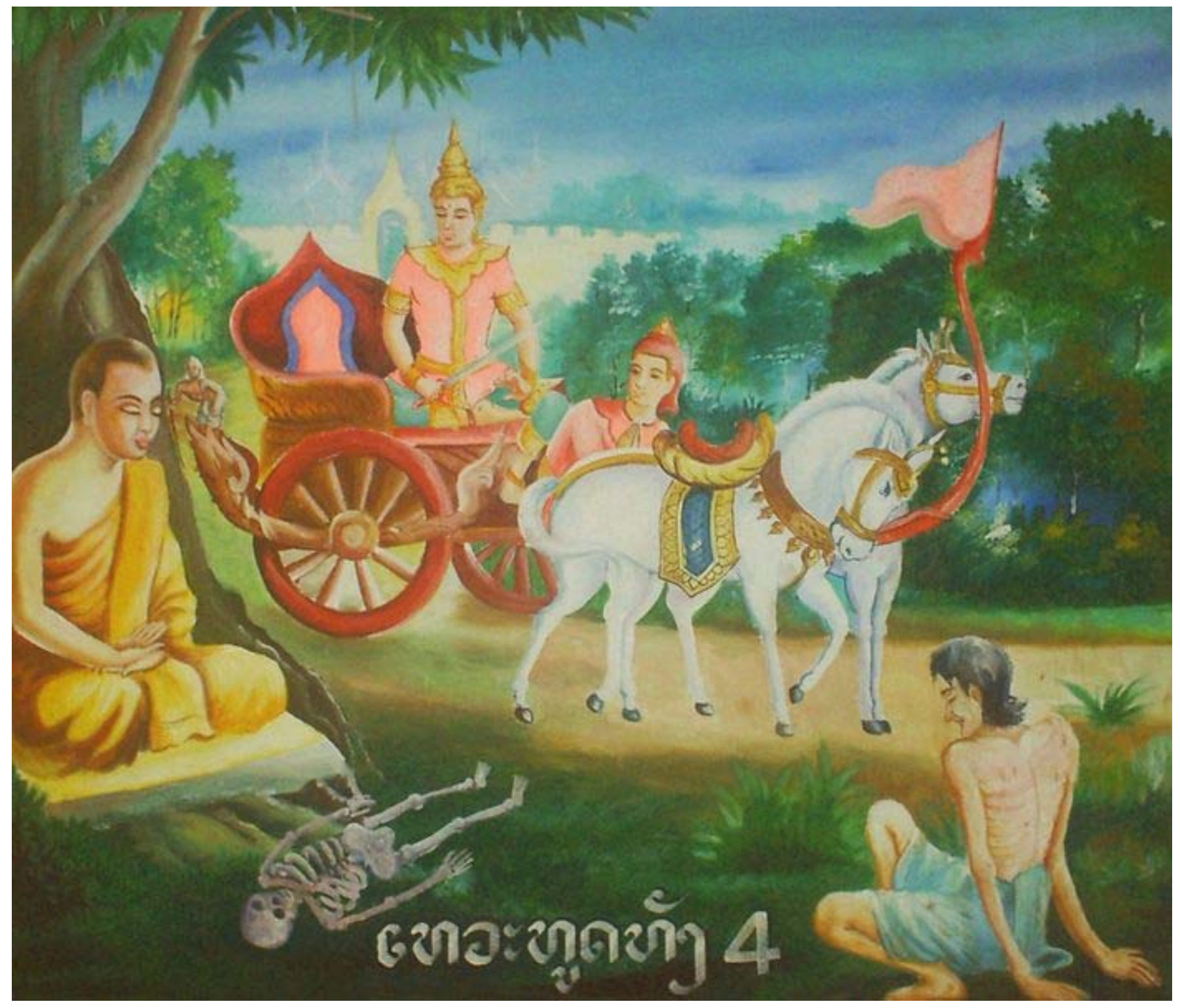


Figure 9: Painting from a Laotian Temple depicting Siddhārtha Gautama leaving his ascetic comrades. 89

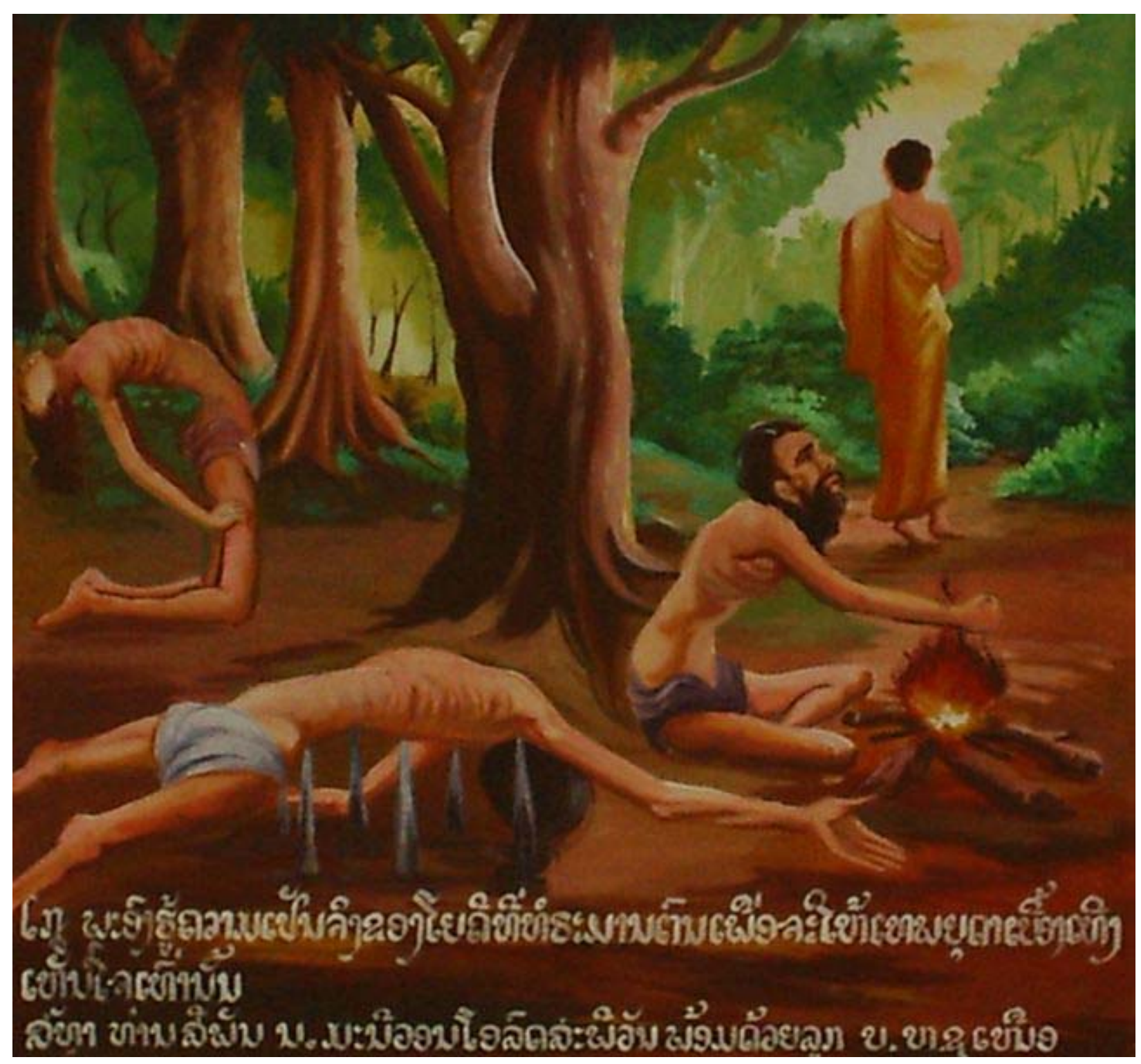




\section{Combining Elevators and Staircases}

When used in combination, sociomental express elevators and sociomental staircases serve to reinforce one another. In such cases, awakeners typically describe a sudden, elevator-like "snapping" experience ${ }^{90}$ or tipping point that signifies a qualitative change at the beginning, middle, or end of a protracted staircase-like search for answers. The "shock" is nested in the "quest." Film directors Larry and Andy Wachowski use such a combination of the elevator and the staircase to portray Neo's awakening in The Matrix. Before his awakening, Neo is haunted by doubts about the authenticity of the world. He is searching for something but he is not sure what that something is. The character Morpheus, who plays the role of a cognitive authority figure, offers Neo a choice between two pills, one red and one blue. If he chooses the red pill, he will know the truth but can never return to his life of ignorance. If he chooses the blue pill, he will return to his delusional world without the haunting hint of its false character. After choosing the red pill, Morpheus warns, "Remember, all I am offering you is the truth. Nothing more." Neo is then uncontrollably thrust into a shocking awakening and quickly learns exactly how the world he has always known is an illusion. This jolting realization, however, does not end Neo's quest, but rather catapults it to a new level. Neo continues to search for answers and discover pieces of the truth throughout the trilogy. Thus, the Wachowski brothers nest an elevator-like experience within a staircase-like quest for enlightenment that only ends in the third film of the trilogy when Neo realizes his destiny. The directors blend qualitative and quantitative transformations of mind to depict Neo's awakening. They also combine themes of 
agency (Neo chooses to know) and destiny91 to cast Neo as a powerful figure ("The

One") who is both free and at the whim of forces much larger than himself.

Arguing that all sudden, radical changes of mind are actually defining moments

in a more protracted, unfolding process of realization, Arthur Koestler argues,

The moment of truth, the sudden emergence of a new insight, is an act of intuition. Such intuitions give the appearance of miraculous flashes, or shortcircuits of reasoning. In fact they may be likened to an immersed chain, of which only the beginning and the end are visible above the surface of consciousness. The diver vanishes at one end of the chain and comes up at the other end, guided by invisible links. ${ }^{2}$

While he is writing about the creative process, Koestler stresses the notion that mental express elevators are actually only a defining moment in a larger process of transformation (the links of Koestler's chain are equivalent to steps in a staircase). It is notable that Koestler himself is a re-awakener who rejected his long-held communist worldview only after a lengthy journey of discovery. 93 Reflecting on his past awakening to communism, Koestler writes,

I began for the first time to read Marx, Engels and Lenin in earnest. By the time I had finished with Feuerbach [Marx] and State and Revolution [Lenin], something had clicked in my brain which shook me like a mental explosion. To say that one had "seen the light" is a poor description of the mental rapture which only the convert knows (regardless of what faith he has converted to). The new light seems to poor from all directions across the skull; the whole universe falls into pattern like the stray pieces of a jigsaw puzzle assembled by magic at one stroke. There is now an answer to every question, doubts and conflicts are a matter of the tortured past - a past already remote, when one had lived in dismal ignorance in the tasteless, colorless world of those who don't know. 94 (emphasis in original) 
Koestler later reinterprets this once-believed elevator-like awakening to communism as a false awakening in a more protracted journey - a link in his chain-like journey to truth.

Alternatively, Thomas Kuhn argues that the notion that cumulative development drives scientific discovery is a myth. Instead, Kuhn argues, science moves forward by radical paradigm shifts - sudden changes of ways to see the world that are comparable to perceptual gestalt switches. 95 Whether one emphasizes a world-shifting event (like Kuhn) or the cumulative process (like Koestler), each of these phenomena represents a narrative mechanism that awakeners can combine and use to explain quite radical changes of mind. When using elevators and staircases in combination, awakeners often stress how quantitative, cumulative changes reinforce qualitative transformation, and vice versa.

Former communist Louis Fischer describes an elevator-like experience in the middle of his staircase-like re-awakening. After describing how "the draconian Soviet suppression of the sailors' revolt on the Island of Kronstadt near Petrograd embittered [anarchist Alexander Berkman] against the entire Soveit regime,"96 Fischer writes, "I had no 'Kronstadt' for many years,"97

Then came the Soviet-Nazi Pact of August 23, 1939 [...] The pact produced my "Kronstadt." [...] But since many persons did not understand why I postponed my "Kronstadt" so long after they had seen the darkness in Russia, I am tolerant of those who are still in the pre-"Kronstadt" phase. The Pact was "Kronstadt" for me. Others did not "leave the train" to stop at "Kronstadt" until Russia invaded Finland in December, 1939. Finland was their ideological melting point. 98

After suffering several disappointments with Soviet ideology and policy, as well as becoming increasingly skeptical of communism in general, Fischer did not experience a 
qualitative transformation of mind until August of 1939. He uses the metaphor of "Kronstadt" to explain how doubt and disillusionment can grow without, and until, one reaches an elevator-like "ideological melting point." While he uses an elevator vocabulary to describe his jump from one worldview to another, Fischer's elevator came in the middle of a growing disillusionment and protracted search for political truth.

Ronn (who we saw earlier went to Iraq with a self-described "kill them all" mentality) also uses the elevator and the staircase in combination to account for a major mind-changing event in the midst of his more protracted discovery of truth about the war. Ronn describes experiencing elevator-like intrusive thoughts after killing an Iraqi Civilian when an incendiary device engulfed part of his convoy on a road between Baquba and Muqdadiyah in Iraq. These thoughts take over his mindset and lead him to the conclusion that killing is senseless and wrong. Ronn writes,

And the more I thought about it, the more I realized I shouldn't [think about it], but I couldn't help it. Who was he? He was probably just someone who woke up that morning in his bed and assumed that he would end his day in the same place. [...] And who was the screaming woman? Was it his wife? His sister? His mother? Was he old enough to have a daughter that age? [...] And it made me think about life in general and how senseless something like war is [...] War is simply people killing each other. What a silly concept!"

In many ways, Ronn's road to Muqdadiyah experience resembles the story of the Christian Apostle Paul. His intrusive thoughts (an official diagnostic criteria of the posttraumatic stress disorder diagnosis ${ }^{99}$ ) overwhelm him and spur him to ask questions about the nature of the war and his position in it. Ronn then proceeds to ask a number of questions and seek answers. His elevator-like experience leads to a staircase-like process, the culmination of which led to, in his words, "the death of a pro-war conservative." With such a title, Ronn uses the metaphor of death - which can be 
culturally conceived as an event and as a process - to describe his sociomental transformation.

Likewise, Jerry describes a religious sociomental express elevator in the middle of his sexual staircase. As he searched for answers about his sexuality, Jerry "fell into a deep depression" after coming across several false leads and dead ends. Jerry writes,

I remember standing in the shower one time, heavy with depression. I felt myself starting to collapse. I thought I was about to have a psychotic breakdown. But all of a sudden I felt these large, supernatural spiritual hands behind my back lifting me back up on my feet. I felt a surge of strength that whispered, "Keep going." I recognized immediately that it was the Lord intervening, giving me his strength to lean on when I couldn't do it by myself any longer. ${ }^{100}$

In Jerry's case, an elevator-like experience comes in as an intermediate intervention in his extended search for truth and meaning about his sexuality. The voice and hands of a spirit-character reinforces his agency and spurs him to keep searching. While not leading to a complete awareness of "truth," this intervention plays a pivotal role in his quest. Like Ronn, he uses an express elevator mechanism to mark a sociomental turning point in his more protracted staircase-like journey. In the same vein, sexual reparative therapist Joseph Nicolosi explains to his client, Albert, that he needs to be prepared for a staircase-like journey when he tells Albert, "You can't hurry the process of selfacceptance [...] "It's not east to change the way we see ourselves. It takes work, based on a gradual process of small successes." 101 The elevator within the staircase arrives when Albert says, "I’ve started making major breakthroughs here. Big bolts of lightening, shocks of awareness." ${ }^{102}$

As Minoi recovers memories of childhood sexual abuse, she combines elevatorlike flashbacks with a staircase-like commitment to the process of healing and personal 
discovery. Many survivors of childhood sexual abuse consider healing and remembering or discovery to go hand-in-hand. Minoi writes,

I was sexually abused by my father from the age of 5 to 11 years old that I know of. I repressed it till my 30's when I had flashbacks which went on for many years because I avoided therapy, thinking it would mean I was crazy, and having been programmed well by the parents to enmeshment with these 2 sick people was severe [sic], as I was an only child. 4 years ago at the age of 44, I entered therapy after my grown daughter told me my father sexually molested her also, and she never forgot it [...] I am no longer in therapy, having come far in my healing process, but I believe survivor's healing is a life-time process and we always need support and love. ${ }^{103}$

Minoi's elevator-like flashbacks come at the beginning of her slowly developing staircase-like process of healing and discovery. Likewise, retractor Beth Rutherford highlights an elevator-like experience that spurs her protracted "journey back home and to truth" when she writes,

What changed my mind? What brought me to the truth? [...] On April 19, 1995 at 9:02 AM, a bomb went off in Oklahoma City. [...] A lot of horrible things happened that day, but one good thing came out of it all. My mom knew that two of her daughters were in Oklahoma City [...] She also knew that she had been told that if she contacted her children it could be used in a court of law against her as harassment.. [...] When worry overcame fear, she called. But I was not home, so she left a message on the answering machine [...] I can remember listening to that message and hearing that "past" mom that I had hidden away in my memory, and I thought of times when she would rock me at night as a little girl or hold me when I was upset. For a brief moment, good true memories crept into my thinking. I quickly shoved them back into the "closet," though, as I felt I had to keep hatred toward them alive. But, it was the next little step in my journey back home. ${ }^{104}$ (emphasis added)

Despite her intention to treat her parents as enemies, Beth experienced an initial involuntary insight, a kernel of the "truth" she would later discover at the end of the journey she calls "the process." She uses this elevator-like experience to explain how she 
discovered the "truth" in stages. Similarly, in the midst of his classic staircase-like quest for truth, Augustine has an elevator experience. He writes,

I was asking myself these questions [about life and the nature of my sins], weeping all the while with the most bitter sorrow in my heart, when all at once I heard the singing voice of a child in a nearby house [...] again and again it repeated the refrain 'Take it and read, take it and read' [...] I stemmed my flood of tears and stood up, telling myself that this could only be a divine command to open my book of Scripture and read the first passage on which my eyes should fall [...] I seized it and opened it, and in silence read the first passage on which my eyes fell [Paul's Epistle to the Romans: Romans 13:13,14] [...] I had no wish to read more and no need to do so. For in an instant, as I came to the end of the sentence, it was as though the light of confidence flooded into my heart and all the darkness of doubt was dispelled.105 (emphasis added)

Similarly, a former Mormon who goes by the name "MsGabbie2u" describes how an elevator-like experience thrust her into a staircase-like drive for answers. She writes,

My "awakening" came abruptly and harshly through a traumatic experience....but that's another story. I found myself questioning everything. Why didn't I feel comforted? Where was the Holy Ghost? I teach the primary children it will comfort them! I speak at their baptisms about this wonderful new gift! But where was it when I needed it the most? ${ }^{106}$

In each of these cases, awakeners combine the ideal-typical components of the sociomental express elevator with the ideal-typical characteristics of the sociomental staircase. Nesting elevator-like events in their staircase-like search for truth, they blend notions of agency with a forfeiture of control, reason with faith, into vocabularies of liminality. Combining such seemingly contradictory components into their autobiographical accounts, awakeners convey the quantitative and qualitative dimensions of their awakening experiences to justify major changes of mind and traverse the sociomental gulf dividing contentious autobiographical communities. 


\section{AUTOBIOGRAPHICAL GULFS AND AUTOBIOGRAPHICAL DISCONTINUITY}

Now that I have explored the ideal-typical characteristics of sociomental express elevators and sociomental staircases, I can turn my attention to a more thorough examination of the formal and structural implications of vocabularies of liminality. Awakeners use vocabularies of liminality to split their lives into discrete autobiographical periods - a past "false" period in which they were "lost" or "blind and a current "true" period in which they have been "found" and can "see." The awakening episode or period of discovery is a necessary component of the story in that it separates two mutually exclusive sections of the awakener's life. Using vocabularies of liminality, awakeners are able to create a sociomental discontinuity or rupture in their life stories by depicting the dramatic complexities involved with their symbolic passage from one worldview to another. Such vocabularies establish a symbolic gulf between two states of being that are in tension with or contradiction to one another. When combined with the flow of autobiographical time (the temporality inherent in the narrative), such a sociomental discontinuity becomes a distinctly autobiographical discontinuity - a form of historical discontinuity ${ }^{107}$ that separates the past and present. The liminal phase of life, like the areas of social seclusion observed by Turner, is necessary in order to convey the cocoon-like sociomental transformation and traverse the "great divide" 108 that separates one period of life from the other (see Figure 10). 
Figure 10: Portraying and Crossing the Autobiographical Gulf.

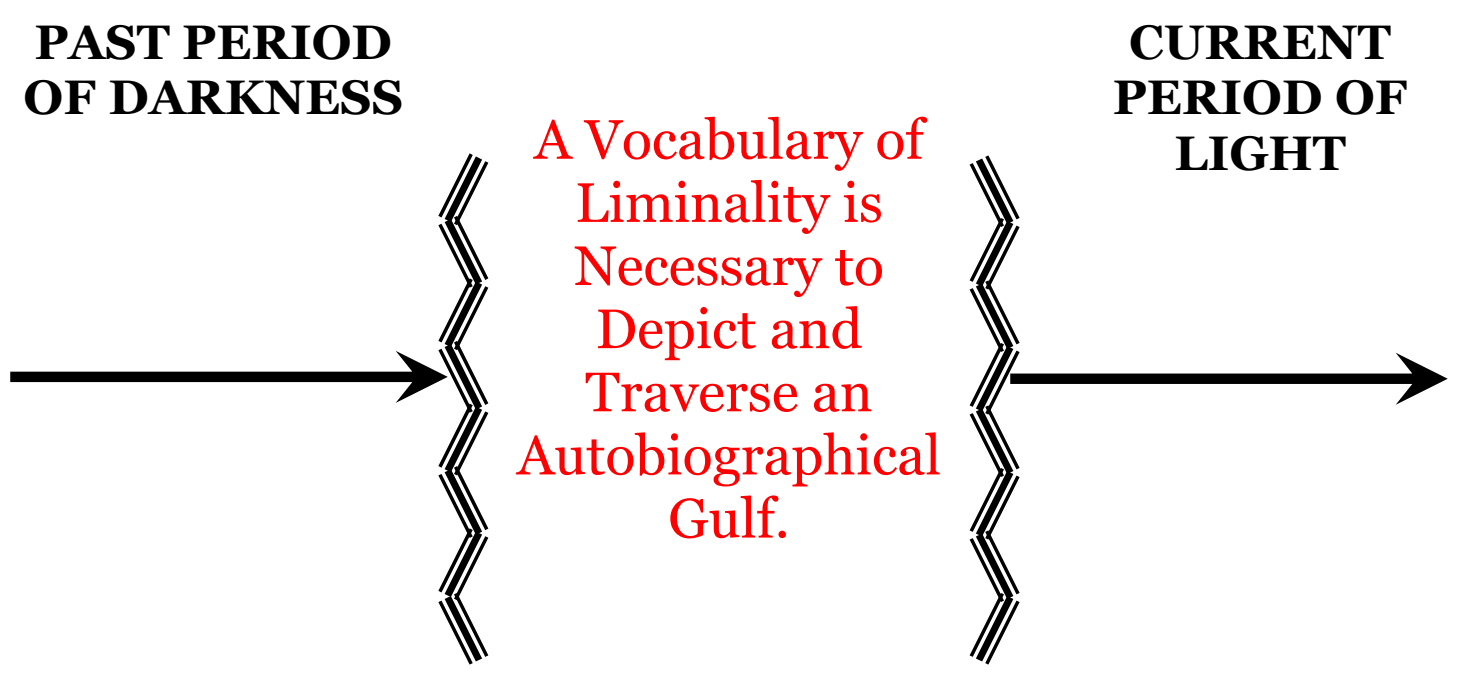


The awakening experience or vocabulary of liminality serves two critical purposes. First, it allows awakeners to treat their past and present as separate, mutually exclusive chunks of autobiographical time. Whether an overwhelming force, a protracted journey, or some combination of the two, vocabularies of liminality provide a narrative "splitting" 109 mechanism that awakeners use to justify ending an older period of life and starting a new autobiographical phase. Such a narrative splitting mechanism also allows awakeners to define each life period by positing a moral contrast between them. Second, it allows awakeners to explain an otherwise awkward shift in narrative standpoint and sociocognitive orientation - from one autobiographical community to another. Unlike the way individuals commonly maintain multiple group affiliations at one time, ${ }^{110}$ awakeners account for their passage between sociomental communities that are in tension with one another. When social groups adhere to antagonistic worldviews an individual cannot be associated with both groups simultaneously. One must do autobiographical work to explain their shift from one to the other. Thus, such autobiographical gulfs and discontinuities are symbolic representations of the sociomental rifts that separate two communities with competing definitions of some significant moral or political concern.

Each of the two purposes served by vocabularies of liminality is exemplified by the structural position of the tunnel in Plato's allegory of the cave. An under-analyzed feature of this well-known allegory, Plato's tunnel provides a buffer zone through which no sunlight passes from the upper world to the lower world of the cave where fire provides the mere illumination necessary to perceive shadows. Without the tunnel, the world of the cave and the world of light would bleed into one another. The cave would resemble a room with windows as opposed to the contained sociomental prison 
necessary to Plato's moral. Consequently, falsehood/illusion and truth/reality would blend together to create a world of cognitive ambiguity. Notably, Plato's escaped prisoner must travel through the tunnel, which provides a figurative passage to cognitive emancipation while also separating his state of emancipation from his past state of bondage. Plato reinforces the gulf between cave and upper world in his comment that one who has seen the light of the sun and attained knowledge of the Good would rather occupy the lowest position of the upper world than the highest position of the lower world. ${ }^{111}$

Just as awakeners use vocabularies of liminality to "split" their past and present life periods, however, they also use such vocabularies to "lump" together a variety of otherwise different events, experiences, perceptions, beliefs, behaviors, and relationships within each period.112 Whereas "splitting entails widening the perceived gaps between entities so as to reinforce their mental separateness," Eviatar Zerubavel explains, "lumping involves playing down mental distances within entities."113 As awakeners use vocabularies of liminality to split past and present eras of autobiographical time, they also engage in a "mental coloring"114 to blend of all the details of each respective autobiographical period so that each is portrayed as one homogenous phase of the awakener's life. This act of mental coloring makes a distinctly diametric moral charging possible, as the past era of ignorance and darkness is typically associated with the "bad" and the current era of knowledge and truth is associated with the "good." 115 Such a mental coloring and binary moral charging is directly evident in Zarathustra's division of the universe into two antagonistic realms - one associated with truth and goodness and the other with lies and evil. Likewise, the diametric moral duality of the universe is the fundamental tenet of the Manichaean rigid division of the 
cosmos into a realm of light and a realm of darkness (an idea that is said to have been revealed to the prophet Mani by a spirit known as "the Twin"116). Such a moral charging is also evident in the theoretical accounts of Kant, Locke, Hobbes, and other Enlightenment theorists who argued that morality stems from enlightened reason or rationality, implicitly linking amorality or immorality to the pre-Enlightenment "dark" ages or state of nature.

To this end, awakeners commonly use symbolic sociomental liminal zones ${ }^{117}$ to describe their experience of awakening and widen the symbolic gulf in their stories, providing for a sharper sense of discontinuity and enhancing the diametric moral charging characteristic of the contrast between their past and present periods of life. Such figurative liminal zones provide a dramaturgical element of setting to complement the props and characters that awakeners use to build their stories and convey their transformative experiences. Thus, awakeners typically use culturally relevant "inbetween" spaces as narrative resources to facilitate the transformative impact of their awakenings. These are culturally defined spaces of receptivity where major changes of mind take place. Saint Paul was struck by lightning on a road in-between Tarsus and Damascus. In the story of Saint Paul, the road, a literal passage way between two points, symbolically compliments Paul's awakening - his cognitive passage from one location to another. Describing his staircase-like awakening to Islam and Black Nationalism, Malcolm X wrote, "Where else but prison could I have attacked my ignorance by being able to study intensely sometimes as much as fifteen hours a day?" 118 Similarly, Arthur Koestler writes,

I spent four months in Spanish prisons, in Malaga and Seville, most of the time in solitary confinement and most of the time convinced that I was going to be shot. 
[...] [Here] I had made the acquaintance of the different kind of reality, which had altered my outlook and values, and altered them so profoundly and unconsciously $[. . .]^{119}$ (emphasis added)

Both Malcolm X and Arthur Koestler experienced profound changes of worldview in prison, a space that is structurally separated from the rest of society and symbolically (and temporally) located in between criminality and reform. Joseph Smith received the "true" vision of Mormonism at night, once in the woods and later in the form of a visit by the angel Moroni as he slept. Nighttime is culturally recognized as a temporary hiatus to the conscious, official world of daytime activity. Freud's patients (along with many survivors of childhood sexual abuse and many "repaired" heterosexuals) awaken to "truth" in psychotherapy sessions - formal meetings that are geographically, temporally, and relationally set aside from quotidian life. Siddhārtha Gautama achieved enlightenment on an extended journey. The prophet Muhammad awoke while retreated to a cave in the mountains. Roman Emperor Julian ("the Apostate") and Fritz (the former Episcopal minister turned humanitarian atheist) awoke while studying at universities. From the perspective of the student, the university (like the prison) is structurally and temporally separated from the rest of life. A figurative liminal zone is also evident in the story of John Newton, composer of the song Amazing Grace. Once a self-described "wretch" and captain of a slave transport ship, Newton is said to have converted to Christianity during a violent storm at sea that almost sunk his vessel. The storm, the sea, and the state of transporting all serve to reinforce Newton's in-between status in the account. After shouting out, "Lord, have mercy on us" during the height of the storm, Newton is said to have received the grace that he later put to music in his most famous hymn. The storm in Newton's story also represents an overwhelming force 
of divine intervention that marked a profound awakening experience, after which Newton adopted a religious worldview and became an Evangelical minister for the remainder of his life.

Such symbolic sociomental liminal zones are also evident in the narrated experiences of self-identified survivors of childhood sexual abuse, who typically describe recovering memories in a therapy session, while watching a movie, during a birthday, or while dreaming, for example. To the same end, veterans account for a change of consciousness during their deployment to a foreign war. Military deployment and war in particular are separated worlds distinguished from "home." They have separate moral codes $^{120}$ and meaning systems. The fact that many Vietnam and Iraq veterans had such profound changes of mind while deployed is not simply a function of seeing war, but is equally a function of being separated from (and at times a function of returning to) “normal life." Likewise, many religious converts awaken in prison, in an Alcoholics Anonymous meeting, or during special visits from Missionaries. Deborah B., a Mormon Convert, writes,

When they were in our home, it seemed as they brought something with them, and when they left it's glow slowly but surely disappeared until the next time they visited. It was a pleasure to have them in our home [...] But learning with them and reading the Book of Mormon opened up a comprehension I did not have before. I knew that what I was learning was the truth, it was as though I already knew it, but the knowledge has been closed to me and the missionaries and church members were helping me to open the door, and little by little the light began to filter in. [...] I do know that this is the truth. The glow that the missionaries once brought to our home, is here now all the time. ${ }^{121}$

The act of sending missionaries "door-to-door" is not only an effective way of reaching large amounts of people in relatively organized fashion, but also places the bearer of truth in the passage between one's personal life space and the outer world. Like Plato's 
ex-prisoner who returns to share the "truth" with his former bondsmen, missionaries cross the threshold into darkness in order to bring the light. Such in-between spaces including special visits, storms, sleeping and dreaming, roads, caves, secluded meetings, deserts, mountains, and the night - allow storytellers to describe their transformative experience by grounding it outside the realm of everyday life.

Awakeners use vocabularies of liminality to center their life-stories on their sociomental transformation, dividing past and present while distinguishing "falsehood" from "truth." The awakening experience is highly marked, central, and sacred in all awakening accounts. It's centrality in a structural sense indicates its centrality in a figurative sense as well. Even when the period prior to the awakening and the period following the awakening take up much greater amount of the narrator's lifetime in an objective sense, the awakening episode often assumes a more highly marked space in the narrator's autobiography. Even though awakeners may describe an experience of awakening that lasts a mere moment or at most a few years, it plays a much bigger role in a narrative sense. This liminal transformative experience takes center stage in the autobiography as a sacred, highly marked aspect of the storyteller's life.

\section{EPISTEMIC PLANES AND OPTICAL NORMS}

While my discussion of autobiographical gulfs, autobiographical discontinuity, and autobiographical periodization focused on the horizontal dimension of the awakening narrative formula (the move from a past period to a present period), I now shift my focus to the vertical dimension (the move from a state of falsehood to a state of truth). Awakeners use vocabularies of liminality to articulate a "mental quantum leap" 
to another epistemic plane. Zerubavel uses the term "mental quantum leap" to describe the experience of traversing socially constructed boundaries. ${ }^{122}$ The term "plane" has geometrical meaning but also means "a level of dignity or character" or "a level of existence, consciousness, or development." 123 Taking a narrative perspective, I borrow these terms to describe the ways that awakeners use vocabularies of liminality to account for their "jump" to a qualitatively different mental state and portray their cognitive emancipation.

When awakeners describe a transformation of worldview, they always move from a figuratively "lower," "darker," and/or "false" plane of awareness to a "higher," "illuminated," "true" plane of awareness. From the awakener's perspective, these distinct ways of seeing and remembering map to a dichotomy of "falsehood" and "truth." From a sociocognitive perspective, such epistemological leaps involve taking on a new set of "optical norms" - established ways of seeing and knowing that are rooted in different communities with defined "optical traditions." ${ }^{24}$ Notably, cultural representations of this dichotomy of enlightenment link "down" with falsehood/ignorance/bad and "up" with truth/knowledge/good. ${ }^{125}$ This vertical structural association is evident in Plato's allegory of the cave, where Plato's hypothetical prisoner is first submerged beneath the ground, contained (physically and perceptually) in the relative darkness of a cave, and later ascends to the surface of the earth, free to move and perceive the world of light. This structural relation is also evident in religious conceptions of "hell" (which, from Zoroastrian conceptions ${ }^{126}$ to more modern descriptions, is associated with an "underworld" or "netherworld") and "heaven" (which is typically associated with the "upper" cosmos), psychological notions that involve raising subconscious or "buried," unconscious motivations to the "surface" 
of conscious awareness, and the political idea that subordinance in political life (as in the "lower" class) maps to subordinated consciousness.

The vertical organization of cognitive emancipation is also evident in William Holman Hunt's The Awakened Conscience (1851-1853) (See Figure 11). In this midnineteenth century piece, Hunt, known for his portrayals of religious conversion, depicts a young prostitute's moment of awakening. As she "sees the light" emanating from a window (perceptible to the viewer only though its reflection in a mirror behind the characters), she rises upward and away from her client-lover, who is left sitting and reclining behind the young, now illuminated woman. Her "conscience," a concept that in the Durkheimian sense and in the French language is inseparable from the concept of "consciousness," is awakened. Given the momentum of her body, she leaves her sexual client in the past as she moves upward and outward toward the light (a vertical organization of experience that is also captured in the common phrase, "take the moral high ground"). Her gaze is directed up and away from her life of prostitution (if she were moving to sit, she would be looking down). In the bottom back left corner of the scene, a cat toys with a captured bird, a symbolic portrayal of the young woman's entrapment in the clutches of her client. Like the bird, she longs to escape up and out to the light (and freedom) emanating though the window. Hunt's painting captures the sociomental structure of the awakening narrative in a visual representation of spiritual transformation. 
Figure 11 - William Holman Hunt's The Awakened Conscience (1851-1853)

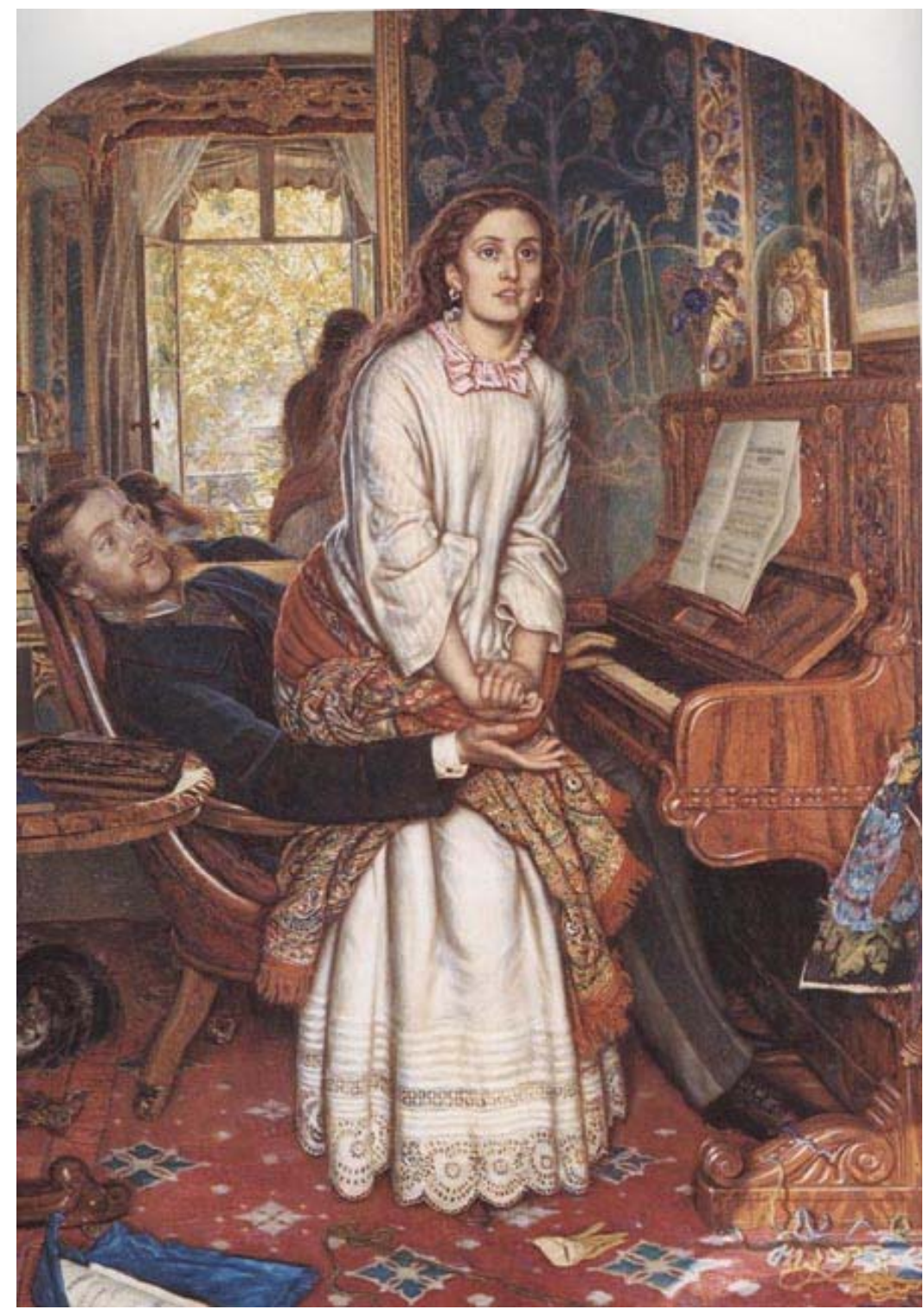


Awakeners use their stories to establish a position of cognitive authority - to strategically establish a position "above" others who subscribe to the worldview that the awakener is now rejecting. They use the social logic of the story formula to establish a cognitive "footing" 127 that derives from the narrated contrast of pre-awakening and post-awakening mindsets. Awakeners link their claims of truth and knowledge to a higher moral and sociomental standing in order to wield their truth as a social power. ${ }^{128}$ Such autobiographical quantum leaps are notably different than the mnemonic "zig-zags" that scholars of narrative associate with previously going "downhill" and now going "uphill." 129 While narrative zig-zags indicate a turning point from decline to progress (or vice versa) as symbolized by a change in slope and direction, the narrative quantum leap indicates a discovery of truth and transformation of consciousness that is best symbolized by a jump to a higher plane of being and knowing (See Figure 12). Regardless of whether the awakener's story is progressive or tragic with regard to their own personal well being, they articulate an epistemic leap in their sociomental status. Many awakeners (for example, many IVAW members or individuals who recover memories of childhood sexual abuse) link a sense of personal deterioration or debasement to their discovery of "truth" that is not sufficiently or accurately described as personal "progress." The quantum leap model thus captures a previously unseen or under-explored sociocognitive and epistemic dimension of our accounts of transformative experiences that is not captured by "zig-zag" models. 
Figure 12. Turning point narrative models compared to an awakening narrative model.

MODEL A: A tragic turning point is typical of victim narratives

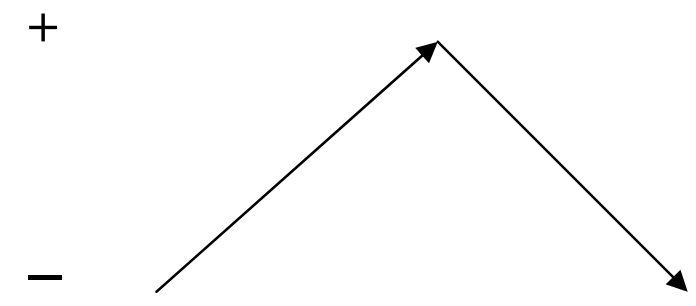

Autobiographical Time

MODEL B: A progressive turning point is typical of heroic or salvation narratives

$+$

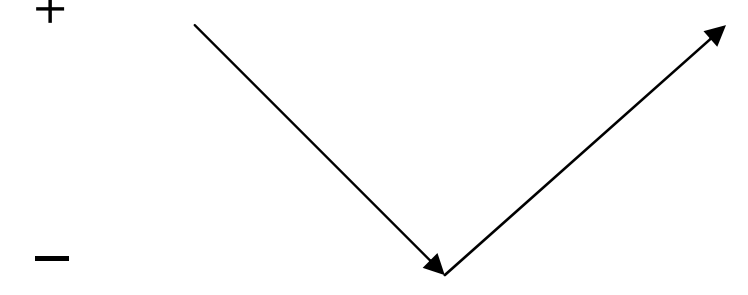

\section{Autobiographical Time}

MODEL C: An epistemic leap is typical of awakening narratives.

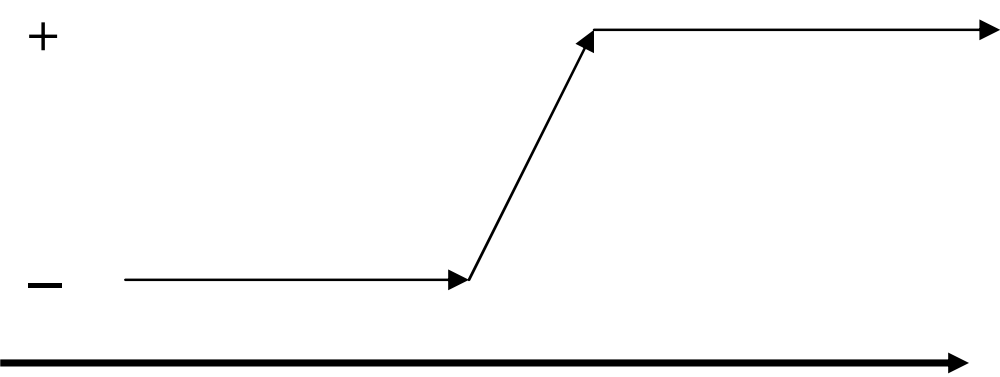

Autobiographical Time 
Focusing on the discovery of truth and superiority of consciousness as opposed to notions of personal or social "progress" and "decline," the awakening narrative formula highlights the epistemological and sociomental dimensions of major life changes. One can have a liminal awakening experience and discover a "truth" that leads to personal progress or decline. In either case, the past and present are always distinguishable by their respective positions on different epistemic planes, regardless of an individual's personal growth or deterioration.

\section{CONCLUSION}

The metaphoric contrast between sociomental express elevators and sociomental staircases heightens our attention to the ideal-typical ways that individuals account for the organization of social forces - including agency, intention, will, authority, and time - when explaining radical changes of mind and justifying their claims to discover truth. These concepts introduce a new sociomental dimension to the question of how individuals ${ }^{130}$ and communities ${ }^{131}$ account for agency in order to cast their roles in social dramas. Awakeners use mental express elevators and mental staircases (at times in combination) to depict and set their liminal personaes in an autobiographical plot as they portray life-changing liminal experiences that separate two distinct periods in their life stories. In the process, they construct and display a sharp epistemic and sociomental discontinuity in their lives. Whether an overwhelming bodily possession ${ }^{132}$ or several years of observation followed by intensive study, ${ }^{133}$ storytellers use such vocabularies of liminality to ground their awakening experience in-between two mutually exclusive moral universes with diametrically opposed worldviews. Individuals use these symbolic 
narrative mechanisms to justify and explain traversing the sociomental gulf between autobiographical communities within contentious autobiographical fields. 


\section{Chapter 5}

\section{The Temporally Divided Self}

"The Yogi looks in the mirror, sees the Commissar, and breaks the glass in rage."

$\sim$ Richard Crossman, Introduction to The God That Failed ${ }^{1}$

Reflecting on his time studying at the Norfolk County Prison in Massachusetts, Malcolm X writes,

I still marvel at how swiftly my previous life's thinking pattern slid away from me, like snow off a roof. It is as though someone else I know of had lived by hustling and crime, I would be startled to catch myself thinking in a remote way of my earlier self as another person. ${ }^{2}$

As Malcolm X accounts for his rejection of one "thinking pattern" in favor of another, he also makes a sharp distinction between his "previous life" and his current life, his "earlier self" and his present, storytelling self. As he rejects his former worldview, Malcolm begins to think of his past self as an entirely different person, as "someone else I know." Moreover, he goes on to strategically undermine and reject that "someone else" in an effort to establish his cognitive authority in the present. By symbolically separating himself into two, temporally divided entities, as well as figuratively engaging, degrading, and defeating his past self, Malcolm X undermines the legitimacy of one mindset and 
bolsters the legitimacy of another. He plays out a sociomental and cultural contradiction in autobiographical form.

All awakeners link their current identities to a newly discovered "truth" and contrast this current sense of self to an old identity that was defined by the awakener's now-rejected worldview. Thus, awakeners understand and articulate "who they are" by negating "who they were." Generally speaking, such identity negations - accounting for who one is by describing who one is not - take variety of forms. For example, in the United States many descendants of Europeans often consider themselves "white" by virtue of the fact that they do not "fit" into any of the more highly marked racial/ethnic categories (such as "black" or "Hispanic"). 3 Further, vegans, virgins, nonsmokers, and straightedge punks define their identities in contrast to those who eat meat, have sexual intercourse, smoke cigarettes, and consume alcohol and drugs, respectively. 4 Likewise, individuals who abandon or exit a long-held identity label like "nun" 5 or "addict" 6 often work hard to leave these labels behind precisely because their current identities are culturally perceived as a rejection of their former roles. In a similar way, awakeners base their newly-established identities on the negation of their old selves. After all, one can only have the experience of "seeing the light" by establishing and rejecting their onceembraced existence in the "dark."

At the level of cognition, awakeners treat the past and the present as mutually exclusive phases of life made separate by a major liminal shift of mind. Structurally speaking, while vocabularies of liminality occur in the middle section of the awakening story (the "starburst" in the center of Figure 1, p. 18), I am now spotlighting the left (or past) and right (or present and future) sides of the story map displayed in Figure 1 with the understanding that these two "acts" or periods in the awakener's autobiographical 
account take on their meaning in contrast to one another. Awakeners portray these past and present periods of life as antithetical with regard to their temporally divided mindsets; they contrast their past and present selves. Further, awakeners portray past and present periods as antithetical with regard to their sociomental affiliations and allegiances; they contrast their past and present communities. Everything within the pre-awakening period of life takes on a unified meaning by virtue of its dialectical contrast with the post-awakening period. Such a temporal division of the life course is exemplified by the Christian account of Saint Paul, who changed his name from Saul to Paul - not to mention his switching sides in the conflict between Pharisees and Christians - after his road to Damascus awakening. Such a strict division of autobiographical periods is also evident in Plato's allegory of the cave, where the structural separation of lower and upper realms symbolizes the temporally divided consciousness of the protagonist. Further, the protagonist's temporally divided consciousness accounts for the sociomental tension between himself and his former bondsmen - he used to be like them and now he is not. In the fashion of Paul and Plato, awakeners typically associate their past era of "ignorance" and "darkness" with an identity-defining cognitive constraint. They associate their current era of "knowledge" and "truth" with an identity-shaping cognitive emancipation. Consequently, awakeners make a subjective epistemic distinction between pre-awakening and post-awakening selves that is much greater than any chronometric measure of time or development. Despite a variety of differences in the ways that awakeners do identity work, they all make a sharp sociomental distinction between past and present selves. Whether they use their awakening stories to signify a "turning point"7 from progress to decline (or vice versa), to advance a "rhetoric of self-change" in order to account for personal 
transformation, ${ }^{8}$ or to adopt a new social role or fill a new identity category, ${ }^{9}$ all awakeners make a sharp cognitive and epistemic distinction between their past and present selves by contrasting their past and present mindsets. Further, they reinforce the distinction between past and present selves by contrasting a community of darkness to a community of light. As opposed to the way that transsexual individuals work to articulate a biographically continuous "true self," ${ }^{10}$ awakeners work to "divorce" the past from the present. ${ }^{11}$ As opposed to the way that identity integrators embrace different identity aspects as parts of their one whole self, ${ }^{12}$ awakeners renounce their past selves. They articulate fractured, antithetical and dueling identities that map to different periods and different sociomental communities in their lives. By focusing on the common ways that awakeners articulate a discontinuity of identity and selfconsciousness when they claim to discover truth and acquire knowledge, I highlight a previously underexplored sociomental dimension of personal life and reveal important narrative tools that various individuals use to do "autobiographical work" 13 in order to portray their lives in strategic ways.

As they divide their lives into discrete autobiographical periods, awakeners perform a figurative interaction between past and present versions of the self. Further, they enact, engage, and symbolically defeat their past self in order to take position in a cultural conflict between different autobiographical communities within a contentious autobiographical field. By symbolically undermining and defeating their past selves, awakeners symbolically undermine and defeat their former communities. They use autobiographical time to distance their current community of "truth" from a former community of "falsehood" as they describe a cognitive migration - a shift in cognitive allegiance - from one community to the other. By considering these sociomental 
dimensions of autobiography, I highlight the ways that various individuals and communities use life stories and perform temporally divided selves to make knowledge claims, mark the cognitive boundaries between mutually exclusive and antagonistic social groups, and weigh in on significant cultural tensions and moral concerns.

\section{THEORIZING THE DIVIDED SELF - FOUR TRADITIONS}

In order to analyze the way awakeners strategically portray a temporally divided self, I consider four theoretical traditions that have advanced the notion that the self is somehow "divided." These are the psychodynamic, the Simmelian, the Meadian, and the late modern/post-modern traditions. I build on aspects of each of these traditions to show how awakeners use a temporally divided self to express cultural tensions in autobiographical form.

\section{The Psychodynamic Tradition}

In the psychodynamic tradition, the self is divided by an internal conflict and has an unconscious dimension laying in wait of discovery. Building on Freud's psychoanalytic theory of the unconscious, both analytic psychologist Carl Jung and existential psychiatrist R. D. Laing posited unique versions of this "divided" self. Both psychological thinkers deviated fairly significantly from classical psychoanalysis. However, both shared Freud's skepticism of traditional neurobiological perspectives on mental illness and both maintained a strong commitment to the dynamic analytic process. 
Jung argued that the self includes both conscious characteristics and an unconscious "shadow self" which contains the most undesirable attributes of our personalities. ${ }^{14}$ According to Jung, failure to raise the "shadow self" to the level of conscious awareness leads to the "projection of the unrecognized evil into the 'other"' 15 and causes both interpersonal and intergroup conflict in the world. For Jung, we must bring this "undiscovered self" to light or we will impose our psychic conflicts on the outer, social world. Notably, Jung also advanced the idea of a "collective unconscious" (breaking from Freud) to argue that part of every individual's undiscovered self includes a "second psychic system of a collective, universal, and impersonal nature" which gives "definite form to certain psychic content." 16 For Jung, the collective unconscious was testament to our shared, ancestral heritage as human beings. The "shadow" was a universal human archetype - a "moral problem" with an "emotional nature."17 However, the unrecognized shadow manifests in our personal unconscious and our "projections change the world [as we see it] into the replica of one's own unknown face." ${ }^{18}$ Further, this act of projection "is an unconscious factor which spins the illusions that veil [one's] world."19 To live without conscious awareness of our shadow, according to Jung, was to live a life of illusion, a life defined by ignorance of the self and of the true nature of the world.

Alternatively, Laing posited the notion that the individual's psyche is a reflection of one's lived experience. Laing developed the concept of "ontological insecurity" to argue that the psychotic individual does not develop a secure sense of his "relatedness to others." 20 Consequently, he "may feel more unreal than real" and develop a sense of being separate from himself (thus a "divided self") as he works "to prevent himself from losing his self." ${ }^{21}$ One of the main characteristics of such individuals is that they cannot 
develop a steady sense of biographical continuity. Later, Laing developed this psychosocial view and argued that psychoses occur when individuals experience conflicting and often irreconcilable demands (what he referred to as "double binds" or "knots") from different social groups (especially the family). ${ }^{22}$ Thus, in advancing a theory of a psychotic self divided by irreconcilable social conditions, Laing argued that the communications and behaviors of the psychotic individual can be understood as "expressive of his existence" 23 - as an expression of the individual's adaptation to contradictions in the world of human relations.

Jung theorized from the psyche outward, arguing that social conflicts have inner, psychic origins. Laing theorized from the social world inward, arguing that psychic conflicts reflected social tensions and antagonisms. Despite these differences in orientation, both psychological theorists advanced a view of the self divided by conflicting components or opposing forces with internal and external manifestations. For both, the divided self is mirrored by a divided social world.

\section{The Simmelian Tradition}

Georg Simmel theorized that an individual is unique in that "he comes to stand at a point at which many groups 'intersect"” and becomes "confronted with the task of reconciling within himself a diversity of group-interests." 24 Focusing on the properties of group membership and the organization of social structure, Simmel was one of the first to posit a "self" that is divided by a simultaneous commitments to multiple and competing social roles that correspond to various "group-affiliations." This idea would later be developed in different ways by Merton"25 (as "role" and "reference group" 
theory), theorists of "Intersectionality," ${ }^{26}$ and those who advance the notion that roleswitching involves sociomental management work. ${ }^{27}$

While conceiving the individual as defined by multiple group affiliations, Simmel did not explicitly consider the temporal dimension of the intersection of group affiliations. In her study of Brazilian youth activist networks, Ann Mische remedies this shortcoming by showing how we can "consider individuals as the intersection of a set of groups through which we pass over time, that is, their trajectory of overlapping affiliations." ${ }^{28}$ Further, Simmel did not explicitly consider situations in which mutually exclusive and antagonistic communities compete for the allegiance of individuals and, further, how this competition might lead to individuals who are defined by a temporally fractured intersection of group affiliations. In such cases, individuals cannot be a part of two (dueling) communities simultaneously but can be affiliated with one group at one time and one at another, later time. Yet, in such situations both groups remain vital to the individual's sense of self. By expanding Simmel's notion of the individual to include multiple time frames, we open the door to a more complex understanding of the way group affiliations shape our identities and the stories we tell about our lives. By combing this temporal view of multiple group affiliations with an explicit consideration of communities divided by sociomental antagonisms, we can consider how awakeners are defined by multiple yet divided group affiliations over time. The awakening individual is a temporal multiplicity of group affiliations that includes the negation of one community as a condition of the embrace of another. While the awakener's past group affiliation is temporally expired, it continues to play an active role (via its negation) in shaping the awakener's present identity. 


\section{The Meadian Tradition}

Building on Cooley's notion that our "looking-glass self" emerges from the way we imagine other individuals see us - from an "imputed sentiment" or "the imagined effect" of our reflection in another person's mind, ${ }^{29}$ George Herbert Mead argued that the self is constituted by different components he referred to as the "I" and the "me." Mead's "me" symbolizes the dimension of self that is defined by the social world - the self that exists as "the organized set of attitudes of others which one himself assumes."

Alternatively, the "I" is the more spontaneous, freely acting part of the self that acts as "the response of the organism to the attitudes of the others." 30 These two dimensions of the self, according to Mead, take form in an inner conversation or dialogue that allows us to engage the social world. ${ }^{31}$ Without the capacity for an "I" we would not have any sense of ourselves as independently acting individuals. Without a capacity for a "me" we would not have any sense of our fit within a community.

Furthermore, Mead also recognized a temporal dimension of this inner dialogue when he wrote,

the "I" in memory is there as the spokesman of the self of the second, the minute, or the day ago. As given, it is a "me" but it is a "me" which was the "I" at the earlier time. If you ask, then, where directly in your own experience the "I" comes in, the answer is that it comes in as a historical figure. $3^{2}$

Thus, according to Mead, we act as an "I" but only end up knowing or reflecting on this "I" in retrospect, after it has ceased to be an "I" (an acting agent) and becomes a "me" (a socially determined self defined in hindsight). When we reflect on ourselves, our acting, reflecting "I" portrays and engages various "I's" that have expired. As we portray our 
acting self of the past, we speak (with agency) of it and thus define our old "self" from our present position. Mead provides a more general articulation of this temporal phenomenology when he writes, "a reality that transcends the present must exhibit itself in the present [...] and from that standpoint rewrites its past." 33 Just as we impose our social "attitudes" on others, we impose them on our past selves. By considering this temporal dimension of self interaction to be an intersubjective (that is, social) process, 34 Mead explicitly addresses some of the shortcomings of Simmel's approach. Further, as Mische notes,

Mead's core idea of "sociality" refers to the capacity of individuals to be both temporally and relationally in multiple systems at once. He argues that the human experience of temporality is based in the social character of "emergence," that is, in interrelated changes occurring throughout the multiple levels of organization within which human beings are embedded. The problematic experience of these intersecting changes leads to reflective evaluation of the past and deliberation over the future. 35

Thus, our present storytelling "I" actively portrays and mobilizes various "me's," which take form as narrative constructs as we engage in ongoing dialogue with others and project ourselves into the future. ${ }^{36}$

Mead's theory of self-interaction spawned the school of symbolic interactionism and gave rise to the general idea that the self emerges as a dialogical entity involving both intrapersonal and interpersonal "conversations." 37 These conversations are set in what Goffman called "occasions" 38 or "situations" 39 in which individuals attribute meaning to the world via an "interpretive process" that occurs in "the social interaction one has with one's fellows." 40 Some have built on Mead's attention to temporality to theorize the self as a trialogic entity in which present self (the "I") engages with the past 
and future selves. ${ }^{41}$ These theories of narrative temporality and other studies in symbolic interaction have illuminated the processes by which we come to understand who we are and our relationship to the world around us by engaging in dialogue with others, including other aspects and older versions of ourselves.

\section{The Late-Modern and Postmodern Traditions}

Drawing from the psychoanalytic, Meadian, and Simmelian traditions, various contemporary theorists have posited a "self" riddled with the tensions and insecurities of an increasingly fast-paced, complex, fractionalized, and unstable world. Highlighting the growing tensions of "late-modernity," Giddens argues that the self is a "reflexive project [...] which consists in the sustaining of coherent, yet continuously revised, biographical narratives" in a world wrought with "high-consequence risks," multiple and competing authorities, and the constant potential for overwhelming existential anxieties..$^{2}$ Advancing a post-modern, deconstructionist view, Gergen argues that the self is "saturated" and we come to feel "each truth about ourselves is a construction of the moment, true only for a given time and within certain relationships." 43 Gergen advances the Foucauldian 44 and post-structuralist 45 view that the self is a discursive formation. Despite many differences, theorists in these late-modern and postmodern traditions typically argue that the individual is faced with the task of navigating a complex and tension-filled social environment where various forces compete for our biographical or ontogenetic allegiance. Here, the self is viewed not only as a tenuous discursive construction, but as a locus of conflict and the production of power. 
Building on these four traditions, I am interested in the ways that awakeners portray a figurative interaction with a temporally expired version of self. From the psychodynamic tradition, I borrow the notion of a self marked by inner conflict and yet nested in a divided social world, as well as the foundational theme that an unconscious dimension of the self is laying in wait of discovery. From the Simmelian tradition, I follow Mische and build a temporal component into the idea of the self standing at the intersection of social circles to theorize the awakening self as an agent who navigates multiple yet contentious or antagonistic social worlds through time. From the Meadian tradition, I develop the notion of doubly dialogical self - the self as a product of both inner and outwardly oriented dialogues and interactions - that takes form with attention to both the past and future. From the late-modern/postmodern tradition, I view the self as a reflexive project and a discursive, narrative construct. Building on these insights, I explore the ways that awakeners construct and portray a temporally divided self in order to express cultural (cognitive and moral) tensions in autobiographical form. More generally, I consider the cultural significance of the temporally divided self to build an understanding of how individuals and communities use awakening narratives to advance a particular worldview and undermine competing versions of truth.

\section{PORTRAYING THE TEMPORALLY DIVIDED SELF}

As awakeners make a temporal distinction between their "false" and "true" views of reality, they perform a figurative interaction between the split personas of a temporally divided self. Like Malcolm X speaking about his pre-awakening criminal life 
or the Christian apostle Paul describing his pre-Damascus existence as a Pharisee who violently persecuted Christians, awakeners commonly describe their past self as if they were talking about a completely different person - one who is "lost" or "blind" to reality. As Denzin notes, such a "second self is a temporal production, lodged in the past but told in the present." ${ }^{6}$ Just as formulaic "dramatis personae" give shape to the folktale, 47 past self and present self function as different characters - ignorant antagonist and enlightened protagonist - that interact in the awakening account and give dramatic life to the story. From a narrative perspective, the awakener's past self has a symbolic, functional position in his/her present life.

Carol, a self-identified survivor of childhood sexual abuse, writes,

I was so young and dumb that I thought it was really a game that big people play and I played like that with my sisters and cousins thinking that I was grown up because some one had taught me what adults did. 48

As Carol recalls her childhood sexual abuse, two versions of self are present - one who is "so young and dumb" the she "thought it really was a game" and one who tells the story, realizing that she was deceived and taken advantage of. In just a few words, Carol makes a distinction between different and mutually exclusive periods of her life that is rooted in her perception and understanding of significant experiences and relationships. It is not that the objective occurrences of her life have actually changed, but rather her perception of them. The social act of writing her story involves establishing a sharp distinction between her past and present mindsets. Carol-as-autobiographer takes a distanced, critical standpoint as she portrays and rejects the perspective of the Carol-asautobiographee - a past version of self who was abused and then unknowingly recreated that abuse with sisters and cousins in her story. She performs a sociomental tension 
between herself as "animator" (the one who transmits the story, bringing it to life) and her past self as "principle" (the described self "of the embedded, reported action"). 49 In the process, she uses her autobiographical account to establish the position of "victim" and levy a controversial accusation in a cultural milieu where memories of childhood sexual abuse are highly suspect.

In a similar vein, those who retract or reject once-recovered memories of childhood sexual abuse also contrast their past and present mindsets to establish a temporally divided self. In a letter to her parents, who she previously accused of sexually abusing her, Dora writes,

Never again will I allow myself to lose control of me [...] Please [...] believe I am now me. And most of all, please believe that monster was NOT me. That monster is dead. 50

In this desperate plea to her parents, Dora completely dissociates her pleading, letterwriting self from her past self - the out-of-control "monster" who once believed she was sexually abused but is now "dead.” Adopting the terminology of sociologists Richard Ofshe and Ethan Watters, whose book Making Monsters ${ }^{1}{ }^{1}$ advances a scathing indictment of recovered memory therapy, Dora uses her personal account to lend credence to the notion that those who make accusations of childhood sexual abuse based on recovered memories are not only wrong, but diabolical. Like Carol, Dora uses her temporally divided self to take a position in an ongoing cultural controversy over the veracity of claims concerning childhood sexual abuse. As she posts her story to the website of the False Memory Syndrome Foundation, her past "monster-self" becomes a proxy for others who make accusations based on recovered memories of childhood sexual abuse. Jon, a member of Iraq Veterans Against the War, expresses a similar 
sentiment when he says, "I am no longer the monster that I once was." ${ }^{2}$ In Jon's case, his past self serves as a proxy for soldiers who are actively and unapologetically waging war in the Middle East.

Similarly, Tina, an apostate to the Mormon church, writes,

Do I think most of the mormons I've known are either dishonest, ignorant, or stupid? Yes. And so was I when I was there [...] I was dishonest in trying to believe that "we" were in the One and Only True Church [...] I was ignorant because I only listened to the adrenalin rushes that burned my bosom instead of also looking at facts [...] I was stupid when I let my ex husband have Priesthood Power in our house [...] I was stupid when I believed that Ezra Taft Benson was a prophet [...].53 (emphasis added)

Like Carol, Dora, and Jon, Tina takes a distanced, critical perspective as she describes and undermines the person she used to be. She crafts a literary picture of her past self and depicts that character as "dishonest," "ignorant," and "stupid" in order to discredit her former mindset along with others who currently subscribe to that worldview. As Goffman notes, such a "self-deprecator [...] is not the self that is deprecated. [One] secretes a new self in the process of attesting to the appraisal he is coming to have of himself.” 54 Further, Tina uses her autobiographical standpoint to engage in a cultural debate over the nature of ontological and ecumenical "truth." In a similar vein, an awakener who goes by the name "Tinkling Brass" expresses a common sentiment among apostates to the Mormon church when he writes, "I am embarrassed to admit that I could have ever been so completely taken in by a con-man [Joseph Smith] that lived nearly 200 years ago.”55 Likewise, Hamar writes,

I have said many times how embarrassed I have been that I truly believed in the whole package for 30 years before I and DW had our awakening. I think many of us that have finally realized how silly it all really is scratch our heads and wonder how we could have been so blind for so long. ${ }^{5}$ 
Likewise, Bardman writes, "my recovery from mormonism is nearly complete. My former life seems almost like a dream." ${ }^{77}$ Another apostate who goes by the name "Life Rocks" writes,

Leaving off your garments...realizing that there will be no lightening striking...and recognizing that it's a process coming out of the shadows of a faith in something that will almost embarrass you that you believed it at all. (I was so committed to the Church...I should have been committed) 58

Despite many differences between people who "recover" or "retract" memories of childhood sexual abuse, Iraq war veterans, and people who abandon a religious faith, each of these storytellers articulates a duality of self marked by a temporally divided consciousness. Like David Horowitz, the New Leftist-turned-conservative pundit who describes his past self as "self-righteous and arrogant and blind,"59 these awakeners convey a self-interaction characterized by antipathy and antagonism in order to weigh in on an ongoing controversy over meaning. While describing their personal awakenings, they portray and perform cultural tensions between different optical communities.

Just as apostates construct a temporally divided self to weigh in on the contentious issue of ontological truth, so do religious converts. While retrospectively describing his Roman Catholic past as "sinful," Van Patrick, now a Born Again Christian, writes, "I didn't know I was a radically-depraved and God-hating person" (emphasis added). ${ }^{60}$ Van Patrick explicitly conveys the sense of discovery that is inherent in every awakener's construction of a temporally divided self. While he once was living in symbolic darkness, he did not fully grasp his state of cognitive constraint until he awoke to "see the light." Highlighting the epistemic distinction behind such conceptions of a 
temporally divided self, Johnny, a Mormon convert writes, "I went from not understanding life to knowing exactly what everything means [...] I would hate to think about where I would be if the church didn't find me." ${ }^{61}$ Jerry, who came out as gay after being "ex-gay" writes, "If someone had told me a few years ago that I would one day be an out, proud gay man, I would not have believed it." ${ }^{62}$ Similarly, apostate MsGabbie2u writes, "I discovered me."63 "Warmfuzzylogic," another apostate, writes, "I didn't understand that the church was controlling everything," and "the remainder of my life will be lived at a level of happiness that I didn't know existed in my youth." ${ }^{4}$ Likewise, describing his transformation into a new, heterosexual self, Scott writes, "I was becoming what I was attracted to in others." ${ }_{5}$ Expressing a similar sentiment, Frank writes, "I have become transformed. I have experienced physical changes in my voice, and most importantly, I have experienced emotional changes [...] I have indeed become a man." 66 In a similar vein, Rod, a Born Again Christian, uses a photograph to portray his past drug, sex, and alcohol-abusing self, commenting, "My life was such a confusing mess when I was 30 years old, and I thought I was living in a world that every man wanted" (emphasis added) (see Figure 13). ${ }^{67}$ Like other awakeners, Rod takes a distanced and critical perspective on his past self as he redefines his past relationships and experiences, undermines his former worldview, and testifies to his newfound reality. He uses his story to engage and undermine this past version of his self from his newly-found narrative standpoint. 
Figure 13. Rod Manney displays, engages, and undermines his past self in his story, "Drugs, Sex, and Booze Just Don’t Get It!"

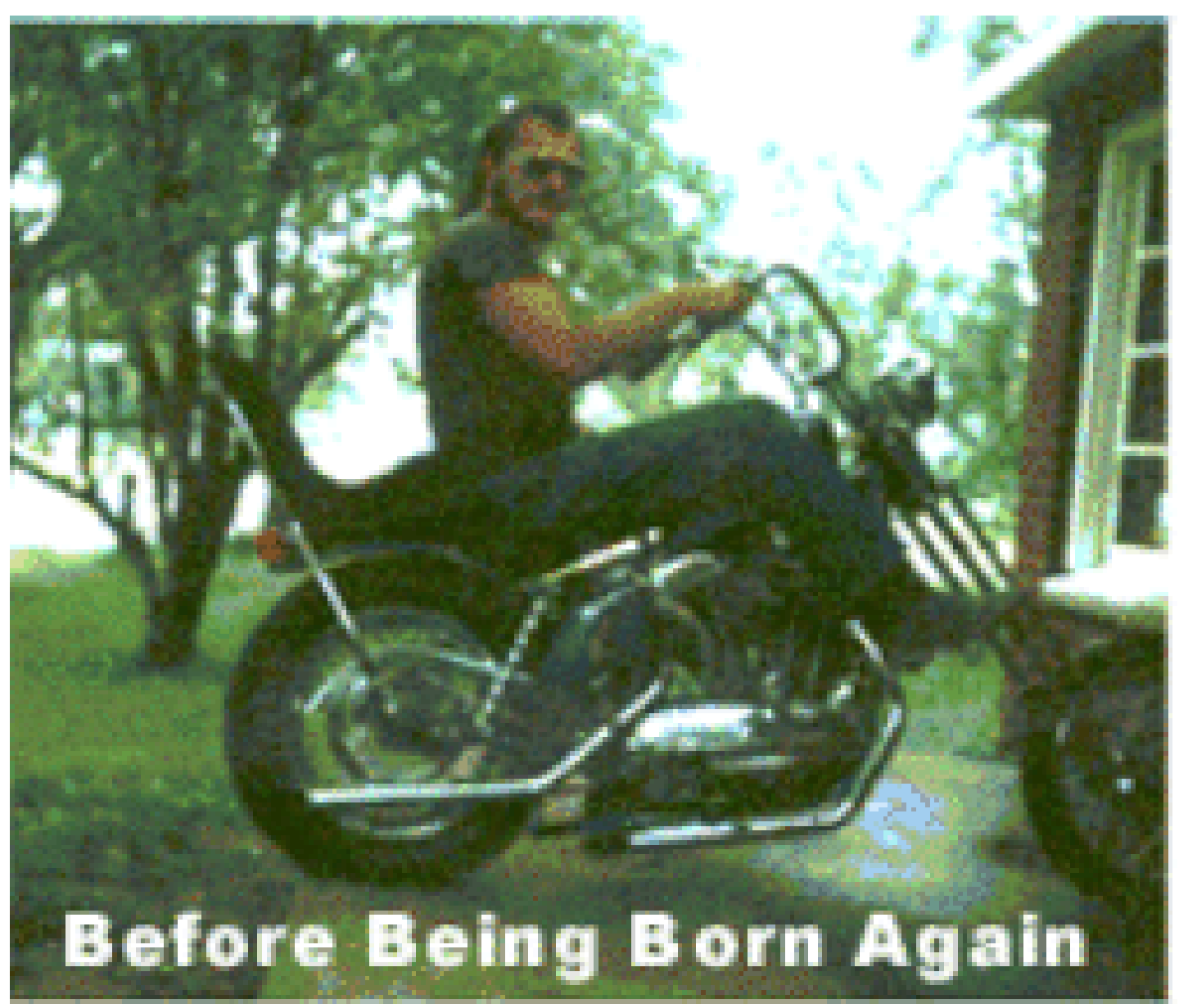


Similarly, Brooke uses photos to contrast her pre-awakening, punk-rock, pagan self with her enlightened, Born Again self (see Figure 14). ${ }^{68}$ While contrasting her past and present selves, Brooke comments, "I had been in such deep darkness for so long, that coming into the Light was a slow and delicate process." Notice the striking difference between her pre-awakening and post-awakening appearance and manner. ${ }^{69}$ As Brooke portrays a figurate interaction between past and present versions of herself, she displays each of these characters in different costumes. Further, she expresses the cultural antagonism between her past and present communities not only as a question of worldview, but also lifestyle. Brooke, like Rod and other awakeners, uses her past self as both ignorant protagonist and literary foil, a character in her autobiographical drama that makes her present self appear morally superior by contrast. 
Figure 14. Brooke, a Born Again Christian, posts three pictures with her awakening story. The first two portray her past self and the last portrays her present self. The captions read in order, "Before Deliverance," "Brooke on Billboard," and "Brooke Now."
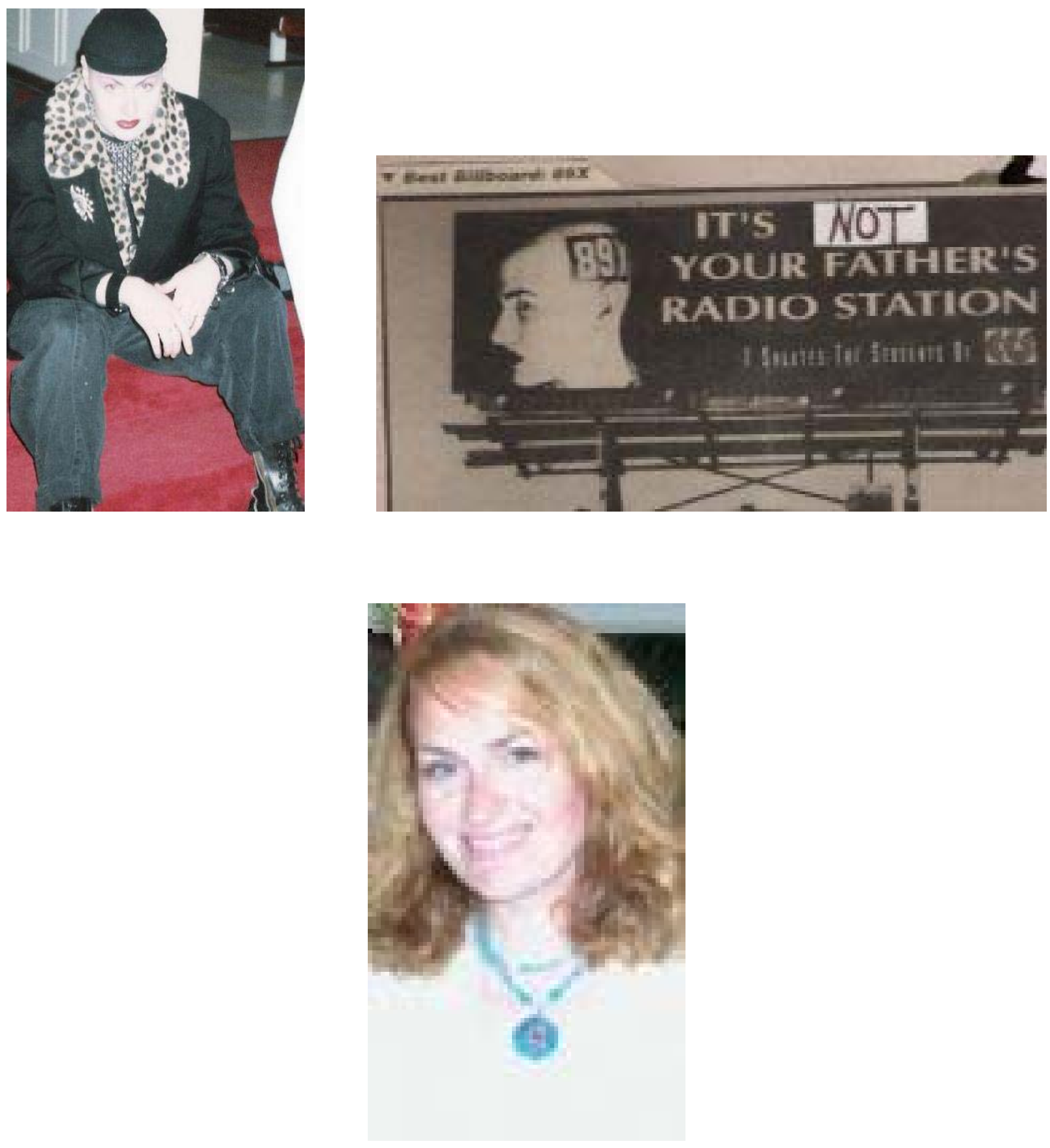
The temporal partition between separate characters in these awakening narratives demarcates a cultural tension between different-yet-contemporary autobiographical communities. Awakeners portray a duality of self in order to personify different socially-rooted worldviews and cognitive norms. The dueling versions of the self - the main characters in the account - serve as symbolic proxies for social groups with contentious perspectives on some significant moral or political concern. Just as anthropologists have used historical time to distance their own cultural group (typically the cultural in which they received both primary and secondary "optical socialization" ${ }^{\circ}$ ) from their culture of study, ${ }^{71}$ awakeners use autobiographical time to distance their current community from a community of "darkness." From a narrative perspective, awakeners perform their "self as a soliloquy" 72 and the social interaction between the "lost" and the "found" is contained and performed within the awakener's autobiography. As awakeners symbolically overcome their past self, they establish a unique epistemic, cognitive, and moral footing - a socially founded right to be self-assured about their present system of beliefs because they have "seen the darkness" and can therefore testify to the false nature of the rejected worldview. This socially established cognitive authority explains why many religions hold converts and returned apostates or "prodigal sons" in an even a higher regard than those who always believed. The convert and the prodigal son, like the awakener and re-awakener more generally, provide living testimony to long-time believers that darkness awaits outside the fold.

Such a socially established cognitive authority also explains why the modern antiwar movement holds anti-war veterans in such high regard, often positioning them at the front of marches and rallies. Sean, a member of Iraq Veterans Against the War, comments, "like so many Americans, I lapped up the spoon fed garbage the government 
fed me and went off to war. It took me over 2 years after I got back home to realize what a fool I had been".73 Daniel, another IVAW member, writes,

I enlisted in September 2005 as an Army Reserve MP. I served three years, from Ft. Leonard Wood, Mo - to Bocas Del Torro, Panama. What I saw in those three years changed a gung-ho MP, ready to kill for God and Country, into a Conscientious Objector willing to die for the truth. 74

Both Sean and Daniel portray their temporally divided selves to weigh in on a morally and politically salient debate over the character of the ongoing wars in Iraq and Afghanistan. They contrast their past and present selves in order to undermine their former political worldviews and justify their current convictions. In the process, they work to discredit others who currently subscribe to their former, pro-war ideology. Despite many differences among these anti-war veterans and the various awakeners cited above, all portray a duality of self marked by a temporally divided consciousness.

To this end, Victor combines photographs of his past self with text to facilitate the figurative interaction between past and present personas in his account (See Figure 15). Victor's photos are accompanied by a caption describing his political awakening on the Iraq Veterans Against the War website. Notice how he switches voices - from the third person (describing the photos as if he were talking about someone else) to the first person to distinguish between his past and present selves. The captions reads,

Former active duty Army Intel Analyst who joined an Army Reserve PSYOPS [psychological operations] unit shortly after 9/11, after a five year break in service, just in case his country needed to call on seasoned ex-warriors for the war with Afghanistan -a war he thought was justified. Having served in Iraq in 2003, where he was awarded the Bronze Star Medal, he has since given up any beliefs he held about the Global War on Terrorism being waged honorably by the current Administration. [switch in voice] You don't defeat terrorism by becoming a terrorist. 75 
Figure 15. Victor, an anti-war activist, displays pictures of his self at war to establish a temporally divided self.
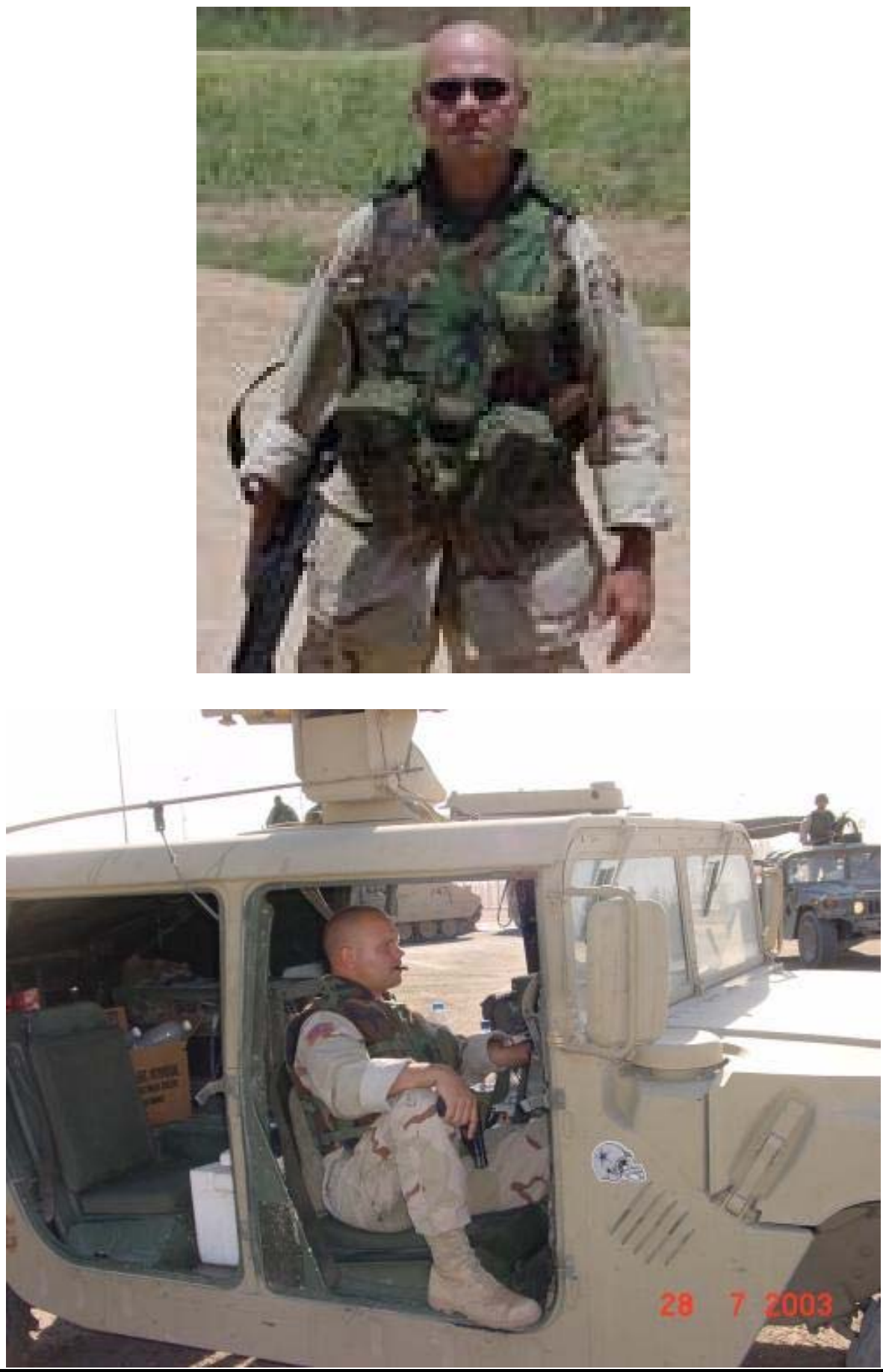
Victor, like many other members of Iraq Veterans Against the War, uses photos to authenticate his veteran status. However, these representational photos only take on meaning because his autobiographical caption serves as a storied performance of his "reorientation," in the terms of Robin Wagner-Pacifici's "political semiotic." Victor displays his old identity as he undoes it and redefines it. Using a change in voice to distance his present, storytelling self from his past self, he performs the "positioning of a new identity after the undoing of the old." ${ }^{6}$ Gayatri, a self-identified survivor of childhood sexual abuse, uses a similar strategy when she writes,

The only problem was that her friend's father was a monster. He would want to play monster games and he had big monster hands. He would hurt the little girl with his hands [...] But he said it was a nice game.77

Speaking about herself in the third person, Gayatri describes her childhood perspective in order explain how her abuser masked sexual contact and led her childhood self to perceive it as a "monster game." She distances her past and present selves as she portrays her past self as a proxy for child victims who are too young to comprehend sexually abusive experiences. As a self-identified survivor posting her account to the Safeguarding Our Children - United Mothers website, Gayatri now clearly understands her experiences, not as a monster game, but as sexual abuse. As she portrays her temporally divided self, Gayatri both describes and undermines her childhood view of important experiences and relationships. Likewise, Victor undermines his former beliefs and actions by describing his past self as a "terrorist." In the process, he portrays his past self as a proxy for others who currently justify the war as an effective venture of counter-terrorism. 
To the same end, Paul and other members of Iraq Veterans Against the War reenact scenes from the Iraq war as "street theater" in the United States. Staging battle scenes not only allows veterans to expose and confess their war time activities to a civilian audience, but allows them to separate themselves from these activities, which are now "keyed" 78 as a skit, and redefine them as they undermine the justification for war in their present performances. By reenacting a wartime scene, Paul portrays his past soldier life from a present, critical standpoint - that of an awakened anti-war activist who is "reliving the nightmare" of Iraq. However, for Paul this event was more than just a political action, it was an evocation and embodiment of his past self. He writes,

It was just like I remember it, the screams, the detentions, the pushing, and the chaotic reaction as we put our imaginary rifles in their faces. It was real, very real [...] Personally, as soon as we began patrolling the streets, I caught myself slowly shifting into the role I had once performed on the streets of Iraq. Perhaps people saw us and thought us to be acting, but I can only say of myself, after a short period I found myself honestly checking windows of tall buildings looking for snipers. My arms had become rigid as if they were made to hold a rifle. No longer was an alley just that, they all became danger areas I needed to use increased vigilance while crossing. In short, within just a short while I was reliving a nightmare $[\ldots] 79$

Not only did Paul assume his past mindset, but he also assumed the "direct embodiment" of his past self, the "inculcation of the dispositions" that once "remodeled [him] according to the specific demands of" 80 the military and war. Even the world changed around him as he performed his past self. After the event, Paul also relived his post-war transformation of self. He writes,

Once the action had ended, I was able to slowly re-emerge from the soldier I once had been what seems like a lifetime ago. As time went on, I gradually checked windows for snipers less and less. It became easier to walk by an alley without checking it for "the enemy." Most importantly, I viewed people as, not a potential threat like I had during the patrol, but as what they really were, Human 
Beings. It was a reminder to how much we dehumanized each other while at war, and I was thankful that I was able to recognize how wrong engaging in such a process of degradation is. ${ }^{81}$ (emphasis added)

Such strategic reenactments of the past self take a variety of forms. For example, Sylvia Fraser uses a childhood voice to perform her past, abused child self when she writes,

I cry when my mother puts me to bed. I didn't used to be afraid of the dark but now I know that demons and monsters hide in the cubbyholes of my bed. I am afraid one will jump out at me, and rub dirty dirty up against me with his wetums sticking out. 82

Fraser, like Abernathy and other awakeners, gets into character in order to perform a temporally expired version of self. In the process, she makes a sociomental distinction between past and present mindsets in her life. Likewise, Julia Sweeney performs various manifestations of her past Christian self as she accounts for her religious apostasy in her live performance, "Letting go of God." 83 Notably, Sweeney opens her performance by describing an interaction with her father that occurred on the morning of her seventh birthday, at which time he told her (and she believed) that she was "now capable of committing any and all sins against God and Man.” Sweeney portrays her seven-yearold self in order to begin undermining her former religious beliefs and start sketching a critical picture of her former religious community. Like Paul, both Sylvia Fraser and Julia Sweeny perform their past selves to convey important transformations of mind in their stories.

When portraying a temporally divided self, all of these awakeners use various narrative devices to distance their present selves from their past selves. To achieve such an autobiographical distance, Christine recalls her childhood sexual abuse in a second 
person voice, describing it as if it is happening to an alternate "you" when she writes,

"Frank H., your mother's boyfriend, raped you when you were eleven years old." 84

Likewise, Linda accounts for a temporally divided self by explaining her tendency towards dissociation. She writes,

As I write this, I'm stepping so far away from it that once again it seems like it happened to another person and not to me. I became so adept at distancing myself from his abuse as a child that as an adult it's difficult to stay present long enough to talk about what he did. I feel as if it happened to someone else and my mind took a video of it for me to take out and look at it from a safer distance. 85

Dan uses a related discourse of repression when separates his a "repaired" heterosexual self from the injured "inner child" that, he believes, was the root cause of his past homosexual self. He writes,

By establishing contact with this subconscious, inner child, I was able to find out each day how my inner child was feeling and what his needs were. Then I could consciously find ways to either help my inner child understand and deal with his inappropriate feelings or find ways to meet his needs in a healthy way. In a sense I became parent to myself. I was amazed at how resourceful my adult self could be when it was asked to parent my inner child. I was also amazed at how much my inner child could tell me about things that were repressed. Over the months I was able to raise those unconscious feelings and fears to a conscious level where I could deal with them and get past them. ${ }^{86}$ (emphasis added)

Later, Dan reflects, "looking back, I am astonished that I was so blind, that I was in such a state of denial [...] I faced my shadow, my demon, and walked away a new man [...]" 87 In a striking example, Yvonne, a self-identified survivor of childhood sexual abuse, distances her present self from her past self by splitting her life into two personas, each with a different name. She recounts the death of Anita and the birth of Yvonne in a third person voice in her account titled "Becoming Yvonne." She writes, 
Earthly years place her at nearly thirty seven and yet she is only nine and a half months old [...] Nine and a half months ago Yvonne was born [...] as she looks out to sea she sees that the immense space ahead portrays the beginning of her life [...] Like a chick that gains strength from breaking its own shell, Yvonne had to enable her birth herself [...] Nine and a half months ago Anita was released [...] Yvonne, Anita can now after thirty six heavy and exhausting years hand over her physical body. She knows that Yvonne will take better care of it than she did [...] Anita knows that in Yvonne all her dreams that were so horribly taken from her, the dreams that she only dared to dream of in her make believe garden that she escaped to when bad things happened, in Yvonne these dreams can become true. 88

Marking her divided self by a shift of "belief system," she continues,

Yes Anita is ready to let go, she has sorted her lost memories, she has sorted her coping strategies, she has sorted her misplaced loyalties, she has sorted her wrong belief system out, she has sorted her self esteem out. She has cut the twisted and misguided and brainwashed ties given to her by her family. She recognizes abuse for what it is and what it does. Yes Anita is ready to let go. ${ }^{89}$

Likewise, Robin fractures her self into multiple personalities, an extreme form of the temporally divided self portrayed in all awakening narratives, when she writes, "My alters [alternate personalities] hold most of the memories so this is much more their story than mine. I thank them for what they have done for me." 90 Such a fracturing of the self into multiple identities, each with their own name and voice, is an extreme form of a more common tendency for awakeners to take on a new title (such as "survivor" or "Mormon") or rename themselves after an awakening experience. it is not so uncommon. Reflecting on his name change after awakening to radical Islam, Malcolm X writes,

[...] during this time [in Detroit] I received from Chicago [Nation of Islam Headquarters and residence of NOI prophet Elijah Muhammad] my "X." The Muslim's "X" symbolized the true African family name that he never could know. For me, my "X" replaced the white slavemaster name of "Little" which some blueeyed devil named Little had imposed on my paternal forbears. The receipt of my 
"X" meant that forever after in the nation of Islam, I would be known as Malcolm $X$. Mr. Muhammad taught that we would keep this "X" until God Himself returned and gave us a Holy Name from His own mouth. ${ }^{91}$

Such new names and new titles are identity markers that reinforce the gulf separating past and present selves in the awakener's story.

Awakeners use photos, voice, street performances, and other narrative mechanisms as dramaturgical strategies to portray a temporally divided self and strategically undermine their past mindsets. They use their autobiographical accounts to perform a temporal duality of self to establish cognitive and mnemonic authority. By enacting, engaging, and symbolically defeating their past selves, they base their current belief system on the rejection of their former worldview.

Some awakeners construct a temporally divided self by portraying and injured, younger version of self. Mellissa, a self identified survivor of childhood sexual abuse, describes a haunting regression to a former, abused self when she writes, "I keep feeling like a little girl in a grownup body." 92 Similarly, Mary Ellen describes her past self as if she is talking about another person when she writes,

I have only begun to see it [...] I am different. I am a 10 year old girl in bed with Stephen [...] I want little Mary Ellen to heal. I want her to grow up. I want her to know that the world is safe. I want her to know that I will take care of her.93

Using a similar theme, one that is common to those who undergo "sexual reparative therapy," Alan describes his past homosexual self as developmentally stunted. He then casts this past self in contrast to the self-described "mature" and "responsible" heterosexual man he is today. He writes, 
I was an 8-year-old boy in a 38-year-old man's body [...] Physically and intellectually mature, a part of me was stuck in preadolescence. I could not fully and effectively take on my responsibilities as a husband and a father - as a man because the qualities needed to play such important and difficult roles had never developed in me [...] I came to realize that I simply had not grown up. 94

By depicting his past self as "an 8-year-old boy in a 38-year-old man's body" who was "stuck in preadolescence," Alan uses his autobiographical account to distance his present self from his former homosexual self. In doing so, he defines homosexuality as a developmental disability. From this perspective, "healthy" people "progress" into heterosexual adulthood, but homosexuals are "stuck in preadolescence" and are consequently in need of serious "healing" and "growth." Today, Alan can testify to this because his present, "mature," "healed," heterosexual self stands in marked contrast to the homosexual self he used to be. Alan associates heterosexuality, like both the psychoanalyzed Freudian subject and the enlightened nation-state, with evolutionary progress and enlightened maturity. Likewise, Jason writes, "Even though I became an adult chronologically, I was still a teenager emotionally and had relationship needs that still needed to be filled."95 Albert says,

I continue to understand my upbringing and its effects on me in the present. The messages I bought into as a little kid were, 'You're weak, you're not macho, you're this little nothing.' In adolescence that got translated into 'You must be gay." Now I am rejecting that false identity others tried to impose - an identity that others made me believe was me. No, I'm not gay. Now, I am determined to be the man I want to be - not to fall in love with him. (emphasis in original) ${ }^{96}$

As Alan, Jason, and Albert make a temporal distinction between their past his past and present selves, they use their personal account to undermine those who regard "coming out" as homosexual to be an honest expression of truth. They use autobiographical temporality to establish cognitive authority with regard to this 
contentious cultural issue. Like religious converts, apostates, war veterans, those who "recover" memories of childhood abuse, those who "retract" memories of abuse, and other awakeners, Alan, Jason, and Albert once embodied the characters they now disavow. Experientially, they were there. Now they situate their present selves (and current sexual worldviews) in reactive contrast to their past selves (and past sexual worldviews). Like other "repaired" heterosexuals, their rigid-minded disavowal of the homosexual worldview and lifestyle is accompanied by an equally rigid embrace of the sociomental position they diametrically oppose to homosexuality (as evidenced by the fact that they reject any sexually-integrative notion of bi-sexuality as well). To this end, Bob and Alan C. display photographs of themselves standing with their heterosexual spouses to portray their current, happy, and enlightened heterosexual selves when telling their awakening stories (see Figure 16). Conversely, in an effort to rebuke and undo the sexual reparative worldview, Eric, David, and Randy portray pictures of themselves with same sex partners to depict their happy, enlightened homosexual selves (See Figure 17). 
Figure 16. Bob Davies and Alan Chambers display their enlightened, heterosexual selves.

Bob Davies displays a photo of himself with his wife, Pam Davies, along side his awakening story on the Exodus International website. 97

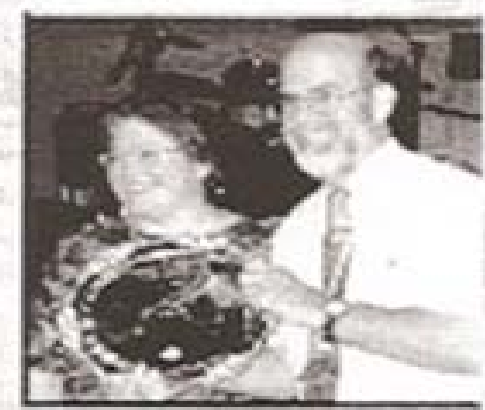

Bob \& Pam Davies at the 1999 conference, receiving bis atvard.

Alan Chambers displays a photo of his marriage and a more current picture of himself dancing with his wife. These pictures accompany his awakening story on the Exodus International website. 98
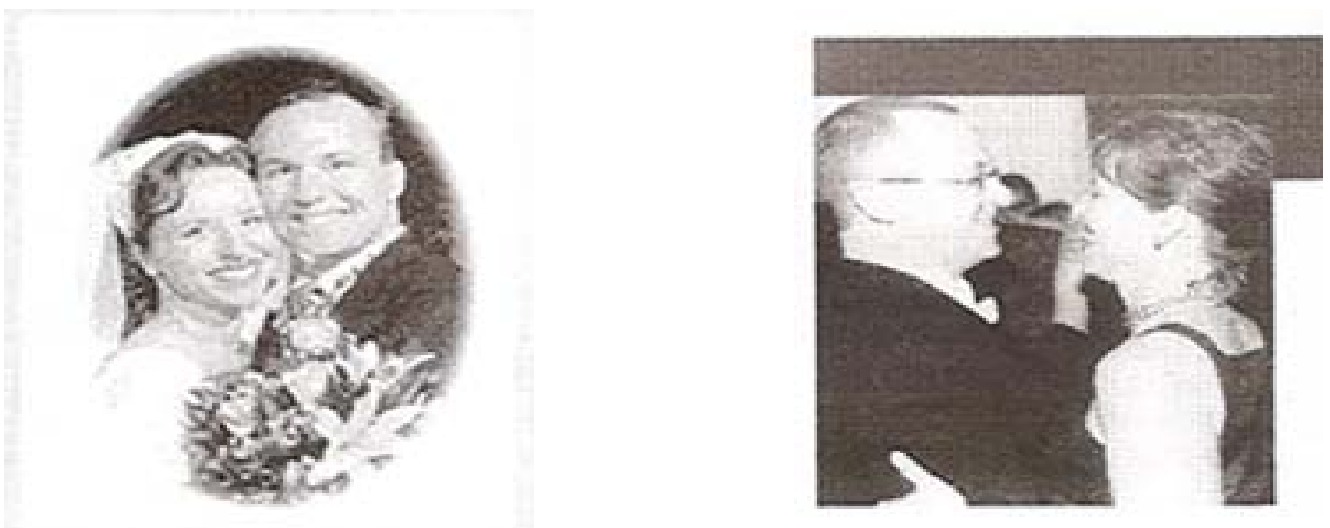
Figure 17: Eric, David, and Randy display their enlightened, homosexual selves.

Eric includes this photo with his story on the Beyond ExGay website. 99

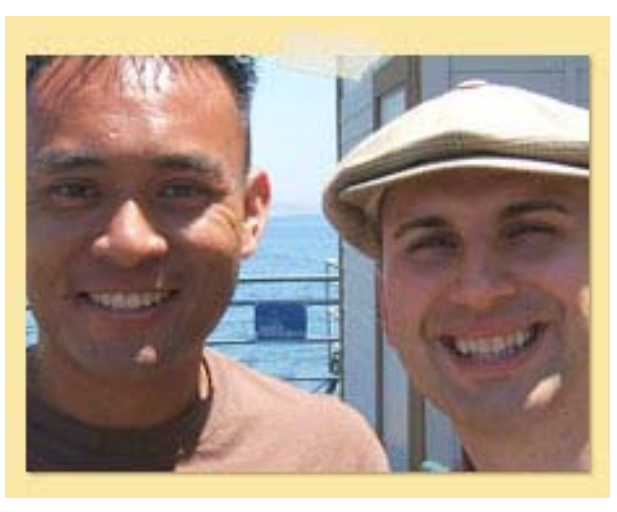

David includes this photo with his story on the Beyond ExGay website. ${ }^{100}$

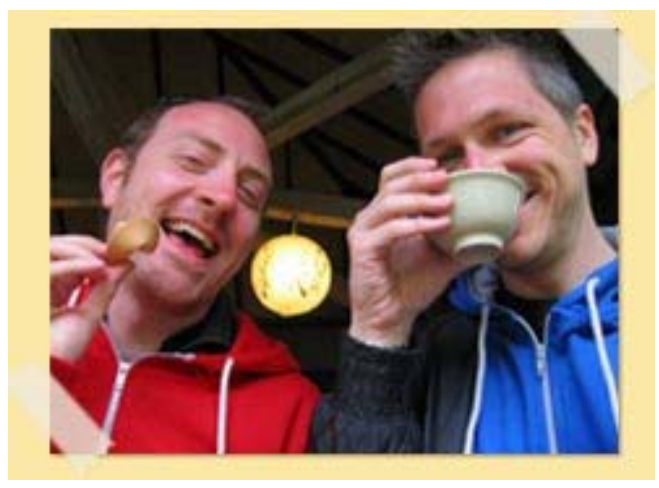

Randy includes this photo with his story on the Beyond ExGay website. ${ }^{101}$

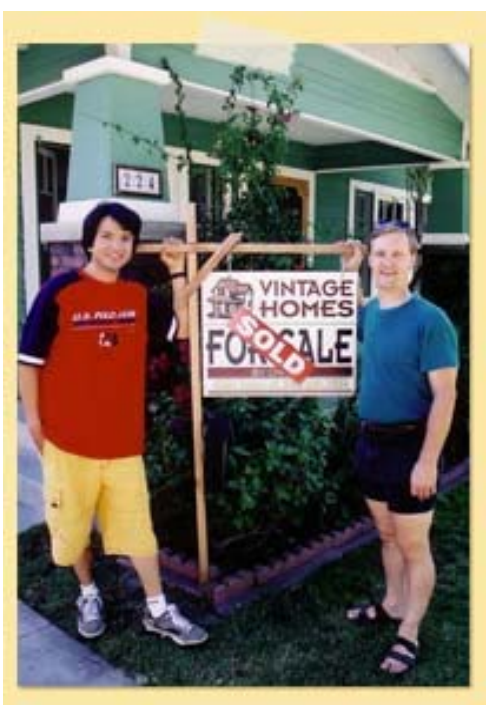


All of these awakeners invoke, portray, engage, and undermine their past selves. Despite many differences among them, they all use their autobiographical accounts to make a sociomental distinction between two personas in their lives. As they portray a temporally divided self, they redefine significant experiences and relationships and establish a future-oriented trajectory of self in contrast to their past beliefs. As they invoke and undermine the past self in the autobiographical drama, awakeners also denounce a version of "truth" and "reality" that is still very much a part of a broader autobiographical field. They construct a temporally divided self to mark the boundaries between contentious autobiographical communities and weigh in on cultural and epistemic disputes.

\section{COMMUNITIES OF DARKNESS AND COMMUNITIES OF LIGHT}

As awakeners make a temporal distinction between past and present versions of self, they articulate the sociomental tensions that separate contentious autobiographical communities in a broader autobiographical field. Using their life stories to define and contrast communities of darkness and communities of light, awakeners articulate a cognitive migration out of one autobiographical community and into another. Such cognitive migrations come with social consequences. As awakeners portray a figurative interaction between past and present versions of self, they also express distressing feelings of cognitive alienation and intense sentiments of cognitive solidarity as they plot themselves in a social drama concerning the definition of contentious moral and political issues. 
As opposed to the conventional notion of migration, which refers to the physical movement of an individual or group from one geographic location to another, the notion of cognitive migration refers to a shift in an individual's sociomental allegiances - a change in orientation to the social source of one's worldview. Such major changes of mind - marked by one's adoption of new optical norms ${ }^{102}$ - often precede any change in physical, structural, or geographic location. In fact, awakeners often remain tied to, or find themselves stuck in, their former communities after they have already mentally abandoned them. Such a situation is exemplified by the character Cuiqiao, the young Chinese peasant girl in Kaige Chen's 1984 film The Yellow Earth. Cuiqiao experiences an awakening after a young, educated communist soldier visits her isolated rural village. After spending time with the young man, Cuiqiao comes to see her village to be, like Plato's cave, a space of darkness and confinement. Well before she attempts to physically leave her village (which ultimately results in her drowning in the Yellow River), she experiences a cognitive migration that Chen so aptly portrays with a shot of Cuiqiao running against the collective flow of her fellow villagers as they move together in a ceremonial feudal ritual. By portraying the young girl running opposite to her fellow village members' concerted direction, Chen symbolically depicts how she has already left her community and "lifeworld" 103 in a subjective sense, despite her physical presence. Likewise, Edna Pontellier, the protagonist in Kate Chopin's The Awakening, suffers a fate similar to Cuiqiao's when, at the end of the novel, she ultimately swims far into the ocean and drowns. Both characters drown (a death by actual suffocation to symbolize their social suffocation) after they awaken to discover their confinement but remain unable to transcend the physical and socio-structural boundaries that contain them. 
In a more hopeful and liberating vein, Frederick Douglass also portrays a cognitive migration that precedes his physical migration and legal emancipation. After defeating his brutal slave master, Mr. Covey, in a physical fight, Douglass comments,

After resisting him, I felt as I never felt before. It was a resurrection from the dark and pestiferous tomb of slavery, to the heaven of comparative freedom. I was no longer a servile coward, trembling under the frown of a brother worm of the dust, but my long cowed spirit was roused to an attitude of independence. I had reached the point at which I was not afraid to die. This spirit made me a freeman in fact, though I still remained a slave in form. (emphasis in original) 104

Douglass tells us that he ceased to be a slave even though he remained (physically, legally, and geographically) in bondage. He abandoned the mindset of slavery and took on the mindset of freedom. Like ex-Mormons who awaken to "truth" years before they remove their names from the church membership roles, ${ }^{105}$ his cognitive emancipation preceded his official legal emancipation. Illustrating the sentiment behind Frederick Engel's statement that "freedom is the recognition of necessity," ${ }^{106}$ Douglass's cognitive migration - his awakening to the "spirit" that made him "a freeman in fact" - preceded his eventual geographic migration to the free territories in the Northern United States.

Inversely, just as one might experience a major change in mind without or before a corresponding structural shift in location, one may also experience frustrating "optical" difficulties when one traverses a structural or geographic divide between two separate cognitive worlds, two distinct realities, without a corresponding mental transformation. H. G. Wells combines optical and geographic metaphors to show the difficulties involved with such a scenario. Wells locates his "lost Country of the Blind"107 in the deep recesses of a mountain range, separated and hidden from the rest of the world by a nearly impassable terrain. When Wells's protagonist, Nunez, discovers this 
world (by falling down into it), he learns that every one of its citizens lacks the biological capacity for sight. Upon his arrival, Nunez is first greeted by a local man who asks, "And you have come into the world?" "Out of the world," Nunez replies (emphasis in original). Their initial exchange thus calls attention to their differing perspectives on reality that stem from their contrasting sociomental standpoints. While Nunez is first ridiculed, harassed, and feared by the citizens of the Country of the Blind, they later give him a condition that he must satisfy in order to stay and marry Medina-sarote, a woman with whom Nunez falls in love. He must give up his eyes. Ultimately, Nunez rejects this condition (rejecting the optical change that would allow him to "see" the world by this community's optical standards) and is forced to leave the country. Using the metaphoric contrast of blindness and sight to signify contrasting ways of perceiving reality, ${ }^{108}$ Wells portrays the often frustrating difficulties and painful consequences encountered when one traverses the structural divide between sociomental camps without a corresponding change in mindset. More generally, as these examples serve to show, cognitive migrations are distinct social phenomena that can be studied in-and-of themselves. For awakeners, such cognitive migrations involve a distinctly mental movement - a shift in cognitive allegiances - from one community to another.

As awakeners portray their cognitive migrations, they typically use vocabularies of cognitive constraint to define their past communities. As they cast a figurative shadow of darkness on their past self, they simultaneously cast that shadow on the worldview and optical norms of an autobiographical community to which they previously belonged. They define their prior community as a space of darkness and falsehood. In the process, awakeners also convey a sense of distress and cognitive alienation from their former sociomental affiliations. Consequently, awakeners depict 
former thought partners (who are often still present in the awakener's life) as closedminded, constrained, and intolerant.

Simultaneously, awakeners use vocabularies of cognitive emancipation to define their current communities. When they shine a figurative light on their present self, awakeners simultaneously shine that light on the worldview and optical norms of an autobiographical community to which they now belong, whether religious, psychological, political, sexual or otherwise. They define their newly-embraced "lifeworld" as a space of light and truth. In the process, awakeners convey a sense of security and cognitive solidarity that comes with finding "truth" in the company of likeminded others. They depict new thought partners (who are often geographically distant) as open-minded, free, and accepting.

Awakeners compliment their temporally divided selves by accounting for a cognitive migration from a community of darkness to a community of light (See Figure 18). From a narrative perspective, the awakener's disavowal of past self corresponds to a sociomental "separation" from one's former lifeworld. The act of telling the awakening story corresponds to a sociomental "incorporation" into a new optical community. ${ }^{109}$ Whether a particular autobiographical community is defined as a space of "light" or a space of "darkness" depends on the sociomental standpoint of the awakener - the sociomental "location" of their present, storytelling self. While Durkheim ([1893] 1984) showed that social solidarity operates as a moral force with a cognitive dimension, ${ }^{110} \mathrm{I}$ define cognitive solidarity as the expressed interpersonal bonding and feelings of comradery that result when individuals agree on the definition of some morally salient issue. Cognitive alienation refers to the expressed interpersonal tensions and feelings of loss and isolation that result when individuals define the world differently. Cognitive 
solidarity and alienation take narrative form when awakeners depict these social forces in order to portray their cognitive migrations and temporally divided selves. In the process, awakeners plot themselves as ostracized, yet authentic "awakened-ones" who find a new "home" and a new "family" that is "open" to "seeing" the truth. 
Figure 18. Awakeners Portray a Cognitive Migration, Shifting their Cognitive Allegiance from a Community of "Darkness" to a Community of "Light"

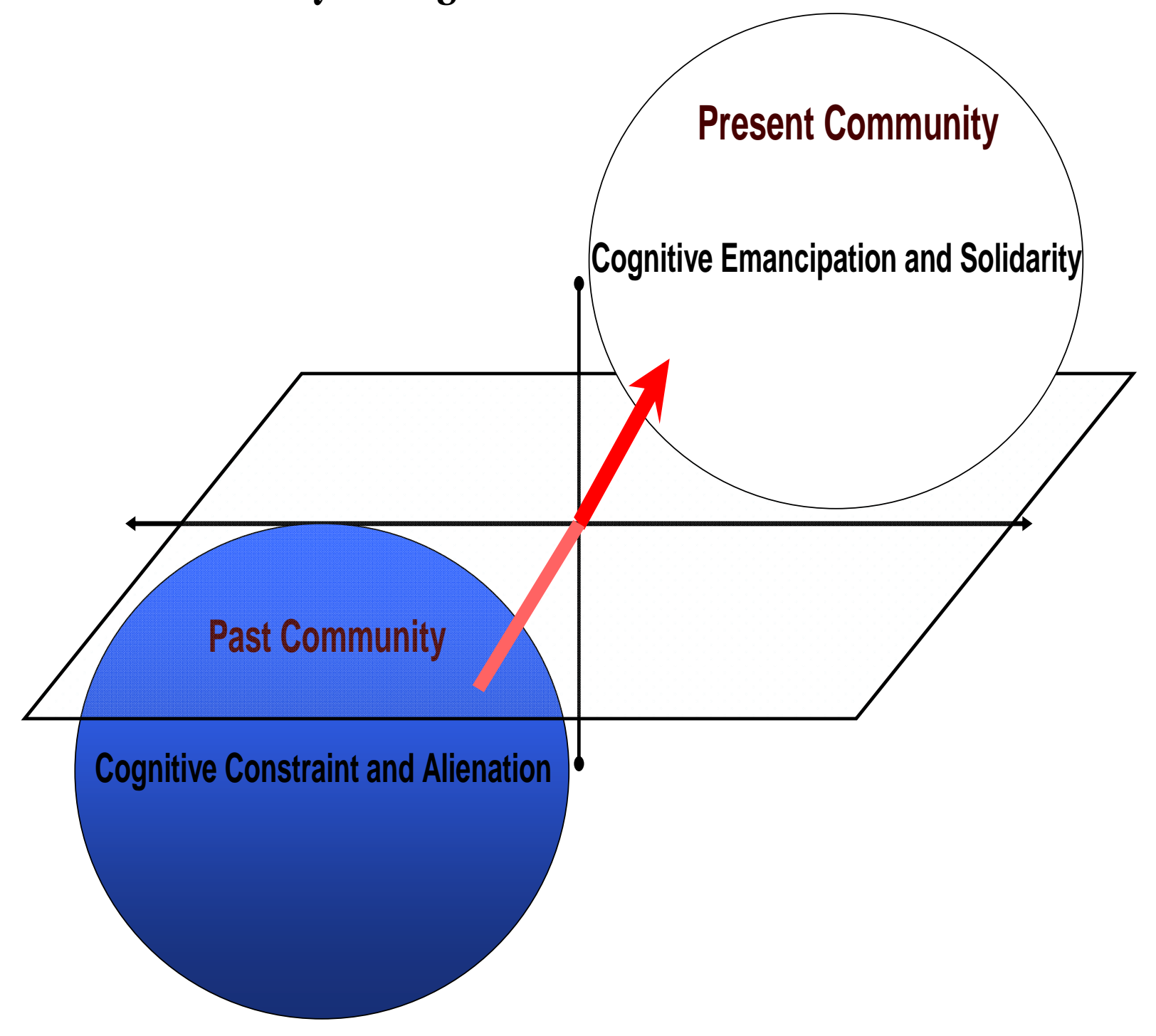




\section{Metaphors of Cognitive Constraint and Cognitive Emancipation}

Awakeners use a variety of metaphorical vocabularies to define the various social spaces, relationships, and experiences that are central to their cognitive migrations. ${ }^{111}$ They use socially structured, binary metaphoric contrasts to depict cognitive constraint and cognitive emancipation, signify the distinction between contentious autobiographical communities, and weigh in on disputes over salient moral and political concerns.

Metaphor, and language more generally, can be regarded as a gateway to sociocognitive and cultural reality. Taking the view that one's consciousness reflects one's social situation, Marx described language as the "practical" manifestation of consciousness that "only arises from the need, the necessity, of intercourse with" other human beings. ${ }^{112}$ Durkheim advanced the notion that concepts are "an interpersonal representation" of human thought, arguing that "the various elements of language are therefore collective representations." 113 Arguing that our conceptual framework is structured metaphorically, George Lakoff and Mark Johnson write, "The most fundamental values in culture will be coherent with the metaphorical structure of the most fundamental concepts in the culture." 114 We use metaphors to structure society in our minds, to organize society into different socially shared mental categories, making distinctions that shape our personal and collective identities and our understandings of the world. ${ }^{115}$ Awakeners employ a variety of conventional metaphors to shape the vocabularies they use to classify the world into morally charged autobiographical communities. 
There are three ideal-typical families of metaphoric contrasts that awakeners use to construct symbolic worlds of cognitive constraint and symbolic worlds of cognitive emancipation in their autobiographical stories. These include,

1. Asleep versus awake. Awakeners use this family of metaphors to define the symbolic experience of cognitive constraint and cognitive emancipation from the perspective of the storyteller. Even when we sleep, we "see" to some extent as we dream. However, dreaming more closely resembles the illusions of Plato's cave or the realm of the unconscious in Freud's psychoanalytic framework than it does the intersubjective, agreed upon world of everyday life. Further, sleeping and dreaming involves an intense personal isolation, a sort of solipsistic mental experience, while being awake involves and typically requires an intersubjective corroboration with others. Notably, the act of waking up (note the vertical implication as well), is culturally linked to a social time of consciousness and activity. Using metaphors of sleep (including symbolic "illusion" or "delusion") and waking up (including variants of the phrase "eye opening"), awakeners account for their prior lack and more recent attainment of the "consciousness" of "truth" in the world. For example, former communist Louis Fischer uses the asleep versus awake familt of metaphors to argue that other, current communists will eventually reject their political worldview when he writes, "They too will awaken from their dreams. Every Communist is a potential anti-Communist and should be wooed."116 Likewise, Albert, a "repaired” heterosexual, describes his experiences living as a homosexual by saying, "the realities of life turned everything into a bad 
dream." 117 Finally, sleeping and waking are culturally associated with our next family of metaphors, darkness and light.

2. Darkness versus light. Awakeners use this family of metaphors to define various environmental conditions and social groups with regard to truth and falsehood. They use "darkness" to define the contexts and conditions of cognitive constraint and "light" (including enlightenment, fire, illumination, elucidation, dawning, and more) to define the contexts and conditions of cognitive emancipation. Further, light also carries a positive moral connotation, as in the Old Testament's Book of Genesis where it is written that "God said, 'Let there be light"” and soon after the words follow, "God saw that light was good, and he separated the light from the darkness" ${ }_{118}$ (emphasis added). Notably, the contrast between darkness and light is related to the contrast between blindness and sight (as in "seeing the light"). Historically, light and the sun are typically associated with sight and knowledge. The Egyptian sun god, Ra, was said to be able to see everything. His bird, the Bennu, is a symbol of fire and rebirth. The Greek god Apollo is associated with light and the sun as well as truth and prophecy. Taking a modern example, Richard Wright combines metaphors of darkness and light to convey a frustrating sense of alienation after leaving the communist party, writing, "I headed home alone, really alone now [...] Perhaps, I thought, out of my tortured feelings I could fling a spark into this darkness [...] I would hurl words into this darkness and wait for an echo [...]." 119 Using metaphors of 
darkness and light, awakeners account for their prior lack and more recent attainment of "senses" with which to "see" and know "truth" in the world.

Awakeners combine the themes inherent in the asleep/awake and darkness/light metaphoric contrasts to portray their sense of looking at the world through a new set of eyes. Such distinct optical metaphors clearly express their taking on new optical norms and explain their newfound social roles as awakeners. After her elevator-like awakening experience, Gerilena, a retractor, writes, "I began to look at it with all new eyes."

Likewise, Iraq Veterans Against the War member Derek writes, "I was never to see the world through the same eyes."120 Using very few words, both individuals use optical metaphors to account for their awakenings and convey a temporally divided self. David, a "repaired" heterosexual writes, "my whole vision of myself changed completely." 121 Concerning his former communist worldview André Gide writes, "It is time that eyes should be opened to this tragic failure in which all our hopes have foundered." ${ }^{122}$ Reflecting on his former New Left mindset, David Horowitz writes, "I closed my eyes to evidence $[\ldots]$ and averted my eyes from the truth." ${ }^{123}$ Likewise, Bill, an apostate to the Mormon church, uses optical metaphors and quotation marks to redefine Mormonism, once his community of light, as a community of darkness. He writes,

As a missionary I used to boast how right my emotions were and all other religious believers were wrong as they just felt the "light of Christ," were mistaken, or were deceived by the devil. Today I see things differently [...] I am now happy enjoying my freedom to think without a cloud of dogma blurring my natural vision. ${ }^{124}$ (emphasis added)

Further, Freud, who uses of the term "enlightenment" 125 to describe the results of psychoanalysis, also uses a variety of other light and optical metaphors to convey Dora's 
awakening to "truth" including "her eyes were opened," 126 "sheds a clear light,"127 "the conclusive proof of its correctness came to light," ${ }^{28}$ and "she was able to throw a light upon." 129

3. Lost versus found. Awakeners use this family of metaphors to define the symbolic experiences of cognitive alienation and cognitive solidarity. When one is lost, one is typically in an unfamiliar and perhaps threatening setting. When one has been found, one returns to a space of familiarity, a home base where one is supposed to be. Awakeners often convey the experience of being "lost" by describing their isolation and loneliness, or depicting the inauthenticity of the "false" relationships. Awakeners often convey the experience of being "found" with metaphors of family and homecoming. Johnny, and Mormon convert, writes, "I may have lost one family [...] but I gained a new church family and an amazing understanding of life, love, marriage and everything in between." 130 Reflecting on his newfound place in the Mormon church, Chad writes, "I felt something that I don't believe that I had felt in a long time. I knew I was home." ${ }^{131}$ Likewise, comparing his existence as a Leftist to living the life of an alien, Peter Collier describes his final rejection of his leftwing mindset, writing,

I felt that I cold finally tear up my political green card and discard the status as a legal alien under which I had lived for twenty-five years. I felt that I had finally come home. ${ }^{132}$ 
Using the metaphoric contrast of lost and found, awakeners account for their prior state of being without a community of like-minded others and their more current state of finding a sociomental "family."

The darkness versus light, asleep versus awake, and lost versus found families of metaphor are certainly interrelated, but each serves to highlight a different symbolic dimension of the awakening narrative formula. Awakeners use and combine metaphors of darkness, sleep, and being lost in to construct symbolic worlds of cognitive constraint. These metaphors are inherently retrospective in that they are culturally associated with being prior to the perceptual norms of the awakener's newly-found community. Awakeners use and combine metaphors of light, waking, and being found to construct symbolic worlds of cognitive emancipation. These metaphors are inherently emergent and projective in that they are culturally associated with being after darkness, sleep, and a state of being lost. Awakeners use these metaphor-families to describe the process of acquiring new cognitive norms and to distinguish between different autobiographical communities in a contentious cultural arena.

Sherry, an apostate to the Mormon church, uses a variety of interrelated metaphors to structure the contrast between old and new autobiographical communities in her account. Arguing for the importance of officially resigning from the Mormon Church, Sherry writes,

I saw that glaring shadow [...] the one that says, "If you exit, you will wind up in outer darkness ALONE [...] I used to be afraid that if I climbed all the way out of the box, the light would be too bright. I might wilt. Instead, it's been empowering, calming, healing and quite good company [...] I am also consumed with the knowledge that I am now part of deconstructing old constructs. This is a new day and it won't light up without new thinking. Dear friends, I implore you 
to help take down this structure. It won't fall unless your letters [of resignation] get there [...] We probably wouldn't see the entire collapse within our lifetimes but we would be the match that sets the fire. We are already trying to light it [...] you will find your truth and that leads to finding "family/friends" that aren't necessarily connected by blood or doctrine ("us" for example). You won't be ALONE.133 (italics added, capitals in original)

Sherry uses a metaphoric contrast between darkness and light to contrast the Mormon Church to her newfound apostate community online. Light and fire thus represents the truth of the new and a force to destroy the old. It frees and burns, enlivens and kills. She uses metaphors of lost (being "alone") and found ("family/friends") to express cognitive alienation and solidarity. Awakeners use these metaphoric toolkits to depict environments of cognitive constraint and environments of cognitive emancipation. In the process, they account for their cognitive migration out of one autobiographical community and into another.

\section{Portraying Cognitive Migrations}

Wendy ${ }^{134}$, a retractor, describes how she reinterprets a once-embraced space of light and truth to be a space of darkness and cognitive constraint. She writes,

If anyone had told me when I was in therapy that I was wrong and the therapist was wrong, I would have defended the "truth" as I saw it as fiercely as I'd defend my own children. There's no rationale when you're there, no sense of reality outside the Therapist's belief and support, nothing to fill up the longings you feel except to immerse yourself completely in the falsehoods you so truly believe. There feels like there is no escape once you're in it, nowhere to go. ${ }^{135}$

Describing her time in therapy, Trish writes, "When I look back now I define the last four years like I was in a cult; the only member of the cult was me and the cult leader 
was my therapist." Using a similar vocabulary of cognitive constraint, Elizabeth writes, "It was almost like joining a cult, with my therapist as guru and me a faithful disciple, the pitiful casualty of a horrendous crime." ${ }^{36}$ Similarly, Catherine, who once identified with an "ex-gay" ministry but has since awakened to embrace her identity as a lesbian, reinterprets a once-perceived community of light to be a community of darkness.

Making an analogical reference to George Orwell's 1984, Catherine writes,

I entered the "ex-gay" ministry, Love in Action, in the fall of 1986 and for the first time in my life, I felt like I finally belonged [...] [Over a year later] My therapist helped me see how cult-like this "ex-gay" ministry was. The rules were set up to control our thinking and behavior. The whole premise was to use "group-think" to put pressure on us to change our ways. ${ }^{137}$

Using a similar vocabulary of cognitive constraint, Paul reflects on his seven years as a Jehovah's Witness, writing,

I am here to say that "ex-gay" ministries are snake oil and the salespeople are the pseudo-scientists of religious-political organizations. Do the testimonies of socalled "ex-gays" really impress me? No. I have personally come to realize that the mind is powerful enough to create a self-illusion of being "cured." "Ex-gay" therapy offers only mind tricks and the delusion of progress. I know because I played such magic tricks with myself. 138

Contrasting the world of the church with her new-found therapy, Tracey writes,

I decided to seek the help of a mental health professional. It didn't take long for me to realize that I am a lesbian, and happily so. My therapist said that the church did no more than brainwash me, and I now know that "reparative therapy" - which purports to be able to change one's sexual orientation from homosexual to heterosexual - is a lie. ${ }^{139}$

As these examples show, such re-awakeners redefine once-embraced communities of light and emancipation to be communities of darkness and constraint. 
By contrasting such social worlds, they express their cognitive migration from one to the other. Capturing the tension between the anxieties that accompany the loss of one's former community and worldview, on the one hand, and the freedom inherent in the process of escaping cognitive constraint, on the other hand, an apostate to the Mormon church writes, "I must say that migrating out of the church paradigm (both practically and philosophically) has been the most painful, frightening and liberating experience of my life" ${ }^{140}$ Likewise, Insanad, responding to another apostate in the ExMormon Forums, accounts for the feeling of freedom and emancipation that accompanied her cognitive migrations. She writes,

I didn't discover the anti-mormon stuff till the last couple of years and it's been an eye opener but I left on similar grounds as you, mainly that logic and reason weren't welcome and anyone using such novel ideas is quickly shunned or expelled. I got both!!! Whoo hoooo. I call myself Emancipated but some LDS take that offensively because it doesn't show a twat of contrite spirit or broken heart as those shameful "Excommunicated" types. ${ }^{141}$

Awakening narratives capture the social tension inherent in cognitive migrations as the awakener simultaneously separates and joins, rejects and embraces, mourns and celebrates. Expressing a distressing sense of cognitive alienation after awakening to abandon his evangelical religious faith, Charles Templeton writes,

It seemed that all of life was showing me its nether side. My faith was gone, my marriage was dead, my mother was dying. I was cutting myself off from the hundreds of friends I had made during nineteen years in the church. I was abandoning people who looked to me, including thirty-six men and women who were in the ministry or on mission fields because of my work. I felt like a betrayer [...] But there was no real choice. I could stay in the ministry, paper over my doubts and daily live a lie, or I could make the break. ${ }^{142}$ (emphasis added) 
Despite suffering from intense feelings that he was betraying his longtime community, Charles had already abandoned them on a cognitive and epistemic level. His cognitive migration left him with "no real choice" other than to "make the break" and physically depart from their space and presence. Describing the social consequences of her cognitive migration, Susie 143 comments in the online "Recovery from Mormonism" forum,

For those of us who have Mormon family, they don't support us at all. Hell, most of us who HAD Mormon friends [they] dumped us, because we're suddenly too evil to be around. Suddenly, all of the people you depended on and care about tell you that you're the scum of the earth and they don't want anything to do with you, or they insist you conform. Intolerance continues [...] until it is unbearable. [The online Recovery Forum is] not support to stop attending church, it's support to fill in for the "friends" [notably, in quotes] and family who dumped us cold because they are intolerant enough to view us as evil.144 (emphasis in original)

Susie uses a vocabulary of cognitive alienation and cognitive solidarity to account for the social repercussions of her awakening. She locates the blame for her ostracism on her former thought partners, who she describes as "intolerant," closed-minded, and disdainful, and casts herself as unjustly persecuted due to her new-found "truth." As all of these accounts show, one's personal discovery of "truth" typically leads to an uncomfortable sociomental distance from one's former autobiographical community (even when the members of this former community remain geographically nearby). When Plato's freed prisoner returns to the cave to share his newfound "truth" with his former bondsmen, they want to kill him. When Wells's Nunez tries to teach the citizens of the Country of the Blind about sight, they laugh at him and eventually want to remove his eyes. When David Horowitz tries to publicly share his newfound political "truth," he was "demonized for [his] second thoughts" and faced "savage personal attacks by [his] 
former comrades that were designed to warn others to remain within the fold." 145 In each case, the awakener is cast as a victim of intolerance and blind, rigid-minded contempt.

Likewise, those who once engaged in sexual reparative therapy but now embrace the "truth" of their homosexuality typically define the world of sexual reparative therapy and the ex-gay ministries as an intolerant community of darkness. Cheryl, who identifies as a "survivor of 'ex-gay' ministry," describes her cognitive alienation in the wake of her sexual awakening and coming out as homosexual. She writes,

[...] my support system failed. The perception by my friends and fellow churchgoers of my "sinful" life divided us. And so, I was forced to make a choice between my sexual orientation and their allegiance. In a matter of eight months, my church and friends disappeared into the shadows of self-righteousness [...] As a result of the emotional brutality I experienced, I began to question both God and the church. I wasn't sure I wanted to be involved in an institution that promotes such hatred, fear, sexism and homophobia [...] Because of the pain and anger I feel when I even enter a church, I no longer participate in institutionalized religion. My journey continues. ${ }^{146}$

Cheryl's sexual awakening prodded an emerging alienation from her religious community, a cognitive alienation that ultimately led her to question her religious views. Bill, an apostate to the Mormon church, reflects on a similar sense of cognitive alienation and then explains it to be the consequence of Mormon policy. Notice how Bill portrays the perspective of the Mormon church in order to undermine it. He writes,

The LDS church labels me an "apostate," which is a label that is meant to stigmatize and warn Mormons to beware. I'm for Mormons what a Muslim would call an infidel, "an unbeliever with respect to a particular religion." I'm condemned for being honest! [...] Think about it, if more LDS members tried to understand the former member, they might start to sympathize with them, and affiliate with them, which might lead to them asking questions and thinking objectively outside the box. So the church leaders were smart in making it a rule for a Temple Worthy Mormon not to associate with former Mormons. ${ }^{147}$ 
Sharing her story with an online community, an apostate who goes by the name, MsGabbie2u describes the alienation she experienced after her self-described “awakening." She writes,

My family, in-laws and Mormon friends thought I was going through a mid-life crisis. I didn't understand why they didn't see what I saw, and our relationships became strained. I pulled away from them and they withdrew, which exaggerated my feelings of abandonment. ${ }^{148}$

Despite many differences among them, all of these awakeners describe a distressing sense of cognitive alienation as they account for their cognitive migrations. However, such cognitive migrations also typically lead to a sociomental nearness to a newfound community, whether a support group, a church, an online forum, or a political organization, for example. Highlighting simultaneous themes of cognitive alienation and cognitive solidarity, Jared, a member of Iraq Veterans Against the War who enlisted in the army in 2003 in order to fight in Iraq, writes,

What is a family anyways? Is a family only defined by bloodlines whose only purpose is to spend birthdays and holidays with? What happens when your family won't support you anymore because you speak out against an illegal war, something they haven't begun to comprehend. Yes, I have a family. I have a mother and father to spend holidays with, just so long as i don't mention Iraq Veterans Against the War. Then that family begins to look and sound like two strangers with a distant grasp on reality [...] I have met a new family recently at the Midwest [IVAW] strategy retreat [...] And to this family I would like to say thank you, regardless of whether or not our fight ends the war in Iraq and brings back our brothers and sisters, the bonds I share with all of you will live in my heart forever. ${ }^{149}$

Jared's awakening to the "truth" about the war created a formidable sociomental tension with his biological family who, given their continued commitment to Jared's former 
worldview, now "look and sound like two strangers with a distant grasp on reality." Jared uses a vocabulary of cognitive alienation to describe his relation to a social world that he now associates with cognitive constraint. Inversely, he uses a vocabulary of cognitive solidarity to account for his membership in a "new family," a political organization in this case (the same purpose that is served by a strictly online community for Susie and others). His "bonds" to this new family are inseparably connected to this group's shared cognitive norms and autobiographical conventions. ${ }^{150}$ Likewise, responding to a first-time participant on PostMormon.org, Jamech, an apostate to the Mormon church, writes,

I feel like a stranger in my family and my community. The hurts go pretty deep [...] As you've probably already seen, the world opens up a lot once you take that step outside. What you've done takes a whole lot of courage and strength of character, which I imagine, many of the people closest to you probably can't see or appreciate. But there are a whole lot of people here on PostMormon.org that can truly respect and admire you and celebrate with you on your journey! Welcome aboard! 151

In order to distinguish between a community of darkness and a community of light, Jerry contrasts what he calls "the gay world" with what he calls the "the male world." He describes the gay world as inundated with "contempt for men, hatred of men, mockery of men," "exaggerated effeminacy" and "promiscuity," "pain," being "trapped," "craving," and "fear," as well as "gossip [...] bitterness [...] lying, deceit, and denial." He characterizes the "the male world" as a world "bonding, acceptance, and inclusion," "masculine affirmation," "healthy relationships," "love," and "courage," commenting, "My sense of alienation from men began to fall away [...] I was becoming free $[. .$.$] Today, I identify with other heterosexual men as my peers, my brothers and my$ equals." As he tells his story, Jerry associates his former "gay circles" with cognitive 
constraint and alienation. He associates the sexual reparative community with cognitive emancipation ("becoming free") and solidarity (with newly-found "peers [...] bothers [...] and equals"). ${ }^{152}$ Accounting for a similar cognitive migration, Peter writes,

I once felt such intense estrangement from men and, out of fear, did everything I could to avoid them. As a result, my innate need for male connection could only be fulfilled sexually. [Now], I help men to find spiritual and emotional healing and my love for men as brothers preclude [sic] sexual desire for them. ${ }^{153}$

Likewise, Frank describes his newfound community of men by writing, "these [...] men are my brothers. They are my fathers. They are my peers. They are my connection to the world of men to which I belong and had not been a part of before." 154 Similarly, Scott contrasts the "male world" and "masculine environments" to "homosexual thoughts, feelings, and culture." 155 Rick contrasts the "gay scene" with a "community of men." 156 Richard contrasts the "world of men" with the "homosexual world" and "sad, 'gay' world." 157 Jerry, Peter, Frank, Scott, and Rick like IVAW member Jared and many others, describe their newly-found community of "truth" with metaphors of family and home. Awakeners use such vocabularies of cognitive solidarity to establish new sociomental allegiances based on shared ways of accounting for salient moral and political concerns and shared ideas about truth. Just as biological families provide the social context of our primary socialization into the world, ${ }^{158}$ such communities of "truth" provide a context for optical re-socialization as awakeners learn to see the world and account for their lives in a new way. ${ }^{159}$ As awakeners describe such cognitive migrations, they ground different conceptions of their selves, past and present, in different communities. 
Likewise, Diana, a retractor, describes her therapy - where she previously recovered memories of sexual abuse - as a "cult [...] a nightmare world [...] a world of unreality and madness" where she "lived in total fear" with a "delusional belief system." She then contrasts her therapy world with her biological family, who she previously believed had ritually abused her, commenting, "I am ever grateful for my loving family who never gave up hope that I would come to my senses, forgave me the immense pain and suffering I caused them and accepted me with unconditional love when I finally awoke from the trance." Similarly, another retractor contrasts her family (a group she now views as a community of light and truth) with a former therapy group (a group she once believed to be a community of light and now views to be a community of darkness and falsehood). As she tells her story, she expresses solidarity with a new autobiographical community, in this case a community of retractors and their families represented by the False Memory Syndrome Foundation. Publishing her story in an FMSF newsletter and on the group's websites, she writes,

In October of 1993 I was finally reunited with [my parents] after three horrible years of being involved with a "bad" counselor and learning first hand what the false memory syndrome was all about. Today I am very thankful to God to be back together with my family!!! I have friends that I was in a SRA/MPD [satanic ritual abuse/multiple personality disorder therapy] group with that are still in the same boat I was in and they will no longer speak to me since I am now the 'enemy.' My parents have been so forgiving and I am so thankful that we have been reunited. My deepest thanks to FMSF [False Memory Syndrome Foundation] for sharing with my parents that they were not alone and for providing them with much encouragement. ${ }^{160}$

When retractors tell such homecoming stories, they often explicitly portray their former therapy-based communities as a "false" or "imposter" family. ${ }^{161}$ Referring to her former therapy group, Laura writes, "Everybody in the group was encouraged to divorce their 
families and make the group their new family." 162 Referring to her therapist, she writes, "Steve was my mother, my father, my brother, my sister, my best friend, my husband, boyfriend [...]"163 Similarly, Jaye describes her experiences in the psychiatric unit of a hospital:

Nurses and attendants became mommies and siblings of sorts. The hospital was home and a skewed sense of family was created after I assumed the role of dependent, little-girl patient [...] Old memories of the father, who raised me by working hard five days a week to provide for our family, quickly receded [...] Dr. Stratford eagerly stepped in as the emotional Daddy he believed I needed [...] I became totally dependent upon Daddy Stratford and my hospital family. ${ }^{164}$

Using such a narrative strategy, retractors cast therapy as a community of cognitive constraint and contrast it to the "light" that comes when they embrace the False Memory Syndrome Foundation and rejoin their once-rejected biological families. Likewise, former communist Ignazio Silone recalls,

So I had to adapt myself, for a number of years, to living like a foreigner in my own country. One had to change one's name, abandon every former link with family and friends, and live a false life to remove any suspicion of conspiratorial activity. The party became by family, school, church, barracks; the world that lay beyond it was to be destroyed and built anew. 165

Similarly, former feminist Carol Iannone reinterprets feminism and the feminist practice of "consciousness raising," a symbolic representation of the second wave feminist community, as a community of darkness. She writes,

Consciousness raising inflames the discontent that is bound to be in every woman's life and then the ensuing disarray invites her to see it as the oppression of being seen as a sex object, or whatever, and to look to alleviate it in political terms. To the extent that the personal becomes political, the woman loses contact with herself. She is constrained for seeing how many "feminine" problems are more moral and characterological than social or political, and that regardless of origin, can only be overcome by the individual [...] the preliminary result of the 
politicization of the internal life may seem liberating but the end result is enslavement, since it diminishes the individual's sense of control over her own destiny and weakens her self-discipline by encouraging her to blame others. ${ }^{166}$ (emphasis added)

Explicitly highlighting the affective and perceptual consequences of her cognitive migration, Lindsay, a Mormon convert, uses vocabularies of cognitive alienation and cognitive solidarity as she accounts for her awakening. Lindsay writes,

When I visited all those churches over the years, nothing ever felt right to me. I always felt that there was something missing. I'd go to a church, and just feel...empty and lost. Nothing ever touched my soul [...] [Later] I clicked around on Mormon.org [a site with personal stories and a chat feature]. I was overcome with the feelings of peace, it felt like coming home. I have always wondered why so much of my life was suffering [...] [Later] When the Gospel was explained to me at church, it just made sense to me [...] I knew that I was where I belonged. It was as if I had been living in darkness all these years and suddenly, there was light [...] Suddenly I noticed everything was different, old songs I listened to no longer had meaning, tv shows I'd once enjoyed now seemed empty, clothes I'd once worn I didn't want to wear anymore because they didn't fall under modesty standards. ${ }^{167}$ (emphasis added)

When Lindsay discovers a new community of "truth," she comes to perceive the world around her in a new way. Her awakening is accompanied by new meanings, feelings, tastes, and optical conventions. Likewise, describing the intense sensory transformation that accompanied her awakening, Insanad, an apostate the Mormon church, writes,

I swear, food tastes better when you leave the church. Sex is better, Sundays are WAAAAAY better, movies are better, and even though you may lose a lot of so called "Friends," you will make new ones. ${ }^{168}$ (emphasis in original)

In the same vein, Arthur Koestler reflects on his now-rejected awakening to communism by writing, "Our literary, artistic, and musical tastes were similarly reconditioned." 169 As these awakeners account for their cognitive migrations and their accompanying sensory 
transformations, they reinforce the distinction between their past social locations of "darkness" and their current communities of "light" while they simultaneously distinguish between their past and present selves. In all of these cases, awakeners use their autobiographical accounts to draw a line between dueling camps in a cultural contest over meaning and truth.

Drew, a member of Iraq Veterans Against the War, stresses a social imperative to story-sharing that often provides an interactive foundation for the expression of cognitive solidarity. During an interview with the political newsletter, CounterPunch, Drew is asked, "If you could share one aspect of your experience from soldier to antiwar vet with a GI or Marine currently in Iraq or Afghanistan, what would it be?” Thus prodded to account for a central aspect of his own awakening, Drew comments,

It is impossible to deal with this alone, you know that things are different and its hard to even identify why. Coming together with other vets that feel the same way makes you realize so overwhelmingly how we are all still connected, and always will be. What we remember, our stories and ideas that we share with each other is really empowering, because you realize that you are not alone. Things can get better, but you have to come out of the woodwork, come out and talk with other vets, its an important part of the process to remember and resolve, you know, and listen, like friends are supposed to. ${ }^{170}$ (emphasis added)

Such a cognitive solidarity through storytelling is also a central objective of sexual reparative support groups whose members share stories about struggling with unwanted homosexual attractions as they awaken to a new sexual worldview. ${ }^{171}$ When awakeners share their stories, they often discovery autobiographical similarity and heighten our attention to commonality among autobiographical community members. In Brekhus's words, "the similarities of the marked category [in this case, the awakened community, or community of "truth"] become far more important than their differences." ${ }^{172}$ Such a 
cognitive solidarity is evident in Laura Davis's personal statement in the preface to the controversial self-help book for survivors of childhood sexual abuse, The Courage to Heal. Davis writes,

There were tremendous similarities in the stories. The Black ex-nun from Boston and the ambassador's daughter from Manila described the stages of their healing process the same way. A pattern started to emerge. What I was going through started to make sense. ${ }^{173}$

Davis makes sense of her own life as she finds commonality in the lives of others. Expressing a similar sentiment of autobiographical solidarity on a website for survivors of childhood sexual abuse, Jennifer writes,

I can actually say I am getting better now. For many years I blocked it out. I can barely remember any of my childhood [...] For all of you who are going through the same thing.....I wish you luck. You are not alone. Maybe someday we can find peace. Good Luck. ${ }^{174}$

Likewise, a survivor who goes by the name "Hopeful and Healing" posits a solidarity through storytelling as she posts her story on the Susan Smiles website. Notice how she contrasts the amorphous "they" with a "we" that is slightly more defined as those who post and read stories about sexual abuse on the site. She writes,

Thank you so much Susan for having this website up. It was one of [...] the things that really made me realize there are other survivors out there and that there really is hope in this world. To anyone that is reading this that is being abused right now, please don't give up!!! Your life is precious and there is hope and love out there. Don't believe what they tell you! We as survivors took so much onto our shoulders and carried so much pain and hurt. Don't hide your face or be scared. As survivors of sexual abuse we are strong to have taken so much hurt and still be alive! Please don't ever give up. ${ }^{175}$ (emphasis added) 
Expressing a similar autobiographical solidarity, Blondie writes, "I was inspired to write about my abuse after reading about so many other stories. I hope that my story will be of some help to someone." ${ }^{176}$ Likewise, Fiona writes,

Knowing others are out there also takes away my worst feeling - being isolated [...] The best thing I ever read was in "Courage to Heal": About how living through the abuse is the hardest part, and how we've survived it. And we are strong $[\ldots]$ Thanks for listening $[\ldots]$...

Like survivors of childhood sexual abuse, apostates to the Mormon church express a sense of relief and cognitive solidarity that stems from sharing their stories online. An apostate that goes by the name "cynical" writes,

It has already done my heart good to know that I am not alone. THANKYOU [...] I freed myself from "the church" almost 12 years ago [...] I am relieved to have access to this discussion forum and hope to participate often. ${ }^{178}$

"Free thinker" responds, writing, "Welcome Cynical [...] It IS a relief, isn’t it, to find out that you're not alone! [emphasis in original]"179 Likewise, Mountaingirl writes,

First, this is so refreshing to find "others." I would like to be able to discuss things that nobody else would understand. In the process, I'm sure it also validates our feelings and helps reinforce our sanity. ${ }^{180}$

Despite the many significant differences among them, all of these awakeners portray a shift in sociomental allegiances - a cognitive migration from one autobiographical community to another. Using their stories to justify and defend one version of truth while undermining at least one other, they mark the divisions and define the distinctions between dueling communities in a contentious cultural arena. 


\section{CONCLUSION}

The formal analysis advanced in this chapter illuminates the role of awakening narratives (in particular) and autobiography (in general) in a sociocognitive epistemology. As awakeners construct a temporally divided self, they simultaneously reject one set of cognitive norms and adopt new conventions of perceiving, remembering, and recounting. They put self-interaction into autobiographical form to engage in dialogue with at least two contemporary audiences - one symbolically represented by the awakener's past self and the other symbolically represented by the present, storytelling self. Awakeners thus formulate (as narrative) and deploy (as social action) autobiographical accounts in dialogic relation to various social groups. This dialogue is expressed as the figurative interaction between separate personas of the awakener's temporally divided self. Attending to the way awakeners construct and portray temporally divided selves and account for cognitive migrations opens new avenues for a uniquely sociological epistemology. As awakening narratives show, we can use our identities, as well as our expressions of solidarity and alienation, to make knowledge claims and assert the "truth" in a contentious cultural landscape.

Awakening narratives elucidate the intersection between the social foundations of identity and meso/macro level cultural contentions. As awakeners construct a temporally divided self, they account for interpersonal tensions and harmonies in order to distinguish between different autobiographical communities in a broader autobiographical field. They also use autobiography to establish a social position in such a contentious social environment. As they tell their stories, awakeners articulate symbolic kinships ties that form based on a community's common adherence to certain 
ways of perceiving the world around them. Awakeners express collateral bonds of cognitive solidarity based upon their optical commonalities with one group and their optical differences with another. Such a cognitive solidarity provides a sociomental foundation for injustice frames, ${ }^{181}$ social problem claims, and other moral justifications for social change. One might think that someone who experiences such a cognitive migration might be more open to the prospect of switching sociomental camps in the future. If it happened once - if all that was "solid melts into air"182 - then why shouldn't it happen again? Actually, many awakeners exhibit a rigid commitment to their newlyfound community as they espouse the notion that they are "home" and will never change again (even though, as we see in the stories of re-awakeners, they might).

While awakeners use their personal accounts to distinguish between communities of truth and falsehood, communities, in turn, use and display awakening accounts to establish and defend their cognitive authority. Many of the awakening stories quoted above are embedded in the online "cognitive face"183 of a particular community. These personal stories are framed by text, images, and links that express the collective sentiments, beliefs, memories, and ideologies of a group, whether an established institution, a social movement organization, or a more loosely defined thought collective. All of these websites actively cultivate a sense of community via story-sharing by prompting visitors and community members to post their stories, many explicitly expressing the sentiment, "you are not alone.” Other awakening stories I have explored appear in published collections of personal stories that were organized and produced with specific agendas in mind. In all of these cases, awakening stories serve to validate the broader sentiments and objectives of a community. They provide 
autobiographical models that potential believers can use to "see the light" and "migrate" to a particular community's collective worldview. 


\section{Chapter 6}

\section{Toward a Cultural and Cognitive Sociology of Autobiography}

"[...] our problem is not how to deal with a kind of knowledge which shall be "truth in itself," but rather how man deals with his problems of knowing."

Karl Mannheim, Ideology and Utopia, p. 168

"What we feel to be an impossibility is actually mere incongruence with our habitual thought style." ${ }^{1}$

$\sim$ Ludwick Fleck, Genesis and

Development of a Scientific Fact, p. 48

Taking a broad, comparative approach to the sociology of autobiography, I have mapped and detailed the patterned characteristics of the awakening narrative formula. This story formula transcends multiple realms of social life and historic contexts. When awakeners tell stories about their lives, they demarcate the boundaries of cultural and epistemic tensions concerning the nature of truth and the definition of various moral and political issues. When they account for a transformative awakening experience and portray a temporally divided self, awakeners symbolically defeat their past self in order to engage those who subscribe to their former worldview. They convey a sense of 
discovery and moral growth to assert a distinctly sociocognitive authority that comes with wielding the "truth," whatever that truth may be.

The formal analysis advanced in this book shows how individuals express cultural tensions in their autobiographical stories. More generally, it illuminates a place for autobiography in a cultural and cognitive sociology. As awakeners tell stories about personal discovery, they explicitly redefine their perception of past experiences and relationships. They perform a cognitive migration from one autobiographical community to another, simultaneously rejecting one set of cognitive and mnemonic norms while adopting new conventions of perceiving, remembering, and recounting. Such autobiographical communities take form in dialogic and often contentious relation to one another in broader autobiographical fields that contain multiple and competing versions of truth. Combative autobiographical fields provide cultural settings where individuals craft their seemingly personal stories about discovering truth in solidarity with some and in reactive contrast to others. By exploring the ways that awakeners define autobiographical communities in mutual relation to one another, we can illuminate the social contours of our seemingly personal identities and memories. Further, we can elaborate the cognitive and storied dimensions of the sentiments of solidarity and alienation in order to better grasp the ways that social distinctions shape our lives.

Awakening stories, like autobiographical stories more generally, are embedded in the larger collective discourses of various communities, including religious groups, social movements, therapeutic support groups, sexual identity groups, families, nations, and other interested parties. Throughout this book, I have primarily focused my analysis on the formulaic characteristics and sociocognitive implications of the autobiographical 
awakening narrative. I have focused on the patterned ways that individuals tell stories about their lives and considered what these stories mean in larger cultural arenas. However, individuals tell such autobiographical stories in symbiotic relation to their autobiographical community of reference. They draw on the community's collective narratives of transformation and/or iconic biographical accounts to model their individual stories. For example, when a self-identified survivor describes recovering memories of childhood sexual abuse, that awakener makes use of a shared story model that is grounded in a broader community of self-identified survivors. More generally, that awakener draws on foundational, psychodynamic theories of dissociation, repression, resistance, discovery, and healing. When another individual awakens to the truth of Mormonism by describing a visitation by a spirit-being that occurred after years searching, to no avail, for the right religion, that awakener draws on the collective, iconic account of Joseph Smith to craft a personal, autobiographical story. In both cases, such awakeners look to a specific, though diasporatic, community to shape their autobiographical accounts. The community, including other awakeners who tell similar stories, offers the story model that individuals can use to express their sociomental allegiance to the group. In turn, individuals construct and mobilize their autobiographical stories in a way that upholds and defends that community's version of the truth in the face of competition.

When we consider that individual awakeners are embedded in communal discourses, new questions arise concerning the personal and social conditions in which awakening stories are told. Are there certain social conditions or periods of history that favor collective awakening narratives or predispose individuals to tell autobiographical stories about discovering “truth?” Early religious and philosophical awakening 
narratives arose during a historical epoch that Jaspers referred to as the Axial Age. This period in history was marked by violent upheaval and conflict ${ }^{2}$ and, as religious scholar Karen Armstrong notes, the Axial sages (including Plato, the Buddha, Zarathustra, and others) sought to bring moral order to the world. Further, "in [later] times of spiritual and social crisis, men and women have constantly turned back to this period for guidance."3 Like the philosophers and spiritual leaders of the Axial Age, theorists if the Western Enlightenment developed their own (collective) version of an awakening narrative in response to violence and conflict in their time. Hobbes wrote Leviathan to justify the need for civil society after witnessing the atrocities of the English Civil War. Rousseau wrote Discourse on the Origin of Inequality in order to address the injustices he perceived to plague $18^{\text {th }}$ century France. Later, Marx and Engels posited their own version of a collective political awakening narrative to propose a historical solution to what they perceived as brutal and expanding class exploitation in the era of industrial expansion. In each of these historical cases, theories and foundational models of awakening emerged during times of social upheaval. In each case, religious, philosophical, and political theorists provided story models and collective discourses that individuals can look to in order to construct their personal awakening stories.

While early foundational awakening narratives (at least those that are collectively remembered) arose during times of social crisis, such crises are defined by marked breakdowns in moral order and solidarity, a condition that Durkheim referred to as anomie. ${ }^{4}$ However, such marked social crises do not appear to be necessary to foster autobiographical awakening stories in the modern world. Indeed, some individuals tell awakening stories in direct response to conditions of social unrest (war, for example, on a national level, or due to abusive conditions within a family). However, many others tell 
similar stories without reference to such a crisis, typically expressing a more amorphous malaise, fear, isolation, or dissatisfaction with the status quo of their current situation. All awakeners express a sense of sociomental alienation and many convey a deep sense of betrayal, but awakeners do not appear to stem from a particular social location or tell their stories in response to any one particular situation. Perhaps, as Kenneth Gergen argues, such conditions of upheaval are the norm in this age, an unavoidable consequence of the "social saturation" and "multiphrenic condition" that defines modernity. ${ }^{5}$ As awakeners tell their stories, many express a relief at having found a community of truth in the world, a secure place in a complex and threatening environment. When they do, however, they may be unintentionally and unavoidably driving the very phenomenon of cultural conflict that creates conditions of insecurity and contention around them. As they tell their stories in public arenas, embracing one truth upon the rejection of another, awakeners fuel the cultural conflict from which they seek relief in their community of like-minded others.

Previous studies of autobiography have highlighted the way that contexts and occasions shape how we present ourselves to an audience or cooperate with significant others to account for our lives. By highlighting the context or the occasion of storytelling, such work inherently emphasizes the interactive small group dynamics that shape our personal accounts. ${ }^{6}$ Admittedly, I am not primarily concerned with the interactive dynamics of storytelling, but rather I am focused on a story formula that spans multiple groups, substantive issues, and historical contexts. I have shown how various groups, with various interests, make use of the same story formula to advance strikingly different, and often oppositional, claims about truth and reality. They use the same story formula in pursuit of very different objectives. As opposed to focusing on the 
internal dimensions of small group interactions, I have instead been driven by questions about how individuals and communities use autobiography in a broader cultural arena. What cultural purpose do such stories serve? And I have looked to the narratives themselves for answers. Further, I have highlighted the role of community over the role of context and occasion. Communities are not bound by the same spatial and temporal constraints. They cohere at certain times in certain spaces (including online environments) but they manifest primarily as the sociomental allegiances of their members. They are imagined, 7 sociomental constructions that individual members keep alive in various ways, one of which involves adhering to the group's storytelling conventions.

Autobiographical communities are a particular type of what Eviatar Zerubavel terms an optical community. ${ }^{8}$ They are reference groups with sociomental norms that shape the way adherents see, know, and remember the world. Such groups shape the contours of our objectives and concerns - what we deem to be important and what consider to be a "going concern." 9 Further, as Fleck notes with regard to thought communities more generally, these groups shape our perception of the possible. ${ }^{10}$ However, compared to the traditional notion of an optical or thought community, the concept of autobiographical community specifically highlights the way that such social groups are made up of members who tell patterned stories about their lives. Membership in such communities requires that one accounts for one's life in a particular way. In the case of autobiographically communities, they are first and foremost evidenced by autobiographical stories themselves. The communities take form via the stories individuals tell about their lives and such stories provide a window into 
the organization of cultural life. This seemingly personal, storied dimension of self has an important place in a cultural and cognitive sociology.

In order to elaborate the process by which certain events come to be seen, understood, and felt as “traumatic," Jeffrey Alexander, building on Weber's comparative analysis of religion, ${ }^{11}$ describes the role of "carrier groups" in a cultural "trauma process." 12 Alexander shows how such groups work to make an experience carry the meaning of "traumatic." They work to win adherents to their definition of a morally significant situation. According to Alexander,

Carrier groups have both ideal and material interests, they are situated in particular places in the social structure, and they have particular discursive talents for articulating their claims - for what might be called "meaning making" - in the public sphere. ${ }^{13}$

Like carrier groups, autobiographical communities are engaged in a similar process of meaning making. Some groups work to define war. Others work to attribute meaning to sexuality and sexual orientation. Some are focused on the consequences of trauma and others on the nature of the divine. Despite their many differences, however, autobiographical communities use life stories to convince a wider audience that a certain morally and politically salient events ought to be defined and understood in a particular way. While they make "use of the particularities of the historical situation, the symbolic resources at hand, and the constraints and opportunities provided by institutional structures,"14 autobiographical communities also draw on historically durable and generic story formulas to make their claims. The awakening narrative formula is one of such durable, socially patterned, and flexibly applicable cultural tools. Others might include "rags to riches" story formulas that individuals use to portray a 
self-made triumph and success (like the story Josiah Bounderby in Charles Dickens's novel, Hard Times, which is formally quite similar to the biographical story of AfricanAmerican community leader Booker T. Washington, or the iconic biographical account of Abraham Lincoln) or formulaic moral tales about personal sacrifice for the greater good (like the Christian story of Jesus, which is formally reproduced by C. S. Lewis as the character Aslan, the lion in book one of The Chronicles of Narnia). Such formulaic autobiographical stories, like the awakening narrative formula, are durable cultural resources that individuals and communities adapt to their particular concerns and situations. They follow the same social pattern across divergent settings. Such autobiographical formulas are an important part of the cultural toolkits ${ }^{15}$ we draw from to make meaning in the world.

Building on insights from Zerubavel's cognitive sociology and Alexander's theory of cultural trauma, we can use the interrelated themes I have identified throughout this analysis to outline what a more general cultural and cognitive sociology of autobiography might involve. Generalizing from this analysis of awakening narratives, such a sociological approach to life stories should entail five main interrelated principles.

First, autobiography is a form of social memory. As individuals tell stories about their lives, they do more than recount the personal past. They also define past actions, experiences, and relationships that involve other people and they direct these mnemonic accounts to various audiences. Some individuals mobilize their personal memories to define socially relevant events, both ongoing and already passed, as they work to shape the dominant collective mnemonic record of such events. Others use their personal accounts to shape the socially accepted frameworks of individual memory with regard to 
particular issues. Autobiographical communities, in turn, use life stories to assert mnemonic authority in the face of competition. Like the groups in this study who display personal accounts online, they deploy life stories as tools in contentious mnemonic battles and argue that the past has a certain meaning because their individual members offer personal testimony in support of that particular meaning. A cultural and cognitive approach to autobiography certainly has a place in the growing field of social memory studies.

Second, related to the question of memory, autobiography is a form of social time. All narratives have their own temporalities. ${ }^{16}$ As opposed to any notion of chronometric time or developmental time, autobiographical time flows by its own storied logic. When telling stories about their lives, many individuals (like the awakeners cited throughout this book) split their lives into discrete periods. They apply a logic of periodization ${ }^{17}$ to their personal accounts to mark more socially relevant distinctions between different historical periods, communities, or ways of seeing. Others express continuities between past and present, often asserting chains of cause and effect in order to find the root of current personal troubles in past socially relevant issues, situations, and circumstances. ${ }^{18}$ Such individuals use a logic of historical continuity to create a sense of community stability and durable collective identity as they share their stories with others. ${ }^{19}$ Finally, some individuals may portray autobiographical time as a cycle to convey the sense that a socially shared history is repeating itself. Individuals use autobiographical time -storied continuities, discontinuities, and cycles - to advance particular claims and explanations as they work to make meaning in the world. Such an explicit focus on the formulaic, socially constituted structure of autobiographical time 
will allow us to consider how individuals and communities use the life course as a cultural tool.

Third, autobiography is a form of social epistemology. Ever since the pioneering work of Karl Manheim ${ }^{20}$ and, later, Thomas Kuhn, ${ }^{21}$ sociologists have been interested in the social construction and organization of knowledge. Advancing an "evaluative and dynamic" 22 sociological theory of knowledge, Mannheim recognized the culturally contentious nature of contending realities when he wrote,

All the conflicting groups and classes in society seek [...] reality in their thoughts and deeds, and it is therefore no wonder that it appears to be different to each of them [...] But as we proceed, it becomes more and more evident that it is precisely the multiplicity of the conceptions of reality which produces the multiplicity of our modes of thought $[\ldots]^{23}$

While Mannheim and other social epistemologists consider the individual to be a vessel of culturally and historically situated knowledge, they have not explicitly considered autobiography as an analytic domain. In one exception, Patricia Hill Collins considers the published autobiographies of prominent African American women as evidence of the experiences typical shared by African American women in general, experiences that provide a social standpoint that serves as a basis for their unique knowledge of the world. ${ }^{24}$ However, Collins limits her analysis to a normative evaluation of these accounts. She does not consider the social function of autobiography in the social sphere. If a central goal of a social epistemology is to reveal "how knowledge operates as a principle of social organization - for example, by motivating people to act in certain ways with regard to each other and their environments," 25 then autobiographical stories are important, expressive manifestations of social knowledge. They both reflect and seek 
to advance certain cultural conceptions of knowledge and reality in the world. As awakening stories show, individuals use life stories to make knowledge claims and define the parameters of truth and falsehood. Further, awakeners use their autobiographical stories to make epistemic distinctions between dueling communities and establish their social standpoint or sociomental location in the world. In short, one way people deal with the "problem of knowing" 26 is be telling stories about their lives and sharing those stories with others.

Fourth, autobiography is a form of social drama. The accounts we construct about our lives are worlds of meaning with morals and plotlines. They contain characters, props, settings and scenes, acts and events, agents and attributions of agency, purposes and intentions. Such a perspective expands Kenneth Burke's pentad of dramstism ${ }^{27}$ to include many of the more interactive and performative elements identified by Goffman, such as the use of figurative props and the performance of self. ${ }^{28}$ However, in the cultural and cognitive analysis of autobiography, we should seek to reveal how such dramatic scenes, acts, motives, and interactions take storied form. Further, we should ask what these storied dramas say about the optical norms and storytelling conventions of the storyteller and the storytelling community. Life stories contain performative and dramaturgical dimensions that facilitate the ascription of meaning and motive. As awakening narratives show, individuals use their autobiographical accounts to construct and portray their own agency and forfeit agency to other beings, real or imagined. They use stories about life experiences to attribute cognitive authority to themselves as well as locate such authority in a god, a therapist, a political organization, or the merits of experience, for example. They use narrative props and settings to convey transformative, liminal experiences. They can divide themselves 
into two or more characters, portraying a temporally divided form of self-interaction that mirrors cultural and cognitive divisions between communities. Further, individuals use autobiographical stories to portray social bonds of solidarity and express the rifts and sentiments of social alienation.

Finally, autobiographical stories are communicative acts ${ }^{29}$ that are directed at a multifarious audience. The process of telling a story about one's life - whether sharing the story in person, posting it online, or including it in a published collection - is a social action designed to win others over to a common understanding of some issue or situation. Like the awakeners whose stories are displayed throughout this analysis, individuals use their life stories as testimony. Further, such testimonials often contain multiple dialogical orientations. As they tell autobiographical stories, individuals wield their experiences as evidence. They work to establish cognitive authority and win the hearts and minds of others as they advance certain claims that pertain to important issues. Given such a perspective, autobiographical communities use autobiographical stories to draw others into the fold. Like Everett Hughes's "going concerns," ${ }^{\circ}$ or Alexander's carrier groups, autobiographical communities seek to control "the means of symbolic production" ${ }^{11}$ and expand the adherents to their collective worldview.

A cultural and cognitive sociology of autobiography should take these five dimensions into account. Using such an approach, we can illuminate the ways that social movement organizations, religious groups, therapeutic support communities, sexual identity groups, and other institutions use autobiographical stories to do cultural work perform meaning. Further, we can explore the ways individuals use life stories to establish their authority to define the tensions and solidarities that characterize families, nations, and other communities. We can also explore the genre differences among 
diaries, internet profiles, published memoirs, and confessions. A cultural and cognitive sociology of autobiography can illuminate the role of autobiography as a vehicle for making social problems claims, defining psychological concerns, expressing one's faith, and proclaiming one's sexuality. By explicitly focusing on autobiography as an analytic domain, we can reveal important ways that individuals and communities work to make meaning in the world by telling stories about life experiences. 


\section{APPENDIX A - METHODOLOGICAL NOTE}

This is a theme-driven narrative analysis. In each chapter, I develop a central argument by highlighting a diverse array of examples from multiple otherwise different realms of social life. Such an approach to narrative analysis requires a careful balance of interpretive work and the social pattern analyst's commitment to social geometry and cross-contextual similarity. ${ }^{1}$ With particular attention to autobiographical stories that are focused on political, psychological, religious, and sexual issues, I combine a focused analytic interpretation, with an adapted two-prong version of what Gubrium and Holstein call "analytic bracketing"2 in order to advance what Glaser and Strauss refer to as multi-area formal theory. 3

My general interest in awakening narratives proceeds from more of a phenomenological perspective than Gubrium and Holstein embrace. 4 However, I apply their use of bracketing as "a way of temporarily putting some matters of empirical interest aside in order to bring other matters into focus." 5 Such an approach to using narrative as sociological data fits beautifully with the imperative of social pattern analysis to "focus on, and thereby uncover, generic patterns." 6 My application of analytic bracketing involves two levels. First, I select the passages that I quote in this book from sites that contain multiple and sometimes hundreds of stories. Following Zerubavel, I consider my "deliberate effort to view" my cases "selectively as a methodological virtue, a necessary precondition for staying analytically focused.” Similarly, Edward S. Casey explains how such a selection of examples is required by the phenomenological method. He writes, 
there is no need to analyze every example that occurs or might occur within a given domain of experience. Typically, only the most promising are seized upon those that exhibit an essence or essential structure with a maximum of evidential lucidity. For this reason, considerable care must be taken in the preliminary choice of examples, since it is by their examination that we are to achieve eidetic insight. 7

Second, I further hone my methodological focus by carefully bracketing of the parts of those narratives that serve to illustrate the analytic theme at hand. Awakeners often construct lengthy narratives that are too complex and cumbersome to cite as a whole. In such cases, I select specific sections of their stories in order to highlight the particular theme of concern and emphasize the patterned commonalities shared by multiple stories that are otherwise viewed as very different. Consequently, I relegate other aspects of these stories to the methodological backburner in order to sustain my theme-driven focus. Further, I use bracketed ellipses - [...] - to signify the parts of the story that I have removed for the purpose of focus and brevity. I then hone my interpretation of the quotation in order to signify its empirical and theoretical relevance to the current theme-based discussion. Such a two-pronged bracketing strategy allows me to illuminate common social patterns among a quite diverse set of stories.

In addition to these strategies of selectivity, I often interpret the sociomental dimensions of the stories I put forth. I provide a focused interpretation to emphasize the way that the story segment fits into my larger argument. Part of such a focused interpretation involves highlighting analytic commonalities that would otherwise be less clear - actively pointing out what one story has in common with others. This focused interpretative work allows me to advance what a multi-area formal theory - I focus on multiple, otherwise different manifestations of awakening stories in order to advance theoretical insight into their shared awakening narrative formula. Highlighting the 
social patterns that emerge from multicontextual evidence, ${ }^{8}$ I restrict my interpretation of each quotation to show it's relevance to a greater theme. After demonstrating this analytically-focused relevance, I then leave each particular example and move on to another in order to remain committed to the particular analytic point of concern. Using such a combination of analytically-focused interpretation and analytic bracketing allows me to treat groups of otherwise very different stories as a cluster of narratives. 9 In other words, the interpretive pay off of the analysis only emerges over the course of several illuminating examples. Each story is only relevant in-so-far as it adds to my building discussion of a common theme. Thus, I combine analytic bracketing and focused interpretation along with the framework of multi-area formal theory in order to advance a narrative-oriented social pattern analysis of awakening stories. 


\section{APPENDIX B - DESCRIPTION OF DATA}

I analyze autobiographical stories that individuals post on various websites pertaining to political, psychological, religious, and sexual concerns. I consider these websites to be virtual narrative environments. They are online storytelling contexts where individuals post stories about life-changing discoveries of "truth." Virtual narrative environments allow for autobiographical communities that span previously obstructive geographic and temporal divides to cohere in a common space and share autobiographical stories. They are perpetually accessible spaces where individuals share life stories about salient concerns, many of which may not arise in face-to-face contexts where social norms and taboos prohibit their discussion. When individuals post such stories online, the World Wide Web becomes a medium that facilitates a transmission of knowledge, emotion, and memory. Further, this virtual medium becomes a space where individuals cooperate, even when they are not simultaneously present, to develop shared ways of seeing the world - shared cognitive norms. Internet technology allows public and analytical access to multiple narrative environments while elucidating the ways that personal accounts reinforce various conceptions of "truth." These research sites allow me to explore the sociological implications of new media technologies while also considering the connection between autobiographical and collective accounts of the past as I reveal the social logic behind our seemingly personal discoveries of "truth."

Each of the sites I study represents a broader autobiographical community. In some cases, individuals use the Internet to form durable autobiographical communities. In other cases, previously formed communities and organizations use the Internet to circulate stories and make stories available to a public audience. In either situation, 
these websites are social locations that display the cognitive norms and storytelling conventions of the community that is hosted there. In this appendix, I give a brief description of each online site from which I gathered and analyzed awakening narratives.

\section{Iraq Veterans Against the War - http://ivaw.org}

Upon visiting the homepage of the social movement organization, Iraq Veterans Against the War (IVAW), one is greeted by a slogan next to the organization's insignia that reads, "You are not alone." IVAW was founded by six returning veterans of the Iraq war with the guidance of anti-war Vietnam veterans at the summer convention of Veterans for Peace (a coalition group) in 2004. Its members are all individuals "who have served or continue to serve in the U.S. military since September 11th, 2001.” The group officially advocates, "Immediate withdrawal of all occupying forces from Iraq [...] Reparations for the human and structural damages Iraq has suffered" and "Full benefits, adequate healthcare (including mental health), and other support for returning servicemen and women." ${ }^{1}$ While these principles are put forth as the condition for membership, many (though not all) of the group's members are also highly critical of the U.S. military as an institution as well as the international policies and objectives of the U.S. government. Some IVAW members claim that they were against the Iraq war from its inception, but most joined the military and war effort in support of the war. These individuals describe awakening to the "truth" about the war and, more generally, the political policies of the U.S. government. 
In addition to the various statements of purpose, information about the organization's upcoming events, relevant documentary film trailers, and membership application procedures, the IVAW website hosts a large "Member Profiles" section and a "Member Blog" where individual IVAW members post various stories about their service experiences and commentaries on war-related political issues. The IVAW boasts over 1,700 members and nearly 250 maintain some sort of online presence at the organization's website. Some members limit their post to a single, short blurb about themselves. Others write multiple detailed stories about their experiences and often elaborate why they have chosen to oppose the war and join IVAW. Many of these accounts contain at least one photo and, more so recently, members are posting videos of themselves at political actions. This site (like most in this study) does not allow members to directly interact with one another online. However, aside from the annual IVAW convention, the group's website is the only space where individuals from many of the group's chapters, which are spread throughout forty-eight states in the U.S., maintain a collective presence. This is an important space where the group's members can share their stories with each other and the world at large.

\section{Susan Smiles - Surviving Childhood Sexual Abuse - http://www.susansmiles.com/}

The stated purpose of the Susan Smiles - Surviving Childhood Sexual Abuse website is "to provide a safe and comforting place where survivors may know they are not alone in their fight to survive the trauma of childhood sexual abuse.” The site was started by an individual self-identified survivor of childhood sexual abuse who posts her 
own story and writes, "This web site is dedicated to my inner child. She is a strong and resourceful little girl.”2 Like the Iraq Veterans Against the War site, the Susan Smiles site provides a space where individuals who would otherwise not be able to meet can come together and share personal stories. Unlike the case of IVAW, however, such individuals do not belong to an official organization that hosts annual conventions. Many of these individuals would otherwise never meet with this autobiographical community without the Internet. Further, the Susan Smiles site allows them to discuss the controversial topic of sexual abuse outside of their immediate environments, where their accusations might lead to threatening social repercussions from family or community members.

In addition to poetry, links to other survivor-oriented sites, and other relevant information, there are over one hundred stories posted by self-identified survivors of childhood sexual abuse on the Susan Smiles website. Some individuals report that they have always remembered their abuse and others describe recovering memories of the abuse years after it occurred. Some individuals post their stories with a first name and include a contact email address. Others remain anonymous. The site does not allow for writers to directly interact online. However, in addition to offering a space for individuals to post stories about their experience of abuse, the Susan Smiles site also hosts a pen pal service through which survivors can contact one another in order to develop a relationship of correspondence. Further, many survivors comment that they read several stories of others before they posted their own. Finally, many survivors who post stories to this site express a sense of relief and gratitude for being able to share their story with others who have had similar experiences. Despite the lack of actual interaction on the site, there is a clear sense of community. 


\section{Safeguarding Our Children - Uniting Mothers - http://www.healthyplace.com/abuse/soc-um/about-safeguarding- our-children-united-mothers/menu-id-821/}

Safeguarding Our Children - United Mothers (SOC-UM) was founded in 1994 by Debbie Mahoney, the mother of a victim of abuse, and others in order "to assist in the fight for public disclosure of California's registered sex offenders." 3 Since the organization's inception, its purpose has expanded to include more widely focused educational and policy-oriented initiatives. Since the time I initially discovered the organization (in 2003), its web domain has moved three times: from soc-um.com to socum.org and then to its current location where it exists as a sub-page to HealthyPlace.com, a site focused more broadly on a wide variety of mental health issues. In its current manifestation, the SOC-UM site does not host any survivor stories. However, it once hosted a collection of stories posted by self-identified survivors of childhood sexual abuse. Like the Susan Smiles site, SOC-UM allowed individuals who would otherwise never meet to "gather" in a safe environment in order to share stories about this difficult subject matter. There is currently no explanation as to why the stories are no longer available at the SOC-UM site. However, the site still provides a variety of resources and links to material relevant to childhood sexual abuse. In addition, the "about us" page reports,

SOC-UM has remained an all volunteer organization, assisting with the passage of laws that facilitate mental health and safety to our children. Additionally, we will continue to develop programs that provide children 
the needed safety tools. We will fight for those whose very souls are stolen by the silent trappings of manipulative persons. 4

\section{The False Memory Syndrome Foundation - http://fmsfonline.org/}

The False Memory Syndrome Foundation (FMSF) was founded in 1992 by current executive director, Pamela Freyd, and others. Notably, Pamela Freyd is the mother of renowned psychologist and recovered memory theorist, Jennifer Freyd (who is herself an awakener). Pamela Freyd founded the FMSF after her daughter recovered her own memories of abuse. 5 Thus, in some ways, the cultural debate between those who recover and those who retract once-recovered memories of abuse was sparked by an intra-familial dispute. The FMSF reports that Pamela Freyd and other parents founded the group "because they saw a need for an organization that could document and study the problem of families that were being shattered when adult children suddenly claimed to have recovered repressed memories of childhood sexual abuse."6 The foundation redefines recovered memories to be "false memories," pathologizes the condition of believing that one has recovered memories, and is highly critical of psychotherapists who claim that such recovered memories are legitimate. The stated goals of the organization are "to seek the reasons for the spread of FMS [False Memory Syndrome] that is so devastating families, to work for ways to prevent it," and "to aid those who were affected by it and to bring their families into reconciliation." 7

Unlike the other sites in this study, most of the stories posted on the website of the False Memory Syndrome Foundation were previously published in the 
organization's newsletter, which is now distributed to members in electronic format. Selected retractor stories are reproduced in HTML format and the newsletter itself, which was published between six and twelve times per year from 1992 through 2002 and now comes out quarterly, is archived on the organization's website. Some of the stories that appear in the organization's online materials are accompanied by a name and many are anonymous. All, however, are framed with editorial comments and interpretations. The group clearly uses the accounts of retractors, who are all by definition awakeners, to bolster its organizational objective to undermine the legitimacy of recovered memories. Retractor stories are offered as proof that False Memory Syndrome exists and poses a threat to the integrity of loving families. These stories are also put forth, in the group's perspective, as evidence of the pain and suffering caused by recovered memory therapy. While the FMSF website does not allow space for individual retractors to directly interact, the organization does hold conventions where retractors and accused parents gather in person to advance the objectives of the group. ${ }^{8}$

\section{Precious-Testimonies}

\section{http://www.precious-testimonies.com/}

The stated primary purpose of the Precious Testimonies website "is to help share the Good News of the Gospel of Jesus."9 This online, Born Again Christian ministry displays hundreds of Born Again Christian testimonies posted by individuals who have visited the site and chosen to submit their personal story. The ministry also prompts visitors to share their story as part of their obligation to the faith. Each account posted to the site is an awakening narrative that the awakener offers as evidence of the truth of 
Christ's existence and the Christian promise of salvation through faith. Many describe living a miserable, unhappy, and sinful life until awakening to the "truth" of Christianity and becoming "Born Again." Further, many of the stories posted to this site include photos and links. Some include video testimonies. In addition, very few are anonymous and many include contact information so that readers can correspond with the awakener. Finally, at the end of every conversion story, ministry leaders prompt the reader to email their own story, offer additional links to scriptures and ministry statements, and ask the site visitor to make a financial contribution via a Pay Pal account. Sites like Precious Testimonies and Faith Travels (described below) represent an effort to move the traditional evangelical mission online. As such, they provide a narrative sense of the Born Again community that transcends previously limiting boundaries of time and space. Such a group is an autobiographical community by virtue of the fact that its members must tell a personal conversion story to belong.

\section{Faith-Travels}

\section{http://www.faith-travels.org/}

The home page of the Faith Travels website, another online evangelical ministry, begins with the slogan "From one person to another when you share your testimony!"10 Such a slogan emphasizes the interpersonal connections involved with sharing common autobiographical stories and suggests a sense of community in the process. This site contains nearly thirty stories that were submitted by online visitors. Most include photos and some include links to video accounts. Like Precious Testimonies, Faith Travels prompts visitors to share their own conversion accounts, which those who run 
the site define "as a description of God's divine intervention in your life, during a time of stress, tragedy or joy." ${ }^{11}$ Like Precious Testimonies, awakeners who post their stories to this site express a sense of community by virtue of their common sense of having overcome adversity by discovering the "truth" of the Christian gospel.

\section{Mormon Converts}

\section{http://www.mormonconverts.com/}

At the homepage of MormomConverts.com, visitors are greeted with the invitation to, "[j]oin our community of saints who have converted to the Church of Jesus Christ of Latter-day Saints and have shared their story of faith, courage and testimony." 12 The banner at the top of the page displays three photos, all of which depict a man and a woman in a heartfelt, loving interaction. Further, the "about this site" link brings one to a page that reads,

In a day when many are searching for eternal truths; desiring to find peace and happiness in a world filled with hate, war, poverty and seeming injustice, this site will offer hope and an opportunity to find peace [...] We invite you to share your story of conversion to the Mormon Church or join our community of Christians who desire to know the truths that bring eternal happiness. ${ }^{13}$

Just below the "about this site" link is another link that prompts visitors to submit their own awakening stories. Thus, there is a clear sense of community on this site that stresses common commitment to the "eternal truth" of Mormonism.

In addition to an offer to receive a free newsletter, an introductory breakdown of Mormon beliefs with a link to Mormon.org (the "official website of the Church of Jesus Christ and Latter Day Saints"), and a video displaying various Mormon temples, this site 
contains over eighty stories told by those who awoke to discovery the "truth" of, and subsequently converted to, the Mormon Church. Notably, these awakening stories are classified by the awakener's former belief system. While there is an "atheist" category which contains five stories, most awakeners who post stories to these sites were once members of another religion (including Anglican, Baptist, Catholic, Church of England, Church of Ireland, Church of Scotland, Congregational Ministry, Jewish, Lutheran, Methodist, Pentecostal, Presbyterian, Protestant, Unitarian, and Non-Denominational). Further, there is also a section that includes the awakening stories of individuals who were raised Mormon, left the church in search of truth, and returned when they realized that Mormonism was "true" all along. The fact that these multiple categories of rejected religions are included is itself important. Collectively, they help to reinforce a foundational claim of the Mormon Church and a fundamental aspect of Mormon prophet Joseph Smith's awakening story - that all other religions of the earth are "false."

\section{Recovery from Mormonism}

http://www.exmormon.org/

The Recovery from Mormonism site contains over 700 stories posted by “exMormons" as well as online bulletin boards, newsgroups, links to various blogs, as well as numerous links to various relevant topics and other user-generated information, such as an incredibly detailed admonition to those "thinking of joining Mormonism," complete with its own hundreds of notes and links. ${ }^{14}$ According to the homepage of Recovery from Mormonism, the site is "for those who are [q]uestioning their faith in the 
Mormon Church [a]nd for those who need support [a]s they transition their lives to a normal life."15 Thus, like MormonConverts.com, Recovery from Mormonism stresses a clear sense of community. Unlike MormonConverts, this site is "not affiliated with any religion and [does] not advocate any religion." 16

Some of the personal stories posted to Recovery from Mormonism are accompanied by a name and email address. Others are anonymous. Many are posted by individuals who have awoken to the "truth" and rejected Mormonism but remain in close personal contact with "true blue" (their term) Mormon family and friends. Thus, this website offers one of the only sociomental communities to which such individuals have access. Like the Susan Smiles site and the older version of the SOC-UM site discussed above, users are relatively free to post their own accounts to this site. Those who run the site exercise very little editorial control. Further, in addition to the 700+ awakening stories that have been posted to this site, there is an interactive "Biography and Story Board" that contains over 500 additional awakening stories and allows users to comment on one another's accounts. There is also a "Recovery from Mormonism Board" (formerly called the Ex-Mormon Forums) where participants can directly interact with one another and discuss a variety of topics. As of July 2009, there were over 11,000 posts on this discussion board. Within the interactive sections of the Recovery from Mormonism site, members often corroborate each other's sense of repulsion from the Mormon Church. Further, they cultivate a sense of community by stressing the commonalities in their autobiographical experiences. 


\section{PostMormon}

\section{http://www.postmormon.org/exp_e/index.php/home}

Like the IVAW and Susan Smiles site, visitors to the PostMormon homepage are greeted with the statement, "You are not alone! (emphasis in original)" ${ }_{17}$ Above this caption, similar to the MormonConverts site, appears several scrolling picture of friends and families engaged in loving embrace. The sense of community cultivated on the site is clearly expressed by the introduction to the mission statement, which reads,

Post-Mormons are members of a rapidly growing community of families and individuals who have voluntarily left Mormonism. We choose to no longer base our lives, and the lives of our children, on "truths" [notably in quotes] dictated by others. We believe that truth is freely available to any honest, diligent seeker regardless of creed, age, race or sexual orientation. ${ }^{18}$

Like Recovery from Mormonism, PostMormon.org contains a section of "exit stories" (nearly 100) and an interactive discussion forum that is linked under the label "Our Community," in addition to several other resources for site users. Further, also like Recovery from Mormonism, some of the personal stories posted to the Post Mormon site are accompanied by a full name while others are anonymous. In addition, many of these awakeners sign their stories with an online pseudonym like "MsGabbie2u," "warmfuzzylogic," or "Moonshine." Many are posted by individuals who have awoken to the "truth" and rejected Mormonism but remain in close personal contact with activelyengaged Mormon family and friends. In the discussion forum, most participants have avatars, virtual identity symbols that they use to identify themselves. Below these avatars (many of which are satirical or comical) is a description of one's seniority status. 
These include, in descending order, "Administrator," "Long Timer," "Sr. Member," "Member," Jr. Member," and "Newbie." One of the most active discussion threads, titled "Introduce Yourselves - Tag You're It," encourages "Newbies" to share their personal awakening story about rejecting Mormonism. As of July of 2009, this thread had 3,246 posts and 127,314 views. Inevitably, more experienced site users offer comments to reinforce the accounts posted by newer (sociomentally younger) awakeners. Long-time site users often welcome new users and explicitly reinforce aspects of their stories that portray a sociomental alienation form the Mormon Church. Often, other aspects of their accounts are ignored.

\section{People Can Change}

\section{http://www.peoplecanchange.com/}

The slogan of People Can Change, posted at the top of the homepage of this selfdescribed "non-profit educational, outreach and support organization,"19 defines the purpose of the site. It reads, "Men who have overcome unwanted sexual attractions supporting others who seek similar change." ${ }^{20}$ Such a slogan conveys a support group like community while also granting cognitive authority to the awakeners who post stories to the site and the therapists who have treated them. In addition to various resources and information about "sexual reparative therapy" and links leading to information about various support groups, therapists, and "healing weekend" retreats, this site features thirteen autobiographical stories written by men who awoke to know the "truth" about their same sex attractions as they worked to embrace a heterosexual lifestyle. Some of these awakeners once embraced a gay lifestyle. Others struggled with 
their homosexual attractions as they searched for the "truth" about their sexuality. Almost all account for life-changing experiences and discoveries in sexual reparative therapy.

People Can Change is a non-denominational member-group that is part a network of various organizations, some religious, some psychologically-focused, others research-based, that are members of the PATH coalition. ${ }^{21}$ This coalition includes more widely-known groups like that National Association for Research and Therapy of Homosexuality and Courage (a Catholic group described below), among many others. Some of the autobiographical accounts posted to this site are excerpts of longer stories that were originally published elsewhere. Others were written specifically for People Can Change. As of April of 2009, People Can Change launched a blog 22 and as of July 2009 there were eleven registered members but only three posts. Like the Mormon apostate communities discussed above, People Can Change may be looking to build an interactive resource where "older," more committed members can council newer members who are less secure in their adherence to the sexual reparative worldview. If successful, such an interactive discussion forum would bring the dynamics of authority that are characteristic of sexual reparative support groups ${ }^{23}$ and ex-gay ministries online, expanding their reach beyond current temporal and spatial boundaries.

\section{Courage}

\section{http://couragerc.net/index.htm}

Courage is a Catholic group that "ministers to those with same-sex attractions and their loved ones." 24 Upon visiting the site, one is immediately greeted with the 
message, "Welcome to the Courage Community." This site has over forty autobiographical testimonies, most of which were initially given at one of the organization's annual conferences and some of which are written by Priests who struggled with same sex attractions. The site also dons links to many more accounts of those who discovered the "truth" about their sexuality in consultation with an ex-gay ministry, including video testimonies that are accompanied by Catholic sermons. Further, visitors to this site can join online listservs relating to different ex-gay ministry topics and sign up for in-person "reparational groups."

\section{Beyond ExGay}

\section{http://www.beyondexgay.com/}

Described as "an online community for those who have survived ex-gay experiences," 25 Beyond ExGay stresses the process of building community through sharing autobiographical stories. Those who run the site write, "So often healing comes through community and through sharing our stories and experiences with each other." 26 This site actively conveys as sense of "kinship in this journey" 27 in order to stress solidarity among those who once awoke to discover the "truth" as they rejected their homosexuality and have since rejected their prior awakening as "false," embracing their "true" homosexuality and queer-positive worldview. Beyond ExGay was founded by Christine Bakke (who reports, "I [...] re-came out to myself in 2003") and Peter Toscano, both of whom post their awakening stories on the site. Further, Beyond ExGay contains nearly forty autobiographical stories posted by likeminded awakeners, followed by a prompt that invites others to share a personal story. Most of the Beyond ExGay 
awakening stories contain at least one photo and very few are anonymous. In addition to the autobiographical accounts of those who "survived ex-gay experiences," Beyond ExGay provides a variety of resources (including news articles, visual art, video, poetry, and a glossary of terms that new visitors to the community can use to orient themselves to the colloquial terminology). This site also contains information about upcoming inperson meetings and conferences sponsored by the Beyond ExGay community. 


\section{REFERENCES:}

Abbott, Andrew. 2001. Time Matters: On Theory and Method. Chicago, Illinois: University of Chicago Press.

Adam's story 2007. Kokesh, Adam Charles. "The Humanity Shield.” Retrieved June 2007 (http://www.ivaw.org/node/772).

Adler, Patricia A. and Peter Adler. 2008. "The Cyber Worlds of Self-Injurers: Deviant Communities, Relationships, and Selves.” Symbolic Interaction 31:33-56.

Alan Chamber's story. 2005. Chambers, Alan. “A Dream Come True.” Retrieved June 2008 (http://exodus.to/content/view/220/149/).

Alexander, Jeffrey C. 2004a. "Toward a Theory of Cultural Trauma." Pp. Pp. 1-30 in Cultural Trauma and Collective Identity, edited by Jeffrey C. Alexander, Ron Eyerman, Bernhard Giesen, Neil J. Smelser, and Piotr Sztompka. Berkeley: University of California Press.

-----. 2004b "On the Social Construction of Moral Universals: The 'Holocaust' from War Crime to Trauma Drama." Pp. 196-263 in Cultural Trauma and Collective Identity, edited by Jeffrey C. Alexander, Ron Eyerman, Bernhard Giesen, Neil J. Smelser, and Piotr Sztompka. Berkeley, California: University of California Press.

-----. 2007. "The Meaningful Construction of Inequality and the Struggles Against It: A 'Strong Program' Approach to How Social Boundaries Change." Cultural Sociology 1:23-30.

Anderson, Benedict. [1983] 1991. Imagined Communities. London and New York: Verso.

Angel Light's story. 2008. Retrieved August 2008 (http://www.pandys.org/escapinghades/Survivors98.html).

Ann’s story 2006. Retrieved May 2006 (http://susansmiles.com/stories5.html).

Anna's story 2008. Buttimore, Anna. "It Was as though Scales Fell From my Eyes." Retrieved July 2008 (http://mormonconverts.com/anglican/scales-fell.htm).

Anuradha's story. Bhagwati, Anuradha. Retrieved June 2008 (http://www.ivaw.org/user/90).

Anzaldúa, Gloria.1987. Borderlands/La Frontera: The New Mestiza. San Francisco, California: Aunt Lute Books.

APA 1994. Diagnostic and Statistical Manual of Mental Disorders, Fourth Edition. Washington D. C.: American Psychiatric Association. 
Arguello, Xavier. 1989. "Marxism is not Progress." Pp. 111-114 in Second Thoughts: Former Radicals Look Back at the Sixties, edited by Peter Collier and David Horowitz. Lanham, MD: Madison Books.

Armstrong, Karen. 1992. Muhammad: A Biography of the Prophet. San Francisco: Harper.

-----. 2006a. Muhammad : A Prophet for our Time. New York: Atlas Books/Harper Collins.

-----. 2006b. The Great Transformation: The Beginning of Our Religious Traditions. New York: Random House.

Arnold, Michelle M. and Stephen Lindsay. 2002. "Remembering Remembering." Journal of Experimental Psychology: Learning, Memory, and Cognition 28:521-29.

Arnold's story 2003. Steiber, Arnold. “Waking Up To Peace.” The Veteran 33,2. Retrieved February 2008 (http://www.vvaw.org/veteran/article/?id=395).

Astarte Moonsilver's story 2007. Retrieved July 2007 (http://www.postmormon.org/exp_e/index.php/discussions/viewthread/16/P4 $\mathrm{o} /$ ).

Athens, Lonnie. 1994. "The Self as a Soliloquy." Sociological Quarterly 35:521-532.

Augustine [397-8] 1961. Confessions. London and New York: Penguin Books.

Bakhtin, M. M. 1986. Speech Genres and Other Late Essays, edited by Caryl Emerson and Michael Holquist. Austin, Texas: University of Texas Press.

Bamyeh, Mohammed. 2007. Death and Dominion: The Existential Foundations of Governance. Evanston, Illinois: Northwestern University Press.

Bar-On, Dan. 1999. The Indescribable and the Undiscussable: Reconstructing Human Discourse After Trauma. Budapest, Hungary: Central European University Press.

Bardman's story 2008. Retrieved July 2008 (http://exmormonforums.com/viewtopic.php?f=2\&t=370).

Bartlett, Frederick C. 1932. Remembering: A Study in Experimental and Social Psychology. Cambridge: Cambridge University Press.

Bashō, Matsu. [1694] 1991. "The Narrow Road to the Interior," translated by Sam Hamill. Boston" Shambhala Publications. 
Bass, Ellen and Laura Davis. 1994. The Courage to Heal: A Guide for Women Survivors of Child Sexual Abuse. New York: Harper Perennial.

Becker, Howard S. [1963] 1997. Outsiders: Studies in the Sociology of Deviance. New York: The Free Press.

Bellah, Robert N., Richard Madsen, William M. Sullivan, Ann Swidler, and Steven M.. Tipton. 1985. Habits of the Heart: Individualism and Commitment in American Life. New York: Perennial Library.

Benford, Robert D. 2002. "Controlling Narratives and Narratives as Control within Social Movements.” Pp. 53-75 in Stories of Change: Narratives and Social Movements, edited by Joseph E. Davis. Albany, New York: State University of New York Press.

Benford, Robert D. and David A. Snow. 200o. "Framing Processes and Social Movements: An Overview and Assessment." Annual Review of Sociology 26:61139.

Ben's Story. 2007. "A Change of Heart: My Two Years in Reparative Therapy.” Retrieved December 2007 (http://www.peoplecanchange.com/About_Us_Ben2.htm).

Berger, Peter L. 1963. Invitation to Sociology: A Humanist Perspective. Garden City, New York: Anchor Books.

Berger, Peter L. and Thomas Luckmann. 1966. The Social Construction of Reality: A Treatise in the Sociology of Knowledge. New York: Doubleday.

Bernfeld, Suzanne Cassirer. 1951. "Freud and Archeology." American Imago 8:107-28.

Beth's story 2006a. Rutherford, Beth. “The Process.” Retrieved December 2006 (http://fmsfonline.org/retract1.html\#feb94).

-----. 2006b. "My Journey Back Home and to Truth.” Retrieved December 2006 (http://fmsfonline.org/retract2.html\#apr98).

Bill's story. 2006. Kempton, Bill. “Dear Bishop, I'm Leaving the Fold.” Retrieved June 2008(http://www.postmormon.org/exp_e/index.php/pomopedia/Dear_Bishop _Im_Leaving_the_Fold/).

Blondie's story 2003. "X’Blondie Story.” Retrieved March 2003 (http://www.socum.org/survivors/stories/blondie.html).

Blumer, Herbert. 1969. Symbolic Interaction as Perspective and Method. Berkeley: University of California Press.

Bob's story. 2008. Davies, Bob. "Looking Back and Looking Forward.” Retrieved June 2008 (http://exodus.to/content/view/558/149/). 
Boellstorff, Tom. 2009. "Nuri's Testimony: HIV/AIDS in Indonesia and Bare Knowledge." American Ethnologist 36:351-363.

Booker, Christopher. 2004. Seven Basic Plots: Why We Tell Stories. London and New York: Continuum.

Böröcz, József. n.d. "Sticky Features: Narrating in a Single Direction.” Chapter 2 in Social Change by Fusion. Unpublished manuscript.

Boyce, Mary. [1979] 2001. Zoroastrians: Their Religious Beliefs and Practices. London and New York: Routledge.

Brekhus, Wayne H. 1996. "Social Marking and the Mental Coloring of Identity: Sexual Identity Construction and Maintenance in the United States." Sociological Forum 11:497-522.

-----. 1998. "A Sociology of the Unmarked: Redirecting Our Focus." Sociological Theory 16:34-51.

-----. 2003. Peacocks, Chameleons, Centaurs: Gay Suburbia and the Grammar of Social Identity. Chicago: University of Chicago Press.

-----. 2007. "The Rutgers School: A Zerubavelian Culturalist Cognitive Sociology.” European Journal of Social Theory 10:453-470.

Breuer, Josef and Sigmund Freud. 1895. Studies on Hysteria. New York: Basic Books.

Brooke's Story. 2008. “Brooke's Testimony.” Retrieved April 2008 (http://www.faithtravels.org/web/pageid/65420/pages.asp).

Bruner, Jerome. 1987. “Life as Narrative.” Social Research 54:11-32.

Buckle, Stephen. 2007. "Descartes, Plato and the Cave.” Philosophy 82:301-37.

Burke, Kenneth. [1962] 1969. A Grammar of Motives. Berkeley and Los Angeles: University of California Press.

Bushman, Richard L. 1984. Joseph Smith and the Beginnings of Mormonism. Urbana, Illinois: University of Illinois Press.

-----. 2005. Joseph Smith: Rough Stone Rolling. New York: Alfred A. Knopf.

Butler, Judith. 1991. "Imitation and Gender Insubordination." Pp. 13-31 in Inside/Out: Lesbian Theories, Gay Theories, edited by Diana Fuss. New York: Routledge.

-----. 2005. Giving an Account of Oneself. New York: Fordham University Press. 
C. L.'s story 2008. Hanson, C. L. “8os Teen Apostate.” Retrieved July 2008 (http://www.postmormon.org/exp_e/index.php/pomopedia/8os_teen_apostate /).

Carol's Story. 2005. Retrieved May 2005 (http://www.susansmiles.com/anon7.html).

Casey, Edward S. [1976] 2000. Imagining: A Phenomenological Study. Bloomington, IN: Indiana University Press.

Catherine's story 2000. Wulfensmith, Catherine. P. 10 in Finally Free: Personal Stories: How Love and Self-Acceptance Saved Us from Ex-Gay Ministries. Washington D.C.: Human Rights Campaign Foundation.

Cavalletto, George. 2007. Crossing the Psycho-Social Divide: Freud, Weber, Adorno and Elias. Hampshire, England and Burlington, Vermont: Ashgate.

Cerulo, Karen A. 1997. "Reframing Sociological Concepts for a Brave New (Virtual?) World.” Sociological Inquiry 67:48-58.

-----. 1998. Deciphering Violence: The Cognitive Structure of Right and Wrong. New York: Routledge.

-----. 2002 (Ed.). Culture in Mind: Toward a Sociology of Culture and Cognition. New York: Routledge.

-----. 2006. Never Saw it Coming: Cultural Challenges to Envisioning the Worst. Chicago: The University of Chicago Press.

-----. 2009. “Non-Humans in Social Interaction.” Annual Review of Sociology 35.

Chad's story 2008. Nordland, Chad W. "I know that I was Home." Retrieved July 2008 (http://mormonconverts.com/Pentecostal/i-knew-that-i-was-home.htm).

Chayko, Mary. 2002. Connecting: How We Form Social Bonds and Communities in the Internet Age. Albany, New York: State University of New York Press.

-----. 2008. Portable Communities: The Social Dynamics of Online and Mobile Connectedness. Albany, New York: State University of New York Press.

Cheryl's story 2000. Johnson, Cheryl. P. 16 in Finally Free: Personal Stories: How Love and Self-Acceptance Saved Us from Ex-Gay Ministries. Washington D.C.: Human Rights Campaign Foundation.

Chodorow, Nancy J. 1999. The Power of Feelings: Personal Meaning in Psychoanalysis, Gender, and Culture. New Haven, Connecticut: Yale University Press. 
Choksy, Jamsheed K. 2003. "To Cut off, Purify, and Make Whole: Historiographical and Ecclesiastical Conceptions of Ritual Space.” Journal of the American Oriental Society 123:21-41.

Chopin, Kate. [1899] 2004. The Awakening. New York: Pocket Books.

Chopra, Deepak. 2007. Buddha: A Story of Enlightenment. New York: HarperOne.

Christie's story. 2007. Hubbard, Christie. "Member Profile" posted to the website of Iraq Veterans Against the War. Retrieved August 2007 (http://www.ivaw.org/user/158).

Christine's story 1998. Retrieved March 2003 (http://www.socum.org/survivors/stories/christine2.html).

Christopher's story 2000. Camp, Christopher C. Pp. 12-13 in Finally Free: Personal Stories: How Love and Self-Acceptance Saved Us from Ex-Gay Ministries. Washington D.C.: Human Rights Campaign Foundation.

Chu, James A., Lisa M. Frey, Barbara L. Ganzel, and Julia A. Matthews. 1999. "Memories of Childhood Abuse: Dissociation, Amnesia, and Corroboration." American Journal of Psychiatry 156:749-755.

Claire's story 2003. Retrieved March 2003 (http://www.susansmiles.com/stories4.html).

Clanchy, M.T. 1993. From Memory to Written Record: England 1066-1307. Oxford, England: Blackwell Publishing.

Cline, David. 1997. “Jersey City's Secret Memorial.” The Veteran 27,2. Retrieved May 2005 (http://www.vvaw.org/veteran/article/?id=256)

Collier, Peter. 1989. "Coming Home.” Pp. 59-65 in Second Thoughts: Former Radicals Look at the Sixties, edited by Peter Collier and David Horowitz. Lanham, Maryland: Madison Books.

Collins, Patricia Hill. 2000. Black Feminist Thought: Knowledge, Consciousness, and the Politics of Empowerment. New York: Routledge.

Comte, Auguste. [1830-42] 1975. Cours de Philosophie Positive. Pp. 71-306 in Auguste Comte and Positivism: The Essential Writings, edited by Gertrud Lenzer. New York: Harper and Row. 
Condorcet, Nicolas Caritat de. 1796. Outlines of an Historical View of the Progress of the Human Mind. New York: M. Carey, H. and P. Rice and Co., J. Ormrod, B. F. Bache, and J. Fellows. Retrieved June 2009 (http://oll.libertyfund.org/title/1669).

Cooley, Charles Horton. 1922. Human Nature and the Social Order (Revised edition). New York: Charles Scribner's Sons.

Conway, Flo and Jim Siegelman [1978] 2005. Snapping: America's Epidemic of Sudden Personality Change. New York: Stillpoint Press.

Coser, Lewis A. 1971. Masters of Sociological Thought: Ideas in Historical and Social Context. New York: Harcourt Brace Jovanovich.

Cothran, Charlene. 2008. "Redeemed! 10 Ways to Get Out of the Gay Life, If you Want Out." Retrieved November 2008 (http://www.venusmagazine.org/cover_story.html).

Crenshaw, Kimberle Williams. 1991. "Mapping the Margins: Intersectionality, Identity Politics, and Violence Against Women of Color." Stanford Law Review 43:124199.

Cuoto, Richard. 1993. "Narrative, Free Space, and Political Leadership in Social Movements." The Journal of Politics 55:57-79.

Cynical's story 2007. Retrieved July 2008 (http://www.postmormon.org/exp_e/index.php/discussions/viewthread/16/).

Dan's story 2008. "My Journey to Peace." Retrieved July 2008 (http://peoplecanchange.com/About_Us_Dan.htm).

Daniel's Story. 2008. Blain, Daniel. Retrieved December 2008 (http://ivaw.org/member/daniel-blain).

Danna-Lynch, Karen. 2009. The Chameleon Factor: The Mental Management of Multiple Roles (and What it Reveals about the Organization of Culture). Unpublished Doctoral Dissertation. Rutgers University.

Dave's story 2007. Retrieved July 2007 (http://www.postmormon.org/exp_e/index.php/discussions/viewthread/16/P4 $\mathrm{o} /$ ).

David's story 2000. Fettke, David. Pp. 14-15 in Finally Free: Personal Stories: How Love and Self-Acceptance Saved Us from Ex-Gay Ministries. Washington D.C.: Human Rights Campaign Foundation.

David's story. 2007. Christie, David. “Survivor Narrative.” Retrieved July 2009 (http://www.beyondexgay.com/Narratives/David). 
David's story 2008. Matheson, David. “Breaking Free.” Retrieved July 2008 (http://peoplecanchange.com/About_Us_Matheson.htm).

David's story 2009. Retrieved July 2009 (http://www.beyondexgay.com/Narratives/David).

Davis, Fred. 1979. Yearning for Yesterday: A Sociology of Nostalgia. New York: The Free Press.

Davis, Joseph E. 2002. "Narrative and Social Movements." Pp. 2-39 in Stories of Change: Narrative and Social Movements, edited by Jospeh E. Davis. New York: State University of New York Press.

-----. 2005a. "Victim Narratives and Victim Selves: False Memory Syndrome and the Power of Accounts." Social Problems 52:529-48.

-----. 2005b. Accounts of Innocence: Sexual Abuse, Trauma, and the Self. Chicago, Illinois: University of Chicago Press.

Davis, Laura. 1991. Allies in Healing: When the Person You Love Was Sexually Abused as a Child. New York: Harper Collins.

Davis, Murray. 1983. Smut: Erotic Reality/Obscene Ideology. Chicago, IL: University of Chicago Press.

Dbradhud's story 2008. “Could Not Live a Lie.” Retrieved July 2008 (http://www.postmormon.org/exp_e/index.php/pomopedia/Could_Not_Live_ A_Lie/).

Debbie's story. 1996. David, Debbie. "Retraction is a Process.” FMS Foundation Newsletter 5, 7. Retrieved June 2006 (http://www.fmsfonline.org/fmsf96.701.html).

Deborah's story 2008. Wright, Deborah. "Putting Together the Puzzle.” Retrieved June 2008 (http://www.mormonconverts.com/catholic/the-puzzle.htm).

Deborah B’s story 2008. Bartlett, Deborah. "The Brought 'Something' With Them.” Retrieved July 2008 (http://mormonconverts.com/ChurchofEngland/theybrought-something.htm).

DeGloma, Thomas. 2007. “The Social Logic of 'False Memories': Symbolic Awakenings and Symbolic Worlds in Survivor and Retractor Narratives." Symbolic Interaction 30:543-565.

-----. 2009. "Expanding Trauma through Space and Time: Mapping the Rhetorical Strategies of Trauma Carrier Groups.” Social Psychology Quarterly 72:105-122. 
DeGloma, Thomas and Asia Friedman. 2005 "Thinking With Sociomental Filters:

Exploring the Social Structuring of Attention and Significance." Presented at the Annual Meeting of the American Sociological Association, Philadelphia, PA.

Denzin, Norman K. 1987. The Alcoholic Self. Newbury Park, California; Sage

-----. 1989a. Interpretive Biography. Newbury Park, California: Sage.

-----. 1989b. Interpretive Interactionism. Newbury Park, California: Sage.

Derek's story 2007. Giffin, Derek Charles. Retrieved June 2007 (http://www.ivaw.org/user/72).

Derek's Story. 2008. Retrieved September 2008 (http://ivaw.org/member/derekcharles-giffin).

Desi. [1983] 1981. "Story of a Granddaughter." Pp. 139-141 in I Never Told Anyone: Writings by Woman Survivors of Child Sexual Abuse, edited by Ellen Bass and Louise Thornton. New York: HarperPerennial.

DiMaggio, Paul. 1997. "Culture and Cognition.” Annual Review of Sociology 23:263-87.

Dora's story 1994. “The Guilt I Feel.” Retrieved June 2008 (http://www.memoryandreality.org/retract2.html).

Douglas, Mary. [1966] 2005. Purity and Danger. Oxon, UK: Routledge.

Douglass's story 2008. Eckhoff, Douglass. "I Found My Direction Home.” Retrieved July 2007 (http://mormonconverts.com/catholic/found-my-direction-home.htm).

Douglass, Frederick. [1881] 1996. The Life and Times of Frederick Douglass. Hertfordshire, Great Britain: Wordsworth Editions Unlimited.

Durkheim, Emile. [1893] 1984. The Division of Labor in Society. New York: The Free Press.

-----. [1912] 1995. The Elementary Forms of Religious Life. New York: The Free Press.

-----. [1914] 1960. "The Dualism of Human Nature and Its Social Conditions." pp. 325339 in Essays on Sociology and Philosophy, edited by Kurt H. Wolff. New York: Harper and Row.

Dustin's story 2008. "I Had Never Heard Something So Amazing." Retrieved June 2008 (http://www.mormonconverts.com/catholic/something-so-amazing.htm).

Ebaugh, Helen R. F. 1988. Becoming an Ex: The Process of Role Exit. Chicago: The University of Chicago Press. 
Eli's story. 2007. Israel, Eleonai. "The Journey of a VIP Bodyguard, Sniper Against the War.” Retrieved November 2007 (http://www.ivaw.org/node/1522).

Eliasoph, Nina and Paul Lichterman. 2003. "Culture in Interaction." American Journal of Sociology 108:735-794.

Elizabeth's story 1994. Godley, Elizabeth. "My Mother Abused Me, Didn’t She?” Retrieved December 2006 (http://fmsfonline.org/retract1.html\#feb94).

Elliott, Michele, ed. 1994. Female Sexual Abuse of Children. New York: The Guilford Press.

Emerson, Joan P. 1970. "Behavior in Private Places: Sustaining Definitions of Reality in Gynecological Examinations.” Pp. 74-93 in Recent Sociology No. 2: Patterns of Communicative Behavior, edited by Hans-Peter Dreitzel. London: Macmillan.

Emirbayer, Mustafa and Ann Mische. 1998. "What Is Agency?” American Journal of Sociology 103:962-1023.

Engels, Friedrich. 1877. Anti-Dühring. Retrieved February 2009 (http://www.marxists.org/archive/marx/works/1877/anti-duhring/index.htm).

----. [1893] 1970. “Engels to F. Mehring in Berlin.” Pp. 689-692 in Karl Marx and Friedrich Engels: Selected Works. Moscow: Progress Publishers.

Engerman, David C. 2001. "Forward to the 2001 Edition." Pp. vii-xxxiv in The God that Failed, edited by Richard H. Crossman. New York: Columbia University Press.

Eric's story 2007. Alhberg, Eric. Retrieved June 2007 (http://www.ivaw.org/user/63).

Eric's story 2009. Retrieved July 2009 (http://www.beyondexgay.com/narratives/eric).

Erzen, Tanya. 2006. Straight to Jesus: Sexual and Christian Conversions in the Ex-Gay Movement. Berkeley and Los Angeles: University of California Press.

Evans, Sara M. \& Harry C. Boyte. [1986] 1992. Free Spaces: The Sources of Democratic Change in America. Chicago, Illinois: University of Chicago Press.

Ex-Mormon(a). 2007. Retrieved August 2007 (http://www.exmormon.org/mormon/mormono52.htm)

Ex-Mormon(b). 2007. Retrieved August 2007 (http://www.exmormon.org/mormon/mormon258.htm)

Eyerman, Ron. 2001. Cultural Trauma: Slavery and the Formation of African American Identity. Cambridge, UK: Cambridge University Press.

Ezzy, Douglas. 2000. "Fate and Agency in Job Loss Narratives." Qualitative Sociology 23:121-134. 
Fabian, Johannes. 1983. Time and the Other: How Anthropology Makes Its Object. New York: Columbia University Press.

Feinberg, Leslie. 1996. Transgender Warriors: Making History from Joan of Arc to RuPaul. Boston Massachusetts: Beacon Press.

Fichter, Joseph H. 1987. Autobiographies of Conversion. Lewiston, New York and Queenston, Ontario: The Edwin Mellen Press.

Fine, Gary Alan. 2001. Difficult Reputations: Collective Memories of the Evil, Inept, and Controversial. Chicago, Illinois: University of Chicago Press.

Fine, Gary Alan. 2002. "The Storied Group: Social Movements as Bundles of Narratives,” pp. 229-45 Stories of Change: Narratives of Social Movements, edited by Joseph E. Davis. Albany: State University of New York Press.

Fine, Gary Alan and Aaron Beim. 2007. "Introduction: Interactionist Approaches to Collective Memory.” Symbolic Interaction 30:1-5.

Fiona's Story. 2005. Retrieved May 2005 (http://www.susansmiles.com/stories2.html).

Fischer, Louis. [1949] 1950. Pp. 196-228 in The God That Failed, edited by Richard H. Crossman. New York: Columbia University Press.

Fivush, Robyn. 1995. "Language, Narrative, and Autobiography." Consciousness and Cognition 4:100-103.

Fivush, Robyn, Catherine Haden, and Elaine Reese. 1996. "Remembering, Recounting, and Reminiscing: The Development of Autobiographical Memory in Social Context.” Pp. 341-358 in Remembering Our Past: Studies in Autobiographical Memory, edited by David C. Rubin. New York: Cambridge University Press.

Fleck, Ludwik. [1935] 1979. Genesis and Development of a Scientific Fact. Chicago, Illinois: University of Chicago Press.

FMSF Newsletter. 1998. April. Retrieved November 2006 (http://fmsfonline.org/newsletters.html).

Ford, Jeffrey G. 2009. “Reparative Therapy: A Pseudoscience.” Retrieved June 2009 (http://jgford.homestead.com/index.html).

Foucault, Michel. [1969] 1972. The Archeology of Knowledge. New York: Pantheon Books.

-----. 1977. Language, Counter-Memory, Practice: Selected Essays and Interviews. Ithaca, New York: Cornell University Press.

-----. 1979. Discipline and Punish: The Birth of the Prison. New York: Vintage Books 
-----. [1978] 1990. The History of Sexuality, Volume I: An Introduction. New York: Random House.

Frank, Arthur W. 1993. "The Rhetoric of Self-Change: Illness Experience as Narrative." Sociological Quarterly 34:39-52.

Frank's Story. 2008. “Transformed.” Retrieved July 2008 (http://www.peoplecanchange.com/About_Us_Haynes.htm)

Fraser, Nancy. 1995. "From Redistribution to Recognition? Dilemmas of Justice in a 'Post-Socialist' Age.” New Left Review I,212:68-93.

Fraser, Sylvia. 1987. My Father's House: A Memoir of Incest and of Healing. New York: Ticknor and Fields.

Free thinker's story 2007. Retrieved July 2008 (http://www.postmormon.org/exp_e/index.php/discussions/viewthread/16/).

Freud, Sigmund. [1896] 1984. “The Aetiology of Hysteria.” Pp. 251-282 in The Assault on Truth: Freud's Suppression of the Seduction Theory, by Jeffrey Moussaieff Masson. New York: Farrar, Straus and Giroux.

-----. [1899] 1938. “The Interpretation of Dreams.” Pp. 181-549 in The Basic Writings of Sigmund Freud, edited by A. A. Brill. New York: The Modern Library.

-----. [1901] 1938. Psychopathology of Everyday Life. Pp. 35-178 in The Basic Writings of Sigmund Freud, Edited by A. A. Brill. New York: The Modern Library.

-----. [1905] 1963. Dora: An Analysis of a Case History. New York: Touchstone.

-----. [1909, 1911, 1918] 1963. Three Case Histories: The "Wolf Man," The "Rat Man," and the Psychotic Doctor Schreber. New York: Collier Books.

-----. [1910] 1938. "The History of the Psychoanalytic Movement." Pp. 933-997 in The Basic Writings of Sigmund Freud, Edited by A. A. Brill. New York: The Modern Library.

-----. [1930] 1961. Civilization and Its Discontents. New York: W. W. Norton and Company.

Freyd, Jennifer J. 1996. Betrayal Trauma: The Logic of Forgetting Childhood Abuse. Cambridge, MA: Harvard University Press.

Freyd, Jennifer J. and Anne P. DePrince (Eds.). 2001. Trauma and Cognitive Science: A Meeting of Minds, Science, and Human Experience. New York: The Haworth Press. 
Frisch, Michael. 1989. "American History and the Structures of Collective Memory: A Modest Exercise in Empirical Iconography." Journal of American History. 75: 1130-55.

Frye, Northrop. 1957. Anatomy of Criticism. Princeton, New Jersey: Princeton University Press.

Fuller, Steve. [1998] 2002. Social Epistemology. Bloomington, Indiana: Indiana University Press.

Gamson, William A. 1992. Talking Politics. Cambridge, UK and New York: Cambridge University Press.

Gardiner, Eileen (Ed.). 2006. Zoroastrian Hell: Visions, Tours and Descriptions of the Infernal Otherworld. New York" Italica Press.

Garfinkel, Harold. [1967] 1996. "Passing and the Managed Achievement of Sex Status in an Intersexed Person.” Pp. 116-185 in Studies in Ethnomethodology. Cambridge, UK: Polity Press.

Gayatri's story. Retrieved June 2005 (http://www.soc-um.org/)

Gergen, Kenneth. 1991. The Saturated Self: Dilemmas of Identity in Contemporary Life. New York: Basic Books.

Gergen, Kenneth J. and Mary M. Gergen. 1997. "Narratives of the Self," Pp. 161-184 in Memory, Identity, Community: The Idea of Narrative in the Human Sciences, edited by Lewis P. Hinchman and Sandra K. Hinchman. Albany: State University of New York Press.

Germana, Rachelle. 2003. "In-Between and Becoming: Victims, Survivors, and the Narrative of Transformation.” Unpublished manuscript, Rutgers University.

Giddens, Anthony. 1991. Modernity and Self-Identity: Self and Society in the Late Modern Age. Stanford, California: Stanford University Press.

Gide, André. 1950. Pp. 165-195 in The God That Failed, Edited by Richard H. Crossman. New York: Columbia University Press.

Gillespie, V. Bailey. 1979. Religious Conversion and Personal Identity. Birmingham, Alabama: Religious Education Press.

Glaser, Barney G. and Anselm L. Strauss. [1967] 2008. The Discovery of Grounded Theory: Strategies for Qualitative Research. New Brunswick, New Jersey: AldineTransaction.

Goffman, Erving. 1959. The Presentation of Self in Everyday Life. New York: Anchor Books, Doubleday. 
----- 1967. Interaction Ritual: Essays on Face to Face Behavior. New York: Pantheon Books.

-----. [1974] 1986. Frame Analysis: An Essay on the Organization of Experience. Boston, Massachusetts: Northeastern University Press.

Goldstein, Eleanor and Kevin Farmer. 1993. True Stories of False Memories. New York: Sirs Publishing.

Gooer, Asli. 2000. "The Puppet Theater in Plato's Allegory of the Cave.” The Classical Journal 95:119-29.

Graham, Gordon. 1997. The Shape of the Past: A Philosophical Approach to History. Oxford, UK: Oxford University Press.

Gramsci, Antonio. 1971. Selections from the Prison Notebooks. New York: International Publishers.

Gubrium, Jaber F. 1992. Out of Control: Family Therapy and Domestic Disorder. Newbury Park: Sage

-----. 2005. "Introduction: Narrative Environments and Social Problems." Social Problems 52:525-28.

Gubrium, Jaber F. and James A. Holstein. 2009. Analyzing Narrative Reality. Thousand Oaks, California: Sage Publications.

Habermas, Jürgen. 1987. The Theory of Communicative Action, Volume Two: Lifeworld and System: a Critique of Functionalist Reason. Boston, MA: Beacon Press.

Halbwachs, Maurice. [1925] 1992. "The Social Frameworks of Memory." Pp. 37-189 in On Collective Memory, edited by Lewis A. Coser. Chicago and London: University of Chicago Press.

-----. [1950] 1980. The Collective Memory. New York: Harper and Row.

Hamar's story 2007. Retrieved July 2008

(http://www.postmormon.org/exp_e/index.php/discussions/viewthread/16/P4 $\mathrm{o} /$ ).

Hankiss, Agnes. 1981. "Ontologies of the Self: On the Mythological Rearranging of One's Life-History." Pp. 203-209 in Biography and Society: The Life History Approach in the Social Sciences, edited by Daniel Bertaux. Beverly Hills, California: Sage.

Hart, Joseph. 2007. "Queer Magazine Born Again: Founder of Venus, a Publication for Black Lesbians, Repudiates Lifestyle.” Utne Reader 143

(September/October):28-29. 
Harvey, Peter. 1990. An Introduction to Buddhism: Teaching, History, Practice. Cambridge, UK: Cambridge University Press.

Hay, Robert P. 1969. "George Washington: American Moses.” American Quarterly 21:780-91.

Heritage, John. 1984. Garfinkel and Ethnomethodology. Cambridge, UK: Polity Press.

Herman, Edward S. and Noam Chomsky. [1988] 2002. Manufacturing Consent: The Political Economy of the Mass Media. New York: Pantheon Books.

Herman, Judith Lewis. [1981] 2000. Father-Daughter Incest. Cambridge, MA: Harvard University Press.

-----. 1992. Trauma and Recovery: The Aftermath of Violence - From Domestic Abuse to Political Terror. New York: Basic Books.

Hertz, Robert. [1909] 1973. "The Preeminence of the Right Hand.” Pp. 3-31 in Right and Left: Essays in Dual Symbolic Classification, edited by Rodney Needham. Chicago: University of Chicago Press.

Hesse, Hermann. [1922] 1951. Siddhartha. New York: Bantam Books.

Hobbes, Thomas. [1651] 1962. Leviathan. New York: Macmillan.

Hoever, Hugo. [1955] 1974. Lives of the Saints. New York: Catholic Book Publishing Co.

Holstein, James A. and Jaber F. Gubrium. 2000. The Self We Live By: Narrative Identity in a Postmodern World. New York: Oxford University Press.

Hopeful and Healing's story 2003. Retrieved march 2003 (http://susansmiles.com/stories3.html).

Horwitz, Allan V. 1990. The Logic of Social Control. New York: Plenum.

-----. 2002. Creating Mental Illness. Chicago, Illinois: University of Chicago Press.

Horwitz, Gordon J. 1990. In the Shadow of Death: Living Outside the Gates of Mauthausen. New York: Free Press.

Horowitz, David. 1989. "Why I am No Longer a Leftist." Pp. 53-57 in Second Thoughts: Former Radicals Look at the Sixties, edited by Peter Collier and David Horowitz. Lanham, Maryland: Madison Books.

-----. 1997. Radical Son: A Generational Odyssey. New York: Touchstone.

Howard, Jenna. 200o. "Memory Reconstruction in Autobiographical Narrative Construction: Analysis of the Alcoholics Anonymous Recovery Narrative." 
Unpublished Paper, Department of Sociology, Rutgers University, New Brunswick, NJ.

-----. 2006. "Expecting and Accepting: The Temporal Ambiguity of Recovery Identities." Social Psychology Quarterly 69:307-24.

-----. 2008. "Negotiating an Exit: Existential, Interactional, and Cultural Obstacles to Disorder Disidentification.” Social Psychology Quarterly 71:177-192.

Hughes, Everett C. 1984. "Going Concerns: The Study of American Institutions." Pp. 5264 in The Sociological Eye: Selected Papers. New Brunswick, New Jersey: Transaction Books.

Hume, David. [1748] 1961. “An Enquiry Concerning Human Understanding.” Pp. 307430 in The Empiricists. New York: Doubleday.

Hunt, Scott A. and Robert D. Benford. 1994. "Identity Talk in the Peace and Justice Movement.” Journal of Contemporary Ethnography 22:488-517.

Iannone, Carol. 1989. "The Feminist Confusion." Pp. 149-153 in Second Thoughts: Former Radicals Look Back at the Sixties, edited by Peter Collier and David Horowitz. Lanham, MD: Madison Books.

Ifshin, David. 1989. “A Political Journey.” Pp. 81-8 in Second Thoughts: Former Radicals Look Back at the Sixties, edited by Peter Collier and David Horowitz. Lanham, MD: Madison Books.

Insanad's story 2008(a). Retrieved July 2008 (http://exmormonforums.com/viewtopic.php?f=2\&t=386).

Insanad's story 2008(b). Retrieved July 2008 (http://exmormonforums.com/viewtopic.php?f=8\&t=312).

Jackson, A. V. Williams. 1896. "The Moral and Ethical Teachings of the Ancient Zoroastrian Religion.” International Journal of Ethics 7:55-62.

Jacobs, Ron. 2007. "A Conversation with Three Iraq Veterans Against the War." CounterPunch April 14, 2007. Retrieved June 2007 (http://www.vaiw.org/vet/modules.php?name=News\&file=article\%sid=3215).

Jamech's story 2007. Retrieved July 2008 (http://www.postmormon.org/exp_e/index.php/discussions/viewthread/16/).

James, William. [1902] 1987. The Varieties of Religious Experience. Pp. 1-477 in William James: Writings 1902-1910. New York: The Library of America.

Jared's Story. 2007. "Is the United States Military a Terrorist Organization?" and "A Family in IVAW.” Retrieved August 2007 (http://www.ivaw.org/user/159). 
Jason's story. 2008. Park, Jason. "Resolving the Conflict.” Retrieved July 2008 (http://peoplecanchange.com/About_Us_Park.htm).

Jaspers, Karl. 1953. The Origin and Goal of History. New Haven, CT: Yale University Press.

Jaye's story 2008. Barth, Jaye D. “How my Psychiatrist Became 'Daddy'.” Retrieved November 2006 (http://www.stopbadtherapy.com/retracts/daddy.shtml).

Jennifer's story 2006. Retrieved October 2006 (http://www.pandys.org/escapinghades/Survivors9o.html).

Jerry's story 2008. Armelli, Jerry A. “Coming Home.” Retrieved June 2008 (http://www.peoplecanchange.com/About_Us_Armelli.htm).

Jerry's story 2009. Retrieved July 2009

(http://www.beyondexgay.com/Narratives/Jerry).

Johnny's story. 2008. Mills, Johnny. "You Met Him When You Were Supposed To." Retrieved July 2008 (http://mormonconverts.com/NonDenominitional/youmet-him\%20when.htm).

Jon's story 2008. Turner, Jon. Testimony reproduced in "This is Where We Take Our Stand," video trailer. Retrieved July 2009 (http://vimeo.com/5448532).

Jung, Carl. [1936/37] 1971. "The Concept of the Collective Unconscious.” Pp. 59-69 in The Portable Jung, edited by Joseph Campbell. New York: Penguin Books.

-----. [1951] 1971. "Aion: Phenomenology of the Self." Pp. 139-162 in The Portable Jung, edited by Joseph Campbell. New York: Penguin Books.

-----. 1959. The Undiscovered Self. New York: Mentor Books.

Kant, Immanuel. [1781] 1993. Critique of Pure Reason. London: Orion Publishing Group.

-----. [1784] 2001. “Answer to the Question: What is Enlightenment?” Pp. 133-142 in Basic Writings of Kant, edited by Allen W. Wood. New York: Random House.

-----. [1785] 2008. Groundwork of the Metaphysics of Morals. Radford, Virginia: Wilder Publications.

Kate's story 1995. FMS Foundation Newsletter 4, 2. Retrieved November 2006 (http://fmsfonline.org/fmsf95.201.html).

Kathryn's story. 2009. Retrieved July 2009

(http://www.beyondexgay.com/Narratives/Kathryn). 
Kenney, William Howland. 1999. Recorded Music in American Life: The Phonograph and Popular Memory, 1890-1945. New York: Oxford University Press.

Kidron, Carol A. 2003. "Surviving a Distant Past: A Case Study of the Cultural Construction of Trauma Descendant Identity." Ethos 31:513-544.

Koestler, Arthur. 1950. Pp. 15-75 in The God That Failed, Edited by Richard H. Crossman. New York: Columbia University Press.

-----. [1964] 1976. The Act of Creation. London: Hutchinson and Co.

Kövecses, Zoltán. 2002. Metaphor: A Practical Introduction. Oxford and New York: Oxford Univeristy Press.

-----. 2005. Metaphor in Culture: Universality and Variation. Cambridge UK: Cambridge University Press.

Kuhn, Thomas S. [1962] 1996. The Structure of Scientific Revolutions. Chicago, Illinois: University of Chicago Press.

Laing, R. D. 1959. The Divided Self: An Existential Study of Madness. London, England: Penguin Books.

-----. 1961. Self and Others. New York: Pantheon Books.

Laing, R.D. and A. Esterson. [1964] 1990. Sanity, Madness, and the Family. New York: Penguin Books.

Lakoff, George and Mark Johnson. 1980. Metaphors We Live By. Chicago, Illinois: University of Chicago Press.

-----. 1999. Philosophy in the Flesh: The Embodied Mind and it Challenge to Western Thought. New York: Basic Books

LaRossa, Ralph and Cynthia B. Sinha. 2006. "Constructing the Transition to Parenthood.” Sociological Inquiry 76:433-457.

Lenin, Vladimir Ilyich. [1913] 1996. "The Three Sources and Component Parts of Marxism." Retrieved April 2009 from the Lenin Internet Archives (http://www.marxists.org/archive/lenin/works/1913/mar/x01.htm). Originally published as pp. 21-28 in Lenin's Collected Works, Volume 19 (1977). Moscow: Progress Publishers.

Lewis, Bernard. 1975. History: Remembered, Recovered, Invented. Princeton: Princeton University Press.

Lieblich, Amia, Rivka Tuval-Mashiach, and Tamar Zilber. 1998. Narrative Research: Reading, Analysis, and Interpretation. Thousand Oaks, California: Sage. 
Life Rocks 2008. Retrieved July 2008

(http://exmormonforums.com/viewtopic.php?f=2\&t=386).

Lifton, Robert Jay. [1973] 2005. Home From the War: Learning from Vietnam Veterans. New York: Other Press.

Lilita's story 2003. Retrieved march 2003

(http://www.susansmiles.com/stories4.html).

Linda’s Story 2006. Retrieved May 2006 (http://www.susansmiles.com/linda2.html).

Lindsay's story 2008. Hoppe, Lindsay. "Sometimes Only Suffering Will Bring People to God.” Retrieved July 2008

(http://mormonconverts.com/AtheistorAgnostic/bring-people-to-god.htm).

Locke, John. [1690] 1961. “An Essay Concerning Human Understanding.” Pp. 7-133 in The Empiricists. New York: Doubleday.

-----. [1690] 1980. Second Treatise of Government. Indianapolis and Cambridge: Hackett Publishing Company.

Lomsky-Feder, Edna. 1995. "The Meaning of War Through Veterans' Eyes: A Phenomenological Analysis of Life Stories.” International Sociology 10:463-482.

Lopez, Donald S. 2001. The Story of Buddhism: A Concise Guide to its History and Teachings. New York: HarperCollins.

Loseke, Donileen R. 2001. "Lived Realities and Formula Stories of 'Battered Women." Pp. 107-126 in Institutional Selves: Troubled Identities in a Postmodern World, edited by Jaber F. Gubrium and James A. Holstein. New York: Oxford University Press.

Lowental, David. 1985 [1999]. The Past is a Foreign Country. Cambridge, UK: Cambridge University Press

Lukács, Georg. [1920] 1971. History and Class Consciousness. Great Britain: The Merlin Press.

Lukes, Steven. 1974. Power: A Radical View. London: Macmillan.

Macdonald, Gail. 1999. Making of an Illness: My Experience with Multiple Personality Disorder. Sudbury Ontario: Laurentian University Press. Retrieved January 2007 (http://www.stopbadtherapy.com/retracts/macdonald.shtml).

Mahieu, Brian. 2006. "My Story: A Journey Toward Living an Authentic and Integrated Life.” Retrieved June 2009 (http://www.brianmahieu.com/my_story.html).

Mannheim, Karl. [1928] 1952. "The Problem of Generations." Pp. 276-322 in Essays on the Sociology of Knowledge. London, England: Routledge. 
-----. 1936. Ideology and Utopia: An Introduction to the Sociology of Knowledge. San Diego, California: Harcourt.

Manning, Philip. 2005. Freud and American Sociology. Cambridge, UK: Polity Press.

Maratea, Ray. 2008. "The e-Rise and Fall of Social Problems: The Blogosphere as a Public Arena." Social Problems 55:139-159.

Martin, John Levi. 2002. "Power, Authority, and the Constraint of Belief Systems." American Journal of Sociology 107:861-904.

Martin's Story. 2007. “From Cocaine to Christ.” Retrieved August 2007 (http://www.precious-testimonies.com/BornAgain/a-c/Briseno.htm).

Marx, Anthony. 1997. Making Race and Nation: A Comparison of South Africa, the United States, and Brazil. Cambridge, UK: Cambridge University Press.

Marx, Karl. [1844] 1963. "Introduction to the Critique of Hegel's Philosophy of Right," pp. 226-227 in Reader in Marxist Philosophy: From the Writings of Marx, Engels, and Lenin, edited by Howard Selsam and Harry Martel. New York: International Publishers.

-----. [1845] 1963. “The German Ideology: Part I.” Reprinted in Reader in Marxist Philosophy: From the Writings of Marx, Engels, and Lenin. New York: International Publishers.

-----. [1845] 1978. “The German Ideology: Part I.” Pp. 146-200 in The Marx-Engels Reader, Second Edition, edited by Robert C. Tucker. New York: W. W. Norton and Company.

Marx, Karl and Friedrich Engels. [1848] 1978. Manifesto of the Communist Party. Pp. 469-500 in The Marx-Engels Reader, Second Edition, edited by Robert C. Tucker. New York and London: W. W. Norton and Company.

Mary Ellen's story 2003. Retrieved March 2003 (http://www.susansmiles.com/stories4.html).

Masson, Jeffrey Moussaieff. 1984. The Assault on Truth: Freud's Suppression of the Seduction Theory. New York: Farrar, Straus and Giroux.

Mason-Schrock, Douglas. 1996. “Transsexuals' Narrative Construction of the 'True Self.” Social Psychology Quarterly 59:176-192.

Mead, George Herbert. 1932. The Philosophy of the Present. LaSalle, Illinois: Open Court.

-----. [1934] 1967. Mind, Self, and Society: From the Standpoint of a Social Behaviorist. Chicago and London: The University of Chicago Press. 
Mead, Margaret. [1942] 1968. And Keep Your Powder Dry: An Anthropologist Looks at America. New York: William Morrow and Company.

Medinger, Alan. 2008. "Reflections on 25 Years of Healing." Retrieved August 2008 (http://www.peoplecanchange.com/About_Us_Medinger.htm).

Melissa's Story. 2005. Safeguarding Our Children - United Mothers. Survivor Stories. Retrieved November 2005 (http://pub46.bravenet.com/forum/3893375066/fetch/677925/5).

Melucci, Alberto. 1996. Challenging Codes: Collective Action in the Information Age. Cambridge, UK: Cambridge University Press.

Merton, Robert K. [1949] 1964. Social Theory and Social Structure. London: The Free Press of Glencoe.

Michele's story 2008. Retrieved October 2008 (http://www.pandys.org/escapinghades/Survivors98.html).

Mills, C. Wright. 1940. "Situated Actions and Vocabularies of Motive." American Sociological Review 5:904-913.

-----. [1959] 2000. The Sociological Imagination. Oxford, UK: Oxford University Press.

Minoi’s story 2003. Retrieved March 2003 (http://www.susansmiles.com/penpal.html).

Mische, Ann. 2008. Partisan Publics: Communication and Contention Across Brazilian Youth Activist Networks. Princeton, NJ: Princeton University Press.

Moonshine's story. 2008. “A Tale of Two Cities and Two Towers.” Retrieved June 2008 (http://www.postmormon.org/exp_e/index.php/pomopedia/A_Tale_of_Two_C ities_and_Two_Towers/).

Mormon.org. 2009. retrieved July 2009 (http://www.mormon.org/mormonorg/eng/basic-beliefs/the-restoration-oftruth/the-restoration-of-truth).

Mountaingirl's story 2007. Retrieved July 2008 (http://www.postmormon.org/exp_e/index.php/discussions/viewthread/16/).

MsGabbie2u's story 2008. "My Awakening.” Retrieved July 2008 (http://www.postmormon.org/exp_e/index.php/pomopedia/My_Awakening/).

Mueller, Carol McClurg. 1994. "Conflict Networks and the Origins of Women's Liberation.” Pp. 234-263 in New Social Movements: From Ideology to Identity. Enrique Larana, Hank Johnston, and Joseph R. Gusfield, Eds. Philadelphia, PA: Temple University Press. 
Mullaney, Jamie L. 2006. Everyone Is NOT Doing It: Abstinence and Personal Identity. Chicago: The University of Chicago Press.

Muravchik, Joshua. 1989. "A Cure Worse Than the Disease.” Pp. 161-165 in Second Thoughts: Former Radicals Look at the Sixties, edited by Peter Collier and David Horowitz. Lanham, Maryland: Madison Books.

Murdoch, Adrian. [2003] 2008. The Last Pagan: Julian the Apostate and the Death of the Ancient World. Inner Traditions: Rochester, Vermont.

Nell's story. 1995. pp. 345-351 in Pendergrast, Mark. 1995. Victims of Memory: Sex Abuse Accusations and Shattered Lives. Hinesburg, Vermont: Upper Access Books.

Newton, Sir Isaac. 1687. Philosophiae Naturalis Principia Mathematica. Retrieved February 2009 (http://www.archive.org/details/newtonspmathemaoonewtrich).

Nicolosi, Joseph. 1993. Healing Homosexuality: Case Studies of Reparative Therapy. Northvale, New Jersey: Jason Aronson, Inc.

Nietzsche, Friedrich. [1891] 1917. Thus Spake Zarathustra. New York: The Modern Library.

Nigosian, S. A. 1993. The Zoroastrian Faith: Tradition and Modern Research. Montreal: McGill-Queen's University Press.

Nippert-Eng, Christena. 1995. Home and Work: Negotiating Boundaries through Everyday Life. Chicago: University of Chicago Press.

O’Rourke, P. J. 1989. “The Awful Power of Make-Believe.” Pp. 203-209 in Second Thoughts: Former Radicals Look at the Sixties, edited by Peter Collier and David Horowitz. Lanham, Maryland: Madison Books.

Ofshe, Richard and Ethan Watters. 1994. Making Monsters: False Memories, Psychotherapy, and Sexual Hysteria. New York: Charles Scribner's Sons.

Olick, Jeffrey K. 1999a. "Genre Memories and Memory Genres: A Dialogical Analysis of May 8th, 1945 Commemorations in the Federal Republic of Germany." American Sociological Review 64: 381-402.

-----. 1999b. "Collective Memory: The Two Cultures." Sociological Theory 17:333-348.

Olick, Jeffrey K. and Daniel Levy. 1997. "Collective Memory and Cultural Constraint: Holocaust Myth and Rationality in German Politics." American Sociological Review 62:921-936.

Olick, Jeffrey K. and Joyce Robbins. 1998. "Social Memory Studies: From 'Collective Memory' to the Historical Sociology of Mnemonic Practices.” Annual Review of Sociology 24:105-140. 
Orbuch, Terri L. 1997. "People's Accounts Count: The Sociology of Accounts.” Annual Review of Sociology 23:455-78.

Ostler, Blake. 1982. "The Idea of Pre-Existence in the development of Mormon Thought." Dialogue: A Journal of Mormon Thought 15:59-78.

Packman, Richard. 2007. "To Those who are Investigating 'Mormonism'.” Retrieved July 2009 (http://www.exmormon.org/tract2.htm).

Pasley, Laura E. 1993. “Misplaced Trust.” Pp. 347-65 in True Stories of False Memories, Eleanor Goldstein and Kevin Farmer. New York: Sirs Publishing.

-----. 1995. pp. 330-335 in Pendergrast, Mark. 1995. Victims of Memory: Sex Abuse Accusations and Shattered Lives. Hinesburg, Vermont: Upper Access.

Patterson, Wendy. 2002. "Narrative Imaginings: The Liminal Zone in Narratives of Trauma." Pp. 71-87 in Strategic Narrative: New Perspectives on the Power of Personal and Cultural Stories, edited by Wendy Patterson. Lanham, Maryland: Lexington Books.

Paul's story 2000. Williams, Paul. P. 18-19 in Finally Free: Personal Stories: How Love and Self-Acceptance Saved Us from Ex-Gay Ministries. Washington D.C.: Human Rights Campaign Foundation.

Paul's story 2007. Abernathy, Paul. "Reliving the Nightmare.” Retrieved June 2008 (http://ivaw.org/membersspeak/ofc-ii-reliving-nightmare).

Pendergrast, Mark. 1995. Victims of Memory: Sex Abuse Accusations and Shattered Lives. Hinesburg, Vermont: Upper Access Books.

Perinbanayagam, R. S. 1991. Discursive Acts. New York: Aldine De Gruyter.

Peter's story 2005. Hollow, Peter. “Turning Weakness to Strength.” Retrieved June 2008 (http://www.peoplecanchange.com/About_Us_Peter.htm).

Phelan, Shane. 1993. “(Be)Coming Out: Lesbian Identity and Politics.” Signs 18:765790 .

Plato. [ 380 BCE] 1941. The Republic of Plato. Francis MacDonald Cornford, Trans. London, England: Oxford University Press.

Plummer, Ken. 1995. Telling Sexual Stories: Power, Change and Social Worlds. London and New York: Routledge.

Polletta, Francesca. 1999. "Free Spaces' in Collective Action." Theory and Society 28:138.

-----. 2006. It Was Like a Fever: Storytelling in Protest and Politics. Chicago, Illinois: The University of Chicago Press. 
Polletta, Francesca and John Lee. 2006. "Is Telling Stories Good for Democracy? Rhetoric in Public Deliberation After 9/11." American Sociological Review 71:699-723.

Prager, Jeffrey. 1998. Presenting the Past: Psychoanalysis and the Sociology of Misremembering. Cambridge, Massachusetts: Harvard University Press.

Preston's story 2007. Retrieved July 2008 (http://www.postmormon.org/exp_e/index.php/discussions/viewthread/16/P4 $\mathrm{o} /$ ).

Propp, Vladimir. 1968. Morphology of the Folktale. Austin, Texas: University of Texas Press.

Rambo, Lewis R. 1993. Understanding Religious Conversion. New Haven, Connecticut: Yale University Press.

Randy's story 2009 (http://www.beyondexgay.com/Narratives/RandyB).

Remini, Robert. 2002. Joseph Smith. New York: Penguin Group.

Retractor 1994. “The Guilt I Feel.” Retrieved August 2008 (http://www.fmsfonline.org/retract2.html\#may94).

Retractor 2007. “I Became the Enemy.” Retrieved September 2008 (http://fmsfonline.org/retract2.html\#may94).

Reverend Jerry's story 2000. Stephenson, Jerry. P. 10 in Finally Free: Personal Stories: How Love and Self-Acceptance Saved Us from Ex-Gay Ministries. Washington D.C.: Human Rights Campaign Foundation.

Richard's story 2007. “Coming Out Straight.” Retrieved July 2008 (http://peoplecanchange.com/About_Us_Cohen.htm).

Richard G.'s Story 2008. Gaines, Richard. “I Found the Truth.” Retrieved June 2008 (http://www.mormonconverts.com/catholic/I-Found-The-Truth.htm).

Richard J.'s story 2008. Johnson, Richard. “A Quiet Whisper... 'This is True!” Retrieved July 2008 (http://mormonconverts.com/methodist/a-quiet-whisper.htm).

Rick's story 2008. “A Hard-Work Miracle.” Retrieved June 2008 (http://www.peoplecanchange.com/About_Us_Rick.htm).

Rieff, Philip. [1962] 1963. Introduction to Dora: An Analysis of a Case History. New York: Touchstone.

Robin's story 2005. Retrieved November 2005

(http://www.gentletouchsweb.com/Stories/Robin.html). 
Rod's Story. 2008. “Drugs, Sex and Booze Just Don't Get It!” Retrieved September 2008 (http://www.precious-testimonies.com/BornAgain/o-r/RManney.htm).

Ronn's Story. 2007a. "The Death of a Pro-War Conservative -or- The Day I got Away with Murder." Retrieved August 2007 (http://ivaw.org/membersspeak/onesoldiers-musings).

-----. 2007b. “What, Exactly, Are We Dying For?” Retrieved August 2007 (http://ivaw.org/membersspeak/what-exactly-are-we-dying).

Rousseau, Jean-Jacques. [1755] 1994. Discourse on the Origin of Inequality. Oxford and New York: Oxford University Press.

-----. [1762] 1968. The Social Contract. London and New York: Penguin Books.

Rubin, Henry. 2003. Self-Made Men: Identity and Embodiment among Transsexual Men. Nashville, Tennessee: Vanderbilt University Press.

Ryan, Dan. 2006. "Getting the Word Out: Notes on the Social Organization of Notification.” Sociological Theory 24:228-254.

Sagha's story 2003. Retrieved March 2003 (http://www.susansmiles.com/stories4.html).

Saussure, Ferdinand de. [1972] 1992 Course in General Linguistics. La Salle, Illinois; Open Court Publishing.

Schooler, Jonathan W. 2001. "Discovering Memories of Abuse in the Light of MetaAwareness." Pp. 105-136 in Trauma and Cognitive Science: A Meeting of Minds, Science, and Human Experience, edited by Jennifer J. Freyd and Anne P. DePrince. New York: Hawthorn Press.

Schuman, Howard and Jacqueline Scott. 1989. "Generations and Collective Memories." American Sociological Review 54:359-381.

Schutz, Alfred. [1945] 1973. Collected Papers, Volume I: The Problem of Social Reality. The Hague: Martinus Nijhoff.

Schutz, Alfred and Thomas Luckmann. 1973. The Structures of the Life World. Evanston: Northwestern University Press.

Schwartz, Barry. 1981. Vertical Classification: A Study in Structuralism and the Sociology of Knowledge. Chicago, Illinois: University of Chicago Press.

-----. 1982. "The Social Context of Commemoration: A Study in Collective Memory." Social Forces 61:374-402.

----. 1987. George Washington: The Making of an American Symbol. New York: The Free Press. 
Schwartz, Barry and Howard Schuman. 2005. "History, Commemoration, and Belief: Abraham Lincoln in American Memory, 1945-2001.” American Sociological Review 70:183-203.

Scott, Marvin B. and Stanford M. Lyman. 1968. "Accounts." American Sociological Review 33,1:46-62.

Scott's story 2008. Anderson, Scott. "Becoming the Man I Was Attracted To." Retrieved June 2008 (http://www.peoplecanchange.com/About_Us_Andersen.htm).

Scott, Wilbur J. 1990. "PTSD in the DSM-III: A Case in the Politics of Diagnosis and Disease.” Social Problems 37:294-310.

Sean's Story. 2007. Retrieved September 2007 (http://ivaw.org/view/profiles?apage=M).

September 11 Archive. 2007. The September 11 Digital Archive. Retrieved October 2007 (http://911digitalarchive.org/parser.php?object_id=705).

Shadow's story 2003. Retrieved March 2003 (http://www.susansmiles.com/penpal.html).

Shahbazi, A. Shapur. 1977. “The ‘Traditional Date of Zoroaster' Explained.” Bulletin of the School of Oriental and African Studies: University of London 40:25-35.

Shay, Jonathan. 1994. Achilles in Vietnam: Combat Trauma and the Undoing of Character. New York: Scribner.

Shephard, Ben. 2001. A War of Nerves: Soldiers and Psychiatrists in the Twentieth Century. Cambridge, Massachusetts: Harvard University Press.

Sherry's story. 2008. Retrieved June 2008 (exmormonforums.org).

Shibutani, Tamotsu. 1955. "Reference Groups as Perspective." American Journal of Sociology 60:562-69.

Shils, Edward. 1981. Tradition. Chicago: University of Chicago Press.

Simmel, Georg. [1922] 1955. "The Web of Group Affiliations." Pp. 125-195 in Conflict and the Web of Group Affiliations. New York: The Free Press.

-----. 1950a. "The Stranger." Pp. 402-408 in The Sociology of Georg Simmel, edited by Kurt H. Wolff. New York: The Free Press.

-----. 1950b. “The Field of Sociology.” Pp. 3-25 in The Sociology of Georg Simmel edited by Kurt H. Wolff. New York: The Free Press.

Simpson, Ruth. 1994. ““I Was There: Establishing Presence at Events.” Paper presented at the annual meeting of the American Sociological Association. 
-----. 1996. "Neither Clear Nor Present: The Social Construction of Safety and Danger." Sociological Forum 11:549-562.

Smelser, Neil J. 2004. "Psychological Trauma and Cultural Trauma." Pp. 31-59 in Cultural Trauma and Collective Identity, edited by Jeffrey C. Alexander, Ron Eyerman, Bernhard Giesen, Neil J. Smelser, and Piotr Sztompka. Berkeley: University of California Press.

Smith, Adam. [1776] 2003. The Wealth of Nations. New York: Bantam Classics.

Smith, Anthony D. 1999. Myths and Memories of the Nation. Oxford: Oxford University Press.

Snow, David A. and Richard Machalek. 1983. "The Convert as a Social Type.” Sociological Theory 1:259-289.

Snow, David A., E. Burke Rochford, Jr., Steven K. Worden, and Robert D. Benford. 1986. "Frame Alignment Processes, Micromobilization, and Movement Participation." American Sociological Review 51: 464-481.

Somers, Margaret R. 1994. "The Narrative Constitution of Identity: A Relational and Network Approach.” Theory and Society 23:605-649.

Spillios, Gerilena. 1993. "The Truth Set Me Free." Pp. 333-45 in True Stories of False Memories, Edited by Eleanor Goldstein and Kevin Farmer. Boca Raton, Florida: SIRS Books.

Spillman, Lyn. 1995. "Culture, Social Structure, and Discursive Fields." Current Perspectives in Social Theory 15:129-54.

-----. 1998. "When Do Collective Memories Last? Founding Moments in the United States and Australia." Social Science History 445-477.

Spillman, Lyn and Brian Conway. 2007. "Texts, Bodies, and the Memory of Bloody Sunday." Symbolic Interaction 30:79-103.

Spinoza, Benedict de. [1670] 2007. Theological-Political Treatise. Cambridge, UK: Cambridge University Press.

Starbuck, Edwin Diller. [1889] 1911. The Psychology of Religion. New York: C. Scribner's Sons.

Stein, Arlene. 1997. Sex and Sensibility: Stories of a Lesbian Generation. Berkeley and Los Angeles: University of California Press.

-----. 2009. “'As Far as They Knew, I Came from France’: Stigma, Passing, and Not Speaking about the Holocaust.” Symbolic Interaction 32:44-60. 
-----. n.d. "Our Holocaust: The Identity Politics of the 'Second Generation'." Unpublished manuscript.

Steinberg, Marc W. 1999. “The Talk and Back Talk of Collective Action: A Dialogic Analysis of Repertoires of Discourse among Nineteenth-Century English Cotton Spinners." The American Journal of Sociology 105: 736-780.

Stephen's story 2008. Merritt, Stephen. "Searching all the Wring Doctrines." Retrieved August 2008 (http://www.precious-testimonies.com/BornAgain/L$\mathrm{N} /$ merritt.htm).

Stephanie's story 2003. Retrieved March 2003 (http://www.susansmiles.com/stories.html).

Steve's story 2007. “Terrible Truths.” Retrieved June 2008 (http://lowcountrysurvivors.com/?p=31).

Strauss, Barry S. 1997. "The Problem of Periodization: The Case of the Peloponnesian War," Pp. 165-75 in Inventing Ancient Culture: Historicism, Periodization, and the Ancient World, edited by Mark Golden and Peter Toohey. London: Routledge.

Sweeney, Julia. 2005. Letting Go of God. Transcript of the Compact Disc Recording. Recording November 19, 2005 at the Ars Nova Theater in New York.

Swidler, Ann. 1986. "Culture in Action: Symbols and Strategies." American Sociological Review 51: 273-286.

Tal, Kali. 1996. Wolds of Hurt: Reading the Literatures of Trauma. Cambridge, UK: Cambridge University Press.

Tannen, Deborah. 1993. Gender and Conversational Interaction. Oxford and New York: Oxford University Press.

Tanya's story 2003. Retrieved September 2003 (http://www.escapinghades.com/Survivors133.html).

Taylor, Verta and Nancy E. Whittier. 1992. "Collective Identity in Social Movement Communities: Lesbian Feminist Mobilization.” Pp. 104-29 in Frontiers in Social Movement Theory, edited by Aldon D. Morris and Carol McClurg Mueller. New Haven and London: Yale University Press.

Teeger, Chana. 2009. "Collective Memories and Collective Fears: South Africans Narrate Crime against the Backdrop of Apartheid." Paper presented at the annual meeting of the Eastern Sociological Society, Baltimore Maryland.

Teeger, Chana and Vered Vinitzky-Seroussi. 2007. "Controlling for Consensus: Commemorating Apartheid in South Africa." Symbolic Interaction 30: 57-78. 
Templeton, Charles. 1982. “An Anecdotal Memoir.” Retrieved January 2009 (http://www.templetons.com/charles/memoir).

Terr, Lenore. 1994. Unchained Memories: True Stories of Traumatic Memories, Lost and Found. New York: Basic Books.

Thomas, W. I. [1923] 2002. “The Unadjusted Girl.” Pp. 105-115 in Self, Symbols, and Society, edited by Nathan Rousseau. Lanham, Maryland: Rowman and Littlefield Publishers, Inc.

Tina's story 2007. Retrieved May 2007 (http://www.exmormon.org/mormon/mormono52.htm).

Tinkling Brass's story. 2006. Retrieved July 2008 (http://www.postmormon.org/exp_e/index.php/discussions/viewthread/16/).

Tracey's story 2000. St. Pierre, Tracey. P. 20 in Finally Free: Personal Stories: How Love and Self-Acceptance Saved Us from Ex-Gay Ministries. Washington D.C.: Human Rights Campaign Foundation.

Tthom's story 2007. Retrieved July 2007 (http://www.postmormon.org/exp_e/index.php/discussions/viewthread/16/P4 $\mathrm{o} /$ ).

Turner, Victor. [1964] 1970. "Betwixt and Between: The Liminal Period in Rites de Passage." P. 93-111 in The Forest of Symbols: Aspects of Ndembu Ritual. Ithaca and London: Cornell University Press.

van der Hart, Onno and Barbara Friedman. 1989. "A Reader's Guide to Pierre Janet on Dissociation: A Neglected Intellectual Heritage.” Dissociation 2:3-16.

van der Kolk, Bessel A., Paul Brown, \& Onno van der Hart. 2005. "Pierre Janet on PostTraumatic Stress.” Journal of Traumatic Stress 2,4:365-378.

van der Kolk, Bessel A., James W. Hopper, and Janet E. Osterman. 2001. "Exploring the Nature of Traumatic Memory: Combining Clinical Knowledge with Laboratory Methods." Pp. 9-31 in Trauma and Cognitive Science: A Meeting of Minds, Science, and Human Experience, edited by J. J. Freyd and A. P. DePrince. New York: Hawthorn.

Van Gennep, Arnold. [1909] 1960. The Rites of Passage. Chicago: University of Chicago Press.

Van Patrick's Story. 2008. "Set Free from the Lies of Roman Catholicism." Retrieved June 2008 (http://www.precious-testimonies.com/BornAgain/ac/CaguladaVP.htm). 
Vaughan, Diane. 2002. "Signals and Interpretive Work: The Role of Culture in a Theory of Practical Action.” Pp. 28-54 in Culture in Mind: Toward a Sociology of Culture and Cognition, edited by Karen A. Cerulo. New York: Routledge.

VFF 2008. "Vets for Freedom.” Retrieved June 2008 (http://www.vetsforfreedom.org/default.aspx).

Victor's story 2008a. Blazier, Victor. "What have we Become?” Retrieved June 2008 (http://ivaw.org/membersspeak/what-have-we-become).

-----. 2008b. Blazier, Victor. 2008. Retrieved June 2008 (http://www.ivaw.org/user/85)

Vinitzky-Seroussi, Vered. 1998. After Pomp and Circumstance: High School Reunion as an Autobiographical Occasion. Chicago: University of Chicago Press.

-----. 2001. "Commemorating Narratives of Violence: The Yitzhak Rabin Memorial Day in Israeli Schools.” Qualitative Sociology 24:245-68.

-----. 2002. "Commemorating a Difficult Past: Yitzhak Rabin's Memorials." American Sociological Review 67:30-51.

Wagner-Pacifici, Robin. 1994. Discourse and Destruction: The City of Philadelphia versus MOVE. Chicago: University of Chicago Press.

-----. 2005. The Art of Surrender: Decomposing Sovereignty at Conflict's End. Chicago: The University of Chicago Press.

Wagner-Pacifici, Robin and Barry Schwartz. 1991. "The Vietnam Veterans Memorial: Commemorating a Difficult Past.” American Journal of Sociology 97:376-420.

Walker, Katherine. 2000. "It's Difficult to Hide It': The Presentation of Self on Internet Home Pages.” Qualitative Sociology 23:99-120.

warmfuzzylogic 2008. "My Story, My Therapy.” Retrieved June 2008 (http://www.postmormon.org/exp_e/index.php/pomopedia/My_Story_My_Th erapy/).

Weber, Max. [1915] 1946. "Religious Rejections of the World and Their Directions." Pp. 323-359 in From Max Weber: Essays in Sociology, edited by H. H. Gerth and C. Wright Mills. New York: Oxford University Press.

-----. [1930] 1992. The Protestant Ethic and the Spirit of Capitalism. London and New York: Harper Collins Academic.

-----. 1968. Economy \& Society. Berkeley, California: University of California Press.

Wells, H. G. 1904. "The Country of the Blind.” Retrieved January 2008 (http://www.online-literature.com/wellshg/3/). 
Wendy's story 2006. "I Never Stopped Loving My Real Parents.” Anonymous story posted to the website of the False Memory Syndrome Foundation. Retrieved December 2006 (http://fmsfonline.org/retract2.html).

Weston, Joan. 2007. "Visualizing the Hipster: Photoblogs and Grassroots Cultural Production in the Midwest." Culture, Newsletter of the American Sociological Association Culture Section 22 (Autumn).

White, Hayden. [1974] 1978. "The Historical Text as Literary Artifact." Pp. 81-10o in Tropics of Discourse: Essays in Cultural Criticism. Baltimore, MD: Johns Hopkins University Press.

-----. 1980. "The Value of Narrativity in the Representation of Reality." Critical Inquiry 7:5-27.

Whitfield, Charles L. 1995. Memory and Abuse: Remembering and Healing the Effects of Trauma. Health Communications, Inc.: Deerfield Beach, Florida.

Wiley, Norbert. 1994. The Semiotic Self. Chicago: University of Chicago Press.

Williams, Fritz. 2004. "Born Again: A Conversion Story.” Retrieved June 2007 (http://baltimoreethicalsociety.org/Conversion.php).

Willis, Ellen. 1992. Beginning to See the Light: Sex, Hope, and Rock-and-Roll. Hanover and London: Wesleyan University Press.

Wollstonecraft, Mary. [1792] 1975. A Vindication of the Rights of Woman. New York: Penguin Group.

Wright, Richard. [1944] 1950. Page 115-162 in The God That Failed, Edited by Richard H. Crossman. New York: Columbia University Press.

X, Malcolm. 1964. The Autobiography of Malcolm X (As Told to Alex Haley). New York: Ballantine Books.

Young, Allan. 1995. The Harmony of Illusions: Inventing Post-Traumatic Stress Disorder. Princeton, New Jersey: Princeton University Press.

Young, Brigham. 1857. Journal of Discourses. Volume 4:289. Retrieved July 2009 (http://www.journalofdiscourses.org/volume-04/).

Yvonne's story 2003. "Becoming Yvonne.” Retrieved October 2005 (http://susansmiles.com/yvonne.html).

Zaretsky, Eli. 2004. Secrets of the Soul: A Social and Cultural History of Psychoanalysis. New York: Alfred A. Knopf.

Zerubavel, Eviatar. 1991. The Fine Line: Making Distinctions in Everyday Life. Chicago, Illinois: University of Chicago Press. 
-----. 1997. Social Mindscapes: An Invitation to Cognitive Sociology. Cambridge, Massachusetts: Harvard University Press.

-----. 1998. "Language and Memory: 'Pre-Columbian' America and the Social Logic of Periodization.” Social Research 65:315-330.

-----. 2003. Time Maps: Collective Memory and the Social Shape of the Past. Chicago, Illinois: University of Chicago Press.

-----. 2006. The Elephant in the Room: Silence and Denial in Everyday Life. Oxford and New York: Oxford University Press.

-----. 2007. "Generally Speaking: The Logic and Mechanics of Social Pattern Analysis." Sociological Forum 22:1-15.

Zerubavel, Yael. 1995. Recovered Roots: Collective Memory and the Making of Israeli National Tradition. Chicago, Illinois: University of Chicago Press.

Zussman, Robert. 1996. "Review: Autobiographical Occasions.” Contemporary Sociology 25:143-148.

-----. 2000. "Autobiographical Occasions: Introduction to the Special Issue." Qualitative Sociology 23:5-8. 


\title{
NOTES:
}

\section{NOTES FOR CHAPTER 1:}

\begin{abstract}
${ }^{1}$ Website of Iraq Veterans Against the War, emphasis added. Retrieved April 2009
\end{abstract} (http://ivaw.org/wintersoldier)

2 The original "Winter Soldier Investigation" was a three-day testimonial (Detroit, Michigan, January 31 February 2, 1971) organized by Vietnam Veterans Against the War at which 109 Vietnam Veterans and 16 civilians testified to their knowledge of war crimes in Vietnam. These testimonials provided the basis of John Kerry's nationally televised address to congress in March of 1971, which propelled the young retired Navy officer into the national political spotlight.

3 The term "winter soldier" was coined by members of Vietnam Veterans Against the War with reference to Thomas Paine's words in the December 1776 issue of The American Crisis. Paine, whose comments are reprinted on the website of Iraq Veterans Against the War, stated, "These are the times that try men's souls. The summer soldier and sunshine patriot will, in this crisis, shrink from the service of his country; but he that stands it now, deserves the love and thanks of man and woman." By referencing the Thomas Paine quote, both Vietnam Veterans Against the War and Iraq Veterans Against the War insinuate that the war is itself a "crisis" and that their duty to their country involves opposing that war.

4 On the social significance of testimony, see Clanchy, M.T. 1993. From Memory to Written Record: England 1066-1307; Boellstorff, Tom. 2009. "Nuri's Testimony: HIV/AIDS in Indonesia and Bare Knowledge." American Ethnologist 36, p. 351-363. On the social significance of the witness, see WagnerPacifici, Robin. 2005. The Art of Surrender: Decomposing Sovereignty at Conflict's End, pp. 29-58. See also Tal, Kali. 1996. Wolds of Hurt: Reading the Literatures of Trauma, pp. 23-59.

5 See Simpson, Ruth. 1994. “I Was There: Establishing Presence at Events.” Unpublished Manuscript.

${ }^{6}$ Lifton, Robert Jay. [1973] 2005. Home from the War: Learning from Vietnam Veterans, pp. 217-263. The American actor, John Wayne, was a well-known conservative icon and anti-communist spokesman during the McCarthy era. He was also a symbol of American machismo and bravado. The American rock band, Country Joe and the Fish, was known for their anti-war stance and their communist sympathies. Their best-known song, "I-Feel-Like-I'm-Fixin'-To-Die Rag," famously performed at Woodstock in 1969, had explicitly anti-Vietnam War lyrics (the chorus of the satirical song starts, "And it's one, two, three, what are we fighting for? Don't ask me, I don't give a damn. Next stop is Vietnam!”). By evoking this profound analogy, Lifton captured the transformation of worldview and cultural orientation he personally witnessed in many returning Vietnam veterans.

7 See Wagner-Pacifici 2005, p. 41 on this contradiction as it manifests between, in her words, "the 'thirdparty' understanding of a witness and the 'bearer of experience' meaning of witness."

8 On the "definition of the situation," see Thomas, W. I. [1923] 2002. "The Unadjusted Girl" pp. 105-115; Goffman, Erving. 1959. The Presentation of Self in Everyday Life.

9 Berger, Peter L. and Thomas Luckmann. 1966. The Social Construction of Reality: A Treatise in the Sociology of Knowledge, p. 162.

10 Berger, Peter L. 1963. Invitation to Sociology: A Humanist Perspective, p. 54. 
${ }^{11}$ Various scholars have discussed story types or story forms and developed story typologies. See, for example, Propp, Vladimir. 1968. Morphology of the Folktale; Frye, Northrop. 1957. Anatomy of Criticism; White, Hayden. [1974] 1978. "The Historical Text as Literary Artifact"; Bruner, Jerome. 1987. "Life as Narrative"; Somers, Margaret R. 1994. "The Narrative Constitution of Identity: A Relational and Network Approach"; Gergen, Kenneth J. and Mary M. Gergen. 1997. "Narratives of the Self”; Cerulo, Karen. 1998. 1998. Deciphering Violence: The Cognitive Structure of Right and Wrong; Zerubavel, Eviatar. 2003. Time Maps: Collective Memory and the Social Shape of the Past; Booker, Christopher. 2004. Seven Basic Plots: Why We Tell Stories.

12 Denzin, Norman K. 1989a. Interpretive Biography, pp. 70-73; See also Denzin 1989b. Interpretive Interactionism. Pp. 128-131.

${ }_{13}$ Burke, Kenneth. [1962] 1969. A Grammar of Motives; Mills, C. Wright. 1940. "Situated Actions and Vocabularies of Motive.” See also Scott, Marvin B. and Stanford M. Lyman. 1968. “Accounts;” Denzin 1989a, 1989b; Plummer, Ken. 1995. Telling Sexual Stories: Power, Change and Social Worlds; Orbuch, Terri L. 1997. "People's Accounts Count: The Sociology of Accounts."

14 Burke [1962] 1969, p. xv.

${ }_{15}$ Mills, C. Wright. 1940. Burke also used the term "vocabularies of motives." See Burke [1962] 1969, p. 440.

${ }^{16}$ Mills 1940, p. 904.

17 White, Hayden. 1980. “The Value of Narrativity in the Representation of Reality," p. 1.

${ }_{18}$ Davis, Joseph E. 2005a. "Victim Narratives and Victim Selves: False Memory Syndrome and the Power of Accounts," p. 192.

19 Stein, Arlene. n.d. “Our Holocaust: The Identity Politics of the ‘Second Generation'.,” p. 1.

${ }_{20}$ Plummer 1995, p. 18; see also Polletta, Francesca. 2006. It Was Like a Fever: Storytelling in Protest and Politics.

${ }^{21}$ Because I am concerned with "truth" and "falsehood" as narrative accomplishments, I enclose these words in quotation marks to remind the reader that I am analyzing claims people make, not the actual veracity of their accounts. When I specifically refer to the storyteller's perception, account, claims, or description of truth and falsehood, I do not use quotes. By treating the truth as relative in this way, I am not implying that there is no such thing as truth or reality. Rather, my phenomenological approach to "truth" and "falsehood" exposes unseen social constructionist dimensions of the stories we tell, dimensions that are often buried or masked when we treat the truth as objective or absolute.

${ }^{22}$ Weber, Max. [1915] 1946. "Religious Rejections of the World and Their Directions."

23 On the question of the divergent cultural logics of variant discourses, see Foucault, Michel. [1969] 1972. The Archeology of Knowledge, [1978] 1990. The History of Sexuality, Volume I: An Introduction; See also Wagner-Pacifici, Robin. 1994. Discourse and Destruction: The City of Philadelphia versus MOVE.

24 On cognitive authority, see Martin, John Levi. 2002. "Power, Authority, and the Constraint of Belief Systems"; See also DeGloma, Thomas. 2007. "The Social Logic of 'False Memories': Symbolic Awakenings and Symbolic Worlds in Survivor and Retractor Narratives;" On the cognitive dimensions of power, see Lukes, Steven. 1974. Power: A Radical View, p. 24; Zerubavel, Eviatar. 2006. The Elephant in the Room: Silence and Denial in Everyday Life, pp. 33-45. I conceive of cognitive authority to be both a constructive force and a descriptive resource. On the one hand, cognitive authority is a social force and cognitive authority figures teach individuals to derive particular meanings from their experiences and interpret 
their lives in patterned ways. On the other hand, cognitive authority often takes on meaning in the narratives and memories we produce. Cognitive authority figures are central characters in the stories we tell about our lives, especially when explaining our personal discoveries of "truth" and accounting for our rejection of previously held beliefs.

25 Snow, David A. and Richard Machalek. 1983. “The Convert as a Social Type,” pp. 269-73.

${ }^{26}$ See, for example, Wagner-Pacifici and Schwartz's discussion of Vietnam Veteran Jan Scruggs, who embodied the multimodal character of the Vietnam Memorial. Wagner-Pacifici, Robin and Barry Schwartz. 1991. "The Vietnam Veterans Memorial: Commemorating a Difficult Past," p. 39.

${ }^{27}$ As part of his "Grammar of Identity" in his study of gay suburbanites, Wayne H. Brekhus defines "identity integrators" as those individuals who treat their gay identity as "just one of a number of facets by which they organize their life and identify themselves." See Brekhus, Wayne H. 2003. Peacocks, Chameleons, Centaurs: Gay Suburbia and the Grammar of Social Identity, p. 29.

${ }_{28}$ Zussman, Robert. 1996. "Review: Autobiographical Occasions,” p. 143; See also Davis, Joseph E. 2005b. Accounts of Innocence: Sexual Abuse, Trauma, and the Self; Somers 1994.

${ }^{29}$ See, for example, Ebaugh, Helen R. F. 1988. Becoming an Ex: The Process of Role Exit; Frank, Arthur W. 1993. "The Rhetoric of Self-Change: Illness Experience as Narrative"; Howard, Jenna 2006.

"Expecting and Accepting: The Temporal Ambiguity of Recovery Identities"; Mason-Schrock, Douglas. 1996. "Transsexuals' Narrative Construction of the 'True Self'."

30 On "thought collectives," see Fleck, Ludwik. [1935] 1979. Genesis and Development of a Scientific Fact. Pp. 38-51. See also Mannheim, Karl. 1936. Ideology and Utopia: An Introduction to the Sociology of Knowledge.

${ }^{31}$ Zerubavel, Eviatar. 1997. Social Mindscapes: An Invitation to Cognitive Sociology, p. 8 (emphasis in original).

$3^{2}$ For a foundational discussion of cognitive sociology, see Zerubavel 1997; DiMaggio, Paul. 1997. "Culture and Cognition," For a foundational sociological epistemology, see Mannheim 1936; Fleck [1935] 1979; Kuhn, Thomas S. [1962] 1996. The Structure of Scientific Revolutions.

33 For various formal or structural approaches to the question of narrative, see Frye 1957; Propp 1968; White [1974] 1978; Denzin 1989a; Zerubavel 2003; Howard 2006; DeGloma 2007.

34 See DeGloma 2007

35 Elliott, Michele, ed. 1994. Female Sexual Abuse of Children, p. 176.

${ }^{36}$ Eli's story 2007

37 Horowitz, David. 1989. "Why I am No Longer a Leftist," p. 280.

${ }^{8}$ Throughout this book, I provide several "maps" or graphs to illustrate the formulaic characteristics of the awakening narrative formula. The strength of such visual displays lays in the fact that they illustrate the basic, foundational structure shared by a collection of otherwise diverse narratives. However, the weakness of such displays is that they inevitably simplify otherwise rich and complex stories. I ask the reader to view these structural story maps with these strengths and weaknesses in mind. While they show the foundational pattern inherent in multiple accounts, my textual interpretation of these stories reveals rich complexities that the models cannot display.

39 DeGloma 2007 
40 For a sociological approach to a psychoanalytic case study, see Prager, Jeffrey. 1998. Presenting the Past: Psychoanalysis and the Sociology of Misremembering. Even though Prager brilliantly details the social significance of the psychological themes that emerge from his case, his analysis is based on a therapeutic engagement with a small number of individuals that he fashions into one biographical sketch. Prager's analysis thus rests on the traditional psychoanalytic model of extrapolating and generalization from a single case or personality profile.

${ }^{41}$ Fichter, Joseph H. 1987. Autobiographies of Conversion, p. 1

${ }^{42}$ See, for example, Davis, 2005a; Mason-Schrock 1996; Vinitzky-Seroussi, Vered. 1998. After Pomp and Circumstance: High School Reunion as an Autobiographical Occasion; Young, Allan. 1995. The Harmony of Illusions: Inventing Post-Traumatic Stress Disorder.

43 Frank 1993

44 Butler, Judith. 1991. "Imitation and Gender Insubordination"; Phelan, Shane. 1993. "(Be)Coming Out: Lesbian Identity and Politics”; Plummer 1995.

45 Gillespie, V. Bailey. 1979. Religious Conversion and Personal Identity; James, William. [1902] 1987. The Varieties of Religious Experience; Rambo, Lewis R. 1993. Understanding Religious Conversion.

${ }^{46}$ Ezzy, Douglas. 2000. "Fate and Agency in Job Loss Narratives."

47 Zerubavel, Eviatar. 2007. "Generally Speaking: The Logic and Mechanics of Social Pattern Analysis.”

${ }^{48}$ See Simmel, Georg. 1950a. "The Stranger"; 1950b. "The Field of Sociology.”

49 Simmel 195ob, p. 15

$5^{\circ}$ Coser, Lewis A. 1971. Masters of Sociological Thought: Ideas in Historical and Social Context, p. 182.

${ }^{51}$ Lieblich, Amia, Rivka Tuval-Mashiach, and Tamar Zilber. 1998. Narrative Research: Reading, Analysis, and Interpretation, p. 110. Lieblich and colleagues advance an illuminating structural psychology of life stories. Arguing "that the structure of the story may reflect the deeper personality of the teller [...] while the contents manifest the particular culture within which the story unfolds," these authors show how a formal narrative analysis can illuminate the concerns of psychology. What Lieblich and colleagues call "self-actualization narratives" might indeed reveal something about the "underlying personality" of the storyteller. Further, certain individuals may be attracted to such story types and to the process of adopting what Somers (1994, p. 610) calls "totalizing fictions" or narrative identities where "a single category of experience" takes over the whole of the storyteller's identity. However, by treating awakeners as a social type of storyteller I stress their generic social-relational location at the expense of the particulars of personality or personality-type.

$5^{2}$ Berger and Luckmann. 1966, pp. 156-63; see also Berger 1963, pp. 49-65.

53 Snow and Machalek 1983.

54 Zerubavel 2007, p. 134 (emphasis in original).

55 Bakhtin, M. M. 1986. Speech Genres and Other Late Essays, p. 91 (emphasis in original).

${ }^{6}$ Ibid, p. 89; see also Wagner-Pacifici 1994, pp. 5-7 
57 Jeffrey K. Olick's "Genre Memories and Memory Genres: A Dialogical Analysis of May 8th, 1945 Commemorations in the Federal Republic of Germany" (1999a) shows how attention to the temporal dimension of dialogue can advance social memory studies. Applying Bahktin to the study of collective memory and commemoration, Olick advances a theory of "memory genres," arguing that the "past includes not only the history being commemorated but also the accumulated succession of commemorations, as well as what had occurred between those powerful moments" so that "earlier commemorations shape later ways of seeing, whether or not subsequent speakers are aware of any specific earlier commemoration" (p. 383). While I am not specifically addressing the collective act of commemoration, I build on Olick's temporal expansion of a Bahktinian framework when I consider how awakeners orient their narratives towards a past community as well as a past version of self.

$5^{8}$ On the notion of "ontological security," see Laing, R. D. 1959. The Divided Self: An Existential Study of Madness; Giddens, Anthony. 1991. Modernity and Self-Identity: Self and Society in the Late Modern Age.

59 Mead, George Herbert. [1934] 1967. Mind, Self, and Society: From the Standpoint of a Social Behaviorist; see also Cerulo, Karen A. 2009. "Non-Humans in Social Interaction."

${ }^{60}$ As my conception of dialogical orientation implies, awakening narratives give us access to "one side" of a dialogue or interaction. They are thus valuable in that they tell us how awakeners use the awakening narrative formula to situate themselves in a broader, multifarious social context. Given this, these stories shed considerable light on the character of the dialogue or interactional context, especially when seen through a broad comparative perspective. For a similar argument, see Stein, Arlene. 2009. "As Far as They Knew, I Came from France’: Stigma, Passing, and Not Speaking about the Holocaust.”

${ }^{61}$ On the sociological analysis of dialogue and discourse, see Perinbanayagam, Robert S. 1991. Discursive Acts; Steinberg, Marc W. 1999. "The Talk and Back Talk of Collective Action: A Dialogic Analysis of Repertoires of Discourse among Nineteenth-Century English Cotton Spinners"; Tannen, Deborah. 1993. Gender and Conversational Interaction; Wagner-Pacifici 1994.

${ }^{62}$ Swidler, Ann. 1986. "Culture in Action: Symbols and Strategies."

${ }^{6} 3$ Zussman, Robert. 2000. “Autobiographical Occasions: Introduction to the Special Issue.”

64 Gubrium, Jaber F. 1992. Out of Control: Family Therapy and Domestic Disorder; Young 1995.

65 Vinitzky-Seroussi 1998.

${ }^{66}$ See Denzin, Norman K. 1987. The Alcoholic Self; Holstein, James A. and Jaber F. Gubrium. 200o. The Self We Live By: Narrative Identity in a Postmodern World, pp. 171-182; Howard, Jenna. 2000. "Memory Reconstruction in Autobiographical Narrative Construction: Analysis of the Alcoholics Anonymous Recovery Narrative."

${ }^{67}$ Gubrium, Jaber F. 2005. "Introduction: Narrative Environments and Social Problems”; Gubrium, Jaber F. and James A. Holstein. 2009. Analyzing Narrative Reality; Davis 2005b

68 Zussman 1996, p. 143

${ }^{69}$ Zussman 2000, p. 5

${ }^{70}$ Gubrium 2005, p. 536

${ }^{71}$ On the contextual organization of reality, see Emerson, Joan P. 1970. "Behavior in Private Places: Sustaining Definitions of Reality in Gynecological Examinations"; Davis, Murray. 1983. Smut: Erotic Reality/Obscene Ideology; Goffman, Erving. 1959. The Presentation of Self in Everyday Life; DeGloma, 
Thomas and Asia Friedman. 2005 "Thinking With Sociomental Filters: Exploring the Social Structuring of Attention and Significance."

${ }^{72}$ On the artful negotiation between personal creativity and social forces in storytelling, see Holstein and Gubrium 2000; See also Davis 2005a, pp. 530-531. On the social significance of the audience to autobiography, see Vinitzky-Seroussi 1998, pp. 59-77.

73 Fleck [1935] 1979, pp. 38-51

74 Shibutani, Tamotsu. 1955. "Reference Groups as Perspective," p. 563. Regarding reference groups more generally, see Merton, Robert K. [1949] 1964. Social Theory and Social Structure.

75 Vinitzky-Seroussi 1998, p. 56. On the autobiographical occasion as social control, see Vinitzky-Seroussi 1998, pp. 42-58; see also Loseke, Donileen R. 2001. "Lived Realities and Formula Stories of 'Battered Women." On social control more generally, see also Foucault, Michel. 1979. Discipline and Punish: The Birth of the Prison, [1978] 1990; Horwitz, Allan V. 1990. The Logic of Social Control; Benford, Robert D. 2002. "Controlling Narratives and Narratives as Control within Social Movements"; Durkheim, Emile. [1912] 1995. The Elementary Forms of Religious Life.

${ }^{76}$ Zerubavel (1997) uses the term "optical community" (33) to refer to a social group for which membership "entails learning to 'see' the world through its particular mental lenses" and thus taking on shared cognitive norms. He defines "mnemonic communities" (1997, pp. 96-99) as social groups that share common ways of remembering and interpreting the past. Like Zerubavel, I use the term "cognitive norms" to refer to a community's shared normative patterns and collectively-rooted rules of thought and cognition. For a discussion of social mindsets, see also Davis 1983. Other relevant discussions include Snow and Machalek's (1983) discussion of a "master attribution frame"; Goffman, Erving. [1974] 1986. Frame Analysis: An Essay on the Organization of Experience, on "primary frameworks"; Benford, Robert D. and David A. Snow. 2000. "Framing Processes and Social Movements: An Overview and Assessment," on the "master frame"; and Berger and Luckmann (1966, p. 157) on the concept of "plausibility structure."

77 On the connection between ontological security and biography, see Giddens 1991.

${ }^{78}$ Manheim 1936, p. 99

79 On the concept of "group style," see Eliasoph, Nina and Paul Lichterman. 2003. "Culture in Interaction." Eliasoph and Lichterman define group style "as recurrent patterns of interaction that arise from a group's shared assumptions about what constitutes good or adequate participation in the group setting [...] elements of culture [...] [that] are patterned and relatively durable." (737) I borrow this term to denote how various awakeners can use the same widespread narrative formula (analogous to Eliasoph and Lichterman's treatment of "collective representations") while filling this narrative formula with group-specific, culturally grounded meanings that arise in the particular community to which they belong. In short, awakeners combine a durable, generic narrative formula with a "group style" of storytelling when they tell stories about their lives.

8o See Foucault [1969] 1972.

${ }^{81}$ It was Karl Mannheim who first developed a conception of standpoint theory (though not by that name) when he wrote, "In the realm of the social, particularly, truth is not merely a matter of a simple correspondence between thought and existence, but is tinged with the investigators interest in his subject matter, his standpoint, his evaluations, in short the definition of his object of attention. (emphasis added)." See Mannheim 1936. For a more modern conception of standpoint theory, see Collins, Patricia Hill. 2000. Black Feminist Thought: Knowledge, Consciousness, and the Politics of Empowerment. As opposed to Collins, who elaborates a standpoint theory and "its accompanying epistemology" (270) by stressing demographic variables that are "situated in a context of domination" (269), I use the term 
standpoint, in the tradition of Mannheim, to indicate the sociomental communities to which we belong and from which we define the world. However, my emphasis on intersubjective and sociomental dynamics does not downplay the power relations inherent in cultural contests over meaning and truth.

${ }^{82}$ Spillman, Lyn. 1995. "Culture, Social Structure, and Discursive Fields," p. 139.

83 Ibid., p. 144; see also Bakhtin 1986 on the concept of speech genres; Wagner-Pacifici 1994; WagnerPacifici and Schwartz 1991.

84 Wagner-Pacifici 1994, p. 4.

85 Nicolosi, Joseph. 1993. Healing Homosexuality: Case Studies of Reparative Therapy, p. viii.

86 Ibid., p. viii-ix.

87 Engerman, David C. 2001. Forward to The God that Failed, pp. viii-ix.

88 Ibid., p. xxv.

89 On the cooperative development of autobiographical memory is a social context, see Fivush, Robyn. 1995. "Language, Narrative, and Autobiography;" Fivush, Robyn, Catherine Haden, and Elaine Reese. 1996. "Remembering, Recounting, and Reminiscing: The Development of Autobiographical Memory in Social Context."

90 See Zerubavel 1997, p. 33; see also Kuhn [1962] 1996.

${ }^{91}$ Moonshine’s story. 2008. "A Tale of Two Cities and Two Towers."

92 On the metaphor of the journey, see Kövecses, Zoltán. 2002. Metaphor: A Practical Introduction.

93 Berger, Peter L. and Thomas Luckmann. 1966, p. 160; see also Berger 1963, p. 56

94 Zerubavel 2003, p. 82-100. Such a historical discontinuity is different than the process of what Teeger and Vinitzky-Seroussi (2007, "Controlling for Consensus: Commemorating Apartheid in South Africa") call "divorcing the past." While awakeners make a sharp distinction between their past and present mindsets, the past is continually relevant to their personal accounts.

95 Halbwachs [1950] 1980. The Collective Memory.

${ }_{96}^{6}$ Notable exceptions include Zerubavel $(1997,2003)$, who illuminates patterns of time and memory that span individual and collective levels of analysis. Olick distinguishes between group-level collective memories and the "collected" memories of individual group members. See Olick, Jeffrey. 1999b.

"Collective Memory: The Two Cultures." See also Olick, Jeffrey K. and Joyce Robbins. 1998. "Social Memory Studies: From 'Collective Memory' to the Historical Sociology of Mnemonic Practices." For studies of the personal or autobiographical memories of collectively relevant events, see Schuman, Howard and Jacqueline Scott. 1989. "Generations and Collective Memories;" Lomsky-Feder, Edna. 1995. "The Meaning of War Through Veterans' Eyes: A Phenomenological Analysis of Life Stories;” Schwartz, Barry and Howard Schuman. 2005. "History, Commemoration, and Belief: Abraham Lincoln in American Memory, 1945-2001;" Teeger, Chana. 2009. "Collective Memories and Collective Fears: South Africans Narrate Crime against the Backdrop of Apartheid.”

97 Halbwachs, Maurice. [1925] 1992. "The Social Frameworks of Memory," p. 40.

98 On the concept of “projection” see Emirbayer, Mustafa and Ann Mische. 1998. "What Is Agency?" See also Cerulo 2009. 
99 Kuhn [1962] 1996.

100 Turner, Victor. [1964] 1970. "Betwixt and Between: The Liminal Period in Rites de Passage.”

${ }^{101}$ Somers 1994, p. 617.

102 Propp 1968.

103 Cerulo 1998; On metaphorical structuring and experiential gestalts, see Lakoff, George and Mark Johnson. 1980. Metaphors We Live By, pp. 77-86.

104 See Heritage, John. 1984. Garfinkel and Ethnomethodology, pp. 262-263; Tannen 1993, pp. 189-227

105 Propp op. cit.

${ }_{106}$ Frye 1957, p. 33-67; White [1974] 1978

107 Zerubavel 2003

${ }^{108}$ See, for example, Fabian, Johannes. 1983. Time and the Other: How Anthropology Makes Its Object; Graham, Gordon. 1997. The Shape of the Past: A Philosophical Approach to History; White [1974] 1978; Zerubavel 2003

109 See, for example, Bruner 1987; Gergen and Gergen 1997; Hankiss, Agnes. 1981. "Ontologies of the Self: On the Mythological Rearranging of One's Life-History;” LaRossa, Ralph and Cynthia B. Sinha. 2006.

"Constructing the Transition to Parenthood."

${ }^{110}$ See Davis, Joseph E. 2002. "Narrative and Social Movements."

${ }_{111}$ Zerubavel 2007; see also Brekhus, Wayne H. 2007. "The Rutgers School: A Zerubavelian Culturalist Cognitive Sociology.”

${ }^{112}$ Simmel $1950 b$

${ }_{113}$ Zerubavel 2007, p. 1; see also Vaughan, Diane. 2002. "Signals and Interpretive Work: The Role of Culture in a Theory of Practical Action.” Pp. 30-33

114 Cerulo 1998, 2006. Never Saw it Coming: Cultural Challenges to Envisioning the Worst.

${ }_{115}$ See Horwitz, Allan V. 1990

${ }^{116}$ See Mullaney, Jamie L. 2006. Everyone Is NOT Doing It: Abstinence and Personal Identity.

${ }_{117}$ See Ryan, Dan. 2006. "Getting the Word Out: Notes on the Social Organization of Notification.”

118 Glaser, Barney G. and Anselm L. Strauss. [1967] 2008. The Discovery of Grounded Theory: Strategies for Qualitative Research, pp. 82-89.

119 On Julian the Apostate, see Murdoch, Adrian. [2003] 2008. The Last Pagan: Julian the Apostate and the Death of the Ancient World; The other apostasy narratives listed include Templeton, Charles. 1982. "An Anecdotal Memoir;” Williams, Fritz. 2004. “Born Again: A Conversion Story;” Sweeney, Julia. 2005. Letting Go of God. 
120 For example, Hobbes, Thomas. [1651] 1962. Leviathan; Spinoza, Benedict de. [1670] 2007. Theological-Political Treatise; Locke, John. [1690] 1961. "An Essay Concerning Human Understanding;" Kant, Immanuel. [1781] 1993. Critique of Pure Reason; Rousseau, Jean-Jacques. [1762] 1968. The Social Contract.

${ }^{121}$ See Marx, Karl. [1845] 1963. “The German Ideology: Part I;” Gramsci, Antonio. 1971. Selections from the Prison Notebooks; Lukács, Georg. [1920] 1971. History and Class Consciousness.

${ }^{122}$ See Koestler, Arthur. 1950; Wright, Richard [1944] 1950; Gide, André 1950; Fischer, Louis [1949] 1950; Horowitz, David 1989, 1997; Collier, Peter 1989; O’Rourke, P. J. 1989; Arguello, Xavier 1989; Ifshin, David 1989; Iannone, Carol 1989; Muravchik, Joshua 1989

123 On psychoanalytic and psychodynamic theories of the unconscious, see Freud. Sigmund. [1899] 1938. “The Interpretation of Dreams;” Jung, Carl. 1959. The Undiscovered Self; Laing 1959; Laing, R. D. 1961. Self and Others. On modern clinical theories of dissociative amnesia, see Chu, James A., Lisa M. Frey, Barbara L. Ganzel, and Julia A. Matthews. 1999. "Memories of Childhood Abuse: Dissociation, Amnesia, and Corroboration;" Freyd, Jennifer J. 1996. Betrayal Trauma: The Logic of Forgetting Childhood Abuse; Schooler, Jonathan W. 2001. "Discovering Memories of Abuse in the Light of Meta-Awareness;" van der Kolk, Bessel A. and Rita Fisler. 1995. "Dissociation and the Fragmentary Nature of Traumatic Memories: Overview and Explanatory Study;" van der Kolk, Bessel A., James W. Hopper, and Janet E. Osterman. 2001. "Exploring the Nature of Traumatic Memory: Combining Clinical Knowledge with Laboratory Methods.” See also Prager 1998.

124 See Freud [1905] 1963. Dora: An Analysis of a Case History; For additional case studies, see Freud [1909, 1911, 1918] 1963. Three Case Histories: The "Wolf Man," The "Rat Man," and the Psychotic Doctor Schreber. See also Freud [1899] 1938.

125 See, for example, Medinger, Alan. 2008. "Reflections on 25 Years of Healing." See also Nicolosi 1993 for a collection of case studies.

${ }^{126}$ For personal stories about the recovery of traumatic memories, see Terr, Lenore. 1994. Unchained Memories: True Stories of Traumatic Memories, Lost and Found. See also Elliot 1993. On theories of traumatic repression or dissociation and memory recovery, see Arnold, Michelle M. and Stephen Lindsay. 2002. "Remembering Remembering;" Bass, Ellen and Laura Davis. 1994. The Courage to Heal: A Guide for Women Survivors of Child Sexual Abuse; Freyd 1996; Freyd, Jennifer J. and Anne P. DePrince (Eds.). 2001. Trauma and Cognitive Science: A Meeting of Minds, Science, and Human Experience; Whitfield, Charles L. 1995. Memory and Abuse: Remembering and Healing the Effects of Trauma.

127 Pasley, Laura E. 1993. “Misplaced Trust.” See Goldstein, Eleanor and Kevin Farmer. 1993. True Stories of False Memories and Pendergrast, Mark. 1995. Victims of Memory: Sex Abuse Accusations and Shattered Lives for a collection.

${ }^{128}$ X, Malcolm. 1964. The Autobiography of Malcolm X (As Told to Alex Haley).

129 Feinberg, Leslie. 1996. Transgender Warriors: Making History from Joan of Arc to RuPaul.

${ }^{130}$ See Wells, H. G. 1904. “The Country of the Blind;” Chopin, Kate. [1899] 2004. The Awakening.

${ }^{131}$ On the online performance of self, see Walker, Katherine. 2000. “'It's Difficult to Hide It': The Presentation of Self on Internet Home Pages;" Weston, Joan. 2007. "Visualizing the Hipster: Photoblogs and Grassroots Cultural Production in the Midwest." Regarding online communities, see Adler, Patricia A. and Peter Adler. 2008. "The Cyber Worlds of Self-Injurers: Deviant Communities, Relationships, and Selves;" Cerulo, Karen A. 1997. "Reframing Sociological Concepts for a Brave New (Virtual?) World;" Chayko, Mary. 2002. Connecting: How We Form Social Bonds and Communities in the Internet Age; Chayko, Mary 2008. Portable Communities: The Social Dynamics of Online and Mobile Connectedness. 
Concerning storytelling or claims-making online, see Maratea, Ray. 2008. "The e-Rise and Fall of Social Problems: The Blogosphere as a Public Arena;" Polletta 2006, p. 82-108; Polletta, Francesca and John Lee. 2006. "Is Telling Stories Good for Democracy? Rhetoric in Public Deliberation After 9/11."

${ }^{132}$ Unlike the other sites in Table 1, most of the stories posted on the website of the False Memory Syndrome Foundation were previously published in the organization's newsletter. Selected stories are reproduced in HTML format and the newsletter itself is archived on the organization's website.

133 Davis 2005a; Gubrium 2005; Gubrium and Holstein 2009, pp. 123-197

134 Evans, Sara M. \& Harry C. Boyte. [1986] 1992. Free Spaces: The Sources of Democratic Change in America; Polletta, Francesca. 1999. "Free Spaces' in Collective Action;” Collins 2000.

135 Melucci, Alberto. 1996. Challenging Codes: Collective Action in the Information Age.

${ }^{136}$ Foucault, Michel. 1977. Language, Counter-Memory, Practice: Selected Essays and Interviews, p. 160; Zerubavel, Yael. 1995. Recovered Roots: Collective Memory and the Making of Israeli National Tradition, pp. 10-12; Olick and Robbins 1998, pp. 126-128;

137 Eliasoph and Lichterman 2003. (see n. 79 above).

${ }^{138}$ Chayko 2008

139 Becker, Howard S. [1963] 1997. Outsiders: Studies in the Sociology of Deviance, pp. 147-163.

${ }^{140}$ Examples of the "message board" type include the websites of Iraq Veterans Against the War, Susan Smiles - Surviving Childhood Sexual Abuse, Safeguarding Our Children - Uniting Mothers, the Recovery from Mormonism Forums, and Postmormon.org. Alternatively, the websites of the False Memory Syndrome Foundation, mormonconverts.com, precious-testimonies.com, faith-travels.org, People Can Change, Courage, and Beyond ExGay more closely resemble the "selective publication" type. Autobiographical accounts posted to most sites of the latter set are typically framed with editorial comments.

${ }^{141}$ Kenney, William Howland. 1999. Recorded Music in American Life: The Phonograph and Popular Memory, 1890-1945.

${ }^{142}$ Habermas distinguishes "communicative" action from "instrumental" action, stressing that the former involves an attempt to arrive at a shared understanding among the participants. See Habermas, Jürgen. 1987. The Theory of Communicative Action, Volume Two: Lifeworld and System: a Critique of Functionalist Reason.

143 Weber [1915] 1946, p. 330

144 For defining statements of this field, see Zerubavel 1997, 2003; DiMaggio 1997; Cerulo (Ed.) 2002. Culture in Mind: Toward a Sociology of Culture and Cognition.

145 For defining statements, see Halbwachs [1925] 1992; [1950] 1980; Davis, Fred. 1979. Yearning for Yesterday: A Sociology of Nostalgia; Schwartz, Barry. 1982. "The Social Context of Commemoration: A Study in Collective Memory;" Olick 1999b; Zerubavel 2003. 


\section{NOTES FOR CHAPTER 2:}

${ }^{1}$ This proverb is commonly printed (sometimes with slight alternations) and widely available. I have never seen it attributed to an original source.

${ }^{2}$ See, for example, Edwards, Tyron. 1908. A Dictionary of Thoughts, p. 588.

3 See, for example, Freudenreich, Oliver. 2008. Psychotic Disorders: A Practical Guide, p. 36.

4 Weber [1915] 1946

5 Foucault [1978] 1990

${ }^{6}$ Jaspers argues that political struggles between states was a defining factor of what he refers to as "the Axial Age," the period of time from approximately 800 to 200 BCE marked by the rise of similar philosophical and religious traditions in Greece, India, China, and Persia. See Jaspers, Karl. 1953. The Origin and Goal of History.

7 On the reflexive organization of self in the "late modern age," see Giddens 1991.

${ }^{8}$ Gergen, Kenneth. 1991. The Saturated Self: Dilemmas of Identity in Contemporary Life, p. 16.

9 Bellah, Robert N., Richard Madsen, William M. Sullivan, Ann Swidler, and Steven M.. Tipton. 1985.

Habits of the Heart: Individualism and Commitment in American Life, pp. 32-51, 333-34.

10 Boyce, Mary. [1979] 2001. Zoroastrians: Their Religious Beliefs and Practices, p. 1.

${ }^{11}$ see Boyce [1979] 2001, p. 2; Nigosian, S. A. 1993. The Zoroastrian Faith: Tradition and Modern Research, pp. 15-16; Shahbazi, A. Shapur. 1977. "The 'Traditional Date of Zoroaster' Explained."

${ }^{12}$ See http://www.avesta.org/gathas.htm for a complete translation. Retrieved June 2009.

13 Boyce [1979] 2001, p. 3

14 Ibid., p. 19; See also Armstrong, Karen. 2006b. The Great Transformation: The Beginning of Our Religious Traditions, pp. 9-14.

${ }^{15}$ See also Choksy, Jamsheed K. 2003. "To Cut off, Purify, and Make Whole: Historiographical and Ecclesiastical Conceptions of Ritual Space," pp. 21-23; Nigosian, 1993, pp. 3-24.

${ }^{16}$ Choksy 2003, p. 20

${ }_{17}$ Avesta: Yansa 30.1-5. Retrieved June 2009 (http://www.avesta.org/yasna/y28to34b.htm).

${ }_{18}$ Jackson, A. V. Williams. 1896. "The Moral and Ethical Teachings of the Ancient Zoroastrian Religion.”

19 Avesta: Yasna 32:16. Ahunavaiti Gatha. Retrieved June 2009

(http://www.avesta.org/yasna/y28to34b.htm).

${ }^{20}$ Boyce [1979] 2001, p. 20

${ }^{21}$ Nietzsche, Friedrich. [1891] 1917. Thus Spake Zarathustra, p. 286. Nietzsche writes, "Well! Take heart! ye higher men! Now only travaileth the mountain of the human future. God hath died: now do we desirethe Superman [Übermensch] to live." 
22 Plato. [ 380 BCE] 1941. The Republic of Plato, p. 231.

23 Image retrieved March 2009 (www.ufh.ac.za/Philosophy/cave.htm).

24 Plato [ 380 BCE] 1941, p. 231.

25 Ibid, p. 229

${ }^{26}$ Ibid, p. 231. Plato was concerned with the issue of political and philosophical authority, reasoning that only the enlightened philosophers were fit to govern over the unenlightened masses. As he distinguished between the mutually exclusive worlds of darkness and light, he was also trying to account for the death of his teacher, Socrates, who despite his lifelong pursuit of truth was tried and condemned to death for corrupting the minds of Athenian youth.

${ }_{27}$ See Buckle, Stephen. 2007. "Descartes, Plato and the Cave.”

${ }^{28}$ See Gooer, Asli. 2000. “The Puppet Theater in Plato's Allegory of the Cave.”

29 Horwitz, Gordon J. 1990. In the Shadow of Death: Living Outside the Gates of Mauthausen.

30 Plato [ 380 BCE] 1941, p. 232

${ }^{31}$ See Lakoff, George and Mark Johnson 1999. Philosophy in the Flesh: The Embodied Mind and it Challenge to Western Thought. I am also in debt to George Lakoff for making this point in a conversation at the Cornell University Institute for Social Sciences, Workshop on Contentious Knowledge and the Diffusion of Social Protest, November 9-10 2007.

32 On the notion of "paradigm shift," see Kuhn [1962] 1996. On "optical communities," see Zerubavel 2003.

33 See also Schooler 2001. Schooler advances a psychological phenomenology while writing about the phenomenon of recovered memories. Schooler states, "Although individuals may engage in... deliberative ruminations about the prior degree of forgetting, it also seems likely that people's immediate phenomenology at the time of recollection [emphasis in original] may also serve as an important factor in their assessment of their prior forgetting. If individuals experience a marked sense of 'aha' or surprise when they recall an event... they are likely to attribute this surprise to having just discovered a previously forgotten memory" (p. 118).

34 Weber [1915] 1946, p. 330; See also Weber [1930] 1992. The Protestant Ethic and the Spirit of Capitalism.

35 See, for example, Chopra, Deepak. 2007. Buddha: A Story of Enlightenment for a popular spiritual rendition of the Buddha's life. For the account as rendered in scholarly works on Buddhism, see Harvey, Peter. 1990. An Introduction to Buddhism: Teaching, History, Practice, pp. 14-22; Lopez, Donald S. 2001. The Story of Buddhism: A Concise Guide to its History and Teachings, pp. 37-42. My modest rendition of the Buddha's life in this section is pieced together from these sources. While of Eastern origin, the story of Siddhārtha Gautama is widely relevant in the modern Western world, as exemplified by the profound cultural impact of Herman Hesse's ([1922] 1951) allegorical novel, Siddhartha.

${ }^{36}$ See Acts 9:3-6, 26:15-18. All New Testament references in this section are taken from The Holy Bible: New Internationalist Version. Zondervan Publishing House: Grand Rapids, Michigan.

37 Harvey 1990, p. 2

${ }^{38}$ Galacians 1:13 
39 Acts 9:3-6

40 Acts 26:15-18

${ }^{41}$ Acts 9:15-16

42 Acts 22:1-22

43 Acts 26:1-32

44 See Acts 7:54-59; See also Hoever, Hugo. [1955] 1974. Lives of the Saints, p. 45.

45 Also known as the Book of Romans

${ }^{46}$ See Armstrong, Karen. 1992. Muhammad: A Biography of the Prophet, pp. 45-49. See also Armstrong, Karen. 2006a. Muhammad: A Prophet for our Time, pp. 33-39.

47 Augustine [397-8] 1961. Confessions, pp. 177-78

${ }^{48}$ See Remini, Robert. 2002. Joseph Smith, pp. 38-39, 43-45; Bushman, Richard L. 1984. Joseph Smith and the Beginnings of Mormonism, pp. 56-61; Bushman, Richard L. 2005. Joseph Smith: Rough Stone Rolling, 39-46.

49 Benford and Snow 2000

${ }^{50}$ Weber [1915] 1946, p. 335

${ }^{51}$ Ibid.

${ }^{52}$ Gergen 1991, p. 16

53 Somers 1994, p. 619

54 See Hobbes [1651] 1962; Newton, Sir Isaac. 1687. Philosophiae Naturalis Principia Mathematica; Locke, John. [1690] 1980. Second Treatise of Government; Rousseau1 [1762] 1968; Smith, Adam. [1776] 2003. The Wealth of Nations; Kant, Immanuel. [1784] 2001. "Answer to the Question: What is Enlightenment?”; Kant, Immanuel. [1785] 2008. Groundwork of the Metaphysics of Morals.

55 Spinoza [1670] 2007, p. 8

${ }^{56}$ Hobbes [1651] 1962; Hume, David. [1748] 1961]. “An Enquiry Concerning Human Understanding.”; Locke [1690] 1961

57 Kant [1781] 1993

${ }^{58}$ Reflecting the Enlightenment project, the French expression for being right or correct employs the word for "reason," as in the expression, "Tu a raison!," which can literally be translated, "You have reason!," but actually means, "You are correct!"

59 Condorcet, Nicolas Caritat de. 1796. Outlines of an Historical View of the Progress of the Human Mind, p. 239. See also Comte, Auguste. [1830-42] 1975. Cours de Philosophie Positive, pp. 279-297, who uses an Enlightenment notion of progress to introduce the field of sociology. 
${ }^{60}$ As a social movement the Enlightenment asks, if a religious view of divine of truth is wrong, how can we know that a secular view of truth is right? This guiding question spurred heated epistemological debates between the empiricists (Locke and Newton, for example) and rationalists (such as René Descartes and Benedict de Spinoza), a debate that Kant later sought to resolve. All Enlightenment thinkers, however, worked to show how knowledge of scientific truth is possible and, further, how it can be used to advance the progress of humanity.

${ }^{61}$ Hobbes [1651] 1962, p. 100

${ }^{62}$ Rousseau, Jean-Jacques. [1755] 1994. Discourse on the Origin of Inequality, pp. 26-29.

${ }_{3}$ See Wollstonecraft, Mary. [1792] 1975. A Vindication of the Rights of Woman.

64 Marx, Karl. [1845] 1978. “The German Ideology: Part I.” p. 154.

65 Marx, Karl. [1845] 1978. “The German Ideology: Part I.” p. 199.

${ }^{66}$ See Marx [1845] 1978, pp. 148-175

${ }_{77}$ True to Marx's dialectical approach, revolutionary upheaval is also a necessary condition for true consciousness. When Marx writes, "The demand to give up the illusions about its [religion's] condition is the demand to give up a condition [class society] which needs illusions," he emphasizes the inseparability of structural and mental/cultural change. For Marx, to wage revolution, one must awaken. To awaken, one must wage revolution. See Marx, Karl. [1844] 1963. "Introduction to the Critique of Hegel's Philosophy of Right," p. 227.

${ }^{68}$ Lenin, Vladimir Ilyich. [1913] 1996. “The Three Sources and Component Parts of Marxism.”

${ }^{69}$ Berger 1963, p. 62

${ }^{70}$ Engels, Frederick. [1893] 1970. "Engels to F. Mehring in Berlin.”

${ }^{71}$ Lukács [1920] 1971

${ }^{72}$ Gramsci 1971, p. 12. See also Herman, Edward S. and Noam Chomsky. [1988] 2002. Manufacturing Consent: The Political Economy of the Mass Media.

73 In this case, Marx links the distinction between the blind and those that see to the class structure of society, regardless of the fact that any material measure of class status will not correspond to such a sociomental distinction. Such a theory allows those advocating revolution to say that they are working in the interests of the oppressed, proletarian class (and therefore the inevitable future of humanity) even when they do not have the support of those who fall within that structural boundaries of that class.

74 Zaretsky, Eli. 2004. Secrets of the Soul: A Social and Cultural History of Psychoanalysis, p. 11; see also Chodorow, Nancy J. 1999. The Power of Feelings: Personal Meaning in Psychoanalysis, Gender, and Culture; Horwitz, Allan V. 2002. Creating Mental Illness.

75 see Freud [1905] 1963; [1909, 1911, 1918] 1963

${ }^{76}$ Zaretsky 2004, pp. 5-6. Zaretsky provides a detailed discussion of psychoanalysis as the "first great theory and practice of 'personal life'."

${ }_{77}$ See Freud [1905] 1963, pp. 5, 6 for an example of his use of the term "enlightenment." For other optical metaphors in Freud's analysis of Dora, see pp. 29, 45, 52. 
${ }^{78}$ Rieff, Philip. [1962] 1963. Introduction to Dora: An Analysis of a Case History, p. xi. See also Berger 1963, p. 64, who compares the psychoanalyst to a "Chinese [communist] brainwasher'."

79 On the sociological dimensions of psychoanalysis, see Manning, Philip. 2005. Freud and American Sociology; Cavalletto, George. 2007. Crossing the Psycho-Social Divide: Freud, Weber, Adorno and Elias. Freud both influenced a variety of sociological theorists, from Talcott Parsons to Jeffrey Prager, and can himself be considered a sociological thinker. For an example of the later, see Freud [1930] 1961. Civilization and Its Discontents.

80 Chodorow 1999, pp. 1-2

${ }^{81}$ Freud, Sigmund. [1910] 1938. “The History of the Psychoanalytic Movement," p. 939. I am grateful to Robin Wagner-Pacifici for pointing out the relevance of the concept of resistance to this discussion.

82 Ibid.

83 Freud, Sigmund. [1901] 1938. Psychopathology of Everyday Life, p. 103.

84 Horwitz 2002

85 Freud [1918] 1963, pp. 283-88

${ }^{86}$ On modern clinical theories of dissociative amnesia, see Arnold and Lindsay 2002; Chu et. al. 1999; Freyd 1996; Freyd and DePrince 2001; Schooler 2001; van der Kolk, Hopper, and Osterman 2001; van der Kolk and Fisler 1995; Whitfield 1995. See also Bass and Davis 1994.

${ }^{87}$ Freud [1899] 1938

${ }^{88}$ Somers 1994, pp. 607-613

89 Fraser, Nancy. 1995. “From Redistribution to Recognition? Dilemmas of Justice in a 'Post-Socialist' Age."

90 Zaretsky 2004, pp. 327-331

${ }^{91}$ For sociological discussions of the modern trauma narrative, see Alexander, Jeffrey C. 2004a. "Toward a Theory of Cultural Trauma;" Alexander, Jeffrey C. 2004b "On the Social Construction of Moral Universals: The 'Holocaust' from War Crime to Trauma Drama;" Bar-On, Dan. 1999. The Indescribable and the Undiscussible: Reconstructing Human Discourse After Trauma; Davis 2005a, b; DeGloma 2007; DeGloma, Thomas. 2009. "Expanding Trauma through Space and Time: Mapping the Rhetorical Strategies of Trauma Carrier Groups;" Eyerman, Ron. 2001. Cultural Trauma: Slavery and the Formation of African American Identity; Herman, Judith Lewis. 1992. Trauma and Recovery: The Aftermath of Violence - From Domestic Abuse to Political Terror; Stein, Arlene. n.d. "Our Holocaust: The Identity Politics of the 'Second Generation';” Stein 2009; Young 1995

92 For an articulation of identity as a function of one's social standpoint at the intersection of such social variables, see, for example, Anzaldúa, Gloria.1987. Borderlands/La Frontera: The New Mestiza; Collins, 2000; Crenshaw, Kimberle Williams. 1991. "Mapping the Margins: Intersectionality, Identity Politics, and Violence Against Women of Color.”

93 Notably, none of the foundational awakening stories I have discussed thus far, with the exception of Mary Wollstonecraft's Vindication of the Rights of Women, are about women. This, to a very large degree, has to do with the social and political marginalization of women before the twentieth century and, more specifically, before the second wave feminist movement. Among other achievements, the second wave 
feminist movement provided a widespread cultural framework for women to awakening to a newly autonomous political consciousness.

94 Collins 2000, pp. 24-25

95 Ibid., p. 271

${ }_{96}^{6}$ Taylor, Verta and Nancy E. Whittier. 1992. "Collective Identity in Social Movement Communities: Lesbian Feminist Mobilization."

${ }_{97}$ Lifton, Robert Jay. [1973] 2005. Home From the War: Learning from Vietnam Veterans.

${ }^{98}$ Davis 2005b, pp. 177-91

$99 \mathrm{X} 1964$

100 Feinberg 1996

101 Gergen 1991; Giddens 1991

102 Willis, Ellen. 1992. Beginning to See the Light: Sex, Hope, and Rock-and-Roll.

103 Freud 1905 [1963]

104 Plummer 1995, p. 49

105 Ibid.

${ }^{106}$ Benford 2002, p. 54. See also Hunt, Scott A. and Robert D. Benford. 1994. "Identity Talk in the Peace and Justice Movement;" Snow, David A., E. Burke Rochford, Jr., Steven K. Worden, and Robert D. Benford. 1986. "Frame Alignment Processes, Micromobilization, and Movement Participation.”

107 Butler, Judith. 1991. “Imitation and Gender Insubordination;” Phelan 1993

${ }^{108}$ See Stein, Arlene. 1997. Sex and Sensibility: Stories of a Lesbian Generation, pp. 154-83

109 Erzen, Tanya. 2006. Straight to Jesus: Sexual and Christian Conversions in the Ex-Gay Movement.

110 The symptoms of Post-Traumatic Stress Disorder include the persistent re-experiencing of a past traumatic event (via intrusive imagery in the form of nightmares and flashbacks, for example), the "persistent avoidance of stimuli associated with the trauma," and "persistent symptoms of increased arousal," including difficulty sleeping and concentrating, irritability, and outbursts of anger (APA 1994. Diagnostic and Statistical Manual of Mental Disorders, Fourth Edition, p. 428). The idea that traumatic experiences can cause psychological symptoms certainly pre-dated the PTSD diagnosis. This notion was central Pierre Janet's theory of trauma, but also informed later psychiatric concepts of "shell shock" (WW I) and "battle fatigue" (WW II). See Scott, Wilbur J. 1990. "PTSD in the DSM-III: A Case in the Politics of Diagnosis and Disease;" Shephard, Ben. 2001. A War of Nerves: Soldiers and Psychiatrists in the Twentieth Century.

${ }^{111}$ See van der Kolk, Bessel A., Paul Brown, \& Onno van der Hart. 2005. "Pierre Janet on Post-Traumatic Stress.”

${ }_{112}$ Very early in Freud's career, Breuer and Freud (See Breuer, Josef and Sigmund Freud. 1895. Studies on Hysteria) defined trauma as an event that was not integrated into consciousness. Freud also attributed hysteria to pre-mature sexual experiences, a notion that he soon-after rejected. See Freud, Sigmund. 
[1896] 1984. "The Aetiology of Hysteria." See also Herman, Judith Lewis. [1981] 200o. Father-Daughter Incest; Masson, Jeffrey Moussaieff. 1984. The Assault on Truth: Freud's Suppression of the Seduction Theory; Zaretsky 2004, p. 29.

${ }^{113}$ Lifton [1973] 2005; Scott 1990, pp. 299-300; Young 1995.

114 Davis 2002, 2005a; Hermann [1981] 2000

115 Alexander 2004b

${ }^{116}$ I originally introduced these ideas in DeGloma 2009. Most of this paragraph is reprinted from that source.

${ }_{117}$ See Evans and Boyte 1992 [1986]; See also Collins 2000, pp. 110-121; Cuoto, Richard. 1993. "Narrative, Free Space, and Political Leadership in Social Movements;" Melucci 1996; Mueller, Carol McClurg. 1994. "Conflict Networks and the Origins of Women's Liberation;" Polletta 1999.

${ }_{118}$ Mills, C. Wight. [1959] 2000. The Sociological Imagination, p. 8

119 Ibid

120 See Young 1995, pp. 159-162

${ }^{121}$ Cline, David. 1997. “Jersey City’s Secret Memorial.”

122 Bass and Davis 1994

\section{NOTES FOR CHAPTER 3:}

${ }^{1}$ Bernfeld, Suzanne Cassirer. 1951. "Freud and Archeology," p. 111. See also Lowental, David. 1985 [1999]. The Past is a Foreign Country, p. 35.

2 Berger and Luckmann 1966, p. 160

3 See also Hankiss 1981; Lewis, Bernard. 1975. History: Remembered, Recovered, Invented; Zerubavel 2003

4 See also Gubrium 1992; Davis 2005b; Young 1995; Prager 1998

5 See also Lomsky-Feder 1995; Olick and Robins 1998

${ }^{6}$ Zerubavel 1997, 2003

${ }_{7}$ Scott and Lyman 1968, p. 46. See also Orbuch 1997

8 E. Zerubavel 1997, pp. 87-92. See also Bartlett, Frederick C. 1932. Remembering: A Study in Experimental and Social Psychology; Y. Zerubavel 1995

9 Halbwachs [1950] 1980. See also Fivush 1995; Fivush, Haden, and Reese 1996

${ }_{10}$ Olick 1999b. See also Schwartz and Shuman 2005; Teeger 2009 
${ }^{11}$ Mische, Ann. 2008. Partisan Publics: Communication and Contention Across Brazilian Youth Activist Networks.

12 Wagner-Pacifici 2005, p. 14

13 Ibid., p. 20.

14 Boellstorff 2009, p. 355. emphasis added

15 Melissa’s Story 2005.

${ }^{16}$ O'Rourke 1989

${ }_{17}$ Angel Light's story 2008

18 Desi. [1983] 1981. "Story of a Granddaughter,” pp. 139-141.

19 Ronn's Story 2007a

${ }^{20}$ Ronn's Story 2007b

${ }^{21}$ Lifton [1973] 2005: 217-263

22 Macdonald, Gail. 1999. Making of an Illness: My Experience with Multiple Personality Disorder.

${ }^{23}$ Augustine [397-8] 1961, p. 49-51

24 Berger 1963, p. 58

25 Goffman 1959

${ }^{26}$ Scott's story 2008

${ }_{27}$ See Freud [1905] 1963, especially p. 63 where Freud writes, “The dream sets up a connection between these two factors - the event during childhood and the event of the present day - and it endeavors to reshape the present upon the model of the remote past."

${ }^{28}$ X 1964, pp. 172-94

29 Frank's Story 2008

${ }^{30}$ Steve's story 2007

${ }^{31}$ See Zerubavel 2006, p. 33-45

${ }^{32}$ Christie's story 2007

33 Ronn's story $2007 \mathrm{a}$

34 Terr 1994, pp. 1-60

35 Chopin [1899]2004, pp. 1-178

${ }^{36}$ Acts 26:17-18 
37 Cothran, Charlene. 2008. "Redeemed! 10 Ways to Get Out of the Gay Life, If you Want Out;" Hart, Joseph. 2007. "Queer Magazine Born Again: Founder of Venus, a Publication for Black Lesbians, Repudiates Lifestyle.”

${ }^{38}$ Goffman [1974] 1986

39 On the cultural significance of the creation narrative, see Bamyeh, Mohammed. 2007. Death and Dominion: The Existential Foundations of Governance.

40 Feinberg 1996

${ }^{41}$ Martin's Story 2007

42 Williams 2004

43 Deborah's story 2008

44 Doctrine and Covenants 93:29

45 warmfuzzylogic 2008

${ }^{46}$ Murdoch [2003] 2008, pp. 23-36

47 Ibid, p. 11

${ }^{48}$ FMSF Newsletter 1998

49 see DeGloma 2007, p. 554

${ }^{50}$ See also Davis 2005a

${ }^{51}$ Macdonald 1999.

$5^{2}$ Kate's story 1995

53 Exmormon(a) 2007

54 Koestler, Arthur 1950, pp. 17, 34-5, 55-6

55 Ibid.: 162.

${ }^{5}$ Ford, Jeffrey G. 2009. "Reparative Therapy: A Pseudoscience.”

57 Mahieu, Brian. 2006. "My Story: A Journey Toward Living an Authentic and Integrated Life.”

${ }^{58}$ Nell's story 1995

59 David's story 2007

${ }^{60}$ Halbwachs [q950] 1980, [1925] 1992

${ }^{61}$ See, for example, Olick 1999a; Olick, Jeffrey K. and Daniel Levy. 1997. "Collective Memory and Cultural Constraint: Holocaust Myth and Rationality in German Politics;" Shils, Edward. 1981. Tradition;

Schwartz 1982; Spillman, Lyn. 1998. "When Do Collective Memories Last? Founding Moments in the 
United States and Australia;" Commemorating Narratives of Violence: The Yitzhak Rabin Memorial Day in Israeli Schools;" Vinitzky-Seroussi 2002. "Commemorating a Difficult Past: Yitzhak Rabin’s Memorials."

62 See, for example, Wagner-Pacifici and Schwartz 1991.

${ }^{63}$ See, for example, Hay, Robert P. 1969. “George Washington: American Moses;” Schwartz 1987; Zerubavel 1995; Smith, Anthony D. 1999. Myths and Memories of the Nation.

${ }^{64}$ See, for example, Teeger and Vinitzky-Seroussi 2007

65 As a notable exception, Vinitzky-Seroussi (1998) discusses the collective dimension of the high school class with attention to American cultural norms in her study of high school reunions as autobiographical occasions. Memory, as in culturally shaped ways of remembering, is also a central aspect of Davis's analysis of retractor (2005b) and sexual abuse survivor (2005a) stories as well as Kidron's and Stein's respective studies of second generation Holocaust survivors. See Kidron, Carol A. 2003. "Surviving a Distant Past: A Case Study of the Cultural Construction of Trauma Descendant Identity;" Stein 2009.

${ }^{66}$ As detailed below, exceptions to this statement differ on how they approach the interplay between individual and collective levels of analysis. These exceptions include Zerubavel (1997, 2003), who illuminates patterns of time and memory that span individual and collective levels of analysis. Olick (1999b) distinguishes between group-level collective memories and the "collected" memories of individual group members. See also Olick and Robbins 1998. Further, Schuman and Scott (1989); Lomsky-Feder 1995; Schwartz and Schuman (2005); and Teeger (2009) study personal or autobiographical memories of collectively relevant events.

${ }^{67}$ See especially Durkheim [1912] 1995

${ }^{68}$ See, for example, Frisch, Michael. 1989. "American History and the Structures of Collective Memory: A Modest Exercise in Empirical Iconography.”

${ }^{69}$ See Olick 1999b, pp. 333, 336, 346

7o See Mannheim, Karl. [1928] 1952. "The Problem of Generations.”

${ }^{71}$ Schuman and Scott 1989, p. 380

${ }^{72}$ Lomsky-Feder 1995; Olick and Robins (1998); Olick 1999b; Schwartz and Shuman 2005; Teeger 2009

73 For "mnemonic traditions" see Zerubavel 1997, pp. 87-91, 2003, pp. 3-5, 95-96. For "mnemonic battles" see Zerubavel 1997, pp. 97-99, 2003, pp. 70-72, 105-110. See also Spillman 1998.

74 Fine, Gary Alan and Aaron Beim. 2007. "Introduction: Interactionist Approaches to Collective Memory," p. 2. As these authors note, the Durkheimian/Halbwachian notion of collective memory has both macro and micro dimensions that inform conventional collective memory studies. The conventional approach of collective memory studies, however, can be contrasted with the basis of the symbolic interactionist perspective that emphasizes the interactive, collective negotiation of meaning and the active creation of intersubjective experience. While my study is admittedly not focused on the nuances of small group interactions, I do consider the agentic use of stories in the construction of memory at the level of the individual storyteller and the autobiographical community.

75 Schwartz and Shuman 2005, p. 200

${ }^{76}$ Smelser, Neil J. 2004. "Psychological Trauma and Cultural Trauma," p. 272. 
77 Polletta 2006:viii

${ }^{78}$ Mead, Margaret. [1942] 1968. And Keep Your Powder Dry: An Anthropologist Looks at America, p. 157; see also Smelser 2004, p. 272

79 See VFF 2008. "Vets for Freedom.” Retrieved June 2008

(http://www.vetsforfreedom.org/default.aspx).

80 Anuradha's story 2008

${ }^{81}$ Ibid.

82 See Zerubavel 2003.

83 Victor's story 2008a

84 For the concept of "frame bridging," see Snow et. al. 1986. On the notion of a temporal frame bridging strategy, see DeGloma 2009

85 Fischer [1949] 1950, pp. 226-7

86 Whereas Snow and Machalek (1983) argue that the "suspension of analogical reasoning" is a defining feature of "the convert as a social type," I have not found this to be the case with awakening stories. In fact, awakeners of all types commonly reason with analogies (both synchronic and diachronic) to redefine the past.

${ }^{87}$ Horowitz 1989, p. 55-6

${ }^{88}$ Arguello 1989, p. 111-12

89 Iannone 1989, pp. 149, 152

90 X 1964, pp. 184-5

${ }^{91}$ X 1964, pp. $185-86$

${ }^{22}$ See Mormon.org. 2009. retrieved July 2009 (http://www.mormon.org/mormonorg/eng/basicbeliefs/the-restoration-of-truth/the-restoration-of-truth).

93 Richard G.’s Story 2008

94 Young, Brigham. 1857. Journal of Discourses. Volume 4, p. 289.

95 See Ostler, Blake. 1982. "The Idea of Pre-Existence in the development of Mormon Thought."

96 Nicolosi 1993, p. 7

97 Nicolosi 1993, p. 10

98 Nicolosi 1993, p. 12

99 Nicolosi 1993, p. 47

100 Nicolosi 1993, p. 5 
${ }^{101}$ Nicolosi 1993, pp. 86-7

102 Medinger 2008

${ }^{103}$ Spillman, Lyn and Brian Conway. 2007. "Texts, Bodies, and the Memory of Bloody Sunday."

104 See Davis 2005b; DeGloma 2007

105 Bass and Davis 1994, p. 22

${ }^{106}$ Linda's story 2006. See also DeGloma 2007, p. 549

107 Ann's story 2006. See also DeGloma 2007, p. 549

${ }^{108}$ Lomsky-Feder 1995, p. 465; see also Olick and Robbins 1998

109 Wagner-Pacifici and Schwartz 1991

${ }_{110}$ Vinitzky-Seroussi 2002

${ }^{111}$ See Schuman and Scott 1989

${ }^{112}$ See Wagner-Pacifici and Schwartz 1991

${ }_{113}$ See, for example, Teeger 2009

114 The term "memory war" is commonly used to refer to the ongoing dispute in the field of psychology over the veracity of recovered memories of childhood sexual abuse.

115 Zerubavel 1997, pp. 87-98

116 Vinitzky-Seroussi 2002

${ }_{117}$ Becker [1963] 1997; Fine, Gary Alan. 2001. Difficult Reputations: Collective Memories of the Evil, Inept, and Controversial, pp. 62-63

\section{NOTES FOR CHAPTER 4:}

${ }^{1}$ Davis, Laura. 1991. Allies in Healing: When the Person You Love Was Sexually Abused as a Child, p. 204-05.

2 This quotation is widely attributed to Mahatma Ghandi. I have never seen it attributed to an original source.

3 Van Gennep, Arnold. [1909] 1960. The Rites of Passage.

4 Turner [1964] 1970; See also Germana, Rachelle. 2003. "In-Between and Becoming: Victims, Survivors, and the Narrative of Transformation."

5 Turner [1964] 1970, pp. 96, 98-99, 105, 106, 108 
${ }^{6}$ Durkheim [1912] 1995, pp. 303-329

7 Turner [1964] 1970, p. 93

${ }^{8}$ See also Patterson, Wendy. 2002. "Narrative Imaginings: The Liminal Zone in Narratives of Trauma."

9 Turner [1964] 1970

${ }^{10}$ See Zerubavel, Eviatar. 1998. "Language and Memory: 'Pre-Columbian' America and the Social Logic of Periodization;" Zerubavel 2003, pp. 82-100; Strauss, Barry S. 1997. "The Problem of Periodization: The Case of the Peloponnesian War;" Lieblich et. al. 1998, p. 106; Berger 1963, p. 61.

${ }^{11}$ Burke [1962] 1969, p. 3

12 Burke [1962] 1969; Mills [1940] 1974

13 Here, I combine Burke's ([1962] 1969) pentad schema (which includes awareness of the act, the scene, the agent and the attribution of agency, and the purpose behind the action) with Goffman's (1959) dramaturgical concepts (props and other characters) to depict the ways awakeners use rich vocabularies of liminality to convey major changes of mind.

14 See James [1902] 1987, pp. 177-238; Starbuck [1989] 1911

15 Kuhn [1962] 1996

16 Schutz, Alfred. [1945] 1973. Collected Papers, Volume I: The Problem of Social Reality, p. 233-34

${ }_{17}$ Davis 1983, pp. 45-85

18 Martin’s Story 2007

19 Fiona's story 2005

${ }^{20}$ Schutz [1945]1973, p. 233-34

${ }^{21}$ Shadow's story 2003

22 Robin's story 2005

23 Sagha's story 2003

${ }^{24}$ Michele's story 2008

25 Tanya's story 2003

26 Terr 1994, pp. 2-3

27 Debbie's story 1996

${ }^{28}$ Spillios, Gerilena. 1993. “The Truth Set Me Free,” p. 341.

29 On non-biological actors, see Cerulo 2009

${ }^{30}$ Mead [1934] 1967, p. 154 
${ }^{31}$ Mountaingirl's story 2007

${ }^{32}$ C. L.'s story 2008

33 Collier 1989, pp. 61-2

34 O'Rourke 1989, p. 203

35 Astarte Moonsilver's story 2007

${ }^{36}$ Dave's story 2007

37 Tthom's story 2007

${ }^{38}$ Dustin's story 2008

39 see Davis 1991, p. 268

40 See, for example, Cline 1997; Adam’s story 2007

${ }^{41}$ Anna's story 2008

42 Richard J.'s story 2008

43 Rod's story 2008

44 Arnold's story 2003

45 Adam's story 2007

${ }^{46}$ Silone 1950, p. 98

47 Richard's story 2007

${ }^{48}$ Cothran 2008

49 Christopher's story 2000

50 David's story 2000

${ }^{51}$ Turner [1964] 1970, p. 96

${ }^{2}$ Burke [1962] 1969, p. 3

53 Fritz's story

54 Ben's Story 2007

55 As opposed to the notion of reason advanced by the Western Enlightenment, I do not contrast reason to religious ideology. Rather, I use this term in the more generic sense to mean "the mental powers concerned with forming conclusions, judgments, or inferences," or "sound judgment, good sense" (Random House Dictionary 2009, retrieved July 2009 from http://dictionary.reference.com/browse/reason). In this more general sense, one can stress the process of reasoning within the religious realm of cultural life as well. Finally, those who contrast reason and religion 
are expressing a cultural tension that emerged between political and religious realms of meaning during the age of Western Enlightenment.

${ }^{6}$ Bill's story 2006

57 Moonshine’s story 2008

58 Preston's story 2007

59 Dbradhud's story 2008

6o Douglass's story 2008

${ }^{61}$ Lindsay's story 2008

${ }^{62}$ Rick’s story 2008

63 Nicolosi 1993, p. 50

${ }^{64}$ Scott's story 2008

65 Dan's story 2008

66 Bashō, Matsu. [1694] 1991. “The Narrow Road to the Interior,” p. 1.

67 Frank's story 2008

68 Stephanie’s story 2003

69 Claire’s story 2003

${ }^{70}$ Lilita's story 2003

${ }^{71}$ Elizabeth's story 1994

${ }^{72}$ Beth's story 2006a, 2006b

73 Cheryl's story 2000

74 Kathryn's story 2009

75 Reverend Jerry's story 2000.

${ }^{76}$ Stephen's story 2008.

77 Ibid.

${ }^{78}$ Jerry's story 2008

79 Sweeney 2005, pp. 47-55

80 Arguello 1989, p. 111

${ }^{81}$ Koestler 1950, p. 15-16 
${ }^{82}$ Ifshin 1989, pp. 81-8

83 Christie's story 2007

84 Eric's story 2007

85 See Jacobs, Ron. 2007. “A Conversation with Three Iraq Veterans Against the War." CounterPunch April 14, 2007.

${ }^{86}$ See Burke [1962] 1969, pp. 3-20

87 Image retrieved June 2009 from the Wikipedia Image Commons

(http://commons.wikimedia.org/wiki/File:4paul1.jpg)

88 Image retrieved June 2009 from the Wikipedia Image Commons

(http://commons.wikimedia.org/wiki/File:Four_Heavenly_Messengers.jpg)

89 Image retrieved July 2009 from the Wikipedia Image Commons

(http://commons.wikimedia.org/wiki/File:Buddha_walking_away_from_ascetics_who_torment_their_ bodies.jpg)

90 Conway, Flo and Jim Siegelman [1978] 2005. Snapping: America's Epidemic of Sudden Personality Change.

${ }^{91}$ This tension between the predetermined world of destiny and the agentic world of choice is highlighted by the character of The Oracle, who in the second film of the trilogy tells Neo, "You didn't come here to make the choice, you already made it. You are here to understand why you've made it."

${ }^{2}$ Koestler, Arthur. [1964] 1976. the Act of Creation, p. 211

93 Koestler 1950

94 Koestler 1950, p. 23

95 Kuhn [1962] 1996

${ }_{96}$ Fischer 1950, p. 204

97 Ibid.

${ }_{98}^{8}$ Ibid, pp. 221-2

99 APA 1994

100 Jerry's story 2008

${ }^{101}$ Nicolosi 1993, p. 8

102 Nicolosi 1993, p. 11

103 Minoi’s story 2003

104 Beth's story 2006b

105 Augustine [397-8] 1961, pp. 177-8 
${ }^{106}$ MsGabbie2u's story 2008

${ }_{107}$ See Zerubavel 2003, pp. 82-100

${ }_{108}$ Zerubavel, Eviatar. 1991. The Fine Line: Making Distinctions in Everyday Life, p. 21-32.

109 Ibid.

${ }^{110}$ Simmel, Georg. [1922] 1955. “The Web of Group Affiliations.”

${ }^{111}$ Plato also compares the cave to Hades, referring to Homer's Achilles. See Cornford's comments in Plato [ 380 BCE] 1941: 230.

112 On the notion of sociomental lumping, see Zerubavel 1991, pp. 21-32. See also Brekhus, Wayne H. 1996. "Social Marking and the Mental Coloring of Identity: Sexual Identity Construction and Maintenance in the United States;" Simpson, Ruth. 1996. "Neither Clear Nor Present: The Social Construction of Safety and Danger."

${ }_{113}$ Zerubavel 1991, p. 27

114 Brekhus 1996; Brekhus, Wayne H. 1998. "A Sociology of the Unmarked: Redirecting Our Focus."

115 On binary moral polarization, see Durkheim [1912] 1995; Durkheim, Emile. [1914] 1960. "The Dualism of Human Nature and Its Social Conditions;" Hertz, Robert. [1909] 1973. "The Preeminence of the Right Hand;" Schwartz, Barry. 1981. Vertical Classification: A Study in Structuralism and the Sociology of Knowledge; Alexander, Jeffrey C. 2007. "The Meaningful Construction of Inequality and the Struggles Against It: A 'Strong Program’ Approach to How Social Boundaries Change.” See also Douglas, Mary. [1966] 2005. Purity and Danger; Zerubavel 1991; Nippert-Eng, Christena. 1995. Home and Work: Negotiating Boundaries through Everyday Life; Cerulo 2006.

${ }_{116}$ Manichaean Scriptures. Translated by Prods Oktor Skjærvø. Retrieved July 2009 (http://www.fas.harvard.edu/ iranian/Manicheism/).

117 Turner [1964] 1970; Patterson 2002

${ }^{118} \mathrm{X} 1964$, p. 181

119 Koestler 1950, p. 67

${ }^{120}$ Lifton [1973] 2005; Shay, Jonathan. 1994. Achilles in Vietnam: Combat Trauma and the Undoing of Character.

${ }^{121}$ Deborah B’s story 2008

122 Zerubavel 1991, pp. 24-28

${ }^{123}$ Random House Unabridged Dictionary. Random House, Inc. 2006; Webster's Ninth New Collegiate Dictionary. Merriam-Webster, Inc. 1988.

${ }_{124}$ Zerubavel 1997, pp. 32-34

125 See Schwartz 1981; Lakoff and Johnson 1980, p. 24 
${ }^{126}$ See Gardiner, Eileen (Ed.). 2006. Zoroastrian Hell: Visions, Tours and Descriptions of the Infernal Otherworld.

127 Goffman 1981, p. 124-159

128 On the power inherent in discourses of truth, see Foucault, Michel. Knowledge and Power.

129 See Abbott, Andrew. 2001. Time Matters: On Theory and Method; Gergen and Gergen 1997; LaRossa and Sinha 2006; Zerubavel 2003; Böröcz, József. n.d. "Sticky Features: Narrating in a Single Direction."

130 See Ezzy 2000

${ }^{131}$ See Eyerman 2001

${ }_{132}$ Rod's Story, 2008

133 Derek’s Story, 2008

\section{NOTES FOR CHAPTER 5:}

${ }^{1}$ Crossman, Richard. 1950. The God That Failed, p. 11.

${ }^{2}$ X 1964, p. 173

3 See Brekhus 1996, 1998; see also Marx, Anthony. 1997. Making Race and Nation: A Comparison of South Africa, the United States, and Brazil.

4 Mullaney 2006

5 Ebaugh 1988

${ }^{6}$ Howard, Jenna. 2008. "Negotiating an Exit: Existential, Interactional, and Cultural Obstacles to Disorder Disidentification,” p. 184, 187.

7 On the notion of the "turning point," see Abbott 2001; Gergen and Gergen 1997; Zerubavel 2003

8 Frank 1993

9 LaRossa and Sinha 2006; Davis 2005a, 2005b

${ }^{10}$ See Mason-Schrock 1996; Rubin, Henry. 2003. Self-Made Men: Identity and Embodiment among Transsexual Men; Garfinkel, Harold. [1967] 1996. "Passing and the Managed Achievement of Sex Status in an Intersexed Person.”

${ }^{11}$ Teeger and Vinitzky-Seroussi 2007

12 Brekhus 2003, p. 29

13 Davis 2005a, p. 530

14 [1951] 1971. "Aion: Phenomenology of the Self," pp. 139-148 
15 Jung 1959, p. 109

${ }^{16}$ Jung, Carl. [1936/37] 1971. "The Concept of the Collective Unconscious,” p. 60

${ }_{17}$ Jung, Carl. [1951] 1971. “Aion: Phenomenology of the Self,” p. 145

18 Ibid, p. 146

19 Ibid, p. 147

${ }^{20}$ Laing 1959, p. 26

${ }^{21}$ Ibid, p. 42-43

${ }_{22}$ Laing 1961; Laing, R.D. and A. Esterson. [1964] 1990. Sanity, Madness, and the Family.

23 Laing 1959, p. 30

24 Simmel [1922] 1955, pp. 141-142

25 Merton [1949] 1964

${ }^{26}$ See, for example, Anzaldúa 1987; Collins 2000

${ }_{27}$ See, for example, Ebaugh 1988; Nippert-Eng 1995; Danna-Lynch 2009

${ }^{28}$ Mische 2008, p. 43.

29 Cooley, Charles Horton. 1922. Human Nature and the Social Order (Revised edition), p. 184

30 Mead [1934] 1967:175

${ }^{31}$ Ibid, pp. 175-209

${ }^{2}$ Ibid, p. 174

33 Mead, George Herbert. 1932. The Philosophy of the Present, p. 11

34 Emirbayer and Mische 1998, p. 969

35 Mische 2008, p. 371, n. 21. See also Emirbayer and Mische 1998, p. 968.

${ }^{36}$ Emirbayer and Mische 1998, p. 998; Cerulo 2009, p. 14

37 See also Perinbanayagam 1991; Wiley, Norbert. 1994. The Semiotic Self.

$3^{8}$ Goffman 1967

39 Goffman 1959

${ }^{40}$ Blumer, Herbert. 1969. Symbolic Interaction as Perspective and Method, p. 2

${ }_{41}$ Denzin 1989a, 1989b; Wiley 1994; Emirbayer and Mische 1998; Cerulo 2009 
${ }^{42}$ Giddens 1991, pp. 4-5

43 Gergen 1991, p. 16

44 Foucault [1978] 1990

45 See Butler 1991, 2005

${ }^{46}$ Denzin 1989a, p. 73

47 Propp 1968, p. 25-65

48 Carol's Story 2005

49 Goffman [1974] 1986, p. 520

50 Dora's story 1994

${ }^{11}$ Ofshe, Richard and Ethan Watters. 1994. Making Monsters: False Memories, Psychotherapy, and Sexual Hysteria.

$5^{2}$ Jon's story 2008. Turner, Jon. Testimony reproduced in “This is Where We Take Our Stand," video trailer. Retrieved July 2009 (http://vimeo.com/5448532).

53 Tina's story 2007

54 Goffman [1974] 1986, p. 521

55 Tinkling Brass's story 2006

${ }^{56}$ Hamar's story 2007

57 Bardman's story 2008

${ }^{58}$ Life Rocks 2008

59 Horowitz 1989, p. 56

6o Van Patrick's Story 2008

${ }^{61}$ Johnny's story 2008

62 Jerry's story 2009

63 MsGabbie2u's story 2008

64 Warmfuzzylogic's story 2008

${ }^{65}$ Scott's story 2008

${ }^{66}$ Frank's story 2008

${ }^{67}$ Rod's story 2008

68 Brooke’s story 2008 
69 On the concepts of "appearance" and "manner," see Goffman 1959

70 On the notion of "optical socialization," see Zerubavel 1997, pp. 32-34, 46-52. On the distinction between primary and secondary socialization, see Berger and Luckmann 1966, pp. 129-47.

${ }^{71}$ Fabian 1983

${ }^{72}$ Athens, Lonnie. 1994. "The Self as a Soliloquy.”

73 Sean's Story 2007

74 Daniel's Story 2008

75 Victor's story $2008 \mathrm{~b}$

${ }^{76}$ Wagner-Pacifici 2005, p. 144. See also pp. 13-14, 135

77 Gayatri's story 2005

${ }^{78}$ Goffman [1974] 1986, pp. 40-82

79 Paul's story 2007

80 Wacquant 2004, pp. 59-60. Building on Bourdieu's thinking about the body, Wacquant uses these quoted words to describe the way professional prize fighters are "kinetically remodeled" (6o) and subject to "a particular (re)socialization of physiology" (59). By portraying his past soldier self in a street theater reenactment, Paul describes his slip back into the socialized embodiment of that self that he most likely began to acquire in boot camp.

${ }^{81}$ Ibid.

${ }^{82}$ Fraser, Sylvia. 1987. My Father's House: A Memoir of Incest and of Healing, p. 7

83 Sweeney 2005

84 Christine’s story 1998.

85 Linda's story 2006

86 Dan's story 2008

87 Ibid.

88 Yvonne’s story 2005

89 Ibid.

90 Robin's story 2005

${ }^{91} \mathrm{X}$ 1964, p. 203

${ }^{22}$ Melissa's story 2005

93 Mary Ellen's story 2003 
94 Medinger 2008

95 Jason's story 2008

${ }_{96}$ Nicolosi 1993, p. 21

97 Bob's story 2008

98 Alan Chambers's story 2005

99 Eric's story 2009

100 David's story 2009

${ }^{101}$ Randy's story 2009

${ }_{102}$ Zerubavel 1997, p. 32

103 Schutz, Alfred and Thomas Luckmann. 1973. The Structures of the Life World.

104 Douglass, Frederick. [1881] 1996. The Life and Times of Frederick Douglass, p. 103.

105 See http://exmormonforums.com/viewforum.php?f=3\&sid=791084da5b67bf1c8104bad83cadff 31 for (as of this writing) sixty-nine discussion threads on the topic.

${ }^{106}$ Engels, Frederick. 1877. Anti-Dühring.

107 Wells 1904

${ }_{108}$ Zerubavel 1997

109 On separation and incorporation as aspects of "rites of passage," see van Gennep [1909] 1960, pp. 65188.

${ }^{110}$ See Durkheim, Emile. [1893] 1984. The Division of Labor in Society.

${ }^{111}$ On the use of metaphor to structure meaning, see Lakoff and Johnson 1980; Kövecses, Zoltán. 2002, Kövecses, Zoltán. 2005. Metaphor in Culture: Universality and Variation. On the general use of linguistic devises to signify meaning, see Saussure, Ferdinand de. [1972] 1992 Course in General Linguistics.

${ }^{112}$ Marx [1845] 1978, p. 158

${ }_{113}$ Durkheim [1912] 1995, pp. 435-436

114 Lakoff and Johnson 1980, p. 22

${ }_{115}$ See also Kövecses 2005, pp. 88-130

${ }^{116}$ Fischer 1950, p. 227

${ }_{117}$ Nicolosi 1993, p. 12 
${ }_{118}$ Genesis 1:3-4. The Holy Bible: New Internationalist Version. Zondervan Publishing House: Grand Rapids, Michigan.

119 Wright 1950, p. 162

${ }^{120}$ Derek's story 2007. Giffin, Derek Charles. Retrieved June 2007 (http://www.ivaw.org/user/72).

${ }^{121}$ David's story 2008

122 Gide 1950, p. 187

123 Horowitz 1989, p. 54

124 Bill's story 2006

${ }^{125}$ See Freud [1905] 1963, pp. 5,6 for example.

${ }^{126}$ Ibid, p. 29

127 Ibid, p. 45

${ }^{128}$ Ibid, p. 52

129 Ibid, p. 71

${ }^{130}$ Johnny's story 2008

${ }^{131}$ Chad's story 2008

${ }^{132}$ Collier 1989, p. 65

${ }^{133}$ Sherry's story 2008

134 Wendy is a pseudonym. This author of this account chose to remain anonymous and simply signed her story “A Retractor."

135 Wendy's story 2006. “I Never Stopped Loving My Real Parents.” Retrieved December 2006

(http://fmsfonline.org/retract2.html).

${ }^{136}$ Elizabeth's story 1994. Godley, Elizabeth. “My Mother Abused Me, Didn't She?” Retrieved December 2006 (http://fmsfonline.org/retract1.html). See also DeGloma 2007, p. 556.

137 Catherine's story 2000

${ }^{138}$ Paul's story 2000

139 Tracey's story 2000. St. Pierre, Tracey. P. 20 in Finally Free: Personal Stories: How Love and SelfAcceptance Saved Us from Ex-Gay Ministries. Washington D.C.: Human Rights Campaign Foundation.

${ }^{140}$ Moonshine’s story 2008.

${ }^{141}$ Insanad's story 2008(b)

142 Templeton 1982 (http://www.templetons.com/charles/memoir/evang-princeton.html)

${ }^{143}$ Susie is a pseudonym I gave to this anonymous apostate in order to keep the flow of the text 
144 Ex-Mormon(b) 2007

145 Horowitz 1997, p. 2

146 Cheryl's story 2000

147 Bill's story 2006

${ }^{148}$ MsGabbie2u's story 2008

149 Jared's Story 2007

${ }^{150}$ The sociomental character of Jared's expression of cognitive solidarity is evident when one considers that he does not feel the same way about all groups of veterans. If feelings of solidarity resulted strictly from shared experience, as some may suggest, then Jared would feel similar "bonds" with veterans and veteran groups who share a pro-war worldview with his biological family. The fact that Jared contrasts the "bonds" that "live" in his "heart" to this particular way of seeing the war shows his sentiments and expressions of solidarity to be fundamentally sociocognitive in essence.

${ }^{151}$ Jamech's story 2007

${ }^{152}$ Jerry's story 2008

153 Peter's story 2005

154 Frank's story 2008

155 Scott's story 2008

${ }^{156}$ Rick's story 2008

157 Richard's story 2007

${ }_{158}$ Berger and Luckmann 1966, pp. 129-137

159 As Kuhn ([1962] 1996) notes, such a process of resocialization resembles the way students learn to acquire the sociomental norms of a new profession.

160 Retractor 2007

${ }^{161}$ See also DeGloma (2007) where I first introduce this idea and explore some of this narrative data.

162 Pasley 1995, p. 334.

163 Pasley 1993, p. 348

164 Jaye’s story 2008; see also DeGloma 2007, p. 557

165 Silone 2000, p. 99

${ }^{166}$ Iannone 1989, p. 150

167 Lindsay's story 2008 
${ }^{168}$ Insanad's story 2008(a)

169 Koestler 1950, p. 46

170 Jacobs 2007

${ }^{171}$ See Nicolosi, p. 177-209

172 Brekhus 1998:519

173 Bass and Davis 1994, p. 16.

174 Jennifer's story 2006

175 Hopeful and Healing's story 2003.

${ }^{176}$ Blondie’s story 2003

177 Fiona's story 2005

${ }^{178}$ Cynical's story 2007

179 Free thinker's story 2007

${ }^{180}$ Mountaingirl's story 2007

${ }^{181}$ On injustice frames, see Gamson, William A. 1992. Talking Politics.

${ }^{182}$ Marx, Karl and Frederick Engels. [1848] 1978. Manifesto of the Communist Party.

183 Chayko 2008

\section{NOTES FOR CHAPTER 6:}

${ }^{1}$ Fleck 1981 [1935], p. 48

${ }^{2}$ Jaspers 1953; Armstrong 2006b, pp. xviii-xix, 3-56.

3 Armstrong 2006b, p. xvii

4 Durkheim [1893] 1984, p. 304

5 Gergen 1991, p. 49

${ }^{6}$ See, for example, Gubrium 1992, 2005; Vinitzky-Seroussi 1998; Young 1995

7 On the notion of "imagined communities," see Anderson, Benedict. [1983] 1991. Imagined Communities.

8 Zerubavel 1997, p. 33

9 On the concept of "going concerns," see Hughes, Everett C. 1984. "Going Concerns: The Study of American Institutions." 
${ }^{10}$ Fleck 1981 [1935], p. 48

${ }^{11}$ Weber 1968

${ }^{12}$ See Alexander 2004a; see also Alexander 2004b; Eyerman 2001; DeGloma 2009

13 Ibid., p. 11

14 Ibid., p. 12

15 Swidler 1986

${ }^{16}$ See, for example, Somers 1994; Zerubavel 2003

17 Zerubavel 1998; see also Lieblich, Tuval-Mashiach, and Zilber 1998.

${ }^{18}$ On the relationship between personal troubles and public issues, see Mills [1959] 2000, p. 8.

19 Such a strategy is perhaps most evident in the case of the transmission of trauma across generations. See DeGloma 2009; Kidron 2003; Stein 2009.

${ }^{20}$ Mannheim 1936

${ }^{21}$ Kuhn [1962] 1996

${ }^{22}$ Mannheim 1936, p. 97

23 Ibid, pp. 98-99

${ }^{24}$ Collins 2000, pp. 102, 116, 147

25 Fuller, Steve. [1998] 2002. Social Epistemology, p. x.

${ }^{26}$ Mannheim 1936, p. 168

${ }_{27}$ Burke [1962] 1969

28 Goffman 1959; [1974] 1986

${ }_{29}$ Habermas 1987, pp. 1-112; See also Alexander 2004a, p. 11-12; Wagner-Pacifici 2005, p. 144

${ }^{30}$ Hughes, Everett C. 1984. "Going Concerns: The Study of American Institutions."

${ }^{31}$ Alexander 2004b, p. 202. See also Olick and Robins 1998, p. 122; Vinitzky-Seroussi 2002, p. 32, 46-47.

\section{NOTES FOR APPENDIX A:}

${ }^{1}$ Zerubavel 2007, pp. 132-34, 136-39.

2 Holstein and Gubruim 2000; Gubrium and Holstein 2009, pp.28-32 
3 Glaser and Strauss [1967] 2008, pp. 82-89.

4 Gubrium and Holstein 2009, p. 28

5 Ibid., p. 29

${ }^{6}$ Zerubavel 2007, p. 240

7 Casey, Edward S. [1976] 2000. Imagining: A Phenomenological Study, p. 23.

${ }^{8}$ See Zerubavel 2007

9 See DeGloma 2009. For a consideration of "bundles of narratives," see Fine, Gary Alan. 2002. "The Storied Group: Social Movements as Bundles of Narratives.”

\section{NOTES FOR APPENDIX B:}

${ }^{1}$ Retrieved July 2009 (http://ivaw.org/membership).

${ }^{2}$ Retrieved July 2009 (http://www.susansmiles.com/index.html).

3 Retrieved July 2009 (http://www.healthyplace.com/abuse/soc-um/about-safeguarding-our-childrenunited-mothers/menu-id-823/).

4 Retrieved July 2009 (http://www.healthyplace.com/abuse/soc-um/about-safeguarding-our-childrenunited-mothers/menu-id-821/).

5 See Freyd 1996, pp. 197-199

${ }^{6}$ Retrieved July 2009 (http://fmsfonline.org/about.html).

7 Ibid.

${ }^{8}$ See Davis 2005a for a description of False Memory Syndrome Foundation conventions.

9 Retrieved July 2009 (http://www.precious-testimonies.com/General/p-t/purpose.htm).

10 Retrieved July 2009 (http://www.faith-travels.org/).

${ }^{11}$ Retrieved July 2009 (http://www.faith-travels.org/web/pageid/43250/pages.asp).

12 Retrieved July 2009 (http://www.mormonconverts.com/).

${ }_{13}$ Retrieved July 2009 (http://www.mormonconverts.com/aboutus.htm).

14 Packman, Richard. 2007. "To Those who are Investigating 'Mormonism'.”

${ }_{15}$ Retrieved July 2009 (http://www.exmormon.org/). 
${ }^{16}$ Ibid.

${ }_{17}$ Retrieved July 2009 (http://www.postmormon.org/exp_e/index.php/home)

${ }^{18}$ Ibid.

$19 \mathrm{http}: / /$ www.peoplecanchange.com/whatispcc.htm

${ }^{20}$ Retrieved July 2009 (http://www.peoplecanchange.com/)

${ }^{21}$ See http://www.pathinfo.org/index2.htm. Retrieved July 2009.

22 Retrieved July 2009 (http://people-can-change.blogspot.com/)

23 See Nicolosi, p. 177-209.

24 Retrieved July 2009 (http://couragerc.net/index.htm)

25 Retrieved July 2009 (http://www.beyondexgay.com/)

${ }^{26}$ Ibid.

27 Ibid. 


\section{Curriculum Vita}

Thomas E. DeGloma Jr.

Colleges Attended and Degrees Earned:

1991-1993 Raritan Valley Community College (transfer before
degree completed)

1993-1997 Rutgers College, Rutgers University

B.A. 1997

1998-1999 School of Management and Labor Relations,
Rutgers University

(transfer before degree completed)

1999-2009 Graduate School, New Brunswick Rutgers University, Department of Sociology

M.A. 2004

Ph.D. 2009

Principle Occupation:

2002-2007

2004-2005

1999-2002
Part Time Lecturer, Rutgers University

Head Teaching Assistant, Department of Sociology, Rutgers University

Teaching Assistant, Rutgers University

Publications:

2007 DeGloma, Thomas. 2007. “The Social Logic of 'False Memories': Symbolic Awakenings and Symbolic Worlds in Survivor and Retractor Narratives." Symbolic Interaction 30, 4: 543-565.

2009

DeGloma, Thomas. 2009. "Expanding Trauma through Space and Time: Mapping the Rhetorical Strategies of Trauma Carrier Groups." Social Psychology Quarterly 72, 2: 105-122. 